


10

I\$,

.




\section{F A R MER'S MINE,}

OR

\section{SOURCE OF WEALTH,}

BEING A COMPILATION, WITH THE ADDITION OF NEW AND MMPORTANT INFORMATION ON THE SUBJECT OF MANURE, TOGETHER WITH THE MOST APPROVED METHODS FOR THE MIANUFACTURE OF VEGETABLE IIANURE, BY WHICH THE FARMER CAN OBTAIN

IN THE SHORTEST POSSIBLE TINE, AS MUCH MANURE OF THE RICHEST QUALITY AS HE PLEASES.

TO WHICH IS ADDED,

\section{PRODUCTIVE FARMING,}

\section{BY JOSEPH A. SMITH.}

'To the Farmer, Manure nust bo the first thing, and it must be the last thing; with it he can do everything, without it, nothing.-GAYLORD.

BY HENR $\mathrm{YHEERMANCE}$.

REVISED AND CORRECTED BY

$$
\text { A. B. AIILEN, }
$$

¿DITOR OF THE AMERICAN AGRICULTURIST.

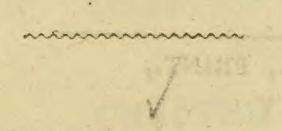

NEW YORK:

PUBLISHED BY HENRY HEERMANCE,

AND FOR SALE BY SAXTON \& MILES,

Office of the American Agriculturist, 205 Broadway.

1843.

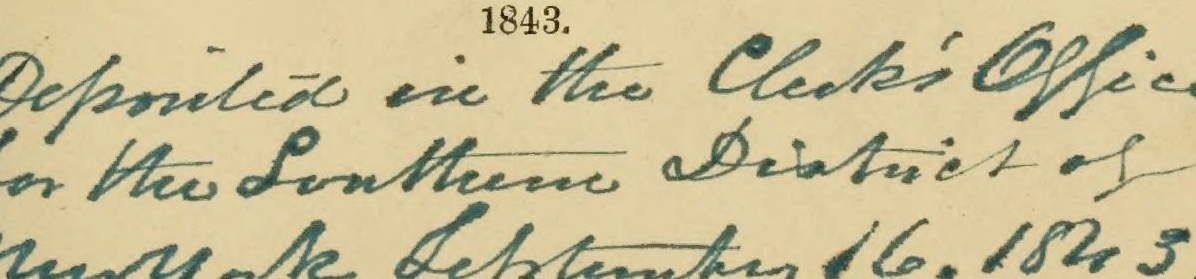


Entered according to the Act of Congress, in the year 1813, by HENRY HEERMANCE, in the Clerk's office of the District Court for the Southern District of New York.

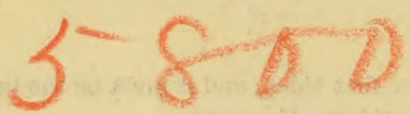

s. W. BENEDICT \& CO., PRINT., 128 Fulton St., N. Y.

5633

.446 


\section{CONTENTS-PART I.}

Introduction, .
$\begin{aligned} & \text { Salts, : } \\ & \text { Marl, . }\end{aligned}$ CHAPTER I.




\section{CONTENTS}

CHAPTER XII.

Manures produced from the herbage of fresh water, .

CHAPTER XIII.

Artificial Manures,

CHAPTER XIV.

Manures produced by Marine plants,

CHAPTER XV.

Animal Manures,

(1)

\section{CHAPTER XVI.}

Animal offals, .

CHAPTER XVII.

Charcoal and Soot,

CHAPTER XVIII.

Excrements of Birds, .

CHAPTER XIX.

Night Soil-Poudrette,

Liquid Manures,

\section{CHAPTER XX.}

CHAPTER XXI.

Animal and Animalized Black,

CHAPTER XXII.

Manufacture of disinfected Manures, .

CHAPTER XXIII.

Yard Manure, .

CHAPTER XXIV.

Composts and Liquids, .

CHAPTER XXV.

Different Methods for the Preparation or Manufacture of

Vegetable Manure, . 


\section{CONTENTS-PART II.}

Preface, _ _ . _ _ _ _ . 185

CHAPTER I.

Introductory Observations,

\section{CHAPTER II.}

Some Account of the Simple or Elementary Bodies found (combined or uncombined) in Animals, Plants, and Soils,

CHAPTER III.

Plants and Animals are both alike endowed with Life; the Elementary Materials and many of the Proximate Principles of Animal and Vegetable matter are precisely identical-they have similar Organs essential to their growth and reproduction, and are nourished or destroyed by the same agencies,

CHAPTER IV.

Of the Elementary Composition of Water; of the Composition of the Atmosphere; and of the artificial Application of Water to Grass Lands, .

\section{CHAPTER V.}

Of the Nature of Vegetable Growth; the true use of Vegetable Mould or Humus; and of the Sources of the Elementary Constituents of Plants,

\section{CHAPTER VI.}

Of the Sources of the Saline, Earthy, and other Unorganized Constituents of Vegetables, .

CHAPTER VII.

Of the necessary Relation between the Composition of a Soil and the Vegetables it is fitted to raise. Fallowing and Green Crops considered as Vegetable Manure, . . 


\section{CONTENTS}

CHAPTER VIII.

Of the Nature and correct Use of the Excrements of Animals considered as Manure; the Mode of its Action and Preservation.-Bone Dust, and dead Animal Matter, . .

CHAPTER IX.

Of the comparative Value of Vegetable Manure, as contrasted with Animal Excrements, . . . . .

CHAPTER X.

Of Manures of Mineral Origin, or Fossil and Artificial or Chemical Manures; their Preparation, and the Manner in which they Act.-Of Lime in its different States ; its Operation as a Manure.-Of Alkalies, and Common Salts, as to their Action upon the Land,

\section{CHAPTER XI.}

Of the Composition of Productive Soils, and of the Agency of the Elements in their Natural Formation, from the Rocks upon which they rest,

\section{CHAPTER XII.}

Of the Chemical Analysis of Soils, and how far this is practicable by the Farmer,

CHAPTER XIII.

Or Advertised "Fertilizers" for the Soil, 


\section{P R E F A C E.}

In the following compilation, I have selected largely from the "Farm House of the 19th Century," also from Dana, Gaylord, Liebig, and several of the agricultural papers of the day. The object has been, to present the subject in a form calculated to interest and instruct our farmers. We have long witnessed the want of economy and skill in fertilizing the soil, and have made some small effort to correct the evil. A full view has been given of the different substances used to enrich the soil, together with the different modes practised in different countries.

It only remains for our farmers to avail themselves of the information furnished here, especially of the improved method for manufacturing vegetable manure, and the feed of their pastures and yield of their harvests will be greatly increased; thereby filling their pockets, and making the book, to them, what its title claims, "The Farmer's Mine, or Source of Wealth."

NEw YoRK, September, 1843.

H. Heermance. 

THE

\section{F A R M E R'S M I N E.}

\section{CHAPTER I.}

INTRODUCTION.

OF all the pursuits to which mankind, from necessity or inclination, have devoted themselves, there is none more honorable-certainly none more useful-than that of agriculture. Perfect agriculture is the true foundation of all trade and industry-it is the foundation of the riches of States. To pursue this business successfully, knowledge, extensive and varied, is required; for, although a man may succeed by following the beaten paths of his predecessors, occasions will frequently arise, when the end desired may be attained by methods much shorter than those usually adopted, if the farmer is able to form and apply them. It is here that science has, within a few years, rendered the most essential aid to agriculture. Sometimes, reasoning from well known effects to their causes, the agricultural chemist has placed in the hands of the farmer the means of producing results, always desirable, but which, under the older systems of farming, with his utmost care, he frequently failed of obtaining. Again, taking well-established facts in animal or vegetable physiology as his starting point, he has arrived at results of the highest practical importance, and is enabled to render more certain and effective the 
more tardy operations of nature. In no department of agricultural industry, it is believed, have the labors of science been more beneficial or more apparent than in that of the preparation and use of manures; certain it is, there is no department more deserving attention, or where an elucidation of the principles and laws that govern the growth of plants, acts with a more direct and energetic influence.

The true farmer, no less a sage than the ancient orator, who gave to action the first, second, and third place in eloquence, will answer, if it is asked him, What is his firsi requisite? Manure. What second? Manure. What third? Manure. These answers are to be united. Action and manure are the first and last requisites in agriculture, and in the attempt to show what is the lust, and how it acts, will be offered every inducement to action.

Definition.-A definition of the term manure may be necessary, in order to treat the subject understandingly, as different individuals use the word in widely different senses, some in a wide, and some in a limited one. A few instances of the meaning put upon the term will be given from a few of the modern writers who have adverted to this topic. Thus Dr. Leiber, in his German Conversations Lexicon, defines manure to be "vegetatle, animal, and mineral matters, introduced into the soil to accelerate vegetation, and increase the production of crops." The Encyclopædia, published by the London Society for the Promotion of Useful Knowledge, thus defines it:- "Every substance which has been used to improve the natural soil, or to restore to it the fertility which is diminished by the crops annually carried away, has been included in the name of manure." Loudon, in his great work on Agriculture, says-" Every species of matter capable of promoting the growth of vegetables, may be considered as manure." Prof. Low, in his Elements of Agriculture, says-"All substances which, when mixed with the matter of the soil, tend to fertilize it, are in common language termed manures." Mr 
Johnson, in his "Farmers' Encyclopædia," lately published, says-_ " A manure may be defined to be any fer. tilizing compound or simple ingredient added to a soil, of which it is naturally deficient." The definitions of Prof. Liebig and Dr. Dana, two of the latest writers on the subject, do not differ essentially from those already given. Of these definitions, I prefer the most simple and comprehensive, that of Loudon, and in this paper shall consider the term manure as embracing every substance capable of promoting the growth of plants.

Manures, by some, are classed as earthy, organic, and saline; others divide them into animal and vegetable, mineral and mixed manures, and some speak of them as composed only of geine or humus and salts. Others class them as organic and inorganic ; but these divisions are of little consequence, as every farmer understands that manure is the result of decomposition or change; and that, whether organic, that is, derived from animal or vegetable matter; or inorganic, such as the earths, clay, lime, the alkalies, \&c., it is only efficient when presented to plants in certain forms, such as decomposition, division or solution. In France they have terms to distinguish those substances which act mechanically in improving the texture of the soil, from those which act directly in the nourishment of the plant. The former class of substances they call amendements, and the latter ones engrais. It is probable, however, that the system which considers all manures as consisting of humus or geire. and sälts, comprehending in the latter term all the mineral substances that enter into the growth or nourishment of vegetables, will eventually be found the most simple, and at the same time the most accurate of all the proposed divisions of manures. Thus, humus constitutes the source of the carbon, forming the principal part of the structure of plants ; and the salts, where they do not enter into the structure of plants, are active in preparing the other inorganic elements, and exciting the vegetable organs in their reception and appropriation of nutriment. 
Humus or Geine, is simply decomposed animal and ves getable matter; and as from it, by the action of oxygen, carbonic gas is derived, to be absorbed by water and taken up by the roots, or mixed with the atmosphere and taken up by the leaves of plants; or, as some agricultural chemists with good reason suppose, is under certain circumstances dissolved, or is soluble, and thus rendered fit for immediate nourishment to plants, it must be considered the most important item in the production of manures. The salts, which are the most efficient in aiding vegetation, or the most active manures, are those formed from the alkalies and their various combinations. Thus, from prure lime or calcium, is formed, by the union with carbo isie acid, carbonate of lime; with phosphoric acid, phosithate of lime, the base of bones, one of the most efficient of fertilizers ; with sulphuric acid, sulphate of lime, or gypsum, the value of which is well understood; and so with the other alkalies, which, in their combinations, form substances of the utmost consequence to plants. It is well known that the outer covering of some kinds of cane contains so much fint or silex as to strike fire with steel; and some of the grasses contain this substance in such quantity that their ashes will melt into glass with potash. Now, this hardness, so necessary to their perfection, could not be attained unless this flint had been rendered soluble by union with an alkali, forming a silicate of potash, and by this solubility been rendered fit for the action and appropriation of the plant.

Food of Plants. -If we would know what kind of food is required by plants, one of the first steps necessary is to ascertain of what the plants themselves are composed. The combinations of matter may be said to be absolutely endless; but the original elements of this multitude of combinations are few in number. Chemistry has detected only some fifty-five substances incapable of further reduction, or what are called simple substances; and of these, strange as it may appear, only four, except in proportions merely accidental, go to the formation of plants. Of these the first is Carbon. This forms from 40 to 50 per cent by 
weight, of the plants cultivated for food; and is therefore most important to animals and to man. Carbon is an elementary substance, endower with a considerable range of affinity. With oxygen it unites in two proportions, forming the gaseous compounds known under the names of carbonic acid and carbonic oxide. The former of these is emitted in immense quantities from many volcanoes and mineral springs, and is a product of the combustion and decay of organic matter. It is subject to be decomposed by various agencies, and its elements then arrange themselves into new combinations. Carbon is familiarly known as charcoal, but in this state it is mixed with several earthy bodies; in a state of absolute purity it constitutes the diamond.

The second of these simple substances, is Oxygen. The quantities of this substance are immense ; and though we are acquainted with it only in the form in which it exists in the air, nearly one-half of the solid crust of the globe, 21 per cent of the atmosphere, eight pounds in every nine of water, and more than one-half of the living bodies of all plants and animals, are oxygen. In an isolated state it is a gaseous body, possessed of neither taste nor smell. It is slightly soluble in water, and hence is usually found dissolved in rain and snow, as well as in the water of running streams. It is the agent employed in effecting the union and disunion of a vast number of compounds. It is superior to all other elements in the extensive range of its affinities. The phenomena of combustion and decay are examples of the exercise of its power.

Hydrogen is the third substance peculiar to plants. This is the lightest of known substances, and forms a small part of the weight of all animal and vegetable bodies; constitutes one-ninth part of the weight of water, but enters into the composition of none of the masses that go to form the crust of the globe, coal excepted. Hydrogen is a very important constituent of vegetable matter. It possesses a special affinity for oxygen, with which it unites and forms water. The whole of the phenomena of decay depend upon the exercise of this affinity, and many 
of the processes engaged in the nutrition of plants originate in the attempt to gratify it. Hydrogen, when in the state of a gas, is very combustible, and the lightest body known; but it is never found in nature in an isolated condition. Water is the most common combination in which: it is presented ; and it may be removed by various processes from the oxygen with which it is united in this body.

The fourth simple substance, entering into the formation of plants, is Nitrogen. This forms 79 per cent of the bulk of the atmosphere; constitutes part of most animal and some vegetable substances; is found in coal to the amount of one or two per cent, but does not exist in any other of the mineral masses constituting the crust of the globe. Although not an abundant substance, the importance of it is not the less decided, and some of its functions are of the most indispensable kind. Its principal characteristic is an indifference to all other substances, and an apparent reluctance to enter into combination with them. When forced by peculiar circumstances to do so, it seems to remain in the combination by a vis inertia ; and very slight forces effect the disunion of these feeble compounds. Yet nitrogen is an invariable constituent of plants, and during their life is subject to the control of the vital powers. But when the mysterious principle of life has ceased to exercise its influence, this element resumes its chemical character, and materially assists in promoting the decay of vegetable matter, by escaping from the compounds of which it formed a constituent.

Plants, then, are composed of carbon, oxygen, hydrogen, and nitrogen; the first derived from carbonic acid, the second from the atmosphere, the third from the decomposition of water, and the fourth from ammonia absorbed by water, and taken up by the roots of the vegetables. Some of the earths are occasionally detected in plants, and salts of some kind are always present. In the preparation of manures, the principal object to be aimed at, it is evident, must be to supply the materials needed to furnish the carbon and the ammonia ; and these are found in the greatest abundance in dead or decomposed animal and vegetable matter. 


\section{CHAPTER II.}

\section{SALTS.}

To preserve due order, we will first notice those substances, which by some are denominated amendments; by others, mineral manures; in the preceding classification, Salts. These may be supposed to act in different ways.

1st. They may act upnn the soil by improving its texture, or by rendering soluble the parts of it which are insoluble, or by otherwise fitting it to promote the growth of plants.

$2 \mathrm{~d}$. They may act immediately upon the plant itself, by being received into its substance.

The manner in which this action takes place upon the organs of the plant may elude our observation; but this much may be admitted, that certain earths, oxides, and alkalies, combined with acids, pass into the substance of the plant, absorbed, it may be, in part, from the atmosphere, but chiefly along with the aqueous portion of the sap, from the earth in which the roots are fixed. Some substances taken up in this latter mode, are known to act as poisons, while others exercise a beneficial action on the plant.

We cannot generally distinguish when a mineral substance acts upon the plant, through the merium of a change in the soil, or when it acts directly upon the plant itself. All that we truly know is, that certain earthy and alkaline bodies, or their saline combinations, applied to the soil, promote the growth of plants, and so, in the language of farmers, are manures. 


\section{Lime.}

Of all the mineral substances known to us, lime is that which performs the most important part in improving the soil and promoting the growth of vegetables. Lime is found in nearly all soils that are capable of sustaining regetation, and, in combination with different acids, in nearly all vegetable substances.

Lime, as employed in agriculture and the arts, is derived from three distinct series or orders of rocks.

1. From the rocks of the primary series. These are very compact and crystalline. They afford the finest of our marbles, and yield a pure lime.

2. From the lower secondary or transition rocks. These, like the last, are hard and crystalline, and yield a lime of good quality.

3. From the carboniferous rocks, or those of the middle secondary order. It is from this source that the largest supplies of the mineral are derived. Of this series is the mountain limestone, which is the most familiar to us, and the most generally employed in agriculture and the arts.

4. From the upper secondary rocks. In this series is the magnesian limestone, which, from its possessing peculiar properties, to be afterwards adverted to, is termed hotlime by agriculturists.

Of the same order of rocks, too, namely, the upper secondary, are the lias and oolite, which are found in some parts of England, and the lime of which is employed for igricultural purposes.

The last of the series of the upper secondary rocks is the chalk, which is found abundantly in the south-east counties of England and in France, extending eastward through the central parts of Europe.

Limestone, from whatever series of rocks derived, when submitted to the action of heat, loses the carbonic acid with which it was united, becomes a substance of an acrid nature, absorbs water with an evolution of heat, and, by this union, forms what is termed a hydrate. In absorbing water, it crumbles down by degrees, while at the same time it begins to imbibe carbonic acid from the atmosphere. 
In absorbing carbonic acid, the water of the hydrate is expelled, the carbonic acid taking its place. In this manner the lime recovers the principles which it had lost by calcination. It becomes again a carbonate, without, however, having recovered its hardness and external characters. In proportion as its recomposition takes place, it loses the properties which it had acquired by calcination, ceases to be acrid and caustic, and its solubility in water is diminished.

Lime is applied to the ground either in a state of hydrate, that is, immediately after being slacked, and when it still retains its caustic properties; or in the state of carbonate, that is, after it has again absorbed carbonic acid from the surrounding medium and become mild.

When the object is to supply calcareous matter to a soil in which it is deficient, it often appears to be unimportant whether it is applied as a carbonate or a hydrate. In the latter state, however, it is more perfectly divided, and may be spread more equally upon the surface, and better mingled with the soil ; and further, in its caustic state, it produces effects which it either does not produce in its mild state, or which it produces in a less degree.

Lime, in its caustic state, is observed to exercise a powerful action in decomposing the ligneous parts of plants. The same effect is indeed produced by the action of mild lime, but in a less perceptible degree.

Caustic lime, while it dissolves vegetable fibre, and renders it soluble, has also the property of forming compounds of a soapy nature with the soluble portion of vegetable and animal substances, which compounds are not dissolved till after a considerable time.

Caustic lime thus performs two functions apparently opposed to each other. It decomposes the inert vegetable matter of the soil, and then forms compounds which are not themselves readily soluble.

Lime forms these insoluble compounds with almost all the soft animal or vegetable substances with which it can combine; but these compounds, exposed to the combined 
action of the air and water, are altered in time; the lime gradually becomes a carbonate, the animal or vegetable matters are by degrees decomposed, and furnish new compounds capable of nourishing plants; so that lime, in performing two functions seemingly opposed to each other, really promotes the fertility of the soil and the growth of plants. It first disposes certain substances insoluble in water to become soluble, while, by combining in part with substances which are soluble, it prolongs the nutritive action of soft vegetable and animal substances beyond the time in which they would have acted, if they had not entered into a combination with lime.

Of this particular mode of action, an example may be given in one of the arts. When it is wished to carry off from the vegetable juices in the manufacture of sugar the animal substances which have been used, lime is einployed, which combines with these substances, and rises with them to the surface of the liquid in the form of a thick scum, which is insoluble in water. This scum, laid upon the fields, is injurious to plants; but when it is deposited in a ditch, and is allowed to ferment for a year, it forms one of the richest manures. Count Chaptal states that he has proved this fact during a period of many years in his manufacture of beet-sugar, by employing in this manner the scum which is obtained by the first operation which is performed on the juice of the beet.

In like manner the application of lime to night-soil, does not hasten the decomposition of this substance, but, on the contrary, forms with it a less soluble compound. It moderates its action, and renders its effects less sudden, but more permanent.

Mixed, too, with any pure animal substance, lime does not waste it, as, reasoning from its action on vegetable fibre, we might infer. It hastens decomposition indeed, but then it forms with the substances decomposed compounds less easily decomposable. Hence it is not opposed to theory that lime should be applied to the soil at the same time with dung and other animal and vegetable substances, as is frequent in the practice of farmers. 
Certain acids and acid combinations often exist in the soil or subsoil, and produce infertility. Lime, by forming new combinations with these bodies, frequently neutralizes their hurtful effects. Thus, if sulphate of iron, or green vitriol, which is a combination of sulphuric acid with the oxide of iron, exists in the soil, and lime be applied, the lime will combine with the sulphuric acid of the vitriol and form gypsum, and thus convert into fertilizing matter a substance which, in excess, is injurious.

Now, the carbonate of lime performs only in part these several functions; and although cases may exist where the application of the carbonate will be as effectual as that of the caustic lime, yet, in the great majority of cases, it is better that lime be applied in its caustic than in its mild state.

Absolute quicklime, however, i.e. lime at once taken from the lime-kiln, will decompose or destroy living plants; but it is never employed in this state by the farmer. It is always slacked, and generally suffered to slack gradually in the air, in which case it also attracts some carbonic acid, and then it may be employed without injury even to plants when growing.

Lime may be applied to the land in different ways, and at different periods.

1. It may be laid on the surface of land which is in grass, and remain there until the land is plowed up for tillage, even though this should be several years afterwards. The lime, in this case, quickly sinks into the soil, and acting upon it, prepares it for crops when it is again tilled.

2. It may be spread upon the ground, and covered by the plow, just after a crop of any kind has been reaped. In this case, it prepares the soil for the succeeding crops.

3. It may be spread upon the surface even when plants are growing. This practice, however, though sometimes convenient, is rarely to be imitated.

4. It may be, and is most frequently, applied during the season in which the land is in fallow, or in preparation 
for what are termed fallow crops. The manner of applying it in these cases will be afterwards explained.

5. It may be mixed with earthy matter, particularly with that containing regetable remains; in this case it forms a compost.

The quantity of lime applied to soils is very various, and is dependent upon the nature of the soils, the climate, and other circumstances. In warmer countries, a smaller quantity need be used than in those that are cold and humid.

The stiff clays for the most part require a larger proportion of it than the lighter soils ; and in the case of such soils as contain much undecomposed vegetable matter, as peat, a quantity should be applied sufficient to decompose effectually the inert fibre.

In the north of England and south of Scotland, a moderate application of lime for the lighter soils is held to be 120 bushels heaped measure, and a medium dose for soils of different kinds about 130 bushels, though a much larger quantity than this is frequently applied in certain clay-land districts. I speak here of newly-calcined limestone; for when it has imbibed moisture and becomes a hydrate, it swells out to about two times its former bulk.

The periods at which doses of lime should be repeated, differ according to the quantity applied and the manner of using it. In cases where the large applications just spoken of are made, an effectual liming need not occur in less than fourteen or fifteen years.

But, in other cases, lime is applied in smaller quantity, and more frequently, and there is nothing. opposed to a sound theory in this practice. Nay, there is reason to infer that a more frequent application of lime, and in smaller quantity, is the most advantageous method of using it.

The application of lime calls into powerful action the nutrient principles of the soil; and hence, if land be severely cropped after lime has been used, it is reduced to a greater state of sterility than if the stimulant had not been applied. Lime, therefore, calculated as it is to produce the best effects in fertilizing a soil, is frequently made 
the means, in the hands of an injudicious farmer, to injure it. This is especially observable in the case of light soils of an inferior kind. These are frequently so injured by injudicious cropping after the application of lime, that they are reduced to a state of the greatest barrenness. When soils are brought to this condition by scourging crops, they cannot be restored to fertility by a subsequent application of lime. So far from this, the future dose generally renders them more barren than before. The only good remedies are the application of vegetable and animal manures, and rest in grass.

But although the stimulating properties of lime may be abused, it is an instrument of production of the highest importance in the hands of the skilful farmer. On land improved and cultivated for the first time, it exercises a very powerful influence, and it is difficult to conceive how in many parts such land could be improved at all without the assistance of this mineral.

Lime is found to improve the quality of plants produced, to render those cultivated more productive of farine matter, and even to cause species that were not before growing naturally to occupy the ground. Thus, lime spread upon a piece of peaty land, is frequently found to eradicate in whole or in part the heaths, and to permit the grasses and clovers to take their place.

Whenever it is found advisable to deepen a soil by plowing up a portion of the subsoil, the application of lime is the most speedy means presented to us of correcting the defects, or stimulating the productive powers, of the new substance exposed.

To admit of the beneficial action of lime, the soil should be freed of superfluous water. Not lime only, but all manures, are inefficient when the land is saturated in consequence of the excess of wetness.

In the 'Farm House of the 19th century,' we have the following valuable article on Lime :-

Lime suits soils which do not already contain in excess the calcareous combinations. Every soil which consists of granitic debris, of slate, almost all the sandy clay soils, 
those moist arid cold soils of the immense argilosiliceous table-lands which confine the basins of our laroge rivers, the ground upon which the fern, the small ajonc, the broom, the little white carex, and the whitish lichens grow spontaneously; almost all the soils infested with beaded oats, dog's-tooth, agrostis, red sorrel and small motherwort; that which yields only rye, potatoes and black grain; where the sainfoin and most of the vegetables of commerce do not succeed; where, however, trees of every sort, and especially those of a resinous nature, the wild pine, the maritime pine, the larch, the Weymouth pine, and the chestnuts flourish better than in better soils; all these soils do not contain the calcareous element, and all the amendments in which it is found will give them the qualities and cause them to yield the product of calcareous soils.

But here, more than elsewhere, we must guard against too much hasie; the liming on a large scale should not take place till after having succeeded in experiments upon a small, in different parts of the estate.

\section{Of the various modes of employing lime upon the soil.}

Three modes are principally in use for spreading lime. The first and the simplest, that which is employed in most places where lime is cheap, cultivation little advanced, and manual labor dear, consists in putting the lime immediately upon the soil in small heaps, distant from each other twenty feet in the mean, and containing, according to the dose administered, from one-half foot to one foot cubic measure. When the lime in consequence of its exposure to the air, is reduced to powder, it is spread upon the soil in such a way as to be equally diffused.

The second method differs from the first in this, that we cover each heap with a thickness of from six inches to one foot of earth according to the size of the heap, and which equals five or six times the bulk of the slacked lime; when the lime begins to swell in slacking, the cracks and crevices of the heap are filled with earth, and when it is reduced to powder it is worked over, to mix the earth and the lime. If work is not driving, the same operation is 
repeated a fortnight "after, and in another fortnight the whole is spread upon the soil.

The third process, used in countries the best cultivated, where lime is dear, and which unites all the advantages of liming without some of its inconveniences, consists in making compost of the lime and earth or mould. For this purpose a bed is first made of earth, mould or turf, one foot thick, of a length double its breadth; the clods are broken; and it is covered with a layer of lime one hectolitre to 20 cubic feet (that is 3,5 cubic feet of lime to 20 of mould, or: about one-sixth), upon this lime is placed a second layer of earth, then a second of lime, then a third layer of earth and of lime, which is finally covered with earth. If the earth is moist and the lime fresh, eight or ten days will suffice to slack the lime; the compost is then cut down and mixed; it is again pitched over before being used, because the older and more perfect the mixture the more powerful is its effect upon the soil, and especially when it may have been made with earth containing more humus. This metlod is most used in Belgium and the Netherlands; it is almost the only one in Normandy; it alone is practised, and with the greatest success, in Sarthe. Lime in compost never injures the soil ; it carries with it the surplus of manure required by a surplus of products. Light gravelly or sandy soils can never be orercharged with it. Finally, this mode of applying lime to the soil seems to us the surest, most effective, and least expensive.

The reduction of lime to powder by means of momentary immersion in water in baskets with handles can much hasten the liming, whether it be done immediately upon the soil or by means of compost; a few hours then suffice instear of waiting a fortnight. If great rains succeed, this operation is not without inconveniences, for then the lime more easily turns into paste and this is what above all things should be avoided.

The reduction of lime to powder, whether done spontaneously or by immersion, produces in the compost a bulk one-half larger than lime in the stone; ten cubic feet, for instance, produce fifteen. 
The liming in use in different countrics.

1. Liming in the Department of Ain.-The use of lime in this country dates back fifty years; the soil limed at that period is still more productive than the neighboring soil not limed. Nevertheless, the liming is only beginning to extend itself, while marling, commenced fifteen years later, has already covered some thousands of acres; this is because marling is an operation within reach of the poor cultivators, because it is effected by manual labor only, while liming requires considerable advances, especially in a country where lime is dear, and the dose employed large.

Indeed the doses vary from 60 to 100 bushels per acre, according to the nature of the soil, or rather according to the caprice of the cultivator.

Although the limings here have not been practised with all the care and economy which are desirable, they have been very efficacious when the soil limed has been sufficiently drained.

The registers of the products of three contiguous estates, during 12 years, 3 before and 9 during the limings, give us the means of appreciating their results. The quantity of seed and the products are calculated in double decalitres. [The decalitre contains about 2 gallons and 1 pint.]

Table of the products of the estate of Croisette.

\begin{tabular}{c|r|r|r|r}
\hline YEARs. & \multicolumn{2}{|c|}{ RYE. } & \multicolumn{2}{c}{ WHEAT. } \\
& Seed. & Product. & Seed. & Product. \\
\cline { 1 - 4 } 1822 & 110 & 600 & 24 & 146 \\
1823 & 110 & 764 & 24 & 136 \\
1824 & 110 & 744 & 24 & 156 \\
1825 & 107 & 406 & 27 & 251 \\
1826 & 106 & 576 & 28 & 210 \\
1827 & 100 & 504 & 30 & 249 \\
1828 & 90 & 634 & 36 & 391 \\
1829 & 82 & 538 & 48 & 309 \\
1830 & 60 & 307 & 60 & 459 \\
1831 & 78 & 350 & 48 & 417 \\
1832 & 55 & 478 & 68 & 816 \\
1833 & 61 & 529 & 52 & 545
\end{tabular}


LIME.

Table of the products of the estate of Meyzeriat.

\begin{tabular}{l|c|c|c|c}
\hline \multirow{2}{*}{ YEARS. } & \multicolumn{2}{|c|}{ RYE. } & \multicolumn{2}{c}{ WHEAT. } \\
& Seed. & Product. & Seed. & Product. \\
\hline 1822 & 120 & 487 & 16 & 100 \\
1823 & 120 & 708 & 16 & 103 \\
1824 & 120 & 644 & 18 & 84 \\
1825 & 112 & 504 & 28 & 228 \\
1826 & 120 & 677 & 20 & 115 \\
1827 & 115 & 594 & 20 & 162 \\
1828 & 118 & 726 & 40 & 328 \\
1829 & 104 & 566 & 41 & 277 \\
1830 & 79 & 298 & 71 & 477 \\
1831 & 91 & 416 & 43 & 326 \\
1832 & 79 & 411 & 75 & 786 \\
1833 & 76 & 661 & 48 & 351
\end{tabular}

Table of the products of the estate of Baronne.

\begin{tabular}{|c|c|c|c|c|}
\hline \multirow{2}{*}{ YEARS. } & \multicolumn{2}{|c|}{ RYE. } & \multicolumn{2}{|c|}{ WHEAT } \\
\hline & Seed. & Product. & Seed. & Product. \\
\hline 1822 & 110 & 505 & 22 & 180 \\
\hline 1823 & 110 & 652 & 22 & 138 \\
\hline 1824 & 110 & 662 & 24 & 149 \\
\hline 1825 & 102 & 398 & 32 & 252 \\
\hline 1826 & 110 & 612 & 32 & 187 \\
\hline 1827 & 107 & 546 & 34 & 204 \\
\hline 1828 & 98 & 696 & 35 & 343 \\
\hline 1829 & 84 & 608 & 40 & 268 \\
\hline 1830 & 91 & 389 & 59 & 374 \\
\hline 1831 & 92 & 411 & 40 & 295 \\
\hline 1832 & 70 & 512 & 80 & 649 \\
\hline 1833 & 75 & 511 & 51 & 471 \\
\hline
\end{tabular}

The use of 3000 hectolitres (8255 bushels) of lime costing 6000 francs ( $\$ 1142)$, upon 32 hectares (72 acres) of ground, successively during nine years, has therefore more than doubled the product of winter grain, the seed being first deducted. The other crops of the estate have received a proportional increase, and the income of the proprietor by doubling has been increased annually by at least two-thirds of the capital sum expended in the purchase of lime, and yet he has not half his arable soil limed, 
since of 76 hectares only 32 have received the amendment.

Numerous other examples confirm these results, and it is shown particularly that the product of wheat is increased from twice to three times the seed, that rye lands pass from a product of from four to five times in rye to one of from seven to eight times in wheat, and that the other products have a proportional increase. The amelioration is much more considerable upon bad farms than upon good ones,- - since it is two-thirds and more in wheat lands, and the crop is threefold in value upon rye lands.

2. Flemish Limings. - The use of calcareous amendments in the department du Nord as well as in Belgium, appears to be as old as their good agriculture; it is much less frequent in Belgium. The former and successive limings have, it would seem, furnished to a great part of the soil all the calcareous matter which is for the present necessary; but the department du Nord still receives lime, marl or ashes, almost whenever lime is not an original constituent of the soil. In this country there is a distinction between deep liming and the liming of the rotation; the first consists in giving to the soil, every 10 or 12 years, before the autumnal sowing, 4 cubic metres or 40 hectolitres (about 110 bushels) of lime to the hectare (nearly 50 bushels to the acre); the ashes of coal and of peat are usually mixed with the lime, and form from one-third to half the bullk.

The liming at each renewal of the rotation or upon the spring grains, is given in compost ; it is the regular practice in this country, more even than in Belgium, upon the meadows and cold pastures which are not subject to irrigation; it warms the ground and increases and improves the products; the older the compost is, the greater is the effect; it is prolonged for 15 or 20 years; at the end of which it is renewed.

The limings of Normandy, the oldest in France, are maintained about Bayeux, whilst elsewhere they are forbidden in the leases. However, they still get all the sur- 
face which has need of them, but instead of an immediate application to the soil as formerly, the lime is almost always in compost.

3. Liming in Sarthe.-Of all modes, that of Sarthe seems to me preferable; it is at the same time economical, productive, and guards the soil from exhaustion. It is applied once in three years-at each renewal of the rotation, at the medium dose of twelve bushels per acre; in compost made beforehand with seven or eight times as much mould or good soil as lime. The compost is used upon the soil for the autumn sowing in alternate rows with dung. This process, which grows daily more successful, is much spread upon the banks of the Loire, and would seem worthy of adoption wherever the soil easily drains.

We thought it our duty to insist upon the propriety and advantages of using lime and manure simultaneously. Here they do better still by employing the compost of lime and earth simultaneously with dung; hence for half a century since the people of Mans commenced their liming; the fruitfulness of the soil has not ceased to increase.

The countries of which we have spoken are those parts of France where liming is most extensive; however, more than half the departments have commenced the practice, I think, and in one fourth it is thoroughly established. Doubtless the first trials may not everywhere succeed, and it would require a union of rare circumstances to cause some successful trials to be imitated by the masses; still, instances of success multiply, and become centres of impulse which will propagate the amelioration.

4. English Liming.-The use of lime in EngIand seems to be established upon a different principle from that in France; it is practised with such prodigality that there is frequently no room for the soil to be improved afterwards. Whilst in France we give lime to the extent of from one thousandth to one hundredth part of the arable bed, that is from 12 to 120 bushels per acre, in England they give from $1-100$ to $6-100$, or from 120 to 720 
bushels per acre. The full success of our method causes us to regard the English method as a piece of useless prodigality. A capital five, six or ten times larger, is sacrificed without securing any better result. And, unless manure be afterwards lavishly bestowed, the future productiveness of the soil may be endangered in the hands of a greedy cultivator. However, on very moist soils there seems to have resulted little inconvenience, probably on account of the nature of the soil; indeed such soils have by this means been rendered healthful and kept so for a long time.

5. Liming upon the surface.-In Germany, where liming and marling, like most other agricultural improvements, have lately taken a great development, besides the ordinary modes we find the use of lime upon the surface. It is sprinkled in spring upon rye with compost containing from 10 to 12 bushels to the acre fifteen days after having sown clover.

It is also applied directly to the clover of the preceding year, in powder, and slacked in the water of the dung heap, in a dose one half less. Its effect upon the clover and the wheat which follows it is exceedingly good.

In the Netherlands where lime is employed mixed with ashes, it is especially for mowing land natural or artificial, and is of course used upon the surface.

\section{Care to be taken in the use of lime.}

Whatever may be the mode in which lime is applied, it is essential that it, as well as all other calcareous amendments, should be employed in the shape of powder and not of paste, upon a soil that is not wet. We must altogether avoid, before covering it, all rain which can wet it, and reduce it to a porridge or paste, which essentially injures its effect, even more than any reasoning can explain.

It should not be placed upon a soil whose surface is not naturally drained. Upon a marshy soil, unless the vegetable bed is well dried, in a very moist soil where the water of the surface does not easily run off, the properties of 
the lime remain chained as it were, and do not appear at all till by new operations we have healed and dried the vegetable bed.

Un a clayey and very damp soil, marl, which is used in large quantity, is preferable to lime, because it more powerfully heals the productive bed. On a soil of this sort a deep plowing is a preliminary condition essential to success, because, while augmenting the depth of the vegetable bed, we also augment the means of healing the surface.

Light, sandy or gravelly soil must not be overcharged; for the inconsiderate use of lime may become dangerous on soils of this sort when they are too warm and not very deep. There are cases of its having burned up the crops.

To have the lime produce its effect upon the first crop, it should be mixed with the soil some time before the sowing; however, when it is used in compost it is sufficient that it should have been made some time previously.

The lime or the compost spread dry upon a dry soil should be buried by a shallow first plowing or half-plowing preceded by a light harrowing, in order that the lime in the succeeding cultivation may remain as much as possible in the middle of the vegetable bed. Indeed, the lime reduced to particles, naturally sinks in the soil ; it slips between the particles of clay and silex, and descending below the sphere of the nutrition of plants, is arrested beneath the arable bed, and when it is abundant, then it forms by its combinations a sort of floor which stops the water and injures the crops very much; this is the mischief of lime in a large dose buried by deep plowing.

\section{Different qualities of lime.}

It is necessary to know the quality of the lime which we use; lime may be pure or may be mixed with silex, clay or magnesia. Pure lime is the most economical, the most active, and can produce the greatest effect with the least volume.

Lime mixed with silex is used in larger quantities; it takes the name of hot lime, like that which precedes, from which it differs little in the application except it requires more. 
Lime mixed with clay is the same as the hydraulic or water lime of the builders; it appears that the two former favor the growth of seed more, and the latter is more favorable to forage, to the growth of the straw, or the legumes; it is more nourishing to the soil, but requires a larger dose.

Magnesian lime is very active, but exhausts the soil if given in too large a dose or not followed with abundant manuring. It has exhausted some districts in England and large tracts in America, and it is to it that most of the reproaches against lime belong. The nature of the lime used may be ascertained by very simple chemical processes. (See the section which treats of the analysis of soils at the end of the preceding chapter.)

\section{of second limings.}

When the field limed returns to the condition in which it was before the operation; when the same weeds appear and the crops are diminished, it is time to renew the lime. The period of the second liming will depend upon the dose of the first. When the dose has been small, it must be renewed entire, as is done in the Netherlands and Normandy. When it has been large it may be reduced to one half. Besides, we should in this case take counsel of the state of the soil and experience, for there are some soils which require and consume larger doses than others.

\section{The doses of lime.}

The doses of the first as well as the second limings vary with the consistence of the soil ; they should be small in light and sandy soils, they can without inconvenience be large in clay soils. The dose should also vary according to the drainage; weals doses on ground where the water does not easily run off are little felt; but if the dose is strong and the plowing deep, the lime facilitates the draining and healing of the soil. It is supposed that the dose ought also to increase with the annual amount of 
rain which falls in a country, because, as this amount increases, the greater is the drainage to be effected.

However, the experiments of the department of Nord and of Sarthe seem to have pointed out the average dose which generally suits. Thus, the deep liming of du Nord which gives the soil every ten or twelve years forty-eight bushels per acre, a little more than four bushels per annum, which agrees with that of Sarthe which gives from ten to twelve bushels every three years; the first gives at once what the other does by degrees. As both are an average, we may conclude that the soil requires four bushels per acre per annum to sustain its fertility. Still, as neither the soil nor the plants consume this lime, it is probable that after a period, longer or shorter, the soil will have received so much as to need no more for a certain space of time.

\section{Management of limed soils.}

After having endued the soil with great fecundity, and put it in condition to produce the most valuable crops, which are often the most exhausting, the farmer must take care to give it manures to compensate for the products obtained, to use in litter and not for food half the straw raised, to cultivate forage on soil which henceforth produces it to advantage, to modify, in short, in the general and in the detail, his cultivation according to the new forces of his soil, the prices of the market and the convenience of the locality. However, there should be no haste to change the rotation: such an operation is long, difficult, very expensive, and should not be undertaken except on thorough preparation.

\section{The effects of lime upon the soil.}

The effects of lime, although analogous, are not identical with those of marl, and the qualities of limed soils differ in some respects from those of calcareous soils; the wheat of limed ground is sounder, fairer, gives less bran 
and more flour than that on soil not limed, on calcareous soil or on marled soil ; the berry on marled soil is greyer, yields more bran and more resembles wheat upon clover, though it is preferable to that; the wheat upon limed soil bears more analogy to that upon land amended with leached ashes. The limed soil has less to fear from drought to its springing grain than the calcareous or the marled; it is not liable to have its crop lodged, in the spring, at the moment of blossoming, when the sowing has been done upon a dry soil. Upon a limed soil the weeds and insects disappear, the ground acquires consistence when it is too light, and grows lighter when it is too clayey. The surface of an argilo-siliceous soil, before compact and whitish, grows mellow and turns reddish and as it were rotten, it dries, hardens and cracks by the heat, and dissolves and slacks by the rain which follows; this spontaneous mellowing very much facilitates the labor of the cultivator, the struggle and progress of the roots through the soil and the mutual action of the atmosphere and the soil which remains open to its influence.

\section{Quantity of lime absorbed by vegetation.}

The vegetables of calcareous soils or those which have become such by amendment, contain in their ashes 30 per cent of carbonate or phosphate of lime which has been lost by the soil. But the products of a limed soil, of a medium quality, are nearly, during two years of the rotation, nine thousand weight of dry products per acre, which contains about one bushel of lime; vegetation has therefore employed half a bushel of lime per year. We have seen that on an average more than three bushels are requir?d per year; vegetation therefore does not absorb in substance more than one-sixth of the lime which can be profitably administered to the soil ; the other five-sixths are lost, carried by descending water to lower beds, or enter into different compounds ; a portion doubtless still remains in substance in the soil, and goes to form that reserve which at length permits liming to be dispensed with for many years. 


\section{Of the exhaustion of the soil by lime.}

Lime, it is said, only enriches old men, or it enriches the fathers and ruins the children; this indeed has been clearly proved by experience, when upon light soils, limed abundantly or without intermediate composts, grain crops have been placed successively, without restoring manure to the soil in due proportion, or when magnesia mixed with the lime has exerted injurious influence upon the soil; but, when the lime has been used in proper measure; when, without overtasking the soil with exhausting crops, the latter are alternated with grasses; when manure has been given back in proportion to the products obtained, the prudent cultivator sees a continuance of the new fecundity which the lime has brought without his soil showing any sign of exhaustion.

Clay soils are nowhere spoken of as having to complain of lime, and the fecundity is sustained in light soils wherever the lime is used in compost and with moderation.

In America where the lime of oyster shells has taken the place of magnesian lime, complaints of the exhausting effect of lime have ceased.

After having presented the above article from the ' Farm House,' which, with what precedes it, must satisfy any reasonable mind, of the advantages to be derived from the judicious use of lime, we shall close what we have to say on this subject with a communication taken from the Farmer's Cabinet, written by a scientific practical farmer, and which presents additional inducements for the use of this salt:

Some years since I purchased a horse, but he had the appearance of laboring under disease; I commenced a course of treatment which I had before pursued in cases similar to appearance, but without effect; I was therefore induced to try the use of lime, as I was confident he was filled with botts, for he had discharged several; I therefore commenced by giving him a table-spoonful of slacked lime three times a week in bran mashes. After pursuing this 
course near two weeks, the botts began to pass away in quantities, varying from ten to twenty, which he would expel from his intestines during the night; in the meantime his appetite began to improve, and in six weeks he was one of the finest geldings I ever saw. From that day to this I have kept up the use of lime amongst my horses with decided benefit; and as an evidence of its good effects, I have not lost a horse since I began to use it. And lime is a certain preventive in keeping cattle from taking: the murrain. As an evidence of this fact, I have used it among my cattle three times a week, mixed with salt, for three or four years, and in that time I have not lost a single animal by this disease; but in the mean time some of my neighbors have lost nearly all the cattle they owned. But I will give a stronger case than even the one above mentioned. One of my neighbors, who lost all his cattle, had a friend living within two hundred yards of him, who had several cattle which ran daily with those that dierl, and his cattle all escaped-he informed me that he made it an invariable rule to give his cattle salt and lime every morning. I have, therefore, no doubt but salt and lime are a sure and infallible remedy for botts in horses and murrain in cattle."

And I am reminded of a circumstance by a friend, who has often before mentioned it; he had two fields of pasture near his house-on one of these he spread lime upon the turf to the amount of more than 200 bushels per acre, but as the other fields lay immediately below his cattle-yard, from whence he had formed drains to carry the water over its surface in the most complete manner, he determined to let that suffice for a dressing; and the effects of the highly impregnated water from the yard was a growth of grass truly astonishing. Both fields were kept in pasture, and when the stock had eaten one of them down, they were removed to the other, and so changed regularly about; but the effect of the different crops on the appearance of the stock, horses and cattle, is not to be expressed, for while feeding on the limed land their coats were close, 
shining and healthy, and their spirits light and cheerful, even when they were compelled to labor hard to obtain a belly-full ; but when turned into the watered grass, six inches or more in height, a difference for the worse could be perceived in 24 hours, and every day after they lost condition amidst the greatest abundance, with coats rough and staring, lax in the bowels and flaccid, with distended paunches, dejected countenances, and sluggish in their movements : they soon exhibited a depreciation in value to the amount of about half their former worth. But the transition to health and vigor and good looks was quite as sudden and apparent on a return to the limed land, for again in 24 hours, or by the time the food had passed through the system, a change, particularly in their air and carriage, was very perceptible. My friend adds, he never had an instance of the murrain or botts while his stock fed on these pastures, but is satisfied he should have had both, but for the change to the limed land; for while feeding on the watered pastures, the stock had always the appearance of a predisposition to that state of derangement of the digestive system, by which he has no doubt these diseases are engendered.

In conclusion, I would ask, is it not quite fair to draw the following deduction from what has been said, namely, that all dairy pastures ought to be heavily limed, it being the most natural thing in the world to suppose that a proper secretion of milk, the best and most wholesome, depends very much on the nature of the focd with which the animals are fed? and must not butter from a cow that is in health and spirits, be of better flavor, color and consistence, than that from one that is lax, washy and weak, from feeding on watery, acid, and soft herbage ? and will not this account for much of the disgustingly rancid, illflavored and ill-looking butter which we so often find in the market? My friend above quoted, and who is now at my elbow, answers, "Yes; for while my cows fed on the watered meadow, the butter was scarcely eatablewhite, soft, and ill-flavored; but it was sweet, firm, and 
flavored, when they were confined to the limed land."." Ergo, lime your pastures, and allow your stock as much salt as they will consume daily, for I am convinced that lime and salt are a remedy for "botts in horses," as well as the "murrain in cattle."

\section{CHAPTER III.}

MARL.

: Marls, which exert so powerful an influence on many soils, derive most of their value from the lime they contain; and with few exceptions, their power as fertilizers may be measured by the per centum of lime shown on analysis. There are some marls, however, which are an exception to this rule; their value appearing to depend on other matters than mere lime. Of this kind is the celebrated green sand marl of New Jersey, and some other points of the Atlantic coast. In this formation, which acts so powerfully as a manure, there is from 6 to 10 per cent. of potash; an agent which, on light soils, is scarcely equalled as a manure. In addition to the lime which marl contains, the influence of the proportions of sand and clay, of which the balance usually consists, must be taken into consideration in determining the value of this substance for particular soils. Thus, on heavy or clay lands, marls abounding in sand will be found preferable to those the base of which is clay; and on light or sandy soils, the latter will be much the most useful, the per cent. of lime in both cases being alike. Marl should be spread over the surface, and pulverized by the action of air and frost before it is plowed under. When so treated, experience proves it is a most valuable manure, and a single dressing exerts an influence for many years. 
But here, as on the subject of lime, we shall draw largely from the 'Farm House.'

\section{Composition, discovery, and choice of marl.}

Natzere and composition of marl.-Marl is a compound of carbonate of lime and clay more or less sandy; it is generally found on the skirts of alluvial plains, and under the bed which forms them, at greater or less depth. Thus Sologne, upon all its banks and in most of the basins which furrow it ; Brosse, under its white soils ; the environs of Toulouse, under their hillocks; Puisaye, beneath its pale earths ; and Normandy, upon its cold soils, find marl as if placed by some benevolent hand to give to these soils an activity and productiveness which nature had not imparted to them.

Marl presents itself under different aspects and varieties and of variable composition. It hardens in proportion to the carbonate of lime, till the latter amounts to 70 per cent. when it begins to be stony; beyond 80 per cent. it ceases to be profitably employed upon the soil. Marls in powder, are met with, which contain a very large proportion of carbonate of lime.

The difference of composition and change of appearance have caused the divisions of marl into clayey, sandy, and stony; denominations rather vague, it is true, but still useful in practice.

The discovery of marl.-The importance of marl in agriculture warrants a search for it whenever it can be of use. Coltsfoot, ononis, sage, yellow clover, briers, thistles and melampyre, are ordinarily signs of marl at no great depth; the digging of ditches and wells often brings it up ; oftener still it is found in gullies upon the declivities; sand beds also indicate it, they almost always cover or support it.

If there are none of these signs it may be sought by soundings; but deep soundings involving much expense, the extraction of the marl would cost too much, and we 
should often meet with water, which would prevent any economical improvement. However, when the water is not in the way, the extraction from considerable depths may be less expencive than its transportation from distant places. The extraction of marl from a great depth is not new in France. Pliny speaks of marl raised in Gaul from a depth of more than one hundred feet; in Normandy it is still extracted in this manner; the use of oxen or horse power much diminishes the labor in this case.

In soil where water occurs at small depths, deep soundings are useless, a small sound suffices. It consists of a bar of iron of ten or twelve feet in length terminated by a point of steel surmounted by a spoon; it is worked by an auger handle which traverses the bar, and is raised or lowered at pleasure and fixed by a tightening screw.

The marl is nearer the surface in places where the soil appears drier or the argilo-siliceous soil is reddish rather than grey. When found, if not deep, it is better to bring it up under the open air; in this case a few veins of water will not hinder the work; the bed so far as opened is thrown up in one day; in the night the hole becomes nearly full of water, and the next day it is cleared out or an opening is made on one side, leaving a dilke on the side next to the water.

When we have found marl, or that which appears to be such, for nothing more resembles the earthy marls than some clays, we prove its nature by touching it with nitric or muriatic acid, or even strong vinegar ; an effervescence announces marl, but if the acid spreads without swelling we have only clay. Again, if we throw into water a piece of dry marl there is at once a slight boiling, its particles separate as if by a repulsion, and form a porridge at the bottom of the vessel; this is itself one of the peculiar properties which it communicates to the soil in a high degree. These characteristics are not all found to the same extent in stony or clayey marls: the stony marl has often need of the aid of frosts upon the soil to bring it to slack.

Soils that are suited to marl.-Marl acts by the carbon- 
ate of lime which it adds to the soil, for clay alone produces only a mechanical effect; the smallest quantity of the calcareous principle makes an impression upon soil which does not contain it, but in calcareous soils its use is oftenest injurious. The use of a few loads of marl before sowing in winter or spring is the best experiment to decide the question.

\section{Modes of marling in different countries.}

There are more different modes of marling than of liming. In most countries marlings are the result of accident. The earth from pits, ditches or wells, has been thrown out upon the soil and produced unexpected fertility; if the cultivator is active and enterprising, he extends the operation to his other grounds, and if he inspires confidence in his neighbors the marling is propagated; but then the modes are regulated by chance, and the doses are almost always too large, because it is thought that the soil cannot have too much of so good a thing.

We do not find between the English and French use of marl the same disparity as in the case of lime. What is most worthy of imitation in the English method is the association of manure with the marl; they unite them often in compost; their doses of marl are greater for the first than for the succeeding marlings ; the first are four or five lines in thickness on the surface, and the second onethird as much or more, and they follow at intervals of fifteen or twenty years. The doses vary afterwards according to the consistence of the soil and quality of the marl. In some districts they marl their pastures and meadows that are not irrigated ; marl is employed to increase the grasses and lime to increase the grains. Marling has changed the face of some whole counties: Norfolk, formerly covered with broom and heath, has become by means of marling the model province in agriculture. The strong marl under the name of calcareous gravcl fertilizes large portions. In Ireland a quantity of it has been placed 
upon the soil sufficient to change its nature and to do away the necessity of repeating the operation.

The use of marl in the Netherlands is as ancient as that of lime. It has there become a regular agricultural operation, and consists of ten two-horse wagon loads to the acre of a very rich strong marl; this dose is nearly equal to five hundred cubic feet per hectare (about two hundred and twenty cubic feet to the acre), covers the soil scarcely two-thirds of a line in thickness, and forms perhaps onehundredth of the arable bed. The arrondissements of Bergue and Hazebrouck use it upon two-thirds of their surface ; and the other arrondissements use it less because they use more lime. The stony marl is taken from the neighborhood of St. Omer; it costs from eighty cents to one dollar per load, because they often go more than a league to get it. The marling is renewed every twenty or thirty years ; this marling costs three times as much as liming upon farms exactly analogous, that is to say, from forty to sixty cents per acre per annum on an average, while the liming costs but from one and a half to two francs.

The marlings upon the argilo-siliceous table land of Puisaye (Yonne) are done with a stony marl and very copiously; they amount to fourteen hundred cubic feet per acre, form a bed upon the soil of four lines in thickness of a marl which contains eighty per cent. of carbonate of lime. This abundance is explained by the fact that the marl slackens with difficulty, and that a winter and often even several years do not suffice to effect it completely. The marling has been practised in some parts from time immemorial, so that there the doses are not more than one-third or one-fourth as much; it only began to extend itself about forty or fifty years ago ; now the surface is nearly all marled, and the soil has tripled its value wherever it has received this amelioration.

The marling in the vicinity of Montreuil in Picardy covers the soil one line in thickness nearly, with a marl of excellent quality, which is extracted from beneath the soil itself by means of pits; this marling, which is renewed 
every twenty years, costs one dollar and seventy cents per acre.

The marlings of Normandy and Upper Garonne would teach us nothing of importance; those of Isère, on the other hand, may give us a useful lesson. They are made upon a soil of siliceous gravel with a gravelly marl which belongs to the suh-soil; this soil is a part of the great alluvion of reddish siliceous gravel which covers three-fourths of the basin of the Rhone, and which is composed of the rounded debris of the primitive Alps, cemented with a reddish earth. These marlings, originating in chance and made with marl close at hand, are very abundant; they cover the soil with a bed of four to five lines in thickness, with a gravelly marl which contains from thirty to sixty per cent. of carbonate of lime. This quality of marl thrown upon a dry soil at least doubles its products; the cultivator formerly had almost without manure every two years a crop of rye which nearly tripled the seed; now he reaps for eight or ten years after the marlings eight to one of wheat; the crop, however, has diminished gradually, and is now, after forty years of marling, reduced to four to one; those who have not seen the crops before the marling complain of the exhaustion of their soil, but the gross product is still three-fold what it was before. Moreover, we here find united all the circumstances which should lead to exhaustion; strong doses of very rich and sandy marl upon a dry gravelly and loose soil; a cultivation void of grass and a succession of the most exhausting crops. Hence it results, that upon the driest parts of this soil, which could not bear a tree and scarcely a shrub, the ground has become still drier, and with winter grains of double the value of the old ones, the spring grains, it is true, and especially the clover, have more than ever to dread from drought. The operation of marling, which could be extended with so much advantage over ten times as much of the same soil from Geneva to the sea, over Bugey, Valbonne, the plains of Valence, the heaths of Comtal and the plain of Cran, is but just beginning to extend beyond $3^{*}$ 
a few cantons of Isère: the successful trials in Ain and Drome have been but little extended.

The marls of the great argilo-siliceous table land covering a part of Ain, of Saone and Loire, and of Jura, are clayey and contain thirty or forty per cent. of carbonate of lime; their efficacy was brought to light by a cultivator of Ain. The old practice, for forty years, of amending the soil with large masses of earth carted, has induced great abundance in the use of marl; they began with a bed of fifteen or eighteen lines over the whole surface, as in the ordinary use of earth. This dose was afterwards reduced one-third, afterwards one-half, a quantity still enormous, since in that country, where the plowings are but three inches at most, the marlings form one-fourth or one-third of the arable bed.

The cultivators of Saone and Loire have imitated these marlings without their abuse ; they give to a similar soil not more than one-fourth of a marl which has frequently not more than thirty per cent. of carbonate of lime, and these marlings are doubtless less durable, but they are as productive as those of Ain.

The strong doses of marl have done injury in some places; in a very clayey soil, the tenacity has been increased and the working rendered very difficult; buckwheat and potatoes have not succeeded so well; and on light and sandy soils, without much improving the consistence, it has rendered the soil too warm and multiplied the wild poppies and rhymanthus.

We find in Sologne a striking instance of the amelioration of light and sandy soils by marls : the dose of clayey marl, similar in composition and appearance to that of Ain, is from seventy-five to one hundred cubic feet per acre, and this dose of two-fifths of a line upon the surface is sufficient to enrich the soil for ten years.

\section{Of the dose of marl to be given.}

Among so many methods we can, however, for soils of a medium consistence, arrive at the reasonable dose of 
marl which will afterwards be modified according to the nature of the soil ; this will be a great service to practical agriculture, which needs precise information on this point.

The object of marling is to bring the soil to possess the qualities and advantages of calcareous soils. Now, the analysis of the better calcareous soils, the better soils of the Netherlands among others ; the practice of the countries where marling is the oldest and best understood; the doses prescribed by THAEn; the review of numerous marlings given by Arthur Young, have led us to conclude, in our essay on marl, that the proportion of three per cent. on an average of carbonate of lime in the arable bed ought to be sufficient; but the marls are more or less rich, and the plowings by greater or less depth give more or less of the arable bed; with the fixed proportion of carbonate of lime which we have assumed, the doses of marl should vary according to the richness of the marl and the depth of the plowing.

To facilitate the application of this result of experience and reason, we give a table which contains all the elements of marling and of which it will be easy to make use; it is adapted to all the different compositions of marls from ten to ninety per cent. of carbonate of lime, and for all arable beds from three inches to eight; by taking the intermediate terms we shall have for all depths of plowing and for all qualities of marl the number of cubic feet to be carried upon one hectare; ${ }^{*}$ the cubic feet will bo estimated from the capacity of the carts because the marl in slacking upon the soil gains a bulk equal to that it occupied in the cart at the time of estimation.

* The hectare is nearly cqual to two and onc-quarter acres.-Trans. 


\begin{tabular}{|c|c|c|c|c|c|c|}
\hline $\begin{array}{r}\text { NUMIEER } \\
\text { A inches. }\end{array}$ & $\begin{array}{l}\text { OF CUB1 } \\
\text { AN ARAB. } \\
4 \text { inches. }\end{array}$ & $\begin{array}{l}\text { IC FEET } \\
\text { LE BED } \\
5 \text { inches. }\end{array}$ & $\begin{array}{l}\text { OF MIARL } \\
\text { OF A THI } \\
6 \text { inches. }\end{array}$ & $\begin{array}{l}\text { NECESSA } \\
\text { CKNESS } 0 \\
7 \text { inches. }\end{array}$ & $\begin{array}{l}\text { RY FOR } \\
\text { F } \\
8 \text { inches. }\end{array}$ & $\begin{array}{l}\text { When one } \\
\text { hundred parts } \\
\text { of marl con- } \\
\text { tain in carbo- } \\
\text { nate of lime. }\end{array}$ \\
\hline Cubic feet & Cubic feet & Cubic feet & Cubic feet & Cubic feet & Cubic fee: & Parts. \\
\hline 7.106 & 9.474 & 11.842 & 14.212 & 16.580 & 18.948 & 10 \\
\hline 3.553 & 4.737 & 5.921 & 7.101 & $8.2 \% 0$ & 9.424 & 20 \\
\hline 2.368 & 3.188 & 3.947 & 4.737 & 5.527 & 6.316 & 30 \\
\hline 1.776 & 9.368 & 2.860 & 3.552 & 4.144 & 4.736 & 40 \\
\hline 1.420 & 1.880 & 3.350 & 2.820 & 3.290 & 3.720 & 50 \\
\hline 1.179 & 1.570 & 1.962 & 2.354 & 2.748 & 3.140 & 60 \\
\hline 1.020 & 1.360 & 1.700 & 2.040 & 2.280 & 2.720 & 70 \\
\hline .888 & 1.184 & 1.480 & 1.776 & 2.072 & 2. .368 & 80 \\
\hline .775 & 1.032 & 1.292 & 1.550 & 1.809 & 2.027 & 90 \\
\hline
\end{tabular}

But this average dose should be varied in many cases; if the marl is clayey on a very clayey soil, the dose should be diminished. So especially should it in proportion as the soil becomes light, and we think the dose ought then to go as low as that in Sologne (two hundred and fifty cubic feet to the hectare), which we consider a reasonable dose and justified by experience as well as economy in very light soils. The proportion ought, on the other hand, to rise with the humidity of the soil; on a very moist soil a small dose can by no means suffice; nevertheless, care must be taken not to render the soil too clayey.

\section{Caution to be used in marling.}

The first condition for the success of marl is that the surface of the soil be well drained of water; the marl itself without doubt aids much in drying the soil, but it is not sufficient to recover a marshy one ; like lime it cannot produce its effect upon the soil except when by nature or art it is relieved of superabundant water.

The carting of the marl should be done in the right weather, that the land may not be cut up and clodded by the animals, men, and wheels ; it requires either dry weather or frost; however, if one has good roads, he can in any weather profit by the leisure of his teams; the marl is 
thrown upon some corner of the picce on which it can be spread afterwards in fit weather with carts or wheelbarrows ; the exposure of the marl to the air before being spread is always useful, without being indispensable.

Upon a moist soil it is best before marling to give a deep plowing, for then there will be a thicker bed for the water to penetrate, and less danger from the moisture, and the bed improved and mellowed by the marl will be thicker.

The marl should be disposed upon the soil in parallel lines in small equal heaps, placed at twenty feet distance between the heaps and between the lines.-(See figure 45.) -The first opportunity of fair weather is to be improved to spread it as erenly as possible; after some days and some alternations of sunshine and rain, the soil is to be passed over again to equalize the marl and make it as nearly as possible cover the soil with its debris; the excellence and promptness of the results depend greatly upon this cause; the marl is then left as long as possible to dry upon the surface; a mutual action is established by the air and the atmospheric changes between the surface of the soil and the marl which prepares and hastens its effects. The marl should not be buried except in fair weather, when it is well slacked and almost dry; by burying it while wet, it recovers its adhesiveness and cannot be mixed with the soil; the plowing, too, should not be deep, so that the marl may be distributed more equally through the thickness of the vegetable bed for the following crops.

When the marling has been too strong, one can, by a deep ploughing, bring to the surface some of the unmarled earth, which will diminish the proportional quantity of the marl; this operation, by increasing the thickness of the mellow bed, diminishes the disadvantages of heavy rains.

Marl is advantageously employed upon winter crops as well as those of spring; it is used very advantageously in compost, either with dung, vegetable mould, or turf; 
however, it is rather more iroublesome to transport and mix them with the clayey than with the stony marl. The English use marl in this way, especially when the marl pit is distant, because, in the case of marl as well as lime, composts are a means of multiplying the effects of a small dose.

The effects of marl are not very apparent upon the first crops. Its effects upon the soil very much resemble those of lime. The soil becomes workable in all weathers, absorbs the rain, becomes more accessible, as well as the plants that grow on it, to all the atmospheric influences; the roots traverse it more easily ; being rendered thus permeable, the juices which form the sap can circulate and consequently be more readily taken up by the roots; it is evident that these qualities improve the soil and its products.

\section{of second marlings.}

Second marlings are not needied, and should be long deferred wherever the first has been very abundant. If they have not succeerled in Ain, Isère and Yonne, it is because doses were used in the first marlings which gave the soil four, five, six, eight, or ten per cent. of carbonate of lime, a proportion much above the need and often even beyond the convenience of the soil, and because the soil retains it for an indefinite time; but, when marling has become a regular operation of agriculture, we can fix upon some data which will throw light upon our course. In analyzing the regular methods of marling cited by Arthur Young, we find that the acre received per annum from twelve to twenty-four bushels of carbonate of lime. In the still more regular marlings of the department du Nord, the soil received every twenty years two hundred bushels of stony marl, which contained at least three-fourths of carbonate of lime; the soil therefore requires ten bushels per annum to maintain its products with the same energy.

A quantity which would suffice for clayey soils becomes too strong for light soils; we have seen that they give in Sologne, every 10 years, from 75 to 100 cubic feet per 
acre of a marl which contains forty per cent. of carbonate of lime, that is five bushels per annum of the calcareous element; our second marlings ought therefore to be given in such a manner as to furnish the soil from five to ten bushels of carbonate of lime per annum according to its consistence.

\section{Exhaustion of the soil by marl.}

When a strong dose of marl has been given to a light or very dry soil, and animal manure has not been restored in proportion to the products taken off, and exhausting crops succeed each other, we see the harvests gradually diminish, and the soil assumes the character of a calcareous one of small fertility ; it still produces more than before the marling, but it is said to be exhausted, and a fresh dose of marl does not restore it to its first fertility ; we have seen this case happen in Isère, where all the unfavorable circumstances conspired. In a clayey soil this result would be manifested with more difficulty and after a long perior. Marl therefore does not dispense with manure, but it is far from exhausting the soil; we think, on the other hand, that to sustain large products, a much smaller dose of manure is necessary. Mlarl doubles the action of manure, and on marled soils we have this great advantage, the power of obtaining large crops with a moderate quantity of manure.

However, we must say that the first marling as well as the first liming produces a sort of first leap of fecundity, the full force of which is not often afterwards preserved. In order that it should be, the very first year of the marling the dung should be applied as usual, or the marl should be put on in compost without withholding the dung, as is done in many second marlings in England. But this is rarely the case ; everybody wishes to profit by the new power given to the soil of producing without dung, and places the manure on grounds which have not yet received amendments. However, Belgium, the department du Nord, Normandy, 
Sarthe, and a large part of England have carefully sustained the first fecundity given by the marl; and this is owing both to the quantity of manure, and to the good culture which they have bestowed upon their marled soil.

\section{Cultivation of the soil after marling.}

After what has been said, it will be perceived that the cultivation of the soil after marling should be conducted with discretion and prudence; the new fecundity of the soil should be profited by with a due economy of those artificial sources which have caused it; manure must be bestowed in proportion to the products, grass and root crops should be multiplied, and the fruitfulness of the soil should be exercised as much in favor of the animals that produce dung as of the granary ; this being done, marl is an immense source of fertility, present and future. We shall not, however, advise any abrupt changes in the rotation; in all agricultural systems crops productive of manure can be introduced.

\section{Purification produced by marl.}

It is established by facts and reasoning that lime and its compounds purify as well as fertilize the soil ; the calcareous agents remove that stagnant water which is injurious to vegetation; the soil becomes porous and permeable, the water circulates through it and of course no longer stagnates and accumulates. All waters which stand upon or run over marl or calcareous stone, remain clear and limpid, carry fruitfulness with them, and purify the soil and its products. Upon a marled soil all the vegetables of a healthy soil grow and flourish; the soil itself is therefore purified as well as its waters and products. Marl, in imparting all the qualities of calcareous soils, gives that of salubrity which especially distinguishes them; and it should act in this point of view more powerfully than lime, inasmuch as it is applied more abundantly. Marl, therefore, as well as lime, and all other calcareous agents, is a principle of salubrity as well as fertility. 


\section{CHAPTER IV.}

\section{GYPSUM。}

Gyrsum is the third principal salt which exerts a powerful influence on plants, and is one of the most valuable of all our mineral fertilizers. It is composed of sulphuric acid and lime, and is called sulphate of lime; but most commonly known among farmers as plaster. It is found in a great variety of forms; sometimes in regular crys tals, or in large crystalline plates and masses, which are perfectly transparent, and as pure as the finest plate-glass. It is sometimes found in snow-white flakes like foam or snow, sometimes semi-transparent like horn; and lastly, it is met with most commonly in large, compact masses, forming rocks, and constituting large and extensive strata. In this form, it exhibits a great variety of colors-white, red, brown, and blueish white. It is used to some extent in the arts, but the most important use of gypsum is for fertilizing the soil.

Much variety of opinion has been entertained respecting the manner in which it exerts its influence or produces its effects on plants; and these opinions can scarcely be said to be harmonized, even at the present time. Davy was inclined to consider it a direct food for the plant, as it is found, to some extent, in those plants on which it exerts the most power. Chaptal referred its power to its stimulating agency on plants, produced by its action when dissolved in water. Liebig ascribes its value to its giving a fixed condition to the nitrogen or ammonia which is brought into the soil, and which is indispensable for the nutrition of plants. Dana, to the action of the lime and acid of which the gypsum is composed, on the organic 
matter and silicates of the soil. He says- "It seems almost incredible that so minute a portion of a mineral can act at all; yet how beautifully is the result explained by the principle that plants decompose first this salt; the lime, for plaster is a sulphate of lime, then acts on geine, which is thus rendered soluble; while the acid, the oil of vitriol or sulphuric acid, immediately acts on silicates." It seems very probable that no single one of these suppositions will be found able to account in full for the action of plaster. That of Dr. Dana appears to approach as nearly to a solution as any of them, if we extend his term silicates so as to embrace those combinations formed by the union of the acid of gypsum with ammonia, after its separation from the lime. If the action of plaster was due to its fixing ammonia alone, then it ought to be equally efficient at all times and places, which it certainly is not; or if it acted directly as nutriment, then its action would be as constant as that of rotted manure or compost, which farmers well know is not the case. Plaster does not act as usefully in the vicinity of the sea, as in the interior; and on heavy wet soils is scarcely felt at all. Light sandy soils, or loamy ones, are those on which plaster acts the most sensibly; and clover, lucerne, potatoes, cabbages, and the leguminous plants, such as peas, vetches, \&c., are the vegetables on which it exerts the most powerful influence. It is much valued as a dressing for wheat, not so much, perhaps, for its direct action on that plant, although that is not trifing, as for its effect in securing and promoting the growth of the clover and other grass seeds, usually, in wheat countries, sown with this crop. So marked is the influence it exerts in this respect, that plaster, clover and wheat, are always associated in the mind of the most successful wheat growers; and its use is the most extensive in the best wheat growing districts of our country.

When the soil and season are favorable, plaster often doubles the product of forage crops; the plants then talee an intense green and an extraordinary vigor, which makes them contrast strongly with the portions not plastered. 
When Franklin wished to introduce the use of plaster into America, to convince his countrymen he wrote upon a field of clover in Washington, with powdered plaster, the following phrase-c"THIS HAS BEEN PLASTEred ;" the effect of the plaster brought these words up in relief in greener and more vigorous stalks; everybody was convinced, and plaster was rendered popular in America.

It is recommended to sow the plaster in spring upon the vegetation already commenced, when the grass is five or six inches in height. However, when sown in the month of August, after harvest, upon clover of the year, it makes it produce a good cutting in the month of October, and the crops of the succeeding year still experience the whole of the good effect.

It is spread by the hand, in the evening or morning upon the dew, or in calm and cloudy weather before or after a slight rain; heavy rains much injure the effect; thus, to avoid the heavy rains of the spring, in the neighborhood of Marseilles, they prefer to use plaster only after the first cutting.

The experiments of M. Soquet seemed to have proved that plaster spread upon the soil without contact with the plants produced no effect; still the practice of the whole country establishes the fact that it succeeds very well upon clover and lucern when they are scarcely out of the ground; and the experiments of Messrs. Sageret and D'Harcourt have proved that plaster sown at the same time with the seed still produced a great effect.

Its ordinary dose is equal in bulk to the seed, or two or three hundred weight to the acre; at this dose it makes upon the soil a layer of less than ${ }_{100}^{1}$ of a line, or ${ }_{6000}^{1}$ of an arable bed of five inches in thickness; at a dose one-half less its effect is still very sensible; of all amendments its effects are produced with the smallest dose.

Plastering ought not to be too often repeated upon the same soil, especially if it is moderately rich; the soil loves to change its manure as well as its crops; and plaster, like many other good things, requires to be used with measure and moderation. 
Plaster used in compost of earth or dung very much increases their activity; the trials upon this subject have not been pushed far enough to result in practical rules; this is much to be regretted, for the experiments made promised the hippiest results.

The plaster while producing upon the leaves and branches of plants an increased growth, produces also a very sensible effect upon the roots. The experiments of M. Soquet have proved that the roots of plastered clover weigh one-third more than the roots of clover not plas tered. It appears thence that longer, stronger, and more branchy roots should draw more from the soil. However, the wheat which follows plastered clover is ordinarily better than that which succeeds clover not plastered; this must be attributed to the greater amount of regetable manure, the more vigorous clover which has left more leaves upon the surface and more roots in the soil ; but this vegetable manure lasts but one year, for the hoed crop which succeeds the wheat must receive more manure after plastered clover than after that which had not been so.

Plaster is sometimes used upon dry meadows, and increases their yield ; it makes the leguminous grasses predominate, and consequently improves the forage ; but its use must be alternated with animal manures, otherwise the fertility which it produces is not sustained, and in a few years of repeated plasterings the product would descend lower than before.

The distinctive character of the legumes is increased by plastering ; their leaves, which are their organs of absorption from the atmosphere, become more vigorous and are doubled or perhaps tripled in surface and consequently in power, while the roots have increased only one-third, and consequently, so to speak, borrowed but one-third more from the soil ; this want, however, must be supplied in moderate soils, where it becomes sensible.

Plastering is therefore an excellent method, but to be used with reserve and circumspection; for this reason in some countries the doses of plaster have been reduced, in 
other's they have been divided to good purpose between two seasons, one half after the harvesting of the grain which covered the forage, and the other half in the succeeding spring.

\section{CHAPTER V.}

\section{ASHES.}

AsHes, leached or otherwise, are of great value as a fertilizer, especially when used on soils that are sandy cr light Unleached, the potash contained goes to form silicate of potash, and gives the supply of silex necessary for the stems of the grasses or corn; and leached, although the potash is the greater part of it separated, the remainingphosphates of lime and magnesia go far to restoring to the fields on which such ashes are strewn, the necessary matters of which previous cropping has deprived them. 100 parts of the ashes of the wheat grain contain 32 parts of soluble, and 44 parts of insoluble phosphates, in all 76 parts. The value of ashes abounding in the required phosphates, when used on grain lands, may be seen at once, as well as the folly of those farmers who waste or sell the ashes produced in their dwellings.

They require to be spread when dry, in weather that is not rainy, and upon ground that is not wet; they favor the vegetation of all crops, both winter and spring, either of grains or legumes.

They give a deep green color to the vegetables which they nourish; they favor the production of the seed even more than that of the straw ; the seed produced resembles that of limed land; it is perhaps even finer and thinner skinned, and like that commands a better price in the market. Ashes are used with great advantage upon meadows and pastures, and their effects are especially remarkable 
upon buckwheat, rape, and hemp. The effect of a small dose is not very durable; at the end of two years it is scarcely perceptible, yet in grounds which have been repeatedly ashed, ten years after the practice has ceased the amelioration is perceptible.

The use of ashes is very common upon the great argilosiliceous table land which belongs to the basins of the Rhone and the Saone, and which extends from the gates of Lyons to the departments of Ain, Saone and Loire, Jura, and Upper Saone.

Lyons, after having furnished leached ashes to the agriculture of its vicinity, which employs them in great abundance, sends them by its rivers to a great portion of their banks and the neighboring countries, which pay for them 1 1-2 to 3 francs per hectolitre (from 10 to 20 cents per bushel). The usual dose is not so large as in the neighborhood of Lyons, yet it is from 60 to 80 bushels per acre. It is sown upon the ground before the last plowing; the earth and the ashes should be dry; and they are left upon the surface of the soil twenty-four hours, if the weather is favorable; the seed is then thrown on and the whole covered by a light plowing. They are also very often used for the seeding of buckwheat upon fallow in the month of June, and insure a crop of that as well as of the wheat or rye which succeed. The effect of ashes is but slightly perceptible after two years; they are then alternated with dung, because they are more profitable to the soil if used only once in four years. In the neighborhood of Lyons they are used with much advantage upon some meadows, to the amount of fifty bushels to the acre ; their effect also is very durable; the doses upon plowed lands are also very strong, and seem rather to be regulated by the low price of the material, which on the spot is from seven to ten cents per bushel, than by the necessities of the soil.

In Sarthe they are very dear and much valued; they are used along with lime, to which they are preferred for light soils; the dose is twelve bushels to the acre, and the effect 
is great upon buckwheat and the wheat which succeeds it.

In Indre they are used, especially for rape, at the rate of twenty bushels to the acre; and with no other manure they gather from twenty to thirty bushels of seed.

Ashes are generally used alone without dung; still, in the country where their value and use are best known, it is believed that as in the case of marl and lime, the mixture with dung doubles the activity of both substances, and very much increases the natural fecundity of the soil. In a commure in the vicinity Louhans (Saone and Loire) ashes are eagerly sought for, for wheat; they join to half the ordinary dose of dung from eight to ten bushels of ashes to the acre, and this half dose of each produces more than the full dose of either by itself. In the commune of St. Etienne, near Bonry, the use of dung is added to that of ashes; the dung gives the advantage of keeping a cold and compact soil somewhat mellow and more accessible to the atmospheric agents.

On moist soils the dose should be increased in proportion to the moisture ; but if the water is stagnant they produce no effect till there has been a thorough draining; hence we see the effect must be small in wet seasons upon such soils.

Ashes, as we have said, are employed in all the seasons except winter. Early in spring they are used upon meadows and pastures; afterwards with the seed of barley, oats, and maize; in the course of the summer they enrich rape and buckwheat; and finally, in autumn they are used with the seed of wheat and rye.

The ashes are covered with a light plowing, or are strewn without being covered upon crops in vegetation. Thrown in spring upon wheat and barley, they improve the crop sensibly, yet this practice is quite rare. Some experiments upon the same crop in the same soil, of ashes covered at sowing and spread upon the surface on the plants in vegetation, have given me a better yield in the soil than on the surface, showing that the practice of covering is preferable. 
Practice also prefers leached to quick ashes; reasoning does not bear this out, but in agriculture more than elsewhere "experientia rerum magistra"-(Experience is mistress). I have convinced myself of this by comparative trials. We shall not conclude, nevertheless, that this result must always take place; upon a soil which would be enriched by saline substances, I think that quick ashes would produce more effect; but upon those for which the phosphate of lime is sufficient, we see that leached ashes which have lost their soluble parts, contain more of it, and consequently produce more effect with the same bulk.

\section{Ashes of peat and coal.}

These ashes are considered in Holland, in the department du Nord, and Belgium, as one of the great agents of vegetation. The ashes of peat are to be distinguished from those of coal.

\section{Holland ashes.}

We give the name of Holland ashes particularly to marine ashes, or the ashes of our domestic peat; the former are much more valuable than the latter; it requires four times less of them to produce the same effect: they are produced by the combustion of the peat of Holland. This peat, which has been formed, or at least has remained a long time beneath the waters of the sea, is a better combustible, and especially gives white ashes of a better quality; these ashes undoubtedly contain a greater proportion of saline and calcareous elements.

They are used, as well as the ashes of peat and coal, upon artificial meadows, upon flax, upon spring grain, and upon meadows that are not watered. They have become indispensable to agriculture in the arrondissement of Lille, where the calcareous amendments are but little used; in the other arrondissements, and particularly in that of Avesnes, they are often mixed with lime from one-half to one-fourth of the whole bulk.

Composts of ashes and lime are particularly useful on meadows and spring grains, at the same dose as of pure 
lime, that is to say 50 bushels to the acre for every ten or twelve years.

Marine ashes are much esteemed for the clovers, from six to twelve bushels per acre are used, and the clover gives a superb crop, and the wheat which succeeds partakes of the fruitfulness of the forage.

The high price at which the Flemish were obliged to buy the marine ashes caused them to discover an amendment not so dear; they get from Picardy and their own soil a mineral which they call black or red ashes, which takes the place of the marine ashes sold at too dear a rate by their neighbors the Dutch; we shall speak of it in the following section.

\section{Coal ashes.}

They are used in default of all the resources which precede; still they are quite active, and compose in part the street mud which is bought at a dear rate in all the cities and large towns. We have to regret that this material should be generally wasted in France: those who collect the mud of Lyons accumulate large quantities of them, and experience their good effects almost without knowing to what they are due.

\section{Peat ashes in general.}

They are used in Picardy in great abundance; the valleys of the Somme and its branches contain great quantities of peat which are very profitably improved for the manufacture of bricks, tiles, and for domestic fires; besides which, a large quantity is burned to get the manure. Peat ashes are there used for meadows, both natural and artificial, and for fall grains; fifty bushels are applied to the acre. Their price is rather high, that is to say, three cents per bushel taken upon the spot.

In England they also make much use of them, but their rules and doses vary with each district. The composition of these ashes is so variable, that precise directions can scarcely be given; still we can say they should be spread 
dry upon soils that have been well drained. They are used either as a top-dressing. or to be plowed in ; the dose should be double in the latter case; united with dung they make an excellent compost.

Twelve loads of peat furnish upon an arerage one load of ashes.

To burn peat in Germany, they have a sort of gridiron, under which wood is placed; upon the gridiron they place peat, and on the top of that some that is wet; the combustion is managed so as to make it last as long as possible, because experience has shown that the ashes are better when the peat is burned slowly.

Still we must say that it is much to be regretted that a fuel fit for so many uses should spend its heat for nothing, while everywhere the brickmakers, lime-burners, potters, and kitchen fires, pay dearly for their fuel. "Happy the country which burns its mother!" This proverb, born in a country which has been enriched by the use of peat, should be a strong lesson to those districts of France where it is found in abundance, and such districts are numerous. Wherever peat is found, therefore, easy of access, without being used either in agriculture or the arts, a treasure is left buried which might give prosperity and riches to the country.

\section{CHAPTER VI.}

SALT.

\section{Of marine salt, or hydro-chlorate of soda.}

THE great question here is of sea salt; the other salts are only of secondary importance. Sea salt is one of the substances which can be furnished by commerce at the lowest price, when the impost which falls upon this article of prime necessity shall have been abolished. On the seashore and in the mines of rock salt the hundred weight 
would cost but ten cents. The mines which furnish it, of which the veins appear to be of indefinite thickness, seem almost inexhaustible; if, therefore, salt can be of great utility in agriculture, with the new improvements in communication in France, there ought to be more than half the surface of our country where the price of salt should be scarcely one franc (nineteen cents) per liundred weight; and, as its effects upon the soil are produced by small doses, and nevertheless appear very great, the results should be of great importance.

Let us look upon the facts which prove its great influence upon the fertility of the soil. The use of salt in agriculture is very ancient: the Hindoos and Chinese, from the remotest antiquity, have fertilized their fields and gardens with it. The Assyrians, PLINY tells us, spread it at some distance around the stems of their palm trees. However, it is known that in a considerable quantity it sterilizes the soil; thus the Bible informs us that Abimelech, having taken Shechem, destroyed that city from its foundations and sowed with salt the place which it occupied.

In modern times the English have studied this question much more than we. Lord BACON proved by his experiments that the use of salt water was profitable in agriculture. More recently, Brownrigg, Watson, and CartWRIGHT, have confirmed by experiment the efficacy of salt upon vegetation. The Agricultural Societies have offered a prize, and Davy, Sinclair, Johnson, and Daore, have verified and advised the use of it. In the county of Cornwall, composts of the impure salt of the salt works with sea sand, earth, mould, or the remains of fish, are frequently employed, and the farmers of Cheshire, we are told by Davy, attribute to them the abundance of their harvests. In the Isle of Man, salt is used to destroy moss in meadows. The usual composition of composts for meadows is eight loads of earth and seventeen bushels of salt per acre.

In many of the cider-making districts the apple trees are rendered more robust and fruitful by burying around 
and at some distance from the trunk a small dose of sea salt. The scions and slips which are sent to a distance, being wet in salt water, sprout more easily on their arrival.

The British government, at the request of the agricultural:interest, orders the salt which is required for the soil to be mixed with soot and sold at a lower price. In Germany, where there is but little sea coast, and where salt is scarcer and dearer, this question has been less considered ; in Bavaria, however, the king has ordered all the salt used in agriculture, either for cattle, or for the soil, to be sold at a low price.

In France a multitude of facts confirm the efficacy of salt as an amendment upon certain soils. The great fecundity produced by sea manure is often due to the salts which it contains; and this is still more evident in regard to the ashes of Pornic, into the composition of which are put the scrapings of the salt heaps, and which are carefully watered during the whole summer with salt water. The practice of Morbihan to water the dung with sea water has doubtless been established upon the proof given by experience of the efficacy of salt united with dung. Finally, the great effect of sea weeds and their ashes, which contain perhaps half their weight of muriate of soda, or soda, must be taken as additional proof. In some districts of the coast soda (salsoda soda) is sowed at the same time with the wheat, upon the salt lands formed by deposits from the water of the sea. When the rains come to diminish the quantity of the salt, the wheat grows beautifully, and the soda remains feeble. When the rains are scanty the soda flourishes at the expense of the wheat.

When the salt is not very abundant, it favors vegetation and gives products of an excellent quality. The salt meadows are esteemed for the quantity and quality of their forage, and the manure of their sheep. I have lived in Picardy near the pastures that are often covered by the high tides: when the rains come to wash the surface and carry off the too great portion of salt, they furnish pasturage in abundance, and of excellent quality. 
Experiments upon the action of salt upon vegetation.

No treatise better demonstrates this action, nor better defines the doses and the attending circumstances of the application, than the experiments of M. LECOQ of Clermont. He has taken a great step in the question, both general and particular, of the use of the different saline substances offered to agriculture by nature and art. We shall proceed to give the results of his experiments, confining ourselves, however, to the facts and instructions which most interest the practical cultivator.

On a field of barley, upon good free soil, dunged the preceding year, he divided a space of thirty-two rods into eight equal portions; upon the six first he spread, on the last of April, progressive doses of salt, and upon Nos. seven and eight he put nothing.

Table of operations and results.

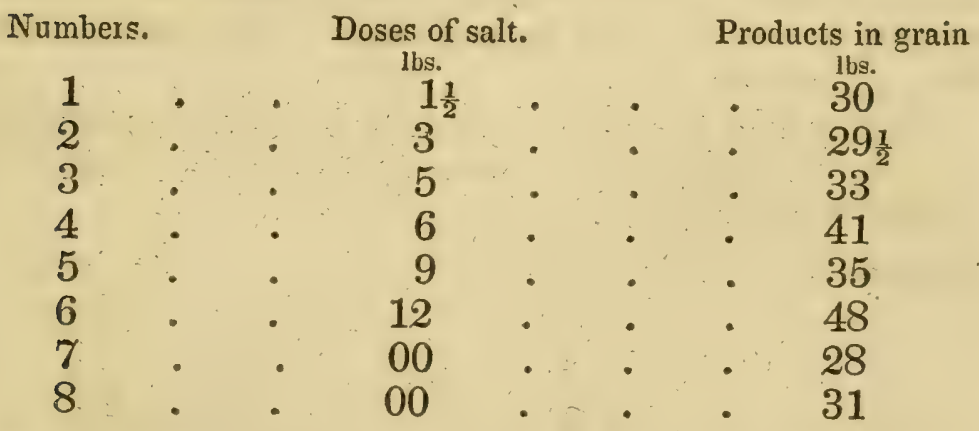

Number one, which received but one pound and a half, differed but little from those which received none; number two had the straw longer and the barley more tufted; number three became still better; number four, vegetation very vigorous, the straw ten inches longer than that which was not salted, and four inches longer than that which was salted less or more. The ears besides were larger, longer, and better filled than the others. Number five, inferior to number four, resembling number two, but higher than that; number six, the strongest dose, seemed diseased, notwithstanding its product in grain was quite 
large; its straw was not longer than that of the numbers not salted

It results from this that the most productive dose for barley should be one and a half pound to the rod or two hundred and forty pounds to the acre. The four rods which received six pounds produced more than numbers seven and eight, which received none,--eleven pounds of grain or four hundred and forty pounds to the acre, or more than three and a half times the seed, which is on an average less than 100 pounds to the acre.

This experiment with the same data was made at the same time upon a field of wheat, upon a soil rather thin, light, and high. The results were found nearly the same, notwithstanding the difference of soil, position, and crops ; still there was little difference between numbers three and four, of which the former received four and a half pounds to the four rods, and the latter six pounds.

The suitable dose for wheat should, therefore, be below one and a half pounds to the rod, or two hundred and forty pounds to the acre.

Upon a field of lucern divided in the same manner and with the same doses upon the same surface, the following: results were obtained:

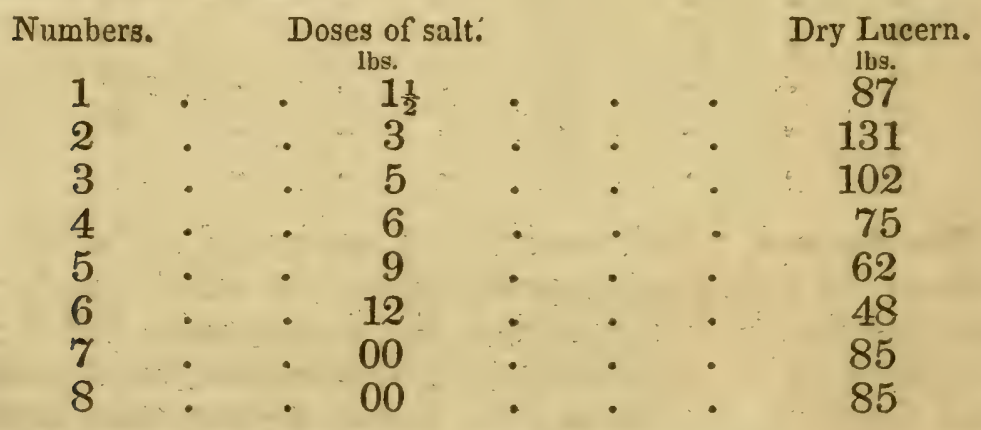

We see that the effect, scarcely sensible in number one, which received but one and a half pounds of salt, rises to its maximum in number two, which had received three pounds of it, and then goes on diminishing to number six which received 12 pounds, the crop of which was reduced to forty-eight pounds or a little more than one-third of 
number two. At the second cutting the result was nearly the same, although the rains had washed the numbers where the salt was in excess, and they had somewhat increased in product.

The most suitable dose for leguminous forage would, therefore, seem to be three pounds to four rods, or one hundred and twenty pounds to the acre, or one half that which suits ground sown in bread stuffs.

The proportion most productive for potatoes should be as for grain one and a half pounds per rod; that is the dose at any rate which gave the most vigor to the stalks.

For flax five pounds to the four rods, or two hundred pounds to the acre, appeared to be the best dose. However, the product in seed is not greater than of flax" not salted. A dose of eight pounds gave a product sensibly less than one of five pounds.

In the use of salt, as of lime, except in strong doses, it produces little effect upon a damp soil; one and a half pounds to the rod spread upon cold meadows and upon dry, doubled the product of the latter, while it only changed the color of the former. Upon oats on damp soil the effect was scarcely perceptible, while upon dry soil the vigor was much increased. Finally, some lots taken upon a damp peaty soil received six, twelve, and twentyfour pounds of salt to the four rods; the two first numbers had the advantage over the parts not salted, and the two last produced much more than the others.

One hundred and thirty pounds of salt upon leguminous forage produced the same effect upon the acre as two thousand and two hundred pounds of plaster, whence it results that sea salt can be substituted for plaster in countries where the latter is scarce and dear. But what is especially remarkable, as in the case of calcareous manures, is the improvement of the quality of the hay upon moist meadows; the cattle consumed it with as much pleasure as they did with little before the experiment.

The general effect of salt upon crops of all sorts is doubtless to increase their taste, and to render them more agree- 
able, and probably more nourishing to cattle. We think the same is true of products destined for men. It is probable also that the products which best suit the instincts and appetites of animals, also give their flesh the best quality and savor, which would also seem to be proved by the high value which the gourmands attach to the mutton of the salt pastures. The general effect of salt upon crops is to increase all the products but the leaves in a greater proportion than the rest. Hence the dose for grass crops is but half that for grains.

Saline manures succeed almost as well in powder as in solution; as the former mode is much more convenient it is consequently preferable, and the more so because in using salt in solution, that it may not be injurious and may cover the whole extent, it is necessary to use it dissolved in a great deal of water.

\section{Of the hydro-chlorate or muriate of lime. (Chloride of calcium).}

The effects of muriate of lime upon vegetation have hitherto been much disputed; it would be quite important, however, that its favorable action upon the soil should be established, because it is presented in large quantities as the residuum of certain chemical manufactures. In the experiments of M. LECOQ, its effects have been almost equal to those of muriate of soda; however, it seemed less energetic upon lucerns, and its most fertilizing dose, instead of being three pounds to the four rods as for common salt, was from three to six.

Its use is more troublesome than that of marine salt, on account of its deliquescence ; it is for the same reason more difficult of transportation and cannot be spread in powder.

We are here confined to experiments on a small scale; but those of M. Dubuc, of Rouen, are very favorable to it. He thinks that leached ashes, charcoal, sawdust of wood, or plaster, should serve as the medium for spreading it, and that twenty-four pounds would be sufficient for the amendment of one acre. 
Its effect was great upon maize, potatoes, trees, and shrubs of different sorts. He thinks that it would suit hemp, flax, and the oleaginous seeds. It doubled the size of onions and poppies to which he applied it.

\section{Of the sulphate of soda.}

The sulphate of soda was employed upon a meadow and a field sown in wheat, at the dose of three, six, and twelve pounds.

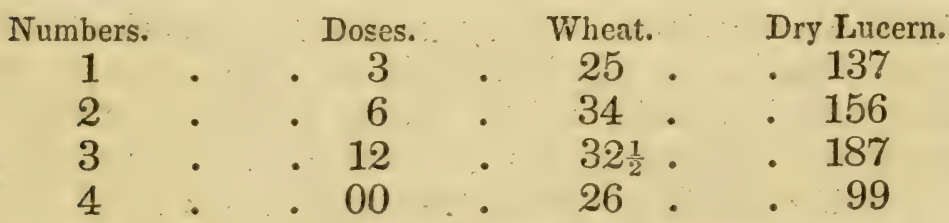

From this it appears that for fields the most suitable dose would be six pounds for four rods, rather above than below, however; and that upon meadows, the advantageous effect would increase up to twelve pounds, and perhaps beyond. This salt can be procured at a low price in the manufactories of soda.

\section{Of the nitrate of potash, or saltpetre.}

Its success upon the soil, disputed by some, has been very great in numerous experiments made in England. Trials comparing it with sea salt appear to have given it the advantage. In England the price of saltpetre which is brought from India, is so low that it can even be used in agriculture with advantage.

The most useful dose of saltpetre is nearly the same as that of sea salt; it varies from one hundred and twenty to two hundred and forty pounds per acre. It has been used with success upon the different bread stuffs ; still, its most remarkable effect is upon natural meadows and upon clovers.

CURLING mixed it advantageously with ashes by which he was able to diminish the dose. Mr. John LeE, who 
used it for fifteen years, thinks that it causes the production of more straw than grain in proportion, and that its effect is prolonged to the second crop; but other cultivators do not entertain this opinion. There is little agreement as to the nature of the soils to which saltpetre is best suited; its action has been advantageous upon a great many varieties, but it seems to have been most satisfactory upon calcareous soils.

\section{General remarles.}

M. LECOQ has moreover fixed many circumstances in regard to the use of saline substances. For example, he spread them in powder in the spring upon the plants in vegetation. A part of the soil sown in wheat, upon which in the month of October he spread a dose of salt, was less productive than another contiguous lot salted in the month of March.

The most favorable time for giving salt to potatoes should be that which just precedes the hilling; it should doubtless be the same with Indian corn; in this case it is upon the soil and not upon the plants in vegetation that the salt is spread.

The effect produced by saline substances is immediate, but it is not very perceptible on moist soils and is of short duration. They act in small doses. In all these circumstances they have the closest similarity to plaster. These substances, therefore, act as stimulants, and there is no reason to fear that they will exhaust the soil, provided a quantity of dung proportioned to the product is joined with them, as is done in the case of sea manure.

After all the developments just given, we have reason to conclude that saline substances powerfully aid vegetation; but unfortunately their effect is not uniform, it is not general, and it is produced. only upon certain soils. Since the Memoir of M. Lecoq, M. de Donibasle has tried salt upon his soil ; but, like lime, it did not succeed with him. We have ourselves made numerous experiments on this subject. Last spring we used the doses that were 
most productive with M. Lecoq, with two varieties of salt, the ordinary salt of commerce and the salt of pickled fish. The latter variety was cheaper, and we thought it ought to act with more energy from the animal particles which it contained. This salt spread upon four portions of meadow of various position and soil, produced no sensible effect: employed upon portions of a wheat field, on gravelly, argilo-siliceous, and calcarcous soils, the effect was the same; buried in the first dressing of potatoes and the hilling of coln, it gave no result; it only seemed to excite a little the vigor of winter vetches.

Sea manure, sand, sea mud or stime, ashes of sea-weed.

All these different amendments which the sea offers to the people on its coasts, are both calcareous and saline. Their effect is great, but is not produced upon all descriptions of soil. These stimulating amendments do not act, in our opinion, upon soils made by the sea, nor upon those which owe to it their formation in modern times, but principally upon argilo-siliceous soils.

When sea manure is sandy it is also active, but not so profitable as when it is slimy and contains animal and vegetable substances in decomposition. In this last case it is a sort of compost of calcareous sand, shells, marine plants, and salt. It is then one of the most fertilizing manures known in agriculture.

Sea manure is used in England as well as France. By this name is denoted in many districts the fucus as well as other marine plants. This is not the place to treat of this vegetable manure, but the mud of the sea is almost as often used as the marine plants; its use, however, cannot extend so far inland, because it costs more for transportation. A beiter state of the roads would much facilitate and extend the use of this powerful means of amelioration, and so much the more because in the interior the quantity of soil which is adapted to it is relatively much greater.

In England it is much esteemed for top-dressing for winter grains and spring grass; it is remarked that the 
wheat, oats and barley to which this amendment has been given are less subject to rust. In Cheshire the sea mud which is taken from the salt marshes is considered the best of all manures; it is found to have the activity of marl and the richness of dung. Composts are usually made of it with dung, which are mixed over from time to time in order to be used at the moment of sowing the wheat.

This amendment is much sought for on the coast of Avranches, in Manche, where it is preferred to lime or marl. With compost made with five or six wagon-loads of sea mud to the acre, which is mixed with one-quarter more of dung, or a proportionate quantity of loam, an excellent manure is formed which produces its effect at least during one whole course of the rotation. In all this country the use of lime is very common; but the moment you approach sufficiently near the sea, and the roads permit the transportation of the sea mud, lime is no longer used.

In Brittany the use of sea sand has also been general for thirty years past, on the coast of Saint Brieuc and Matignon. It used to be unknown except at Hilion, where it has been established for fifty years; but for some time past the whole canton of Matignon, following the example of M. Desmoland, has used it with great profit, and its use would be much more extensive but for the state of the roads; sea sand is adapted to the cultivation of clover, lucern, flax, hemp, and potatoes; upon the meadows it destroys the rush, increases the quantity and improves the quality of the grass, and finally is well adapted to clay soils which it mellows and renders more penetrable by the water.

The mud taken from the mouths of creeks and rivers is preferred, because there it contains more remains both marine and fluviatile, which have been brought there from land and sea by the ebb and flow; elsewhere the sand contains little but its earthly elements, the remains of shells and marine soil.

In countries where the fucus (sea-weed) does not suit 
the soil, or is collected beyond the demand for it, it is burned for its ashes. These can then be sold as containing a little soda of a bad quality; but they are more profitable as a manure. Some trials of them have been made in Scotland, and have succeeded very well for all sorts of crops. Five hundred weight (250 kilog:) of kelp (the name of sea-weed ashes) to the Scotch acre have given a great increase of product. They have been used for a long time in Brittany, and their use within a few years past has been much extended.

On the island of Noirmoutier and some parts of the neighboring coast, they burn the sea-weed of which they make no use, mix it with earth, sand, the scrapings beneath heaps of salt, fresh sea weed, stable dung, shells, and all sorts of vegetable and animal remains; from time to time during the year they wet the heap with salt water; they work it over at five or six different times, and then the mixture resembles ashes. Not many years ago, five or six small vessels were sufficient to convey this manure to the places where it is used; in 1832 there were discharged at Pornic 1236 cargoes almost entirely of ashes, each cargo containing ten cartloads of twenty-seven and a half bushels each.

One hundred and twenty bushels of these ashes are used to the acre. They are applied to all crops, but particularly to buckwheat and summer legumes, as well as to high grass. They are spread at the time of sowing. By mixing them with a small quantity of dung we should diminish by one-third the quantity necessary, and should have a manure as profitable at least.

Amelioration by sea manure ought not to be confined to places near the seashore: the country roads are too bad to permit its easy transportation to a distance; but the navigation of rivers and even creeks at their mouths, by means of the tide, permits the conveying of it at a sufficiently small expense a long distance inland. The quantity necessary to the acre, eighty or one hundred cubic feet or more, is comparatively large; the duration of its effec 
upon the soil is prolonged, therefore, far beyond that of the dung with which it is mixed; the ebb and flow of the sea much facilitates the operation; the loading is effected at low tide upon the uncovered mud, and the high tide wafts away the vessel and its cargo.

\section{FAPTER VII.}

SALT AND LIME MIXED.

SALT and lime, artificially mixed as a manure, promise to be a valuable aid to the farmer in those positions where the soil abounds with insoluble silicates or geine, and where other manures necessary to produce decomposition or fermentation are not at hand. Prof. Johnston recommends a mixture of two parts of lime and one part of salt, the mixture to remain incorporated in a shady place, or covered with sods two or three months before using. Salt and lime should not be used immediately after mixing, as bad results are apt to ensue; but after being well mixed in a dry state and lying as directed, it may be applied at the rate of from thirty to sixty bushels per acre, either before or at the time of sowing. Mixed with soot, salt acts with great power on roots. Mr. Sinclair mixed six and a half bushels of soot with the same quantity of salt, and used the mixture on lands sowed to carrots. The result was, that unmanured land gave twenty-three tons of roots per acre, and the manured yielded forty tons per acre; and Mr. Cartwright found that where unmanured soil gave 157 bushels of potatoes per acre, 30 bushels of soot and six of salt made it produce 240 bushels per acre. Dr. Dana furnishes so beautiful an explanation of the manner in which this manure acts, that it deserves a place entire: "By mixing quicklime with common salt, its soda is let loose, the acid combines with the lime, forming 
a soluble salt of lime, and so long as the soda remains caustic, it has no effect on the muriate of lime, but as soon as the soda becomes mild or carbonated, decomposition of the muriate of lime is produced, and the common salt regenerated. Commencing then with quicklime and salt, we pass to a soluble salt of lime and caustic soda, and from that to mild soda, and to carbonate of lime and the original salt. If these various changes take place in the midst of peat or geine, it is evident that the caustic soda acts upon the geine, and also evolves ammonia from that substance; secondly, that the muriate of lime, in its finely soluble state, insinuates itself among the particles of the geine; that the soda is also equally diffused, and that when the soda becomes carbonated, it produces an almost impalpable carbonate of lime throughout the whole mass, which, by its equal diffusion through the soil with the geine, acts upon the silicates, as has been heretofore explained." To produce these effects, Dr. D. directs to take one bushel of salt and two bushels of lime; to make the salt into strong brine, and with it slack the lime. Mix both well together, and let them remain ten days; then let them be well mixed with three cords of peat, shovelled well over for about six weeks, when it may be used. A quantity of salt sufficient to destroy all vegetation may be applied to a soil with safety when a few months are to elapse before the crop is to be put on ; as the chemical changes which take place, partially neutralize its effect during this time. A small quantity mixed with the soil in each hill of corn has been found to protect it from the wire worm and the cut worm; indeed there is no substance that insects of all kinds more dread than salt. It is probable, therefore, that further experiments will show that not the least value of salt is to be found in its preventive properties against these depredators.

Having noticed the several articles usually classed under the head of amendments, mineral manures or salts, we now proceed to speak of other kinds. Here again we shall be largely indebted to the Farm House. 


\section{CHAPTER VIII.}

\section{ACTION OF MANURES.}

THE various relics of vegetables and animals that have been endowed with life, are destined to serve as aliment for plants; it is while gradually suffering disorganization that they furnish the soluble or volatile products that can be assimilated. Thus, when plants are pulled up and thrown into a heap, a fermentation takes place, warms the mass, disengages vapor of water and gases which discover their odor more or less; some of the altered juice no longer retained in the organic tissues, which are gradually rent, runs out or is dissolved in the rain water; these disengaged gases with the vapor of water, and the substances in solution, are what serve as manure.

The remains of dead animals present similar phenomena; the products of their decomposition, soluble or gaseous, develope a stronger odor; they differ remarkably by a much more abundant production of ammonia, and by a more lively and effective action, for which reason much less is required upon a given surface.

Finally, animal evacuations give directly liquid and gaseous matters assimilable by plants, and which constitute the most active part of all the dungs.

These spontaneous decompositions, which are favored by the oxygen of the air and its temperature, exhale especially carbonic acid, free or combined, of which the plants can extract the carbon, to increase their solid parts.

Many agricultural writers had said, without gaining the concurrence of all, however, that in the fermentation of manures the disengagement of a great part of the volatile products is an important loss of elements useful to vegeta- 
tion. Nevertheless, almost all agriculturists had observed an unfavorable influence more or less marked, of dungs in a raw state, and especially of the various animal matters, such as flesh, blood, viscera, \&c. Thus science indicated all the useful elements, and practice seemed to have learned how much of them it was necessary to lose in order to insure to the residue an indisputable efficacy.

The question was in this state, when the central Society of Agriculture having offered prizes, the memoir which obtained the first demonstrated that we could apply without any loss all organic matters, even the most putrescible, to fertilize the earth, and thus double, triple, and even sometimes increase ten-fold their useful effects. I have since observed also that in fertile soils, a slight alkaline reaction, due either to lime or carbonate of soda or of potash which are found in ashes, \&c., or to the carbonate of ammonia disengaged by animal matters, gives great activity to vegetation. That most of the acids or acid salts are injurious to the germination and growth of plants, but that, on the contrary, they can indirectly aid the process, when without being in contact with the extremities of the roots, they react upon the carbonate of lime, gradually decompose $i$, and liberate the carbonic acid, a veritable aliment of vegetation.

There are other influences not less important, in which practice is made to agree with theory, by a severe examination of all the facts lately often contradictory, and which I have hastened to submit to the scientific as well as to enlightened practical men.

I have already said that manures of organic matter act the more usefully when their spontaneous decomposition is slow and best proportioned to the growth of vegetables; the following results are not less constant.

The most active manures, as well as those which a strong resistance to decomposition renders too slow to act and almost inert, can be put into the favorable conditions aforesaid.

By bringing to the most suitable condition the manures 
whose dissolution and spontaneous decomposition is the most rapid, we can quadruple and even increase six-fold their available effect.*

Muscular flesh, blood, and various animal substances, as well as dungs which were heretofore permitted to change so as to lose from 0.5 to 0.9 of their products, can now be turned to account without experiencing any previous loss.

The strong drying and disinfecting agency of carbonaceous substances, or dull and very porous charcoal, can be applied to the preservation, of very alterable manures, and to the solution of problems of the highest interest to the public health.

Various organic substances dissolved, or in suspension in very small proportions in water, used in abundant irrigation, can effect the most remarkable results of a beautiful vegetation.

Manures, whose partial emanations are not easily moderated, may pass in part without, assimilation into plants, so as to maintain there the strong odor which characterizes them. By previous disinfection, this serious inconvenience can be prevented. A direct experiment demonstrates besides, that certain odorous elements may be secreted even in the flesh of animals, and especially of fishes.

The most striking anomalies in the action of bones used as manure are rationally explained, enter into the general theory, and may be avoided in practice or reproduced at pleasure.

Dull charcoals, in very light powder, impregnated with minutely divided or soluble organic substances, act usefully. 1. By their peculiar faculty of retarding spontaneous decomposition, by which the assimilable emanations are better proportioned to the absorbing power of the plants (for the charcoal alone does not perceptibly yield

* Thus animal carbon, containing 0.15 of dry soluble blood, acts more at an equal weight than soluble blood; that is to say, by retarding the putrefaction the useful effect is rendered six-fold. 
any of its own substance to the action of the spongy extremities of the roots). 2. And moreover, as an intermediate agent capable of condensing the gases and yielding them to plants under the influences of temperature, or humidity, which alter its power of condensation. 3. By absorbing the heat of the solar rays and transmitting them to the soil, and during the night to the parts of plants above ground, thus compensating for the causes which would effect too sudden and great a cooling.

\section{Of different manures.}

After having summed up the general principles relative to organic manures in different conditions, we proceed to apply them to the treatment and use of substances particularly designed to serve as manures in agriculture.

\section{CHA P T E R IX.}

VEGETABLE MANURES.

\section{Of land plants.-Manures produced by the green parts.}

THE use of vegetables as manures has doubtless always been known. The Greeles, we are told by Theophrastus : the Romans, according to Pliny, Columella, and almost all the authors whose works remain, recurred frequently to this means in cultivation upon a large scale. "Sometimes," says VARro, "we sow various plants, not for their own sake, but to improve the following crop, their leaves imparting to a lean soil a greater fertility. Thus it is a common practice to bury, instead of manure, lupines before their pods begin to form, and sometimes beans before they are ripe enough to be harvested." Columella recommends in a still more explicit manner the use of the same means. He advises, in sandy soils, to bury these vegeta- 
bles while they are yet tender, that they may rot more promptly; and in more tenacious soils to let them become hard and woody, that they may the longer be able to keep the clods in a state of division.

The practice of green manuring is also general in Italy. Philippo $\mathrm{RE}_{\mathrm{E}}$ and his excellent translator M. Dupont, give us numerous proofs of it. Throughout Tuscany maize is sown in August to be plowed in the beginning of October. The Bressans employ a similar method upon the light soils on which they propose to sow wheat. They sow lupines upon a second plowing at the time before mentioned, in the proportion of one and one-fourth bushels to the acre. In the Bolonais and the territory of Cesène, after harvest, they take advantage of the first rain to sow beans upon the ridge of each furrow in the proportion of two and a half bushels to the acre; in autumn, when they are in flower, they are buried with the spade to prepare the soil to receive the following March a crop of hemp. In Vicentin, they cut down the beans in January, and bury them just before sowing the crop they are designed to nourish. The Tuscans cut them the last of August or first of September, and use them to ameliorate light soils in which they bury them at the time of sowing. The rocket (sysymbrium), although enlightened cultivators do not consider it one of the plants most advantageous for this purpose, is still employed in a pretty large way in the Bolonese country, and in some parts of ancient Romania. Sown the last of August, at the rate of from four to five pounds to the acre, it is ready to be buried from the middle to the end of November. In the environs of Como French beans (haricot) are preferred. In some parts of the Milanais from time immemorial turnips are turned in green, notwithstanding their value as fodder. Finally, in the valley of the Arno, in the country of Reggia, in Calabria, \&c., \&c., there are sown for the same purpose, according to the different localities, galega or goats-rue, lentiles, vetches, the common sainfoin, and that of Spain, millet, and maize. 
The practice of buried crops is also quite general in some of our southern departments. Lupines and buckwheat are commonly cultivated there for the sole purpose of making up the deficiency of manure. These two plants of rapid growth, not difficult in the choice of soils, rich in foliaceous parts, and whose regetation is proof against drought, can be sown by the aid of a single plowing upon a stubble turned over immediately after harvest and buried at the moment of flowering so as not at all to retard the fall sowing. Buckwheat, of which the seed can everywhere be procured at a low price, and about one bushel and a quarter of which is sufficient for an acre for the present purpose, especially offers great resources to a poor country. It succeeds better than lupines in our northern districts, as do clover, spurry, and radishes, which are cultivated for the same purpose upon light and dry soils. Beans, peas, and vetches, are preferred for clay soils.

It is a custom already quite ancient upon the banks of the Rhone, and particularly in the environs of Bescany, to sow vetches or buckwheat immediately after the harvest of wheat, and to plow them under the last of September to sow rye. After the rye is harvested the same culture is renewed to prepare the ground to receive wheat in October.

According to M. Sutieres, the bean is the best of the green manures for wheat and grass. This plant will in time fertilize the most moderate soils. It is mown in its blossom or a little after, and a furrow is turned upon it with the plow.

The fine hemps of the Bolonais are due to the burying of rye in the blossom, and the people of Turin use the same grain as a manure between the crops of maize and of wheat.

We shall not cite more numerous examples because we shall necessarily have to occupy ourselves yet with buried crops in entering into the details of rotations.

In proportion as we proceed from the south to the north the advantages of green manures are less; so, notwith- 
standing some successful experiments made in England and Ireland, the cultivators of these countries have for the most part given up this mode of manuring, considering it much more profitable to convert the green crops into dung, by having them consumed by cattle, than to bury them.

Time is not always and everywhere found, or weather favorable enough, between harvest and seeding, to obtain a crop fit to be buried at the approach of the latter period. In such a case the manure crops cannot be made available except on a fallow. They take place by a spring sowing, but they prepare an impoverished soil for that of the autumn infinitely better than a summer fallowing, should such be necessary, since they are equivalent to a dunging, and that without any sensible increase of labor or expense, inasmuch as the plowings are not much, if any, more numerous, and with a little care it is always easy to have the necessary seed upon the estate itself.

In some circumstances the burying of green crops precedes the spring sowing. This happens, quite rarely, when upon bad soils we bury successively several crops, the last of which cannot be commenced upon till the approach of cold weather, and we have reason not to plow in till spring an old piece of clover, or any other artificial meadow. At other times after one or more cuttings during the course of the summer, the last is renewed to be buried in autumn. Most commoniy only the roots are buried; but this operation does not belong to the subject with which we are at present occupied.

The herbaceous plants are not the only ones which are used as green manures. Woody plants and shrubs are also used. In clearing ground covered with broom, sedge, and heath, instead of burning, or when burning a part of these plants upon the ground, the tops are buried first beneath the reach of the plow, thus obtaining from them a durable manure, and an excellent amendment of strong soils.

They are also collected in bundles and carried to the 
vineyards exhausted by long production, to restore their fecundity without injuring the quality of their products. In this case a trench is opened between the ranges of props of eight or ten inches broad, without fear of cutting a few fibres, and after having filled it with branches, it is covered by means of the earth raised from the next trench. The effect of this operation, particularly applicable to rather strong soils, is perceivable for a great number of years.

The manures taken from the vegetable kingdom, less than those which come from the animal kingdom, having the inconvenience of changing the savor of fruits, the branches of yew, the clippings of box, \&c., \&c., are almost everywhere esteemed to aid the vigor of fruit trees. Various cistes, the gnaphalium, and other plants which abound in the most arid places in the south of Europe, are carefully collected in Tuscany under the name of tignamiche, and placed at the roots of the olive trees, after having lain in a heap long enough to begin to ferment. I have seen this method also practised in some parts of the heaths of the department of Herault. In short, all the herbaceous or sub-ligneous stalks and all the green parts of vegetables, when no better use can be found for them, can be immediately transformed into manure. They ferment the more promptly in proportion as they contain more parenchymatous substance and less of woody fibre, and as the decomposition of their fibres is facilitated by the abundance of saccharine and mucilaginous matters.

I have said that buried crops as manure are better suited to warm climates than to others. For the same reason they are better suited to dry soils than to moist. The water which they gradually give up while decomposing produces an equal and constant moisture, than which nothing could be more favorable to the growth of plants, when it is accompanied by heat, and when, as in the present case, it is in contact with soluble matters. The richer a plant is in soft and pulpy parts, the better it will serve for a green manure, not only for the reason I have just 
mentioned, but because we may infer from the number and thickness of its leaves that it must have derived from the atmosphere a great part of its nutritive elements.

For clayey and moist localities it would be necessary, on the contrary, to choose branchy and tough stalks of slow decomposition, in order to obtain an amendment. This truth is not new : we have seen that it was perfectly understood by the Romans.

The best time to bury green crops is while in the blossom. Then, especially, they are distended with juice without having taken hardly anything from the soil, for it has been demonstrated that they do not generally begin to exhaust the soil till from the time when the seed begins to form to its ripening.

Green manures are far from being sufficiently valued in all places where they might be employed to advantage.

To the above we may add the following cheap and easy mode of enriching the soil by plowing in green crops.

Commence in the spring with sowing buckwheat on the lot to be improved. When the buckwheat is in full bloom and before the grain forms, turn it under. At the usual time sow again with buckwheat, and at the same time sow one bushel of rye to the acre. In the fall gather your crop of buckwheat, while you let the rye remain. The following season, when the rye is in full bloom, plow it under, and in due time sow again with buckwheat and rye. Continue this course until your land has attained a desirable fertility. By this simple process the poorest soil may be enriched at the small annual expense of one bushel of rye to the acre.

Mr. John W. Sweet, of Tyringham, Berkshire county, informs us that he plants his corn in the following manner, and has realized 110 bushels shelled corn to the acre.

He spreads what manure he intends for the field on the surface of the green-sward; then he plows the land into ridges about three feet apart in the fall-each ridge or row being made of two back-furrows turned upon a narrow strip of sward which is not disturbed. In the spring he 
rolls and harrows these ridges, and on the top of each ridge, 12 or 14 inches apart, he plants his hills of corn, three or four kernels in the hill, and cultivates his corn through the season with the hoe, cultivator and plow, as much as he deems necessary. In this method, he remarked that he was not troubled with weeds or drought.

In the fall, as soon as his corn is ripe, he gathers the ears, then pulls up all the corn-stalks and lays them down lengthways between the furrows, and then splits his ridges with the plow and covers these stalks completely. Thus are made his ridges for his second crop of corn, to be planted the succeeding spring. The 110 bushels was the second crop, planted over the buried stalks.

The above is sufficient to give the rearler an idea of this system. He contends after the first crop he wants no manure for his corn except the stalks applied as we have described.

\section{CH A P T E R X.}

MANURES PRODUCED BY THE DEAD OR DRY PARTS.

Plants in drying lose some of their nutritive quality. Hence in this state they are scarcely employed for the improvement of the soil, except after having been transformed into litter. They then usually form part of the mixed manures of which we shall speak hereafter. The stalks of maize and rye, the stubble and straw of grain, and damaged hay, are particularly useful in this case.

The leaves, which derive a great part of their nourishment from the atmosphere, in precess of time by their deposits fertilize the most ungrateful soil. While it is impossible to imitate with advantage in the large way, by covering whole fields with leaves, the processes which nature employs in the woods, it is at least quite common to turn these valuable products to account in gardens. They are in various ways transformed into light mould 
adapted to the regetation of delicate plants. They are also mixed with the manures to increase and improve the mass, and I know some localities near immense plantations of timber, where this practice is not one of the least advantages of such cultivation.

The ferns in lands where they abound-the leaves of weeds destroyed in the fields or by the road sides before the maturity of their seeds, which would hurt the soil by being permitted to ripen-the mosses-the leaves which can be procured in abundance at so little expense by employing children to gather in the coppices and the forests, yield in many places, and might in many others by the same means, important resources.

Notwithstanding the fertility of the vegetable mould which is found in the decayed trunks of trees, I only mention it here because its use does not belong to agriculture. The same is true of saw-dust, the slow decomposition of which makes it particularly fit to enter into the composition of the soils for artificial heaths.

As to the bark from the vats of the tamers, where it has lost at least a great part of its astringent principles, it is known nevertheless that by itself in this state it is little favorable to vegetation. It is sometimes mixed with poudrette, but it is a fraud doubly criminal, for while increasing the quantity it deteriorates the quality. As the tan is almost entirely composed of woody fibre, to induce fermentation more speedily, Davy recommends the use of line.

The chaff from the threshing-floor, the shives from the preparation of hemp or flax, can also, though they contain little nutritive substance, be converted into manures. In almost all our country they are carelessly thrown upon the dung heap. People are not everywhere so careless. In Frieul they are softened awhile in water before throwing them into heaps. They thus ferment more readily. In Bressan they are spread upon natural meadows at the rate of from six to twelve cartloads to the acre. They serve besides to manure vines and fruit trees. 


\section{CHAPTER XI.}

NANURES PRODUCED BX SEEDS AND FRUITS.

Philippo $R_{E}$ remarks that he has seen the seeds of the irpine put into ovens to take away their germinative power and then used as a manure at the roots of olive and orange trees. The effect of this substance very speedily appears; and there is less reason to wonder at it, inasmuch as, after animal matters, seeds are probably of all parts of vegetables those which have the greatest fattening property for the same bulk. Deprived even of some of their elements, they preserve this property in a high degree.

All the dregs of fruit, when no more profitable use can be found for them, can therefore become manures. Those of grapes, after having fermented for some time in a mass covered, serve to fertilize the vineyards, orchards, meadows, and even the grain crops, in the south of Europe. Almost everywhere it is turned to account in gardening.

The pomace of apples and pears, though less active, can be employed in part for the same purposes. First rotted, then mixed with one-half earth and carried on to dry and arid fields, it produces a good effect. In Normandy it is thought especially to have the property of improving meadows and young orchards.

The grains of malt, the use of which for fattening cattle, and their scarcity in France, hardly permits them to be classed among vegetable substances for fertilizing the soil in our country, in the environs of London, where its production is immense, is in as much demand, almost, as the best of dungs, since the quantity spread on is from twenty-eight to forty bushels to the acre. This effect is explained by the proportion of azotized matter which they retain. 
Finally, the dregs of oleaginous seeds or fruits make specially good manures. The former deserve here a particular notice.

In the department du Nord, the oil cakes have become, so to speak, one of the conditions of the good cultivation of the country. They are employed upon light and free soils, principally for the culture of grains and for the colzas and flax. It is not uncommon there to see farmers spread upon less than forty-five acres, besides all other manures, more than eight thousand cakes of colza or cameline, which cost them in an ordinary year from two hundred and seventy-five to three hundred dollars.

In England, where the oil cake of rape seed is coming more and more into use, and where the price of them has been raised, instead of using as formerly even half a ton to the acre, they now put not more than eight hundred pounds or even less upon the same surface, and it seems the results are still very good. According to TAYLOR, one ton is sufficient to fertilize a field of three acres, sown with turnips broad-cast, and of five acres when sown in drills.

In the south of France the calres of colza are used in very variable doses according to the fertility of the soil. Upon very good ground they succeed with a dose that very little exceeds what I have just mentioned; in other cases it has been extended from six to seven hundred pounds per acre ; in other cases still, for soils of poorer quality, from eight to nine hundred pounds, and even beyond one thousand pounds. Finally, in the Bolonais, for the exhausting crop of hemp, they have gone as high as sixteen or seventeen hundred pounds, next to the calies of colza preferring those of flax-seed and nuts.

The oleaginous dregs are not always used in the same manner. In the Bolonais of which I have just spoken, in almost all of England and some of our own departments, after having pulverized them more or less, they sow them by hand some days before sowing, and corer them at the same time with the seed. In other parts of Italy, in the neighborhood of Lille, of Valenciennes, \&c., \&c., they 
sprinkle it in the spring upon the young plants already come up, as is done in other cases with the strongest manures and stimulants.

Some conclusive experiments have proved that the maceration of oil cakces in water produces a liquid manure of great energy. In the Netherlands, also, they are mixed with the urine of the stables or other animal substances.

The dregs of olives, which contain the skin, the parenchyma, and the kernel, however well prepared, even in the improved mills, contain some oil which is extracted by rotting them in cisterns ; the mud which is left at the bottoms of these cisterns is an excellent manure, which, however, Bosc affirms is scarcely used in the districts of France where the olive is cultivated. I have seen it used here and there in nurseries and at the roots of each tree in olive yards.

For a few years past the attempt has been made to substitute oil itself for the oleaginous cakes. I do not believe that such a practice is to be recommended; for if the cakes produce so good effects upon the soil, it is doubtless to be attributed more to the large quantities of azotized albuminous substance which they contain, than to a certain portion of oil which they retain. Besides, no one can doubt that the question of economy must entirely proscribe the use of oils as manures.

\section{CHA P T ER XII.}

MANURES PRODUCED FROM THE HERBAGE OF FRESH WATER.

Among the grasses which grow in fresh water, we must distinguish, regard being paid to their use as manures, between those which are decomposed under water and give rise to peat, and those which are taken while green, to be used for the benefit of the soil while in that state. 
Peat, in this respect, like all substances organic and inorganic which have been used for a long time, withdrawn from immediate contact with the atmospheric gases, is at first completely unfit for vegetation. In proportion as it experiences a second decomposition under the influence of the oxygen of the air, it becomes a good manure; but this decomposition is excessively slow; hence it is generally preferred to burn it and spread the ashes, rather than use it directly. In many circumstances, however, it may be desirable to use it to increase the mass of manures. This is effected in different ways.

In Ireland, after having simply dried and pulverised it, it is used with the addition of a little lime for all the small crops, and especially potatoes.

As this substance, from its chemical formation, has scarcely any solubility, in order to hasten its fermentation, Lord Meadowbank has judiciously recommended to mix it with other substances less fixed, such as manures easily putrescible and already in a state of decomposition, and this advice has been generally followed with success. The use of magnesian lime, common lime, calcareous marls, and alkaline ashes, had produced similar effects whenever it has been sought by this means either to render peat-bogs cultivable, or to reduce peat to a manure. We can, therefore, reach the same results in two ways. The English writer whom I have just mentioned, proves in fact that one part of warm dung is sufficient to bring three or four parts of peat to a suitable state of fermentation. On the other hand the German KaSteler has satisfied himself from numerous direct experiments, that lime newly slacked and in the state of a hydrate, that is to say, reduced to powder by means of water, on its coming from the kiln, acts upon the peat in such a manner as gradually to transform the fibrous and resinous parts which it contains into humic acid, which indirectly forms the humate of lime, a very durable manure, which might thus be prepared for the wants of agriculture with great facility. The most common practice, which consists in stratifying the stable dung and peat 
dried and pulverized, and a little afterwards mixing them all together, embraces all the advantages of both theories.

Most of the English cultivators often employ peat mould as a top-dressing, that is to say, sowing it in the spring upon the plants already growing. In pursuing this mode they find there is as much to be gained in the effect produced, the economy of labor and that of the manure.

There are few countries where the aquatic plants of marshes and pools are not collected to supply the deficiency of manures or increase the mass. Sometimes these plants are left spread upon the soil several days, after being gathered, and are then simply plowed in; sometimes they are thrown in heaps to decompose, and are transformed into composts, by mixing them with different proportions of earth.

\section{CHAPTER XIII。}

\section{ARTIFICIAL MANURES.}

IN view of the great abundance of muck, or peat, in every section of our country, and the little attention hitherto paid to it as a manure, we present the following valuable article, from Dana's Muck Manual, together with several experiments testing its importance:

Having considered the relative value of the two classes of manure, those composed of salt, and of salt and geine, that consisting chiefly of geine is now to be explained.

First and foremost in this class is swamp muck, mud or peat. This class includes also dry leaves, dry vegetables of all sorts, plowing in of green or dry crops, irrigation. These are fruitful topics. The principles only of their action can be pointed out. The application of the principle must be left to the farmer. The why of things has been shown; the how must be deduced from the why by practical men. 
Peat is too well known to render it necessary to say that it is the result of that spontaneous change in vegetable matter which ends in geine. Peat is, among manures consisting chiefly of geine, what bone dust is among manures consisting of animal matter. Peat is highly concentrated vegetable food. When the state in which this food exists is examined, it is found not only partly cooked, but seasoned.

Peat consists of soluble and insoluble geine and salts. The proportion of these several ingredients must be known before the value of peat can be compared with similar constituents in cow dung. This proportion is exhibited in the following table of constitution of Massachusetts peat per 100 parts.

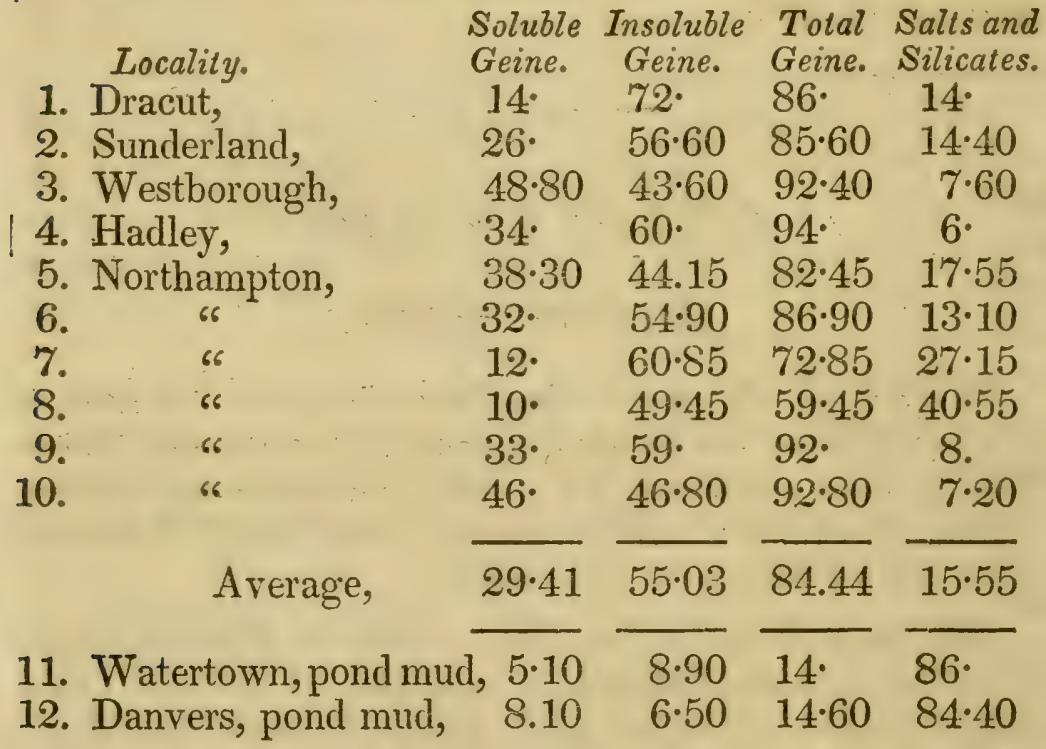

Under the general name of peat are comprised several varieties, which may be distinguished as, 1st. Peat, the compact substance generally known and used for fuel, under this name. 2d. Turf, or swamp muck, by which is to be understood, the paring which is removed before peat is dug. It is a less compact variety of peat. It is com- 
mon in all meadows and swamps, and includes the hassocks. Both these varieties are included in the above, from No. 1 to No. 10. It includes, also, the mud of saltmarshes. 3d. Pond mud, the slushy material, found at the bottom of ponds when dry, or in low grounds, the wash of higher lands. This seldom contains more than 20 per cent. of geine. Nos. 11. and 12 are of this description.

These varieties comprise probably a fair sample of all the peat and swamp muck and pond mud, which occur in the various parts of the country. The results stated, are those of the several varieties, when dried, at a temperature of $240^{\circ} \mathrm{F}$. The composition of peat ashes has been alluded to. They contain, in fact, all the inorganic principles of plants, which are insoluble, with occasional traces of the soluble alkaline sulphates, and of free alkali.

It is well known that all peat shrinks by drying, and when perfectly dried, at $240^{\circ} \mathrm{F}$. loses from 73 to 97 per cent. of water. When allowed to drain as dry as it will, it still contains about 2-3 of its weight of water. It shrinks from $8-3$ to $3-4$ of its bulk. A cord wet becomes 1-4 to 1-3 of a cord when dry. To compare its value with cow dung, equal bulks must be taken, and hence, to dry peat, a bulk of water must be supposed to be added, in proportion above stated, or still better, because easier done, the pile of dry peat is to be estimated by the pit left after digging. It will be found on the above data, that 100 parts of fresh dug peat, of average quality, contain-

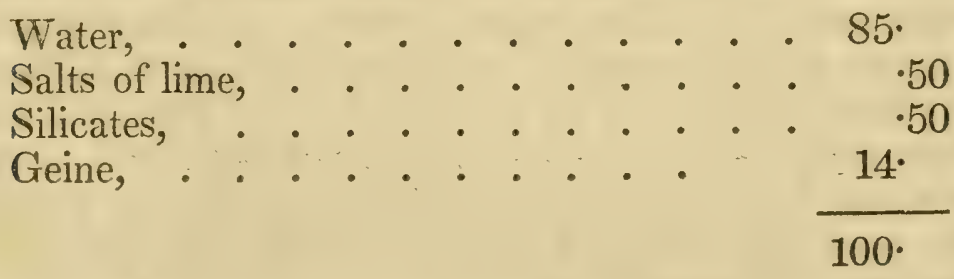

This does not differ much from fresh cow dung, so far as salts, geine, and water are concerned. The salts of lime are actually about the same, while the alumina, oxide of 
iron, magnesia, in the silicates added to the salts of lime, make the total amount of salts, in round numbers, equal that of cow dung.

If the bulks of these are compared, it will be found, that at 90 lbs. per bushel, full measure, and 103 bushels being allowed to a cord,-each contains and weighs as follows, in pounds :

\begin{tabular}{lrrrrr} 
Dung, & 9289 & Geine. & Geine. & Geine. & Lime. \\
No.9 peat of table, & 9216 & 376 & 673 & 1416 & 92 \\
No. 10, “ . .6 & 9216 & 519 & 529 & 1048 & 91 \\
\hline
\end{tabular}

A cord of pond mud (No. 11) weighs when dug, 6117 lbs. and contains solid matter, 3495 lbs., composed of geine, $495 \mathrm{lbs}$; of silicates and salts, 3000 lbs. The salts of lime in pond mud, are $2 \frac{1}{2}$ per cent.

The salts and geine of a cord of peat are equal to the manure of one cow for three months. It is certainly a very curious coincidence of results, that nature herself should have prepared a substance, whose agricultural value approaches so near cow dung, the type of manures. This subject may have been now sufficiently explained. Dcparting from cow dung and wandering through all the varieties of animal and regetable manures, we land in a peat-bog. The substance under our feet is analyzed, and found to be cow dung, without its musky breath of cow odor, or the power of generating ammonia. That process is over-a part of the ammonia remains, still evident to the senses by adding caustic potash. It exists in part, either as a component of crenic and apocrenic acid, or combined with geine, or as phosphate of ammonia, and when the presence of ammonia is added to the salts, whose existence has already been pointed out, it may be said, that peat approaches dung, moistened with the liquid evacuation of the animal.

The power of producing alkaline action, on the insoluble geine, is alone wanted to make peat good cow dung. Reviewing the various matters, from whatever source de- 
rived, solid or liquid, which are used as manure, all possess one common property, that of generating ammonia. The conclusion then of this whole matier, is this; the value of all manures depends on salts, geine, and ammonia; and it is directly in proportion to the last; it follows, that any substance affording these elements, may be substituted for manure.

The great question comes, how is to be given to peat, a substance which, in all its other characters, is so nearly allied to cow dung, that lacking element ammonia? How is that to be supplied? Withont it, cow dung itself would be no better than peat, nay, not so good; for in peat, nearly one-half of the geine is already in a soluble state. Passing by the fact, already alluded to, that peat contains traces of ammonia, which, erolved when treated with caustic potash, exerts its usual action; it may be added, that possibly in the process of regetation, when the decomposing power of the living plant is exerted on peat and the silicates, caustic potash is produced, and ammonia evolved. Considering peat as a source of nitrogen orly, it is evident that the action of alkali is of the highest practical importance.

In this part of the subject of manure, probabilities and possibilities are no longer adinissible. There are two facts well established by expericnee, relating to the action of ammonia in ding. First, it has been shown that dung produces nitrates. Porous substances and alkali possess the power of forming nitrates ; these substances, alkali and porous substances, act like spongy platina, they induce a catalytic power, and the consequence is, that the elements of the air, oxygen and nitrogen, unite, and form nitric acid; this combines with the alkali, and consequently nitrates are produced. The other well established fact, in relation to the action of ammonia in dung, is the power of dissolving and converting geine, which has been previously explained. The most valuable of these two properties is that of producing soluble geine. The formation of nitrates may be quite, and ordinarily is, prevented. It is the alkaline action which is sought. 
cent. of alkali seems enormous. It is stated, in the hope that it may lead to experiments on the free use of alkali. But as it will be hereafter shown, that this is to be reduced by mixing with loam or other matter, this quantity, even if applied to one acre, will probably produce very good effects. It has repeatedly been proved for other purposes, that a cord of fresh dug peat neutralizes $100 \mathrm{lbs}$. of soda ash, or $400 \mathrm{lbs}$. to a dry cord. Further, dry peat, by boiling with, neutralizes $12 \frac{1}{2}$ per cent. of its weight of potash, and in actual practice, allkali to the amount of 6 per cent. of the weight of geine, in pond mud, has been used. It would, therefore, appear to be safe to use the theoretical proportion.

But the nitrogen in cow dung does not all tell. It is impossible but that some portion of the elements of ammonia enter into other combinations, and part also escapes as gas. Besides, it is not all brought at once into action, and hence, a less portion of alkali than above indicated, may be used. It is probable that not a third of the ammonia acts. Let it be taken at that quantity. Then the equivalents are $100 \mathrm{lbs}$. fresh peat, and $10 \frac{2}{3}$ ounces soda, or $1 \mathrm{lb}$. of potash, or 1 per cent. of the weight of the peat in commercial potash.

This proportion will allow in round numbers, to every cord of fresh dug peat, 92 lbs. pot or pearl ashes, or 61 lbs. of soda, or 16 to 20 bushels of common house ashes.

Having no guide here, from experience, of the quantity which may be used per acre, yet in order to arrive at conclusions which could be recommended safely, the alkali has been calculated in the quantity of saltpetre which has been used, with such signal success, by O. M. Whipple, Esq., of Lowell, no less distinguished for the good sense with which he undertakes an experiment, than for the public spirit which urges him onward to its successful conclusion. On the principles which have been developed, when saltpetre is used, the whole alkali is let loose by the action of the growing plant. The experience of Mr. Whipple is a guide to the quantity of alkali which may 
be safely used. He has used from 50 to $150 \mathrm{lbs}$. saltpetre per acre. The real alkali in saltpetre, may be called half of its weight; or the real alkali used, has been from 25 to $75 \mathrm{lbs}=36 \frac{1}{2} \mathrm{lbs}$. and $109_{\frac{1}{2}}$ lbs. pure carbonate, or in round numbers, an average of commercial 1st and $2 d$ quality, of 49 to 149 lbs. per acre-giving an average of $99 \mathrm{lbs}$., which is nearly 1 per cent. of the weight of a cord of green peat, which agrees with the estimate. If, then, this is mixed with the usual proportion of geine, which the dung used contains, equally good effects per acre ought to be produced.

There are other practical facts, which may help to a solution of the question, how much alkali is to be added to a cord of peat. According to the experience of Mr. Phinney of Lexington, an authoity which may not be questioned, a cord of green dung converis twice its bulk of peat into a manure of equal value to itself - that is, a cord of clear stable dung, composted with two of peat, forms a manure of equal value to three cords of green dung. Indeed, the permanent effects of this compost, according to Mr. Phinney, exceed those of stable dung. On this fact, $2 \mathrm{lbs}$. of ammonia in $100 \mathrm{of}$ cow dung, should convert 200 lbs. of fiesh dug peat into good cow dung. The equivalents of these, as has been shown, are $2 \mathrm{lbs}$. of soda ash, or $3 \mathrm{lbs}$. of potash. Allowing the gaseous ammonia to be divided equally among the $300 \mathrm{lbs}$. of dung and peat, this is in proportion of $10 \frac{2}{3} \mathrm{oz}$. of soda ash, or $1 \mathrm{lb}$. of potash to 100 lbs. of fresh peat. Now this calculation, deduced from actual experiment, confirms the theoretical proportions, supposing only one-third of the nitrogen acts, though that was made before the author met with the statement of $\mathrm{Mr}$. Phinney.

There is a coincidence here of proportions, which makes it quite certain that the quantity recommended is a perfectly safe basis for agricultural use. By theory, the proportions are, 1 cord peat, 61 lbs. soda ash, 92 lbs. potash. As deduced from the compounds of dung and peat, $61 \mathrm{lbs}$. soda ash, $92 \mathrm{lbs}$. potash. This proportion gives each cord 
of peat a value equal to that of cow dung; if one-third of its nitrogen acts, it may be composted, as that is, with loam, or still better, mixed up at once with its proportion of peat. If this is done, then the result will be, in round numbers, 1 cord of fresh dug peat,-20 lbs. of soda ash, 30 lbs. potash. In March, 1839, the anthor, in a letter addressed to the commissioner for the agricultural survey of Massachusetts, threw out the following hint, which was published in the second report of Mr. Colman:

"Take $100 \mathrm{lbs}$. of peat as sold, or the fine part from the bottom of a peat stack - at any rate bruise the peat fine, put it into a potash kettle, and $2 \frac{1}{2} \mathrm{lbs}$. of white ash, and 130 gallons of water; boil for a few hours: let it settle, dip off the clear for use, add $100 \mathrm{lbs}$. more of peat, $2 \frac{1}{2} \mathrm{lbs}$. white ash, fill up with water, as much as you have dipped off, boil again, settle and dip off. This may be repeated five times. How much oftener I know not; probably as long as the vegetable part of peat remains. The clear liquor is an alkaline solution of geine. The three first boilings contain geine, alumine, iron, magnesia, and sulphate or phosphate of alkali. The dark-colored solution contains about half an ounce per gallon of vegetable matter.

"It is to be applied by watering grass lands. The ' dregs' may be mixed up with the manure or spread as a top-dressing; or put in the hill. Experience will teachI only suggest."

The principle which should guide the farmer in the making of artificial manure, has now been considered. The author of these pages is not a practical farmer; agriculture is not his pursuit, and he has studied chemistry only as a recreation from the daily duties of life. He has thrown out suggestions, the result of researches undertaken with reference to a totally different object, and these suggestions have been acted upon by practical men, whose results confirm his previous anticipations. He has no theory on this subject to maintain ; his opinions, which must stand or fall by practice, speak for themselves. Yet he is not alto- 
gether indifferent to the practical results which may follow his suggestions, and he should consider that he had inflicted a serious injury on agriculture by the publication of erroneous opinions. When a man's character is to be established in a court of evidence, what is the rule? The good old English rule; to call upon the bystanders, the country present, taken indiscriminately from all who may have known the person. Do not summon persons whose interest may throw a shadow of suspicion on the testimony of the witness. And so here, let it be proved, if it can be, whether the principles here advanced are of practical value, by calling upon the stand those gentlemen who have tested his opinions, and of some of whose operations and results he was ignorant, till he met with them in the agricultural publications of the day, or in accidental conversation; others have been requested to state by letter their results, after these pages were prepared for the press. The evidence on this point is contained in the Statement of Dr. Nichols, beginning on p. 102 of this volume.

Attention might here be called to the extended use of peat composted with lime and animal manure ; but it will be observed, that it is wished to direct the thoughts, at this time, to a compost or artificial manure, without lime or animal manure. The author does not go for lime, but for soluble alkali. Carbonate of lime alone is not expected to produce immediate results, and seldom has, nor can be expected to produce visible effects in the first year of its application. The why and the wherefore of this has been already explained, and it is merely adverted to now to guard against any inference favorable to the action of lime being deduced from the following facts. Mr. George Robbins, of Watertown, is an extensive manufacturer of soap and candles and starch, and still better, a man who employs the refuse of these trades in enriching and gladdening his land. For four years, and it is believed his crops will compare with any of the best cultivators around him, he has not used a spoonful of manure made by any animal, walking either on two legs or on four. He keeps a 
large number of horses and hogs, and several cows; he uses not a shovelful of their manure, but selling that, he uses peat and swamp muck, mixed with his spent barilla ashes. The proportions are, one part of spent ashes to three of peat, dug up in the fall, mixed in the spring. After shovelling two or three times, it is spread and plowed in. The effect is immediate, and so far, lasting. The effects of this spent ashes alone on sandy loam, are excellent; it makes the whole quite "salvy."

The composition of spent ashes has already been alluded to; a certain portion is carbonate of lime; it is well known that, as such, it would produce no better effects than so much chalk. A large part of silicate of soda exists in the spent ashes. This is decomposed by the carbonic acid of the air, the alkali then acts on geine, but this action is greatly assisted by the carbonate of lime. It is, perhaps, the most powerful agent in the decomposition of the silicate of soda. Here, then, the action of carbonates on silicates tells. And it may be worth while to be reminded here, that this action was explained in detail, in order that it might be understood, how spent ashes could act so rapidly on swamp muck.

Alkalies and peat, or swamp muck, are within the command of almost every farmer. Lime is not within reach, and besides, requires no small skill in its management. In the preparation of manure, price is everything. Let the cost be estimated per cord, of artificial manure, prepared in the proportions stated. Peat or muck, may be called worth fifty cents per cord, and the labor of digging, say one dollar,

$92 \mathrm{lbs}$. potash, 6 cts.

$\$ 150$ or, 61 lbs. soda ash, or white ash, 4 cts. or, 24 bush. ashes, $12 \frac{1}{2}$ cts. 3.00 $\begin{array}{r}\$ 552 \\ 244 \\ \text { cts. } 300 \\ 3 \lcm{10 \quad 96} \\ \hline\end{array}$

$244\}$ average of alkalies, 365 
Were they really good hard wood ashes, about 16 bushels would be sufficient, but an excess here is allowed, to compensate for variation in quality. This may appear a very high price, but it is to be remembered, that its value is to be compared with that of a cord of clear cow dung. What is the value of cow dung ? It appears from the barn account of the Merrimack Manufacturing Company, that for $9 \frac{1}{2}$ years, ending Octoher, 1838, a bushel of clear cow dung, costs $21 \frac{1}{3}$ cents. During the same time dung of inferior quality was delivered at the Print-works, by the neighboring farmers, at 20 cents per bushel. Clear dung is delivered at the Print-works in Dover at $12 \frac{1}{2}$ cents per bushel, and at several of the Print-works in Rhode Island, at 16 cents per bushel, giving an average of $17 \cdot 45$ cents per bushel, and as a cord contains, in round numbers, 100 bushels, its price is $\quad \$ 1745$ Deduct from this the price of an artificial cord, $\quad 515$

\section{$\$ 1230$}

It is hence evident that an artificial cord is only about one-third of the price of a natural cord, and if the last may be mixed with two parts of loam or swamp muck, so may the first, which will reduce the price of artificial manure to $\$ 271$. Now this is equal, according to all experience, cord for cord, to stable manure; the value of that may be estimated at $\$ 5$, so that an artificial cord costs only about one-half. The best plan for preparing the artificial manure, would be to dig the peat or swamp muck in the fall; in the spring of the year let this be mixed in the proportion of $30 \mathrm{lbs}$. of potash, or $20 \mathrm{lbs}$. of soda ash, or 8 bushels of common house ashes, to every cord of fresh dug peat, estimating this by the pit dug out, and allowing nothing in the spring for shrinking. If ashes are used, they may be mixed in at once with the muck; but if soda ash or potashes are used, they must be dissolved in water and the pile evenly wet with the solution. The pile is then to be well shovelled over, and used as is other manure. But it has been found by experience, that the peat 
may be dug in the spring, immediately mixed with the alkali, and used forthwith. If spent ashes are used to prepare this muck, add one cord of spent ashes to three cords of peat or swamp muck.

But there are still other forms of cheap alkali, which may be recommended, though it may appear inconsistent with what has been advanced respecting lime ; but, in this case, the lime is converted into a perfectly soluble salt. The soda is eliminated caustic, acts on the geine, renders it soluble. During the exposure to the volumes of carbonic acid, evolved from the peat, the caustic soda becomes carbonated. This carbonate of soda immediately decomposes the soluble salt of lime, and an insoluble salt of lime with a soluble salt of soda, is the result. The effects of these various actions, are, first, the geine is made soluble, ammonia evolved, which is converted into a nitrate, carbonate of lime produced, which acts as that does in spent ashes, and a soluble salt of soda or common salt remains in the mass, producing still farther good effects, when its alkali is let loose by the action of growing plants. Here are rounds of changes taking place, which though the farmer may not readily understand, he may easily produce, with lime and common salt. It may be stated, in further explanation of these changes, that common salt is a compound of soda and muriatic acid, or muriate of soda, using here the old language of chemistry, which is more intelligible to the farmer, though not philosophically correct. By mixing quicklime with common salt, its soda is let loose, the acid combines with the lime, forming a soluble salt of lime, and as long as the soda remains caustic it has no effect on the muriate of lime, but as soon as the soda becomes mild or carbonated, decomposition of the muriate of lime is produced, and the common salt regenerated. Commencing then with quicklime and salt, we pass on to a soluble salt of lime and caustic soda, and from that, to mild soda, and to carbonate of lime and the original common salt.

If these various changes take place in the midst of peat, 
or geine, it is evident that the caustic soda acts upon the geine, and also evolves ammonia from that substance; secondly, that the muriate of lime in its finely soluble state insinuates itself among all the particles of the geine; that the soda also is equally diffused; and that when the soda becomes carbonated, it produces an almost impalpable carbonate of lime throughout the whole mass, which, by its equal diffusion through the soil with the geine, acts upon the silicates, as has been heretofore explained. In order to produce these effects, take,

1 bushel of salt,

1 cask of lime.

Slack the lime with the brine, made by dissolving the salt in water sufficient to make a stiff paste with the lime, which will be not quite sufficient to dissolve all the salt. Mix all the materials then well together, and let them remain together in a heap for ten days, and then be well mixed with three cords of peat: shovel well over for about 6 weeks, and it will be fit for use. Here, then, are produced 3 cords of manure, for about the cost of $\$ 210$ per cord.

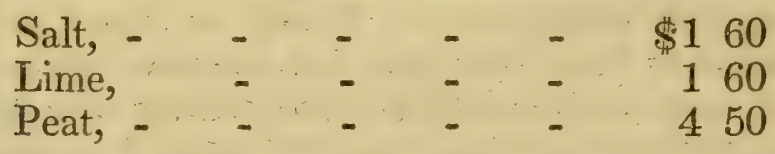

$3) \$ 630(\$ 210$

From experiments made in a small way, it is believed that this will be found an effectual manure; the author suggests it in the hope that it may lead to cautious experiment. But there is still another form in which this artificial manure may be prepared-that is, by the addition of ammonia, the real Simon Pure of cow dung. Take

3 cords of peat

61 lbs. sal ammoniac, 1-4 cask, or about 61 lbs. lime. 
Slack the lime, dissolve the sal ammoniac, and wet the peat well with the solution through every part. Then shovel over, mixing in the lime accurately. We have here then, three cords of manure, at a price as follows:

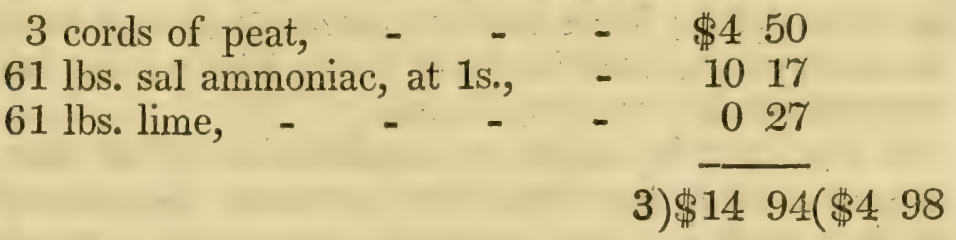

It will be observed that three cords are used in these calculations, because the quantity of salts used is equivalent to the ammonia in a cord of dung, and that is supposed to be composted with 2 cords of loam, or meadow mud. Whether the estimates are correct, each one will determine by the value he may place on his peat and manure, and can apply his own estimate. When a cord of stable or barn-yard manure is usually estimated worth $\$ 4$, the price of a cord of clear pure cow dung will not be thought high at $\$ 17$. In fact, it probably, when mixed with the usual proportion of litter, straw, stalks, and the usual loss by waste of its value, would become worth only about $\$ 5$. But these questions do not affect the principle - that from alkali and peat, as cheap a manure may be prepared, and as good, as from stable dung; for let that be called then adding 2 cords of peat,

$\$ 5.00$

300

3)\$8 00

$\$ 266$ per cord.

There are other sources of alkali for converting peat into soluble manure. Of these the chief is animal matter. Here we have ammonia produced. It has been actually proved by experiment, that a dead horse can convert 20 tons of peat into a valuable manure, richer and more lasting than stable dung; " a barrel of alewires is equal to a 
wagon load of peat." The next great and prolific source of ammonia is urine. The urine of one cow for a winter, mixed up as it is daily collected, with peat, is sufficient to manure half an acre of land with 20 loads of manure of the best quality, while her solid evacuations and litter, for the same period, afford only 17 loads, whose value is only about one-half that of the former.

It need only be added, in confirmation of all that has been arlvanced, that those who have had the prudence to fill their yards and hog-pens with meadow mud, which has thus become saturated with ammonia, have in nowise lost their reward. If they have been satisfied with their practice, perhaps they will be no less firm in their belief of success, when science offers them a reason for the faith that is in them.

DR. NICHOLS'S STATEMENTS, FRON THE ESSEX COUNTY AGRICULTURAL TRAVSACTIONS, 1839-40.

To the Committee to whom was referred the communicution of Andrew Nichols, on the subject of Compost Manures, \&c.

Gentlemen:-Persuaded of the importance of the discoveries made by Dr. Samuel L. Dana, of Lowell, and given to the world through the medium of the reports of Prof. Hitchcock and Rev. H. Colman, to the Legislature of Massachusetts, concerning the food of vegetables, geine, and the abundance of it in peat mud, in an insoluble state to be sure, and in that state not readily absorbed and digested by the roots of cultivated vegetables, lut rendered soluble and very easily digestible by such plants by potash, wood ashes, or other alkalies, among which is ammonia, one of the products of fermenting animal manures, I resolved last year to subject his theories to the test of experiment the present season. Accordingly I directed a quantity of black peat mud, procured by ditching for the purpose of draining and reclaiming an alder swamp, a part of which I had some years since brought 
into a state highly productive of the cultivated grasses, to be thrown in heaps. During the winter I also had collected in Salem, 282 bushcls of unleached wood ashes, at the cost of $12 \frac{1}{2}$ cents per bushel. These were sent up to my farm, a part to spread on my black soil grass lands, and a part to be mixed with mud for my tillage land. Two hundred bushels of these were spread on about six acres of such grass land, while it was covered with ice and frozen hard enough to be carted over without cutting it into ruts. These lands produced from one to two tons of good merchantable hay to the acre, nearly double the crop produced by the same lands last year. And one fact induces me to think, that being spread on the ice, as above mentionerl, a portion of these ashes was washed away by the spring freshet. The fact from which $I$ infer this is, that a run below, over which the water coming from the meadow on which the largest part of these ashes were spread flows, produced more than double the quantity of hay, and that of a very superior quality to what had been ever known to grow on the same land before.

Seventy bushels of these ashes, together with a quantity not exceeding thirty bushels of mixed coal and wood ashes made by my kitchen and parlor fires, were mixed with my barn manure, derired from one horse kept in stable during: the winter months, one cow kept through the winter, and one pair of oxen employed almost daily on the road and in the woods, but fed in the barn one hundred days. This manure was never measured, but knowing how it was made, by the droppings and litter or bedding of these cattle, farmers can estimate the quantity with a good degree of correctness. These ashes and this manure were mixed with a sufficient quantily of the mud above mentioned by forking it over three times, to manure three acres of corn and potatoes, in hills four feet by about three feet apart, giving a good shovelfull to the hill. Miore than twothirds of this was grass land, which produced last year about half a ton of hay to the acre, broken up by the plow in April. The remainder was cropped last year 
without being well manured, with corn and potatoes. Gentlemen, you have seen the crop growing and matured, and I leave it to you to say whether or not the crop on this land would have been better had it been dressed with an equal quantity of pure, well rotted barn manure. For my own part, I believe it would not, but that this experiment proves that peat mud thus managed is equal if not superior to the same quantity of any other substance in common use as a manure among us; which, if it be a fact, is a fact of immense value to the farmers of New England. By the knowledge and use of it, our comparatively barren soils may be made to equal or excel in productiveness the virgin prairies of the West. There were many hills in which the corn first planted was destroyed by worms. A part of these were supplied with the small Canada corn, a part with beans. The whole was several times cut down by frost. The produce was three hundred bushels of ears of sound corn, two tons of pumpkins and squashes, and some potatoes and beans. Dr. Dana, in his letter to Mr. Colman, dated Lowell, March 6, 1839, suggests the trial of a solution of geine as a manure. His directions for preparing it are as follows: "Boil one hundred pounds of dry pulverized peat with two and a half pounds of white ash (an article imported from England), containing 36 to 55 per cent. of pure soda, or its equivalent in pearlash or potash, in a potash kettle, with 130 gallons of water; boil for a few hours, let it settle, and dip off the clear liquid for use. Add the same quantity of alkali and water, boil and dip off' as before. The dark-colored brown solution contains about half an ounce per gallon of regetable matter. It is to be applied by watering grain crops, grass lands, or any other way the farmer's quick wit will point out.

In the month of June, I prepared a solution of geine, obtained not by boiling, but by steeping the mud as taken from the meadow, in a weak ley in tubs. I did not weigh the materials, being careful only to use no more mud than the potash would render soluble. The proportion 
was something like this: peat $100 \mathrm{lbs}$, potash $1 \mathrm{lb}$, water 50 gallons-stirred occasionally for about a week, when the dark brown solution described by Dr. Dana, was dipped off and applied to some rows of corn, a portion of a piece of starved barley, and a bed of onions sown on land not well prepared for that crop. The corn was a portion of a piece of manured as above mentioned. On this the benefit was not so obvious. The crop of barley on the portion watered, was more than double the quantity both in straw and grain to that on other portions of the field, the soil and treatment of which was otherwise precisely similar.

The bed of onions which had been prepared by dressing it with a mixture of mud and ashes previous to the sowing of the seed, but which had not by harrowing been so completely pulverized, mixed and kneaded with the soil, as the cultivators of this crop deemed essential to success, consisted of three and a half square rods. The onions came up well, were well weeded, and about two bushels of fresh horse manure spread between the rows. In June, four rows were first watered with the solution of geine above described. In ten days the onions in these rows were nearly double the size of the others. All but six rows of the remainder were then watered. The growth of these soon outstripped the unwatered remainder.

Mr. Henry Gould, who manages my farm on shares, and who conducted all the foregoing experiments, without thinking of the importance of leaving at least one row unwatered that we might better ascertain the true effect of this management, seeing the benefit to the parts thus watered, in about a week after, treated the remainder in the same manner. The ends of some of the rows, however, which did not receive the watering, produced only very small onions, such as are usually thrown away as worthless by cultivators of this crop. This fact leads me to believe that if the onions had not been watered with the solution of geine, not a single bushel of a good size would have been produced on the whole piece. At any 
rate, it was peat or geine rendered soluble by alkali, that produced this large crop.

The crop proved greater than our most sanguine expectations. The onions were measured in the presence of the chairman of your committee, and making ample allowance for the tops which had not been stripped off, were adjudged equal to four bushels to the acre. In these experiments, 7 lbs. of potash which cost 7 cents a pound, bought at the retail price, were used. Potash, although dearer than wood ashes at $12 \frac{1}{2}$ cents per bushel, is, I think, cheaper than the whitewash mentioned by Dr. Dana, and sufficiently cheap to make with meadow mud, a far cheaper manure than such as is in general used among our farmers. The experiment satisties me that nothing better than potash and peat can be used for most if not all our cultivated vegetables, and the economy of watering with a solution of geine such as are cultirated in rows, I think cannot be doubted. The reason why the corn was not very obviously benefited, I think, must have been, that the portion of the roots to which it was applied, was already fully supplied with nutriment out of the same kind from the peat ashes and manure put in the hill at planting. For watering rows of onions or other vegetables, I should recommend that a cask be mounted on light wheels, so set that like the drill they may run each side of the row and drop the liquid manure, through a small tap hole or tub from the cask, directly upon the young plants. For preparing the liquor, I should recommend a cistern about three feet deep and as large as the object may require, formed of plank and laid on a bed of clay and surrounded by the same, in the manner that tan vats are constructed; this should occupy a warm place, exposed to the sun, near the water, and as near as these requisites permit to the tillage lands of the farm. In such a cistern in warm weather, a solution of geine may be marle in large quantities with little labor and without the expense of fuel, as the heat of the sun is, I think, amply sufficient for the purpose. If from further experiment it should be found 
economical to water grass lands and grain crops, a large cask or casks should be placed on wheels and drawn by oxen or horse power, the liquor from the casks being at pleasure let into a long narrow box perforated with numerous small holes, which would spread the same over a strip of ground, some 6,8 , or 10 feet in breadth, as it is drawn over the field in the same manner as the streets in cities are watered in summer.

ANDREW Nichols.

I certify that I measured the piece of land mentioned in the foregoing statement, as planted with corn, on the 21 st of September, 1839, and found the same to contain two acres, three quarters, thirty-one rods.

$$
\text { John W. Proctor, Surveyor. }
$$

\section{DR. ANDREW NICHOLS'S STATEMENT OF 1840.}

Gentlemen-Having invited the attention of the Trustees of the Essex Agricultural Society to our continued use of, and experiments on, fresh meadow or peat mud, as a manure, it is of course expected that the result of these experiments should be laid before them. The compost with which we planted most of our corn and potatoes the present year, was composed of the same materials, and managed in the same manner as that which we used last year for the same purpose.

Four acres of corn, on the same lkind of soil, were manured in the hill with this compost, and one acre of corn on a more meagre portion of the same field, was manured in the same manner, with a compost consisting of the same kind of mud, half a cord of manure taken from the pigsty, and forty pounds of potash, second quality, dissolved in water, sprinkled over and worked into the heap, with the fork, in the same manner that the dry ashes 
were into the other compost. Of both kinds the same quantity, a common iron or steel shovel full to the hill, was used, and no difference in the crop which could be ascribed to the different manures, could be perceived. The hills were four by three feet apart on an average. In the borders and adjoining this piece of corn, one acre was planted with potatoes. The compost used in some portions of this consisted of rather a larger portion of coarse barn manure composed of meadow hay, corn fodder, waste, \&c., wet with urine and mixed with the droppings of cattle, and less meadow mud. The whole six acres was hoed twice only after the use of the cultivator. The whole amount of labor after the ground was furrowed and the compost prepared in heaps on the field, is stated by the tiller of the ground, H. L. Gould, to have been forty-nine days' work of one man previous to the cutting of the stalks. Pumpkins, squashes, and some beans were planted among the corn. The produce was four hundred and sixty bushel baskets of sound corn, eighty bushels of potatoes, three cords of pumpkins, one and a half bushels of white beans. On one acre of the better part of the soil, harvested separately, there were one hundred and twenty baskets of corn ears, and a full proportion of the pumpkins. On one-eighth of an acre of Thorburn's tree corn treated in the same manner as the rest, the produce was nineteen baskets. A basket of this corn shells out seventeen quarts, one quart more than a basket of the ordinary kinds of corn. The meal for bread and puddings is of a superior quality. Could we depend upon its ripening, for, Thorburn's assertions to the contrary notwithstanding, it is a late veriety of corn, (though it ripened perfectly with us last season, a rather unusually warm and long one), farmers would do well to cultivate it more extensively than any other kind.

The use of dry ashes on our black soil grass lands showed an increased benefit from last year. But our experiments with liquid manure disappointed us. Either from its not being of the requisite strength, or from the 
dryness of the season, or from our mistaking the effects of it last year, or from all these causes combined, the results confidently anticipated, were not realized; and from our experiments this year we have nothing to say in favor of its use, although we think it worthy of further experiments. On the first view of the subject, a dry season or a dry time might seem more favorable to the manifestations of benefit from watering plants with liquid manure, than wet seasons or times. But when we consider that when the surface of the earth is dry, the small quantity of liquid used would be arrested by the absorbing earth ere it reached the roots, and perhaps its fertilizing qualities changed, evaporated, or otherwise destroyed, bythe greater heat to which at such times it must be exposedit is not, I think, improbable that the different effects noticed in our experiments with this substance, the two past years, might be owing to this cause. It is my intention, should sufficient leisure permit, to analyze the soil 'cultivated and the mud used, and prepare a short essay on the subject of peat mud, muck, sand, \&c., as manure, for publication in the next volume of the transactions of the society. . Yours, respectfully,

\section{ANDREW NICHOLS。}

Danvers, December 20, 1840.

EXTRACT FROM DR. NICHOLS'S LETTER.

DANvers, January 28, 1842.

Dear Sir-I am sorry to say that I have no new facts to communicate. Nor have I anything that contradicts my former views on the subject of peat, as manure. We used it in compost on about nine acres of corn and potatoes last summer, one-half of which was the same land on which it was used the preceding season. Its effect seemed. not to be lessened by this second trial in the same soil. The compost was, as formerly, composed by mixing the mud, barn manure, ashes or potash together in the field, in spring, two or three weeks before the corn was planted; 
in a part of it, say, the manure for two acres, about 20 lbs. of nitrate of potash were used. Wherever the nitre was used, worms were absent; other parts of the field were more or less injured by them. This was all the good that we could positively ascribe to the nitre. Our crops were in a most flourishing condition on the morning of the 30th of June; in the afternoon and evening of that day, a violent tempest and two showers of hail, blew down my barn, half my fruit trees, and prostrated and mangled the corn. I should have bargained readily with any one who would have insured me half the crop realized the preceding year from the same land and management. But the healing powers of nature and genial influences of summer suns and showers, in a few days restored the field again to a flourishing condition. A drought more severe than that of the preceding season followed in August; and our crop of corn per acre was about one-fourth less than the crop of that year. My farmer, H. L. Gould, from his success with the mud which you analyzed, was strongly impressed with the belief that other peat mud would not prove as good. I requested him to make an experiment, which he accordingly did, with two cart loads of peat, such as makes good fuel, taken directly from the swamp, mixed with ashes, and used in the same quantity by measure, as. the other compost. He planted with this four rows of corn through the piece. And, contrary to his expectations, if there was any difference, he acknowledged that these rows were better than the adjoining ones. The mud you analyzed, contained, you recollect, a large portion of granitic sand; this peat much less sand but more water, it being quite spongy. The same bulk, therefore, as taker from the meadow and used in our experiment, would probably have weighed, when dry, not more than one-third or one-fourth as much as the other. The quantity of geine in the shovelful of the two kinds, varies not very much after all. I regret that Mr. Gould did not repeat his experiments with the solution of geine last season. My farm is seven miles from my residence, and, like your- 
self, I turn no furrows with my own hand, nor can Ioversee in their various stages, experiments there. I suggest, advise, and leave him to execute. He found himself too much hurried with his work, to attend to this subject at the proper time. In answer to your question I say-that the solution the second year was not applied to the same land, and although used in much larger quantities, it was not as strong as that used the past year.

$$
\text { Yours, respectfully; }
$$

To S. L. Dana, M. D.

Andrew Nichols.

It will be observed that about three cords of swamp mud and 33 bushels of ashes, have been used per acre, in 1839 , and $40 \mathrm{lbs}$. of potash in 1840 .

The number of hills is 3630 per acre. Then, calculating the real potash, there were given to each hill of corn, about half a pint of ashes, or 32 grains of alkali in 1839 , and 45 grains in 1840.

If three cords of swamp muck were used in 1840, about $6 \mathrm{oz}$. of dry geine have been applied per hill-the muck being like pond mud. Now 45 grains of alkali and $6 \mathrm{oz}$. of geine, and $\frac{1}{7200}$ of a cord of pig manure per hill, have here produced effects equal to guano. No new source of nitrogen has been opened to the corn. The effects are due, then, to the alkaline action on geine, and of salts upon silicates. The failure of the solution in the second year is probably owing to the formation of sulphuretted hydrogen.

LETTER FROM HON. WILLIAM CLAKK, JR.

Northampton, 10th February, 1842.

Dear Sir-The results of the few trials 1 have made with alkalies to neutralize the acidity of swamp muck, have not been ascertained with that precision that is necessary to determine conclusively which is best. I will, however, give you the experiments (if they deserve the 
name), as they were made, with the apparent results. The first was with fine well decomposed muck from the swamp of which you had samples, numbered 5, 6, and 7 . In the spring of $1840,16 \mathrm{lbs}$. of soda-ash or white ash, dissolved in water, were carefully mixed with two estimated tons of the muck, and the mixture applied as a topdressing for corn. Two other estimated tons of the muck were served with eight bushels of dry wood ashes, all well mixed together and spread on one side of the muck that was served with the white ash, and further on, an equal quantity of fresh barn-yard manure was spread, and still further on, an equal quantity of compost, made of one part barn manure, and two parts muck, mixed and fermented before using.

The land was a light sandy loam, on the border of a pine plain, and the whole field was treated alike in all respects, except the different kinds of manure, all of which were spread on the turned furrow, and harrowed in before planting. The corn planted where the wood ashes and muck were spread, early took precedence of all the other parcels, and continued apparently much the best through the season. Among the other parcels, no striking difference in growth or yield was manifest. The whole field was harvested together, without separate weight or measurement; and the advantage which the ashes and muck apparently gave over the others, rests (where no experiment should rest) on the opinion of those whose attention was called to it, while the corn was growing.

A similar trial of ashes and muck, and soda and muck, was made the same season on grass land; and the advantage was decidedly in favor of the soda-ash and muck, as, on the corn land, it was in favor of the ashes and muck.

Why the soda-ash should act, relatively, more favorably upon the muck spread on grass land, than when spread on corn land, I am unable to determine, unless it be the partial shade which the grass affords to protect it from the direct rays of the sun, and measurably preserve its moisture and softness. This inference is strengthened by 
the fact that muck, treated as in the above cases-with soda-ash in solution (which makes it somewhat pasty), in the only instance I have tried it-spread on the surface of an old field without a protecting crop, or subsequent harrowings to cover it in the soil, became apparently sunbaked so hard, as to defy, for a time at least, the softening. action oi water. This hardening effect was not observed to take place with the muck treated with the dry ashes, or in the manure compost, and may have arisen from the insufficient quantity of alkali used in the case mentioned.

In another case, one $\mathrm{lb}$. of soda-ash, and one $\mathrm{lb}$. of soft soap, were mixed with four bushels of muck, and all put in a fifty gallon tub, and the tub filled with water, and left to stand five or six days, with an occasional stirring; at the end of that period, the dark-colored water was dipped off and applied to various garden plants and vegetables, and the tub again filled with water, and the muck stirred up, and after a day or two the water was again dipped off and applied as before, and the tub again filled with water. This process was continued for two or three weeks in the early part of the season, and the muck, though gradually wasting, without additional alkali, continued to ferment from time to time, and yield black liquor, to appearance nearly as rich as at first. Rapid growth of the plants followed in all cases when it was applied, and its effect upon a lot of onions would have been ascertained with considerable accuracy, had not a "hired man" took it into his lead that the few rows purposely left for comparison, were suffering by unwitting neglect, and gave them a "double dose," thereby equalizing the growth, and sacrificing the experiment to his honest notions of fair dealing, which required that all should be treated alike. In another case, a muck compost dressing, formed by previously slacking quick lime with a strong brine of common salt, to disengage the acid of the salt, that its soda might act on the muck when in contact, was applied as a top-dressing for corn, without any perceptible effect, perhaps for want of skill in compounding. 
Facts abundantly testify to the fertilizing properties of swamp muck and peat, when brought to a right state, and the subject of your inquiry perhaps yields to no other, at the present time, in point of importance to our good old Commonwealth. Taking your estimate of the weight of fresh dug muck or peat, and Professor Hitchcock's estimate of the quantity in the state, and the saving of one cent per ton, in the expense of neutralizing its acidity, and fitting it for use in agriculture, when applied to all our swamp muck and peat, will amount to an aggregate saving to the industry of the Commonwealth, of over five and a half millions of dollars. Is there a reasonable doubt that more than ten times this one per cent. per ton will be saved over any present process, when chemistry has shed its full light on the subject?

The magnitude and importance of a small saving in this matter, must certainly have been overlooked by some who hare given advice on the subject of making muck compost. Respectfully,

Your most ob't serv't,

William Clark, Jr.

S. L. Dana, M. D., Lowell, Mass.

\section{CHA P ER XIV.}

MANURES PRODUCED BY MARINE PLANTS.

These plants, such as the fucuses, the algo, and the conferves, are still more in request than the others wherever they can be obtained without too great expense. They contain in abundance a mucilaginous substance easily separable, and a quantity of sea salt which doubtless increases their fertilizing properties.

In many cantons they are an important source of fertility; and when they are judiciously employed they never 
fail to enrich the districts upon the sea-coast, whether the herbs are cut upon the rocks, or are washed up upon the shore. However, the effects are far from being as durable as those of dung, for they are felt only upon one or two crops.

Marine plants, applied to arable soils, cannot be spread and ploughed in too soon after they are collected. If this cannot be done immediately, on account of the season or any other cause, they should be made into composts with earth, long dung, or lime.

By spreading these plants upon old pastures not only is the quantity of the grass increased but its quality is improved. Horned cattle as well as sheep eat it with more avidity, flourish better and fatten more readily. This substance does not suit so well as dung for oats or turnips; but it succeeds perfectly well with barley. When it is applied to the young growth of clover after the mowing it destroys it. It can be profitably mixer with the dung of the farm-yard. We use to the acre one-third more, in weight, of sea-weed than of dung.

This manure presents various special advantages: it does not contain the seeds of weeds; it is rapidly decomposed; it is immediately useful to plants without requiring a long process of preparation. By its aid the cultivator can sow more frequently grains or green crops, and thus increase his quantity of dung. Its good effects cannot be called in question, and no objection can be made to its use except perhaps that the grain produced is of an inferior quality.-Agriculture, practical and theoretical, by Sir John Sinclair.

In Normandy and Brittany marine plants have been used from time immemorial ; the wrack of the rocks is preferred, that is to say that which is pulled up at low tide, to the stranded wrack, which, however, evidently contains much more animal matter. The first buried immediately on coming from the sea decomposes more rapidly than the other. It is employed by itself, while the weerls which are drifted upon the shore are ordinarily used only as litter. 
Quite frequently sea-weed is mixed with other manures ; sometimes it is left to rot by itself, or is stratified with earth to be transformed into compost. In Italy these methods appear to be preferred to an immediate burial, which I believe is preferred, and I think justly, in other places. In Ancona hardly any other manure is known than the algre and the zostera reduced to a mould by natural fermentation in a covered place. At other points of the Adriatic coast the weeds are spread upon the roads, and, when they have been partially triturated there, mixed with the urine, the excrements of animals, and the dust of the road, they are arded to the common pile of other manures.

The use of wrack or fucus upon the coasts of France has been considered so important, that an ordinance has fixed the time of their harvest between the full moon of March and that of April, because at that period they have shed their seed and are not covered with the spawn of fish.

\section{CHAPTER XV.}

\section{ANIMAL MANURES.}

Aninials furnish the strongest manures: the muscular flesh, the blood, the horn, the remains of skin and tendons, the wool, the silk, the fecal matter, the bones, and some preparations of these substances, matters of great production in the arts, such as animal black, hold the first rank in this respect. They can be sent to considerable distances, and are an indispensable complement to the vegetable and stable manures. Hence we can say that animal remains and excrements present the richest means of fertilizing the soil. We shall therefore think it our duty to dwell at some length upon this broad foundation upon 
which repose the interests of agriculture, the prosperity of nations, and even, as we shall soon see, the health of great cities.

\section{Of some substances litlle used.}

No certain experiment authorizes us to consider the fatty substances as susceptible of serving directly as manures.

The tendons are generally too difficult of division to form powdered manures; they can only be cut in small pieces.

Hoofs, spurs, nails, horns.-These remains of animals form ore of the richest of azotized manures; but their strong cohesion, and the difficulty of reducing them to powder, as well as often their high price, exactly in proportion to their size and want of color, cause the greater part of them to be reserved for the use of the manufacturer of toys. Those which are defective or too small are sold to the manufacturers of Prussian blue; in short, the horn raspings of the manufacturer are presented as a manure in the most farorable condition. It is best to cover them with earth near the plants, so that the wind may not displace them. This manure, at a high price, has been used with success, as well as those hereafter mentioned, for olive and mulberry trees and vines.

Feathers, bristles, hair, wadding of wool and of silk.Imperfect feathers and quills, and all such as cannot serve either for beds or for writing or for pencil tubes, as well as horse-hair, bristles, hair, wadding, of wool or of silk, which cannot be turned to better account in saddlery, upholstery, or weaving, \&c., will be easily turned to an excellent manure, by putting them in trenches dug near the plants and covered with earth. All these substances, as well as those comprised in the preceding paragraph, however mechanically divided, still offer too great resistance to decomposition to follow the progress of vegetation and realize their greatest effect; we shall presently see that it is the same with another substance, bones, while 
the fiesh, the blood, and the fecal matter, which are perhaps too readily decomposable, can be put into the conditions the most favorable to realize their greatest useful effect.

The flesh of dead animals, roastcd and divided as is described in the book on the Agricultural Arts, and which one might decide not to use for feeding animals, would form one of the best of manures (and even better than any of those prepared as we shall presently describe). To rrake use of it, mix it with about six times its weiglit of field earth, as intimately as possible, in order to spread it in a small quartity and very evenly upon the land sowed with grain. This manure placed by hand at the roots of most of the garden and field regetables, of vines, potatoes, beets, \&c., without being in immediate contact with the stalk, stimulates the vegetation in a remarkable manner. It can also be sown like seed, broad-cast, and fertilizes the land in an extraordinary manner. Mixed with twice its bulk of powdered earth, its application becomes extremely easy, and fifteen hundred pounds of this mixture suffice to manure an acre. We have satisfied ourselves by comparative trials that this substance is sensibly preferable to dry blood in powder.

In the language of Mr. Gaylord, in his Prize Essay on Manure-All animal products capable of putrefaction, can be converted into manures ; fish, flesh, gristle, sinews, skin, horns, hair, wool, and indeed all animal solids or fluids are of this character. The man who allows his dead animals to putrefy, and waste away above ground, is guilty of great improvidence; and converts what might be made a valuable manure into a decided nuisance. A dead horse, covered with earth or vegetable mould, mixed with a little lime or gypsum, will, when decayed and converted into manure and spread on the soil, add to the value of the wheat or corn grown, not enough perhaps to buy a valuable new one, but not unfrequently more than the worth of the original animal. A more disogusting sight can scarcely be imagined, than to see the fences and trees around a 
farmer's yard dressed out with dead lambs or other defunct animals in the spring season. All such should be buried at once, and thus made available in other forms.

\section{Fish.}

Of the substances named above, fish is the one most commonly used as a manure. In the vicinity of the sea, large quantities of fish are annually used in enriching the soil. This is particularly the case on Long Island and in Rhode Island. They are sometimes spread broadcast on the earth and plowed in; at other times deposited in the hills of corn; sometimes spread over the mearlows after the crop is mowed, and allowed to putrefy in the open air. The sterich, where the putrefaction goes on in the open air, is intolerable; and can only be endured by those whose olfactories have been accustomed to the nuisance. This is a most wasteful practice, and should long ago have been abandoned. Treated in this way, but a small part of the actual value of the fish is realized; and it is not to be wondered at, that where the methods of using this manure are so different, widely different ideas of its value should be entertained. Fish should never be used fresh, or thrown at once upon the soil. The true way of preparing them as manure, is to make them into compost, by placing them in layers with muck, rock weed, peat, or even common loam, to putrefy. Where the soil is heavy or inclining to clay, where the compost is to be used, common shore sand, containing as it does large quantities of particles of carbonate of lime, will be found useful as a composting ingredient with the fish. When the fish are decayed or putrefied, the mass should be dug over, the parts thoroughly mixed, and if much ammonia or offensive gas is liberated, a covering of earth should be given, and the mass be allowed further to ferment before using. In this way, fish never fail of being a valuable manure. Rock weed, eel grass, or in short any of those vegetable or animal matters that abound on the sea shore, may be advantageously used in the preparation of these composts. 


\section{Refuse of factories.}

There are many manufactories, particularly those of skins, furs and wool, where large quantities of manures of the most powerful kind are annually suffered to go to waste, though to a much less extent than formerly. The refuse of such establishments, now frequently considered, and justly as now treater, a nuisance, may, by simple application to the soil, or still better by being made into compost, be used as the best of fertilizers. One of the best farmers and most successful breeders of our country was driven into the business of agriculture in self-defence as it were. He was an extensive manufacturer, and the difficulty of disposing of the refuse and waste of the establishment, compelled him to purchase a farm in the vicinity of the city, in enriching which, these matters have been most successfully employed. Those farmers who formerly could not be induced to receive such refuse materials as a gift, would now, after the proof they have seen of their value, be happy to purchase them at a liberal price. The furrier, the tanner, the morocco manufacturer, combmaker, \&c., \&c., are all dealing in materials of the utmost value, when applied to the soil as manure; and the farmer little understands his true interests, who, living in the vicinity of any of these, does not avail himself of these refuse matters to the utmost extent permitted.

\section{Manure of wool.}

Perhaps there is no substance more rich in matters valuable as manures, than the washings and refuse of woollen factories. Chaptal was one of the first to call attention to this matter, and the instances he gave of their fertilizing power were of the most convincing lind. It is but very lately, however, that any attempts have been made in this country to render the refuse of our factories available. All remember, when around every factory and every clothier's shop in the country, piles of refuse wool, clippings, pickings of cards, and sweeping's, accumulated in masses, never thought of as of value, but considered as matter of which 
the owners would most happily be quit. The method of disposing of them, when they could no longer be tolerated, was to throw them into the river; to apply them to the garden or farm was not once thought of. Not long since, in one of our villages, I noticed a garden, the vegetables of which had a luxuriance forming a striking contrast to others near them, and the cause of the difference was asked. "It is all owing to the refuse of that clothier's and carder's shop," was the reply. "I saw in the Cultivator a notice of the value of such manures, and the owner of the shops gladly availed himself of my offer to remove it at my own expense. I gave my garden a good dressing, and as this is the second year, you may judge of the value of the material as a manure. It is probably the last I shall obtain, however," he added, "as the mill owners, after seeing its effect on my garden, are now as anxious "o sare this refuse matter as they were before to get rid f it." The oily or sweaty matter on unwashed wool, is 2. soapy substance having a base of potash, with an ixcess of oily matter, with slight traces of the carbonate and muriate of potash, all valuable as manures; and as all are easily soluble in water, such water should never be lost. A wool merchant at Montpelier had his washing house in the midst of a field, the greater part of which he had, by the use of this wash, with which he watered his plants, transformed into a fine garden. The experiments made by Judge Buel and by Mr. Bement, with hog's bristles and horn shavings, were conclusive as to the value of these substances for manures. In short, as all substances of this nature are nearly pure gelatine, with a slight addition of the phosphates of lime, it is evident their decay must furnish an abundant supply of ammonia to plants, and therefore render them valuable as a manure. 


\section{H A P T R X VI.}

\section{ANIHAL OFFALS.}

\section{Of dried blood.}

Blood.-This liquirl, however, (especially when it has been subjected to boiling, which, by coagulating it, retards its decomposition in the ground), is found so useful to the growth of sugar canes, that it has been lately sent from Paris at a cost of two dollars the one hundred pounds to the colonies, where it arrives, costing four dollars. Blood, in whatever state it is found, and from whatever animal it comes, offers, therefore, to the inhabitants of the country a valuable resource for manure, and, already, in this view, it has formed the base of an important speculation in Paris:

The following is one of the simplest modes of employing it. Some earth free from clods is dried in the oven, after baking bread, care being taken to stir it from time to time with a rake; it requires about four or five times as much as there is of liquid blood; the hot earth is brought to the front of the oven, and is sprinkled with the blood to be preserved, while turned over and over with the shovel ; the mixture is then baked over, and stirred with the rake till the desiccation is complete. It can then be put up in old barrels or boxes, sheltered from the rain, to be used when needed. The earth in this preparation is useful especially to present the blood in a suitable state of division, and to render its decomposition slower and more regular. We can know, moreover, what surface these mixtures will cover as manure, by recollecting that three thousand pounds of liquid blood give seven hundred and fifty pounds of blood coagulated and dried, which is sufi- 
cient to inanure an acre. One hundred poundis of blood in this state equal as a manure three hundred pounds of broken bones, or three loads of good horse-dung, weighing together seven thousand and two hundred pounds. It is a manure by far superior to those known and designated by the names of poudrette, oil cakes, \&c.; it is inferior only to the dried and powdered flesh.

\section{Of the entrails, \&c.}

All the internal parts of animals, such as the liver, lungs, brain, heart, and the offal of the entrails, should be cut or hashed as fine as possible and then mixed along with the emptyings of the intestines, with earth thoroughly dried, the latter in the proportion of six times the bulk of the animal matters. When this composition has been well worked over with the shovel it is spread at the rate of five tons to the acre.

This manure gives excellent results and is particularly favorable to wheat crops. If it cannot be spread immediately after its preparation, it must be preserved in a trench or some other cool place, or at any rate in the shade and covered with earth.

Bones: explanation of the various results of their use in agriculture.

None of the hard substances, the remains of animal organization, offers more remarkable examples of various effects in its action as a manure, than the bones in different states. We find in the numerous agricultural memoirs on the subject the most singular problems which practice could leave to be solved.

The bones which are found in masses of any considerable importance at the disposal of agriculturists and speculators, are presented in the following different forms: Fresh, such as have been taken from animals recently slaughtered, more or less broken, or whole : in each of these three states, their decomposition is almost always too slow, stimulated though it be by the well known influences of 
air, heat and moisture; but, all things being equal externally, enormous differences have been observed, and which seemed inexplicable, in the duration of the decomposition, and consequently in the useful effect produced in a given time.

Some particular experiments have led me to discover the cause of these apparent anomalies. Bones contain in their cellular parts and in various cavities, a fat substance, secreted by itself, of more or less consistence. This substance is free in the adipose tissue of all the crevices which conceal it, for it suffices to open a passage for it by cutting the bones and plunging them in hot water, to bring it out and see it swimming upon the surface of the liquid. The average proportion which can be obtained from the various bones of the butcher is about $\cdot 01$, although the very spongy parts which enclose the most, contain even 05 .

The proportion of fat matter extracted by this process diminishes gradually as the bones are dried; it becomes almost nothing when the desiccation takes place at a high temperature, either in the sun or by a stove. It appears, indeed, that as fast as the water which filled the interstices of the bone has evaporated, the grease liquefied by the heat has taken its place. One of the effects of this penetration has been to impregnate the net-work which encloses the phosphate and the carbonate of lime. This net-work already with difficulty decomposed on account of its cohesion and insolubility, protected moreover by inorganic substances interposed, becomes still less alterable when the greasy matter not only impregnates and defends it from the penetration of water, but, becoming gradually acidified, forms with the lime a calcareous soap, which M. d'Arcet has shown to be undecomposable under atmospheric influence.

Bones in this nearly undecomposable state should, of course, exert but an insensible action as a manure, at least, unless very minutely divided. This also confirms and explains the practical remark, that although spread 
upon the ground for four years these bones scarcely lost 0.08 of their weight, while, when recently taken from animals and deprived of nearly all their grease by boiling. water, they readily permit the decomposition of their organic net-work and lose in the same time from twentyfive to thirty per cent of their weight.

Let us notice three other curious and apparently singular results of the use of bones treated with steam.

The broken bones from which gelatine has been obtained by the action of water and heat, in various processes, form a residuum which has often been tried as a manure. In some experiments a number of cultivators have obtained from these residuums, the first year, more beneficial effects than from bones themselves. In others, an action almost equal to that of bones, but less durable, was observed. More generally, however, little or no favorable infiuence upon vegetation was obtained. A great number of analyses, attentively examined, have enabled me to perceive the different conditions under which this residuum, apparently the same, produced three sets of phenomena so distinct.

Bones treated by the process in question leave a variable residuum; I have sometimes met with it containing from eighty to ninety-five per cent. of the azotic, organic, decomposable matter of the bones, sometimes containing from twenty-five to thirty-three, but more usually one or two per cent.; finally, it sometimes contains scarcely a few thousandths. The following are the causes and effects of these various proportions: The temperature is almost always high in these operations, to the degree of rendering the greatest part of the net-work soluble, and consequently the bones are disaggregated and easily broken. But, although soluble, the organic alterable matter can still beheld in the interstices, either because the washings proper to draw it out have been operated insuffciently, or ill-directed; or further, because the steam may have been chiefly condensed upon the sides of the digesters. This matter soluble in the proportion of 0.8 or 0.9 
of the contents of the bones, will act more rapidly as a manure, since its dissolution and decomposition will be more rapid under the same influences; but, instead of being prolonged four or five years, its action will be almost exhausted in one season-practice has always confirmed this deduction of theory. A washing better conducted but incomplete, easily accounts for the presence and solubility of from 0.25 to 0.33 of gelatinous matter in the residuum; whence, also, we deduce the prompt action, but less and less durable effect than in the preceding case. As to the reduction of 0.01 or 0.02 at the most in the proportion of the azotic decomposable substance, * it evidently makes the residuum inefficacious as a manure. But this state of the case results, as I have proved, from one of the two following circumstances or their concurrence:

When the bones operated upon in the large way have been cut only in the cellular parts and the grease extracted, the division not being sufficiently thorough, the washing or maceration not being sufficient, only from thirteen to fifteen per cent. of dry gelatine is obtained; there should, therefore, remain about fifteen per cent. of fibrous tissue, or the products of its decomposition; but these dregs are scarcely thrown into a heap before a brisk fermentation is developed and ammoniscal vapors are disengaged; thus, the greatest part of the organic matter disappears.

The second circumstance which equally produces a very poor residuum is when a well-conducted treatment is applied to bones sufficiently divided, and finally, when they are exhausted by continued maceration, as in the processes of the hospitals.

We must not therefore generally expect to find in the manufactories of glue any but impoverished residuums and valueless as manures.

Hence the use of them has been abandoned by those

- There always remains besides a variable proportion of from 0.03 to 0.08 of calcareous soap, but which is without influence upon vegetation. 
cultivators $\epsilon$ ven who at first obtained beneficial results ; the differences, however, are now easily explained, and a simple analysis, consisting in the exhaustion by boiling water of a portion dried and powdered, will suffice to test them, à pricri; then drying and weighing anew the powdered exhausted substance we shall find how much the boiling water has diminished the total weight, and consequently the proportion of soluble organic matter, all the rest being almust entirely inert as a manure, and able to act only as a calcareous amendment.

The application of bones to agriculture. - In their natural state bones reduced to powder are an excellent manure, which is spread in the average proportion of fifteen hundred pounds to the acre, and the influence of which is felt in a diminishing degree from three to five successive years according to the soil and the seasons; all sorts of bones moreover are fit for this application, when the distance or want of communications does not permit the better part to be used for the arts which we shall speak of in a future division of the work; ${ }^{*}$ and when, moreover, a machine can be procured to grind them, which is quite expensive in its first cost and requires a large expenditure of motive power.

However, in the absence of this machine, we shall often employ with advantage, especially in the intervals of field labor, the processes of breaking by hand, first cleaving the bones with an axe and then powdering them with a heavy mallet or sledge.

I have remarked that it is much easier to break bones when thoroughly dried and heated than when fresh; it will be best therefore to put them in the oven immediately after baking bread, and break them afterwards while they are warm.

* The bones used for the manufacture of animal black are not lost for agriculture, for we shall see that after having, in the state of powdered charcoal, served to refine sugar, they conceal a portion of coagulated blood, which conduces to render their effect as a manure very remarkable. 
In France broken bones are used as a manure in the department of Puy de Dôme ; in Germany the practice is very extensive. Twelve bushels are there substituted for thirty-five loads of dung for an acre. But the English have applied this manure most in the large way. They derive from Russia and India considerable quantities of bones, besides a large part of those which result from their own large consumption of meat. A bushel of coarsely powdered bones costs the cultivators about one dollar and thirty cents; they use from fifteen to forty-five bushels to the acre; this manuring prolongs its effect during ten to twenty-five years, and enormously increases all the crops, especially those of grass and of turnips. It has been observed that a mixture of wood ashes of equal bulk, or two or three per cent of saltpetre, renders this manure still more efficacious.

Bones in powder can be placed in the trenches with potatoes, or sown upon seed before passing the harrow or roller which covers it with earth.

It is sometimes preferred to mix them with the earth previously plowed and harrowed by passing the harrow and roller over them a second time.

If the bones were in fine powder, they could with advantage be placed upon the transplanted plants, and be covered up in closing the hole of the planter. 


\section{CHAPTER X VII.}

\section{CHARCOAL AND SOOT.}

Charcoal has of late attracted considerable attention as a fertilizer. We find the following interesting experiments and observations on the action of charcoal from wood on vegetation, by Edward Lucas, as an appendix to Liebig's Agricultural Chemistry.

"IN a division of a low hothouse in the botanical garden at Munich, a bed was set apart for young tropical plants; but instead of being filled with tan, as is usually the case, it was filled with the powder of charcoal, (a material which could be easily procured), the large pieces of charcoal having been previously separated by means of a sieve. The heat was conducted by means of a tube of white iron into a hollow space in this bed, and distributed a gentle warmth, such as tan communicates when in a state of fermentation. The plants placed in this bed of charcoal quickly vegetated, and acquired a healthy appearance. Now, as is always the case in such beds, the roots of many of the plants penetrated through the holes in the bottoms of the pots, and then spread themselves out; but these plants evidently surpassed in vigor and general luxuriance plants grown in the common way-for example, in tan. Several of them, of which I shall only specify the beautiful Thunbergia alata, and the genus Peireskice, throve quite astonishingly; the blossoms of the former were so rich, that all who saw it affirmed, they had never before seen such a specimen. It produced also a number of seeds without any artificial aid, while, in most cases, it is necessary to apply the pollen by the hand. The Peireskice. grew so vigorously, that the $P$. aculeata produced shoots 
several ells in length, and the $P$. grandifolia acquired leaves of a foot in length. These facts, as well as the quick germination of the seeds which had been scattered spontaneously, and the abundant appearance of young Filices, naturally attracted my attention, and I was gradually led to a series of experiments, the results of which may not be uninteresting; for, besides being of practical use in the cultivation of most plants, they demonstrate also several facts of importance to physiology. The first experiment which naturally suggested itself was, to mix a certain proportion of charcoal with the earth in which different plants grew, and to increase its quantity according as the advantage of the method was perceived. An addition of two-thirds charcoal, for example, to vegetable mould, appeared to answer excellently for the Gesneria and Gloxinia, and also for the tropical Aroidece with tuberous roots. The first two soon excited the attention of connoisseurs, by the great beauty of all their parts and their general appearance. They surpassed very quickly those cultivated in the common way, both in the thickness of their stems and dark color of their leaves; their blossoms were beautiful, and their vegetation lasted much longer than usual, so much so, that, in the middle of November, when other plants of the same kinds were dead, these were quite fresh, and partly in bloom. Aroidece took root very rapidly, and their leaves surpassed much in size the leaves of those not so treated; the species which are reared as ornamental plants, on account of the beautiful coloring of their leaves, (I mean such as the Caladium bicolor, Pictum, Pcecile, $\& c$.), were particularly remarked for the liveliness of their tints; and it happened here also, that the period of their vegetation was unusually long. A cactus, planted in a mixture of equal parts of charcoal and earth, throve progressively, and attained double its former size in the space of a few weeks. The use of the charcoal was very advanageous with several of the Bromeliacea and Liliaceer, with the Citrus and Begonia also, and even with the Palma. The same advantage was found in the case of almost 
all those plants for which sand is used, in order to keep the earth porous, when charcoal was mixed with the soil instead of the sand; the vegetation was always rendered stronger and more vigorous.

"At the same time that these experiments were performed with mixtures of charcoal with different soils, the charcoal was also used free from any addition, and in this case the best results were obtained. Cuts of plants from different genera took root in it well and quickly; I mention here only the Euphorbia fastuosa and fulgens, which took root in ten days; Pandanus utilis in three months, $P$. Amaryllifolius, Chamadorea elatior in four weeks, $P i$ per nigrum, Begonia, Ficus, Cecropia, Chiococca, Buddleya, Hakea, Phyllanthus, Capparis, Laurus, Stifftia, Jacquinia, Mimosa, Cactus, in from eight to ten days; and several others, amounting to forty species, including Ilex and many others. Leaves, and pieces of leaves, and even pedunculi, or petioles, took root and in part budded in pure charcoal. Among others we may mention the foliola of several of the $C y$ cadece as having taken root, as also did parts of the leaves of the Begonia Telfairia and Jacaranda brasiliensis; leaves of the Euphorbia fastuosa, Oxalis Barrilieri, Ficus, Cyclamen, Polyanthes, Mesembryanthemum; also the delicate leaves of the Lophospermum and Martynia, pieces of a leaf of the Agave Americana; tufts of Pinus, \&c.; and all without the aid of a previously formed bud. "Pure charcoal acts excellently as a means of curing unhealthy plants. A Dorianthes excelsa, for example, which had been drooping for three years, was rendered completely healthy in a very short time by this means. An orange tree, which had the very common disease, in which the leaves become yellow, acquired, within four weeks, its healthy green color, when the upper surface of the earth was removed from the pot in which it was contained, and a ring of charcoal, of an inch in thickness, strewed in its place around the periphery of the pot. The same was the case with the Gardenia.

"I should be led too far were I to state all the results 
of the experiments which I have made with charcoal. The object of this paper is merely to show the general effect exercised by this substance on vegetation; but the reader who takes particular interest in the subject will find more extensive observations in the 'Allgemeine Deutsche Garten zeitung' of Otto and Dietrich, in Berlin; or Loudon's Gardener's Magazine for March, 1841.

"The charcoal employed in these experiments was the dust-like powder of charcoal from firs and pines, such as is used in the forges of blacksmiths, and may be easily procured in any quantity. It was found to have most effect when allowed to lie during the winter exposed to the action of the air. In order to ascertain the effects of different kinds of charcoal, experiments were also made upon that obtained from the hard woods and peat, and also upon animal charcoal, although I foresaw the probability that none of these would answer so well as that of pine-wood, both on account of its porosity and the ease with which it is decomposed.*

"It is superfluous to remark, that in treating plants in the manner here described, they must be plentifully supplied with water, since the air having such free access penetrates and dries the roots, so that, unless this precaution is taken, the failure of all such experiments is unavoidable.

"The action of charcoal consists primarily in its preserving the parts of the plants with which it is in contact -whether they be roots, branches, leaves, or pieces of leaves-unchanged in their vital power for a long space of time, so that the plant obtains time to develope the organs which are necessary for its further support and propagation. There can scarcely be a doubt also that the charcoal undergoes decomposition; for after being used five to six years it becomes a coily earth; and if this is

* M. Lucas has recently repeated these experiments, and found that the animal charcoal obtained by the calcination of bones possesses a decided advantage over all other kinds of charcoal, which he subjected to experiment.-Iiebig's Annalen, Band xxxix. Heft 1, S. 127. 
the case, it must yield carbon, or carbonic oxide, abundantly to the plants growing in it, and thus afford the principal substance necessary for the nutrition of vegetables.* In what other manner indeed can we explain the deep green color and great luxuriance of the leaves and every part of the plants, which can be obtained in no other kind of soil, according to the opinion of men well qualified to judge? It exercises likewise a favorable influence by decomposing and absorbing the matters excreted by the roots, so as to keep the soil free from the putrefying substances which are often the cause of the death of the spongiola. Its porosity, as well as the power which it possesses of absorbing water with rapidity, and, after its saturation, of allowing all other water to sink through it, are causes also of its favorable effects. These experiments show what a close affinity the component parts of charcoal have to all plants, for every experiment was crowned with success, although plants belonging to a great many different families were subjected to trial." (Buchner's Repertorium, ii. Reihe, xix. Bd. S. 38.)

- We make a further extract on this subject, from Vol. I. of the American Agriculturist, by Dr. Raymond.

From an article on Dr. Liebig's Organic Chemistry applied to Agriculture, in the April number of the North American Review, it appears that the most valuable property of a soil, is that of absorbing and giving off those vapors and gases that constitute so considerable a portion of the food of plants. Reflecting on this fact, it occurred to me, that charcoal might prove a most valuable manure; from its well known capacity of absorbing vapors, gases,

* As some misconception has arisen regarding this explanation of the action of charcoal upon vegetation, and an idea propagated that the introduction of these opinions into this work incorporated them with those of Liebig, it is necessary to state that they are merely inserted here as part of the papers of M. Lucas. The true explanation is, that charcoal possesses the power of absorbing carbonic acid and ammonia from the atmosphere, which serve for the nourishment of plants.-ED. 
and saline solutions, and under certain circumstances giving them out.

The ladies make use of charcoal in their flower-pots, from an experience of these results. At this time I did not know of its being used on a large scale. I communicated the idea to Mr. Phineas Sargent, and he remarked he did not know that it had been used as a manure; but he had often observed the charcoal hearths were more productive than the surrounding land. I made further inquiries of Mr. A. B. Allen on the same point, and he had the kindness to furnish me Mr. J. H. Hepburn's valuable paper "Charcoal as a Manure," published in the Trans. of the Ag. Soc. of N. Y., p. 298, 1842. I was not a little gratified to find my speculations sustained by so accurate an observer.

As Mr. $\mathrm{H}$. declined to enter into the chemical character of charcoal, I propose to supply that portion of the subject compiled from such writers as are within my reach.

From Ure's Dictionary of Chemistry, article Gas, we extract: "Of all solid bodies, charcoal is the most remarkable in its action on the gases. In M. De Saussure's experiment, the red hot charcoal was plunged under mercury, and introduced after it had become cool into the gas to be absorbed without ever coming into contact with the atmospherical air.

"One volume of charcoal made from boxwood absorbed of ammonia, - - 90 volumes.

Muriatic acid gas, $\quad-\quad-\quad-85 \quad$ -

Sulphurous acid - $\quad-\quad-\quad-55 \quad$ " 6

Sulphuretted hydrogen, $\quad-\quad-55 \quad$ "

Nitrous oxide, - - - - - $\quad-40 \quad$ "

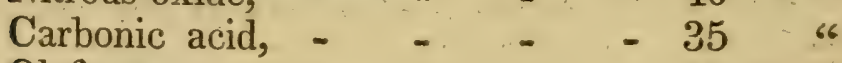

Olefiant, - $\quad-\quad-\quad-\ldots-35$ -

Carbonic oxide, - $\quad \ldots \quad-\ldots \quad-\quad 942$ "

Oxygen, - - - - - - 9.25 "

Nitrogen, - - _ - - $\quad-7.5$ "

Gas from moist charcoal, - $\quad$ - 5.0 "

Hydrogen, - - - - 1.75 " 
"The absorption was not increased by allowing the charcoal to remain in contact with the gases after $\mathbf{2 4}$ hours, with the exception of oxygen, which goes on condensing for years in consequence of the slow formation and absorption of carbonic acid gas. If the charcoal be moistened, the absorption of all those gases that have not a strong affinity for water is diminished. Thus boxwood charcoal, cooled under mercury, and drenched in water, is capable of absorbing only fifteen volumes of carbonic acid gas; although before being moistened, it could absorb thirtyfive volumes of the same gas.

"Dry charcoal saturated with any gas, gives out, on immersion in water, a quantity corresponding to the diminution of its absorbing power. When a piece of charcoal which is saturated with either oxygen, hydrogen, nitrogen, or carbonic acid gas, is put into another gas, it allows a portion of the first to escape, in order to absorb into its pores a portion of the second gas."

Charcoal, when reduced to powder, will absorb but half the quantity of gas that it would when in the lump.

The advantage of this article over every other that has been used as a manure is, that what is not actually consumed or washed away, is retained on the soil, and will continue to absorb and give off the vapors, gases, and saline solutions for an unlimited period. It would therefore be an experiment worthy of trial by our western agriculturists, to make their wood into charcoal and spread it on the soil, rather than reduce it to ashes, which at most will last but a few years.

C. H. RAYMond.

Buffalo, August 6th, 1842.

Sоот is a valuable manure, peculiarly rich in humus as well as salts, and in its composition more nearly allied to the solid substance of animals, than anything else. It contains of humus or geine $30 \cdot 70$, of nitrogen 20 , and of salts of lime 25.31 parts in 100 . It also abounds in salts of soda, potash and ammonia. According to the analysis of Dr. Dana, $100 \mathrm{lbs}$. of soot contain as many of the 
valuable salts as a ton of cow dung, and its nitrogen, compared with that manure, is as 40 to 1 . The ordinary farmer can make but little use of soot, as it is not to be had in the country in any considerable quantities; but those in the vicinity of cities may avail themselves of this manure with much profit. For the gardener or the floriculturist, soot is an excellent manure; but care must be taken not to use it too freely, as we have known tender garden plants at once destroyed by too liberal applications of it, particularly in a dry state. Mixed with water, in the proportion of six quarts of soot to one hogshead of water, it has been found a most efficacious liquid for watering plants, particularly those grown in green houses.

\section{CHAPTER XVIII.}

EXCREMENTS OF BIRDS.

Pigeon dung.-This sort of dung, almost free from straw, presents the excrement almost pure or mixed with remains of feathers, themselves rich in azotic substance, in a state of convenient division. Preserved and dried, also, under shelter, this manure is without question the richest of what are called dungs; but it has far less energy than the powdered manure obtained from animal remains.

Intelligent cultivators well know the excellent effects of pigeon dung, and go far to seek it. On the large farms of Pas-de-Calais, the pigeonries are numerous and very populous ; they are let by the year, or leased for several years, at a rent of $\$ 20$ for the dung collected annually from 500 or 600 pigeons. A pigeonry of this size yields a large wagon load of dung, which thus costs $\$ 20$. A 
load of this dung serves to fertilize two acres ; consequently the manuring costs $\$ 10$ an acre, not including the transportation. This manure is used chiefly for crops for the arts, such as flax, tobacco, colza, \&c.

Dung of aquatic birds.-On the islands of the Pacific ocean, enormous banks of dung have been discovered, accumulated during centuries by the aquatic birds which frequent them. These residuums, rich in organic, azotic putrescible matters, contain also much uric acid. There is an important trade in this manure between the southern part of America and Peru, to which it is sent.

It is probable that this manure, exported under the name of guano, has a strong similarity in its use and effects to the pigeon dung of which we have just spoken. The following is the account of it given by Messrs. HurBOLDT and BONPLAND.

"The guano is found in great abundance in the Southern ocean upon the islands of Chincha, near Pisco; but it exists also upon the coasts and islands further south, at Ilo, Iza and Arica. The people of Chancay who carry on the trade in guano, go and return from the islands of Chincha in 20 days; each boat is loaded with from 1500 to 2000 cubic feet. The substance forms a bed of from 50 to 60 feet in thickness which is worked like bog iron ore. The same islets are inhabited by a multitude of birds, especially the crane and the flamingoes, which spend the night there; but their excrements for three centuries have not formed a bed of more than 4 or 5 lines in thickness. The fertility of the sterile coast of Peru is founded upon the guano, which is a great object of commerce. Fifty small vessels, named guaneros, are going constantly to transport this manure to the coast, and it is scented at a quarter of a league's distance. The sailors accustomed to this ammoniacal odor do not suffer: we sneezed constantly on approaching it. For maize particularly the guano is an excellent manure. The Indians taught the Spaniards the use of it. If too much of the guano is put upon the maize the roots are burned and destroyed." M. de 
Humboldt sent a quantity of the guano to Messrs. FourCROY and VANGUELIN to be analyzed and to determine the uric acid. From their analysis it may be concluded that this manure is nothing else than the excrements of birds.

Similar deposites of dung are met with in several caves formed by the bats. We may mention, for example, the caves of Arcis upon Aube, near Auxerre. All these deposites form a rather warm manure, and which, in regard to their cost, the quantity to be used, and the effects, may be compared to the dung of pigeons, of which we have just spoken.

In the districts where silk-worms are largely reared, the excrements, and the larvæ themselves which remain after the reeling of the cocoons, form also an excellent manure.

\section{CHAPTER XIX.}

\section{NIGHT SOIL.-POUDRETTE.}

NigHT soil, or the contents of privies, is one of the most powerful and valuable of manures ; but prejudices, combined with the difficulties formerly attending its use, have prevented much attention to it in England or the United States, until within a few years. In consequence, a substance of the greatest importance to the farmer has been regarded as a nuisance, and, in the vicinity of large cities, has been truly so. Now, since science has taught the mode of preparing it for use, its use is becoming general, and its value fully appreciated. According to the analysis of manures, made by Boussingault and by Dr. Dana, there is no manure ordinarily accessible to the farmer so rich in the carbonates or salts of ammonia as this. This will be seen by comparing it with horse dung, the value of which is well understood. 
Horse manure, - Night soil .

Geine, . . . . 27. . . 23.

Salts, . . . . . 96 . . $1 \cdot 2$

Carbonate of ammonia, . 3.24 . 15.32

The dung of the fattening hog approaches night soil in value, more nearly than any other ; indeed Dr. Dana supposes that for all the purposes of analysis, these may be arranged under one head. In practical use, Von Thaer, on the Prussian government farm, determined by experiment its comparative value as follows: If a soil without manure would yield three bushels of produce for one sown, manured with different substances the result was,

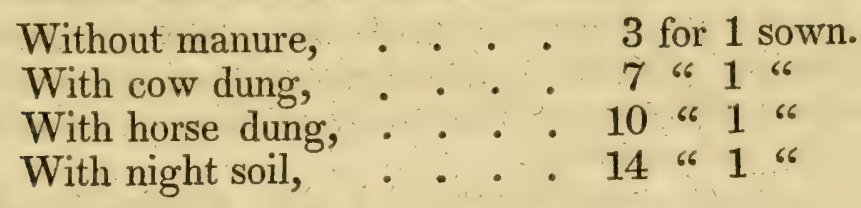

Comparative value of night soil.

In some experiments made by Arthur Young, and detailed in the Annals of Agriculture, the effect of this manure on wheat was as follows:

Simple soil, per acre, . . . .

Bushels of night soil, . . . .

66

66

66

Cubic yards of farm yard compost,

30 do. and 1 cubic yard of chalk, .
$12 \frac{1}{2}$ bushels. $32037 \frac{1}{2}$ “

$24032 \frac{1}{2}$ "

$16031 \frac{1}{4}$ "

6025 "

$3023 \frac{3}{4}$ " 6

25 “

Applied to potatoes, the results were not less decisive: Simple soil produced per acre, . . . . 120 bushels. Night soil, 10 wagon loads, . . . . 600 " Bones, 10 " . . 650 " Hog dung, 60 one horse cart loads, . . 480 " Yard compost, 60 one horse cart loads . 300 "

\section{Poudrette.}

The most common method of using night soil, or at least 
that in which it is most portable and least offensive, is to convert it into poudrette. This is done to the best advantage in large manufactories ; and herice they are usually established in the vicinity of large cities, where the original article is easily obtained. Different processes are adopted, but the most common is to dry the night soil slowly in pans, liaving previously mixed it with plaster or ground peat. The object in adding plaster or peat, is to prevent the escape of ammonia, on which the value of the manure is mainly depending. The dried mass is then pulverized-is perfectly inodorous, resembles a dry brownish powder, and may be used broad cast or in drills. In Paris, a powerful manure is made, also called poudrette, by boiling the offals of the slaughter-houses into a thick soup, making this into a stiff paste by stirring in coal ashes, then drying and grinding.

The following communication on this subject, we find in Vol. II. of the American Agriculturist.

The use of this valuable manure is every year becoming more general. The highly concentrated vegetable nutrition contained in it, and the large and rapid growth it affords when properly applied, is fast acquiring for it a high rank among modern manures. There is no addition made to the value of the original material from which it is made, by the manufacturer; and it is therefore in the power of any farmer or gardener to apply what is within his reach, without adding to it the expense of transportation, packages, and the profit of preparing it. By adding dry peat, refuse tanner's bark, or even turf, with charcoal or ground gypsum, all the offensive effluvia is prevented, and the article can be removed without annoyance.

An excellent plan for effecting this, is given by Mr. Woodfin in the Southern Planter. He says: "I collect the stercoraceous matters separately in large vessels. After the urine has become putrid, which will require but 2 or 3 days in warm weather, and 10 or 15 in cold, add sulphuric acid (oil of vitriol) slowly to the urine. If the urine is putrid, a powerful effervescence will immediately 
take place. The acid must be added till effervescence ceases. By this process the carbonic acid is driven off, and the sulphate of ammonia is formed, which has no volatility, except at a high temperature. Thus is secured the ammonia formed by putrefaction, which would otherwise escape. I then add the liquid to the solid excrement, incorporating them well together, until a very thin batter is formed. Into this mass I stir my finely pulverised charcoal, according to my judgment, without regard to any precise quantity, which is then spread on tight hoards in the open air. Stir frequently till the whole is dried, then pulverise and put it up in barrels for crops."

Now, here is the wholes tory of preparing it nicely for sale. The oil of vitriol is a cheap article, and within any one's reach; but the same object is attained by using gypsum, which is a combination of sulphuric acid and lime. When this is used, a double salt is formed. The acid of the gypsum leaves the lime to unite with the ammonia of the urine, and the carbonic acid of the manure unites with the lime, making a double compound, sulphate of ammonia and carbonate of lime, or common lime, and the object is accomplished at less expense. Dry pulverised peat is a substitute for charcoal, even if it is desired to put up in packages; and, being with many a cheaper material, may be properly substituted for it. Or if required for use on the premises, waste, tan, or common turf, well filled with decayed vegetable matter, may be used. 


\section{CHAPTER XX.}

\section{LIQUID MANURES.}

THE blood and the urine of various animals, the gelatine in a viscous solution, the oleates, stearates, and other fat salts, dissolved or accompanied with organic matter in solution or emulsive suspension, the matters extracted from the intestines more or less liquid, and in general all liquids charged with organic substances and put in the atmospheric circumstances where their decomposition is effected rapidly and in contact with young plants, overtask at first or decompose their feeble organs, then very soon being almost completely dissipated, can no longer contribute to the growth of the vegetables that have outlived the excessive energy of their first action.

However, all these liquids without exception, even those charged with the substances most rapidly alterable, may in certain circumstances be excellent manure; we shall proceed to quote some striking examples.

Diluted with water so as to contain four or five thousandths of the total weight of the dry organic matter, and then used in abundant irrigations, they are all able to produce extraordinary effects upon the progress of vegetation; but in the absence of economical means of irrigation, they would often require labor in watering which would be too expensive.

Thus the suds and wash of kitchens, mingled with the liquids which flow from several butcheries, from numerous stables, and the ley from a multitude of laundries in two populous villages near Paris, carried off at first by a small spring into the ditches of a vast marsh-garden, cause crops there more than double of those usually obtained in this 
small culture ; directed afterwards upon a natural meadow, all parts of which are covered by turns at pleasure, they occasion five abundant cuttings, upon a soil which heretofore gave but one.

I will add that most of the natural waters containing considerable proportions of organic matter, as that which I have met with in analyzing the water of a bored well in the Rue de la Roquette, and as appears from the composition of the waters of the bored wells of Tours, analyzed by M. Chevreul; these waters, I say, used in irrigation would themselves present an aliment for the growth of plants.

If, indeed, we call to mind that different plants may exhale each day into the atmosphere, several times their weight of water, retaining in their tissues, either assimilated, or interposed, almost all the non-volatile matters which were dissolved, we shall understand the remarkable influence of some ten thousandths of these soluble substances upon their weight after a vegetation of several months.

The rich cultivations of Flanders and Belgium demonstrate the profit which may be derived from fluid azotic manures more or less diluted with water.* They are obtained and employed in that country as follows:

Cisterns of mason work are constructed as convenieritly as possible to receive the urine of the stables and the drainings of the privies, and, at the same time, near the roads which lead to the cultivated fields. These mixed matters collected, into this sort of close vessels, buried beneath the ground, are protected from the greatest causes of fermentation, that is to say the access of the air and the elevation of the temperature.

When the liquid is to be used for watering, a portion of it is drawn out and divided with five or six times its bulk of water; the mixture is then put in casks and spread upon the land either by letting it run, when clear, through a

* In the excellent work, L' Agriculture de la Flandre, by M. Cordier, may be found all the details of these nice agricultural processes. 
tube perforated with holes, or upon a plank, when very turbid.

Sown fields and meadows just mown are thus watered. The vegetative force imparted by this watery manure, although of short duration, may have a great influence; for, once covered with green young plants, the ground is defended from an accidental drought; and moreover the plants themselves thus rapidly acquire the necessary strength to resist various adverse infiuences, and to draw from the atmosphere and the soil their ulterior aliment.

The second mode of spreading the Flemish manure is to take it from the cistern without diluting, carry it in casks and pour it out by means of tubs. The handcart employed in Germany may also be used for this purpose.

As the manure is now too active or too easily decomposable to be put in contact with the plants or their roots, it is dipped out by the spoonful and deposited at the foot of each tuft, or again it is made to run in furrows between the plants sowed in rows or drills.

Watering either with urine or water from the privies, or with the pasty matters mixed with these liquids, or finally with powdered oil cakes (dregs of oleaginous seeds) added, requires the following precautions: If these manures are spread upon land already plowed and harrowed before sowing, a moist or slightly rainy time should be chosen, and the harrow should be used before sowing, so as to mix the manure with as much earth as possible, and avoid its immediate contact with the seed.

For the same purpose when we would water after having harrowed and sowed, we should previously cover the grain and beat it down somewhat with two passages of the roller: the greater number of seeds are thus protected by a compressed layer of earth from the contact of a too active manure, which would destroy the radicals and plumules, or even prevent germination.

For drill plants the Flemish manure is also insulated from the stalks, leaves and roots of the plants, by pouring it into holes of the dibble between the roots of the colza, 
pinks, tobacco, \&c., in the same line with them. This plan permits harrowing or hoeing between the rows without deranging the manuring; besides, the mornings are selected, and moist weather, in order to avoid burning the leaves by a too rapid decomposition during the heat of the day.

In the neighborhood of Lille one cask of Flemish manure costs about six cents for purchase, six more for transportation, and twelve for spreading; it contains two hundred and fifty pounds of matter and covers (spread by the ladle or watering cask) a circle of twenty-one feet radius. An ordinary vault in this country costs thirty dollars to fill, and contains eight hundred and sixty-four cubic feet, or two hundred and fifty-six casks.

When the Flemish manure has just been spread in either of the ways above mentioned, a strong putrid odor is exhaled in the vicinity. This phenomenon indicates a rapid disengagement of gas, out of proportion with the absorbing faculty of the plants. It causes a disagreeable taste to the edible products, and sometimes temporarily injures the growth.

In Switzerland a liquid manure is prepared with great care, under the name of lizier. The following is the description of this manure by $\mathbf{M}$. de Candolle, in his notice of the manures of that country: There is made in the stables, behind the place occupied by the animals, a deep trough which receives their urine; their excrements are mixed with it, and the trough may also receive the water from a reservoir ; several times a day, after having stirred it up carefully, the trough is emptied into the lizier pit, a trench with which it communicates, and which should have capacity enough to hold the manure which is produced in a week. This manure should then remain at rest in the trench for a month. Consequently five pits are required, which are successively filled each week till the first is emptied, then the second, and so on. M. Bella, at the model farm of Grignon, has had trenches prepared on a similar plan. 
But liquid manures, or those much diluted, cannot in many localities be employed with economy, in waterings sufficiently frequent or in irrigation. They have besides some real inconveniences which modern improvements enable us to avoid, as we shall see by and by.

Instead of diluting with water, we can sometimes profitably reduce the weight of the manure by evaporation. Thus for the blood of animals several processes of desiccation can be employed, presenting for equal weights remarkable differences in the properties of the products obtained.

The cohesion and insolubility acquired, have evidently the effect of retarding the decomposition of the dried blood thus obtained, and to assimilate it almost, in this respect, to the muscular flesh cooked at $212^{\circ}$ and then dried and powdered.

Blood and muscular flesh brought to a dry state in this manner, follow better and more gradually, in their spontaneous decomposition, the progress of vegetation, and are preferable as manures to blood which, being dried at a lower temperature, has retained its solubility in water. The latter mode of drying should therefore be rejected, though sometimes more economical, at least when the dried blood is not designed for the clarification of beet or cane syrup, or fecula, \&c.

Experience, indeed, has shown that to manure an acre of ground in cultivation, where we employ eight hundred and fifty pounds of soluble dried blood, that is to say, dried in the air at a low temperature, seven hundred and fifty pounds of coagulated insoluble blood or only six hundred and fifty pounds of muscular flesh will also suffice; the two latter agents will furnish the most aid to the latter growth of plants, which it is most important to favor, that is to say, at the periods of flowering and fructification, and will enable us to obtain the greatest proportion of the products which have the most value.

Another means of retarding the decomposition of animal substances, soft or liquid, and thus considerably in- 
creasing their availability as manures, is the intermixture of porous charcoal in powder.

To impress as deeply on the mind as possible the value of this manure, we take the following from Dana.

The more exact analysis of cattle urine, by Sprengel, who has devoted particular care to the subject, gives, as the average of many trials, the following, in $1000 \mathrm{lbs}$.

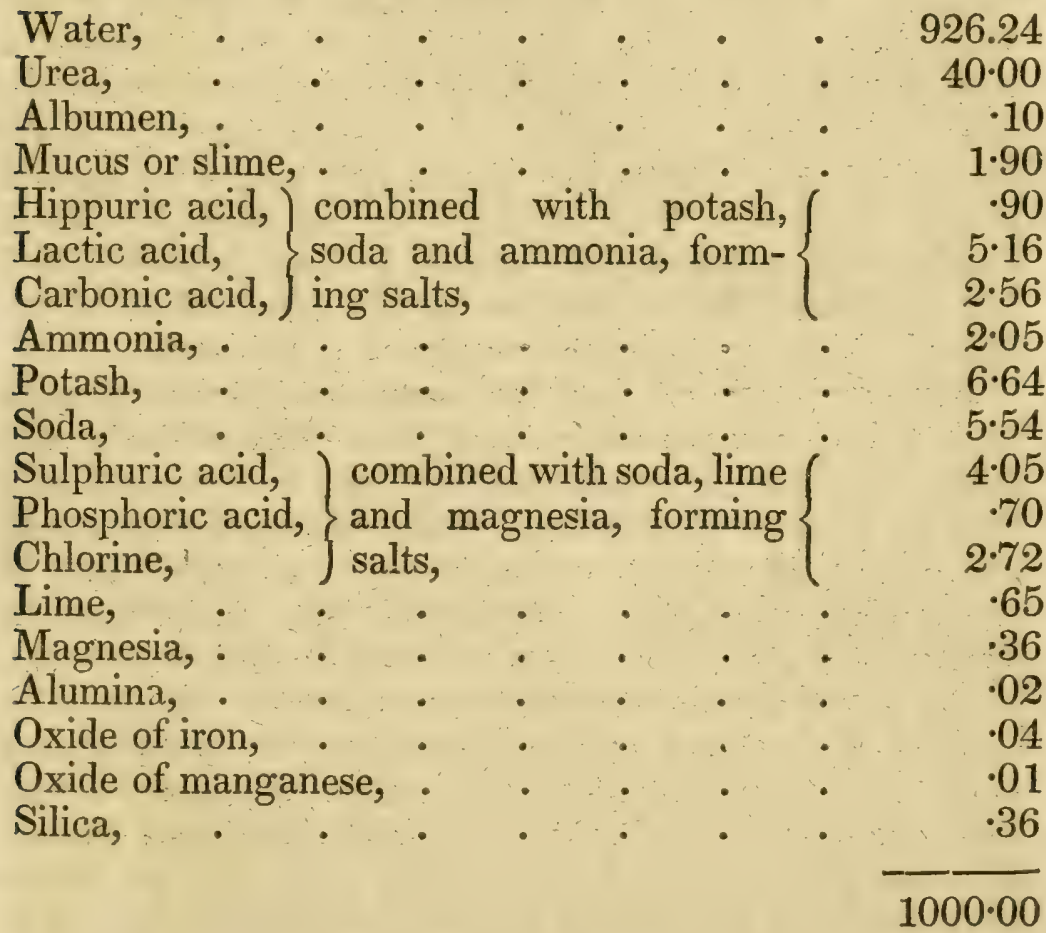

Let this now be compared with the standard of value, cow dung. $100 \mathrm{lbs}$. of that afford $2 \mathrm{lbs}$. of carbonate of ammonia; while this evacuation gives $4 \mathrm{lbs}$. of ammonia in its urea, besides that in its other ammoniacal salts.

The quantity of liquid manure produced by one cow annually, is equal to fertilizing 1 1-4 acres of ground, producing effects as durable as do the solid evacuations. A cord of loam, saturated with urine, is equal to a cord of 
the best rotted dung. If the liquid and the solid evacuations, including the litter, are kept separate, and soaking up the liquid by loam, it has been found they will manure land in proportion by bulk of 7 liquid to 6 solid, while their actual value is as 2 to 1 .

One hundred pounds of cow's urine afford about $8 \mathrm{lbs}$. of the most powerful salts which have ever been used by farmers. The simple statement then, in figures, of difference in value of the solid and liquid evacuations of a cow, should impress upon all the importance of saving the last in preference to the first. Let both he saved. If the liquids contained, naturally, geine, they might be applied alone. It is the want of that guiding principle which teaches that salts and geine should go hand in hand, which has sometimes led to results in the application of the liquor, which has given this substance a bad name.

It has been proved that the ammoniacal salts of urine have a forcing power on vegetation. The value of ammonia was long ago understood by Davy, and its carbonate was his favorite application. Plants watered with a simple solution of sulphate of ammonia, an abundant salt in cow's urine, are fifteen days earlier than those watered with pure water. Grass land watered with urine only, yields nearly double to that not so manured. In a garden on land of very poor quality, near Glasgow, urine diluted with water, nearly doubled the grass. But upon wheat, sown upon clay land, it did no good; it injured barley, potatoes grew rank and watery, and on turnips the effects were only half as good as mere unfermented dung. The circumstance of the soil, in this last case, was probably a deficiency of geine.

The liquid evacuation of the horse is composed of

Water,

Urea,

Chalk,

Carbonate of soda,

Hippurate of soda, Muriate of potash,

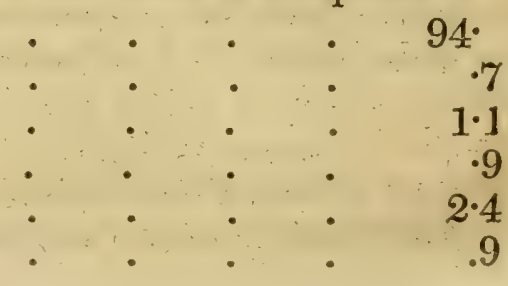


The hippuric acid is not peculiar to the horse. The urine of most herbivorous animals contains hippurate, formerly called benzoate of soda, its acid having the fragrance of gum benzoin. If man takes benzoic acid, hippuric replaces uric acid in the urine. According to the composition, horse stale, pound for pound, is equal to the value of cow dung. Sprengel found the urine of sheep to afford, in $1000 \mathrm{lbs}$,

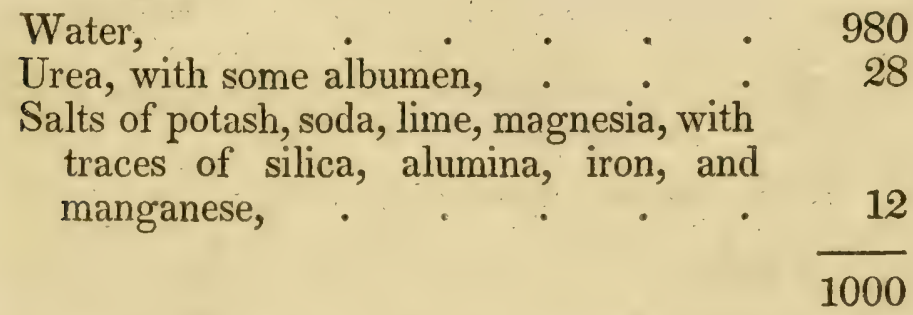

No animal affords more urine than the hog. Owing to a peculiar volatile and unexamined substance, it gives plants and roots a disagreeable taste. Fed on grains and bran, the urine in $1000 \mathrm{lbs}$. affords,

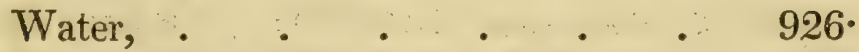

Urea, with a little slime and albumen, $\quad 56 \cdot 40$

Salts, common salt, muriate of potash,

gypsum, chalk, Glauber's salts, .

$17 \cdot 60$

\section{0 .}

But rich as are the liquid evacuations of the stable and cow-yard, they are surpassed by those of the farmer's own dwelling, especially when it is considered with what ease these last may be saved. According to Dr. Thomson, 1000 parts of this substance, the human liquid evacuation, contain $42 \frac{1}{2} \mathrm{lbs}$. nearly of salts, which are,

Sal ammoniac,

Sulphate of potash, $\quad \therefore \quad \therefore \quad \div \quad 2.112$

Muriate of potash, . . . . . 3674 


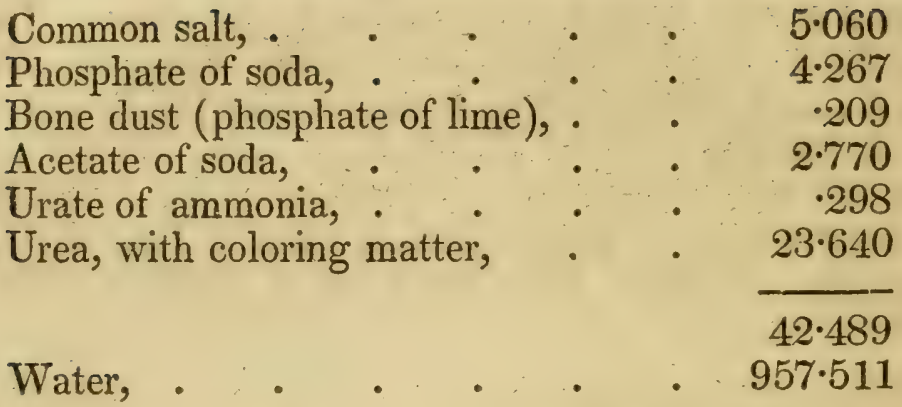

There is scarcely a single element in this liquid which is not essentially an ingredient in all plants.

In every $100 \mathrm{lbs}$. of cow urine, are,

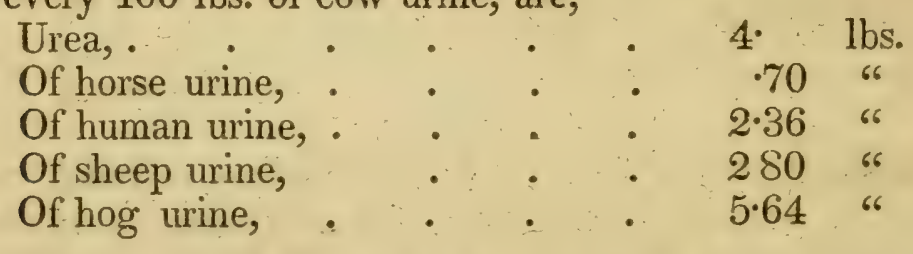

It is at once seen, how valuable are swine as manufacturers of manure.

The urea being called equal to ammonia, it is seen that the ammoniacal salts in human urine are very nearly the same as those in cow dung, but its effects in actual practice are found to be nearly double those in cow dung. The actual amount of salts in 100 parts of human, cow, and horse dung, is, in round numbers, 1 per cent., while in the liquids it averages $5 \cdot 88$, being in the cow $7 \cdot 4$, and in the human $4 \cdot 24$ per cent., horse 6 .

All urine of course varies with the food of the animal, the season, and its age. White turnips give a weaker liquor than Swedish. Green grass is still worse. Distillers' grains are said to be better than either of these. The more water the animal drinks, the poorer the urine. Doubtless the liquids of fattening kine are richer in ammonia during this period, for it contains a part of that nitrogen not carried away in milk. In winter, urine contains much less urea than in summer, sometimes only one 
half. Putrefaction changes urea to ammonia. The time required for this varies. Urine putrefying for a month, contains double the ammonia of fresh urine. It does not wholly decompose in a month; but during all this time gives off ammonia. Unless then mixed with loam, or peat, or swamp muck, or where kept in tanks with its bulk of water, it loses ammonia. Urine is fully ripe, when it contains neither caustic ammonia nor urea. Whatever may be the food, it is evident, from the above statements, that rivers of riches run away from farms, from want of attention to saving that which ordinarily is allowed to be waster.

Each man evacuates annually enough salts to manure an acre of land. Some form of geine only is to be added to keep the land in heart, if the farmer has but the heart to collect and use that which many allow, like the flower unseen, "to waste its sweetness on the desert air."

Think one moment how much is now lost. If every human being voids urine sufficient to enrich an acre of ground, then a family of ten persons, if so minded, could save enough to enrich ten acres; and the three hundred and fifty thousand inhabitants of the city of New York, if means were provided to collect and convert into manure their liquid evacuations, would fertilize three hundred and fifty thousand acres of land. Urine is sometimes mixed with plaster, or other absorbents, and thus formed into an article called Urate. 


\section{CHAPTER XXI.}

\section{ANIMAL AYD ANIMALIZED BLACK.}

I OBSERVED in 1820 and published in 1822, in a Memoir upon charcoals, which received the prize of the Society of Pharmacy of Paris, the remarkable effects of a mixture (a residuum of the refineries) in which coagulated blood formed at most from ten to fifteen per cent of the total weight. Whilst putrefaction had not previously taken anything from this product, of which I made trial as a manure, the presence also of eighty-five or ninety per cent of carbonized inorganic substances still retarded the decomposition of the azotic substance with energy.

In consequence of the publication of this new fact, all the residuums of the refineries, which had till then been thrown away into the public sewers, came gradually into use; soon after, taken from all our own manufactories and imported even from various European countries, they have added annually the enormous mass of forty-five thousand pounds of new manure to the means of fertilizing our soils. It constitutes at present, with the animalized black, the main bulk of transportable manures. The departments of the west, supplied from Nantes by sea, and along the course of the Loire, needing the most manure by the way, have consumed the largest quantity of the charcoal or animal black. Soils lately fallowed one year in two or even two years in three, by its use are sown every year, and have doubled and tripled the value of their net products.

A measure of the power of this mixture gives at once the following astonishing result, which has been experimentally confirmed on a large scale; the fifteen parts of dried blood which it contains act in a more useful manner, 
as a manure, than four hundred liquid parts, representing about one hundred parts in a dry state.

Hence, the organic matter united with charcoal is six times more powerful than alone; this fact explains the enormous consumption of the residuums of the refineries, and the much higher price than of their equal weight in dried blood. They are also spread with the greatest facility, and a remarkable economy of labor; for it is sufficient to sow them after the grain and cover them along with it.

The fertilizing action is constant under the ordinary conditions.

Still, I soon discorered that the charcoal losis none of its weight, subjected during three months to the same atmospheric influences, to the action of distilled water and the roots of plants, even when the growth of the latter is purposely favored by gaseous emanations from azotic substances in putrefaction.

Another curious apparent anomaly was soon offered to our meditations; we shall presently see that it adds a new proof to the support of the general theory which we have advanced. Some residuums of the refineries containing variable proportions between five and fifteen per cent. of dried blood had several times had an unfavorable influence upon the vegetation, and still without further addition of manure, increased the yield of the succeeding crop. This phenomenon determined some cultivators to permit the first fermentation to take place in these residuums before spreading them upon the land. In inquiring what could be the effects of this primary reaction in the case of the residuums which are termed too warm, I discovered the presence of from five to ten per cent. of altered sugar, which gave rise to an abundant production of alcohol and carbonic acid, and subsequently of acetic and hydrosulphuric acid; to these primary products succeed, much more slowly disengaged, carbonate and acetate of ammonia and all the results of the decomposition of azotic substances : from this date the influence of the manure has been 
constantly and evidently very favorable to vegetation. From that it appeared probable to me that the decomposition of the sugar alone could exert the unfavorable influence observer. Indeed in a series of special experiments all the mixtures, in different proportions, of alcohol and acetic acid with charcoal, were uniformly injurious to the progress of vegetation, and the more so the stronger the proportion of the acid. Wishing to know whether these phenomena were independent of the influence of cliarcoal, and if they would take place in presence of liquid azotic products, as from the solid remains of animals, I left in a close vessel and in open ressels mixtures of sugar: 1st, in beaten albumen to saturation; $2 \mathrm{~d}$, in albumen diluted with equal parts of water; $3 d$, in eggs beaten without being separated, such as are used in clarification; 4 th, in the juice expressed from muscular flesh, and finally, in the same liquid containing morsels of flesh. All these mixtures during two years experienced more or less slowly the reactions which produce alcohol and carbonic acid, and afterwards acetic acid, and traces of sulphuretted hydrogen. The pieces of flesh when well washed had not sensibly lost any of their constituent principles nor of their properties. It was therefore evident that the presence of sugar in the residuums employed had occasioned unfavorable reactions; that these must needs take place in whatever state the azotic matter may be, and that it is useful to remove the sugar either by washing: or by a slight fermentation, thus leaving to the coagulated blood interposed in the carbonaceous matter only its own useful action; that finally, a very easy preliminary trial, simply washing some of the black upon a small filter, will enable us to discover the presence of the sugar, and consequently the utility of the aforesaid precautions, or the uselessness of them when the washings have been properly conducted at the refineries.*

* M. Dutrochet has observed that the sugar itself dissolved in water, put in contact with the spongy extremities of the roots, very soon destroys the plants. 
Other experiments show that charcoal may be useful not only to prolong and thus increase the effect of the blood, but, besides, that it may serve as an intermediate agent in absorbing gases and heat, and afterwards transmitting them to the plants. If several plants are made to vegetate comparatively, in two vessels containing pure charcoal, and watered daily with pure water, to one of which is daily added one per cent. of such charcoal, and to the other as much of the same charcoal impregnated with the gases which are disengaged by the spontaneouss fermentation of animal matters, in the latter vessel tlie vegetation will be very beautiful, while in the other it will remain feeble and languishing.

\section{CHAPTER XXII.}

\section{MANUFACTURE OF DISINFECTED MANURES.}

ONE of the most important discoveries in the annals of industry, presenting new facts to be enrolled in the science of agriculture and public health, comes to confirm the system of undecomposed manures, and to add a direct demonstration to the utility of disinfection instead of previous putrefaction.

The carbonaceous residuum from the refineries was already insufficient for the demands of agriculture, when M. SALnion invented the manufacturing for its own sake, of a similar manure, still more efficacious, and especially more constant in its effects. He succeeded, by mixing azotic organic remains, in a state of minute division, with earth rendered exceedingly porous, carbonaceous and absorbent, by calcination in a close vessel.

To show the immense advantage of preserving by this short process all the decomposable parts of the organic substances used as manures, without previously leaving 
the greatest part to be dissipated in the atmosphere ; it is sufficient to remark that the new manure, known by the name of animalized black, produces a useful effect at least ten-fold that which is obtained from an equal quantity of fecal matter, for example, slowly dried according to the usual processes. The ascertained results of a daily manufacture of about eight hundred pounds near Paris, and the facts collected by our most distinguished agronomes, from vast extents of land under cultivation, can leave no doubt upon this subject; already treaties concluded in some of the populous cities insure the extended production of these unconsumed manures.

We have remarked that the desiccation of fecal matter gave rise long ago to large establishments near the cities; and that this desiccation is effected at irregular intervals between the rainy or moist seasons. The poudrette finally obtained is therefore the residuum of a decomposition of several years, during which the greatest part of the assimilable principles being exhaled into the atmosphere, have left in excess all the earihy and inert matters and those which are least decomposable.

To this process, which is in general use even yet, and which diffuses a fetid odor to a great distance, is gradually succeeding the much more rational mode above mentioned. This important application promises to purify by degrees all the great centres of population; applicable also to the immediate conversion into manures of all the liquids sufficiently charged with organic and azotic matter and all the parts of animals that are sufficiently divisible, it constitutes the most general process for the fertilization of the soil, and must gradually everywhere supply the deficiency of dung.

\section{Effects and mode of using the animalized black}

The manufacture of the new manure, the animalized black, is therefore complete; it unites all the useful conditions of a minute division anda slow decomposition. It can be immediately applied to use, put in contact with the seed 
sown, with the radicles, plumules, stalks, and most delicate leaves. It is also evident-1st, that we need never fear in the use of this agent the trouble of the myriads of parasitic insects imported with the dung, the vegetable manures and the ordinary mould. $2 \mathrm{~d}$, that the presence and intimate intermixture of charcoal presents an obstacle, moreover, to the attacks of the small animals which have sometimes devastated lands manured with blood and muscular flesh.

Among other curious examples of the latter kind of danger in the use of unmixed animal substances, we will mention what happened upon the first trial of dried blood in the colonies; a field of sugar cane had just received at the roots of each tuft, a small handful of the powdered manure, deposited near the surface of the ground; thousands of rats came from all parts, and rummaging among the roots, destroyed all hope of a crop for that time.

One of the means of extending the benefits of the carbonaceous powder, the base of the animalized black, would be, to send it to be employed wherever offal rich in animal matter is to be had, and of which the greater part is lost by a too quick decomposition, at the same time that it injures the taste of the products and poisons the air of the vicinity. In this way a simple mixture, in a sufficient proportion to disinfect these matters (and which would vary between one tenth and one fourth of their bulk), would triple at least and often multiply six-fold their useful effect, at the same time banishing all the inconveniences inseparable from putridity. Finally, it could not but prevent the manures of muscular flesh and dried blood from being carried off by rats and other small animals; it would be best also, for these last rich manures, to have recourse to a mixture with from ten to fifteen per cent, of the car bonaceous powder. 


\section{CHAPTER XXIII.}

\section{YARD MANURE。}

AFTER all the various kinds of manure already noticed, one-and that by no means small, compared with the rest, still remains-the great mass of matter collected in the farm yard.

\section{Animal manures.}

A late British writer on agriculture says :- "The chief use of cattle on an arable farm, besides those necessary for the operations of husbandry, is to produce manure for the land. If the cattle repay their food, and the expense and risk attending their keep, the manure is sufficient profit. Even with a moderate loss, they must be kept, when manure cannot be purchased. The loss, if any, on the cattle, must be repaid by the increase of the corn crops. Manure is to a farm what daily food is to an animal; it must be procured at any sacrifice." Common barn-yard or stable manure is the kind to which most farmers must look for the fertility of their farms. This consists of the droppings of the cattle, mixed with the straw userl for littering in stables or thrown into the yards for the animal to feed or lie upon, the coarser hay and weeds refused by the stock, and the urine of the animals kept in the stables or yards.

In the language of a distinguished English writer, this mixed mass is collected during the period of feeding, when it undergoes a certain degree of fermentation. When trodden by the feet of the animals kept in the yards, the effect is to exclude the external air, and to prevent the fermentative process from proceeding with that rapidity which would take place were the mass not compressed. 
The principal animal substances which are mixed with the ligneous fibre of the litter, and which cause it to undergo decomposition, are the dung and urine of the animals.

The properties of this dung, to a certain extent, depend upon the kind of animals and the nature of their food. The dung of horses is easily fermented, and is more readily decomposable, in proportion to the succulence and nutritive qualities of the food consumed. This also holds with respect to the dung of oxen. When the animals are fed on straw and the dried stems of plants, the dung is less rich and decomposable than when they are fed on turnips, oil cake, and other nourishing food ; and the same thing holds with respect to the dung of the hog and other animals. The dung of the different feeding animals is mixed, in greater or less proportion, with their litter, and the greater the proportion of the animal to the vegetable matter, the more rendily will the latter ferment and decompose.

The urine of the animals, again, is in itself a very rich manure, and contains, in certain states of combination, all the elements which enter into the composition of plants. It is necessarily mixed with, and partly absorbed by, the litter and other substances in the yards, and it hastens, in a material degree, the fermentation of these substances.

The urine, however, is apt either to make its escape by flowing out of the yards, or to be imperfectly mingled with the litter. It becomes, therefore, a part of the management of the farm-yard, to provide against either of these contingencies.

The farm-yard should be made level at bottom, and even paved, if the subsoil be very loose and sandy, and the bottom should be sunk somewhat below the surface of the ground. As a portion of the liquid will flow from the stables and feeding-houses, gutters of stone should be made to convey the liquid from these into tanks or other reservoirs adjacent to the yards. The same means are to be taken for conveying away any excess of liquid from the yards themselves. This is not done for the purpose of 
draining the yards of moisture, which would be an error, but for the purpose of preventing any excess of liquid from being lost. The principal cause which produces a great fluw of liquid from the yards, is an excess of rain, which, falling upon the heap faster than it can be absorbed, washes away the urine.

Three methods may be adopted for the management of the liquid which is obtained from the feeding-houses, or which oozes or is washed off from the mass in the yards.

1. It may be pumped from the tank or reservoir into which it had flowed, conveyed back to the farm-yard, and spread over the surface of the heap. In this manner it will be imbibed by the litter, and tend to hasten the decomposition of the mass; or, if there be a compost heap upon the farm, the liquid may be upon it so as to be imbibed by it.

2. It may be pumped up when convenient, and conveyed in barrels to the field, and spread orer the surface; a species of manuring which, under certain circumstances, is exceedingly efficacious.

3. In the bottom of the tank or reservoir to which the liquid is conveyed, may be placed absorbent earths, stems of plants, and other matters. These being saturated, will become very rich manure, and may either be carried from the tank to the field, and applied to the ground, or put into heaps or composts, until the period of using them shall arrive.

Of these methods of applying the excess of liquid from feeding-houses and yards, the most generally applicable to the common practice of farms in this country, is the conveying of the liquid back to the yards, or the spreading of it over the surface of compost heaps, or other collections of absorbent substances. In Flanders, where extreme care is bestowed in the collection and preparation of liquid manures, there is a smaller proportion of straw and hay produced on farms, than in the mixed system of agriculture of Britain. There is not, therefore, so great a proportion of ligneous fibre to be decomposed. The Flemings. 
accordingly, pursue the mode of managing their manure, which the circumstances peculiar to their agriculture render expedient. They can always ferment sufficiently the fibrous matter of the heap of their farm-yards, and therefore they have always a spare supply of liquid in a separate state. But in this country, where we aim at producing a large quantity of hay and the cereal grasses, we require nearly all the liquid of the feeding animals, to moisten and ferment the general mass of the farm-yard.

When the animals of the farm are fed on tolerably rich and succulent food, and where the proportion of straw is not too large, there is no difficulty in fermenting the mass of the farm-yard to the degree required; but when the quantity of straw is very large in proportion to the more moist and succulent food consumed, as sometimes occurs in the case of clay-land farms in certain districts, then there may be considerable difficulty in getting the straw sufficiently fermented and decomposed for use. This may arise from the want of moisture, as well as from a deficiency of animal matter; and as we may not at the time have a power of supplying the latter, we must endeavor to keep the heap moist by soaking it, in the absence of rain, with water. But the permanent remedy for this evil is to increase the quantity of such nourishing food as the farm will produce-namely, cabbages, tares, clovers, and other succulent and nutritive plants.

Sometimes, even when there is no extraordinary excess of dry litter, the fermentation of the heap in the yard, after proceeding to a certain degree, suddenly stops, by which the manure is much injured. This arises from the want of moisture; and when it happens it is often very difficult to renew the fermentation. The best remedy is to turn over the heap, soak it with water, and mix it with horse-dung, or any animal offal that can be obtained.

With these exceptions, the management of the farmyard is not attended with any difficulty. We have seen that the mass consists of a collection of the excrements of the animals kept upon the farm, of the straw and other $8^{*}$ 
substances employed for litter, and generally of any refuse or offal produced at the homestead; and that this mixed substance is accumulated chiefly during the months of winter, undergoing during this period a certain degree of fermentation and decomposition in the yards where it lies.

The substance thus collected and partially fermented, is to be applied to the grounds during the months of spring, summer or autumn, immediately following the winter in which it has been prepared. It should be always applied as soon after it is prepared as possible, there being a waste either in retaining it too long, or in causing it to undergo a greater degree of fermentation than is required.

In the process of the putrefactive fermentation, the elements of the body fermented, in assuming their new forms of combination, partly make their escape in the gaseous state. In the fermentation of manures, the decomposition may proceed so far that the great mass of the substance shall be exhaled, leaving behind only the earthy and alkaline, and a portion of the carbonaceous, matter of which it was composed. In the treatment of this class of substances, therefore, the putrefactive fermentation should neither be continued longer, nor carried to a greater degree, than is necessary for the purpose intended.

In practice, our purpose is to produce certain kinds of crops; and certain kinds of plants, it is found, require a greater action of manures at particular stages of their growth than others. Thus, the turnip, the carrot, and the beet, which are sown, as will afterwards be seen, in the early part of summer, require that the manure applied shall be in such a state of decomposition as to act upon and nourish them in the first stages of their growth; and if this be not so, the crop may entirely fail. In these and similar cases, accordingly, a complete preparation of the farm-yard dung is an essential point of practice.

Certain plants, again, do not require the same state of decomposition of the dung. Thus the potato requires less 
in the first stages of its growth than the turnip, and hence it is not necessary to subject the manure to be applied to the same degree of fermentation.

In some cases, too, as in the process of the summer fallow, to be afterwards described, the manure is mixed with the soil some time before the seeds of the plants to be cultivated are sown. In such a case the manure undergoes the necessary fermentation in the soil itself, and does not require that previous preparation which, in the case of tho turnip and some other plants, is required.

But while no necessity exists for fermenting the matter of the farm-yard beyond the degree requisite for the special purpose intended, it is always a point of good practice to ferment it to that degree. In order to know when dung is sufficiently fermented for the particular use required, a very little practice and observation will suffice. When it is fully fermented, the long stems of straw which formerly matted it together, are in such a state of decomposition, that the parts can be readily separated by a fork. It is not necessary in any case that it be in that extreme state of decay in which we often see it used by gardeners, and when it can be cut by a spade like soft earth. Whenever farm-yard dung has been fermented to this degree, it has been kept beyond the proper time, and the management has been bad.

The mass, we have seen, is collected chiefly during the months of winter, and will always be ready to be applied to the ground in the spring, summer, or autumn immediately ensuing; and there is no case in which it is advisable to keep it beyond the year in which it has been collected.

A common and convenient practice, is to carry it out from the yards where it has been collected to the field where it is to be used, and there to pile it up in one or more large heaps, so that it may undergo the further decomposition required, before being applied to the land. Doubtless there is a certain waste of the volatile matter of the dung by this process, but it is frequently convenient in practice, that the dung be thus carried to the 
field where it is to be used, so as to economize time at the season of more active labor.

When, accordingly, after the clead of winter, as towards the end of December, and during hard frosts and snows, the men and working cattle upon the farm cannot be otherwise employed, we may begin to carry out the dung: to the fields where it is to be used. It is carried out in the carriages of the farm, into which it is lifted by large forks to be afterwards described. This partial carrying out of the dung from the yards proceeds when occasion offers, or when the state of the weather prevents the other labors of the farm from being carried on. And when the feeding cattle are finally remored from the houses and yards, and turned out to pasture, which, in the north of England, is generally by the mildle of May, the whole remaining dung may either be carried to the fields, or remain in the yards till required for use.

The dung, as it is carried out to the fields, is to be laid in large heaps, which may be about four and a half or five feet high, and of such other dimensions as may be convenient. When the dung is placed in these heaps, it is in a state very favorable to further fermentation; for it is to be observed, that in all cases the turning orer of the dung, so as to give access to the air, causes an increase of fermentation, and this is the method adopted by farmers and gardeners, when they wish to give a greater degree of fermentation to any heap. Should the dung in these large heaps not ferment to the degree required, they are to be turned over, and formed into new heaps, the upper part being placed below, and what was before below at the top. By this means the fermentative process will be renewed, and should this turning not be found sufficient, the heaps must be again turned over, so that they may be brought to the degree of decomposition required. The large heaps of this kind should not be placed in a very exposed situation, so as to be too much acted upon by winds; and it is a good precaution, and a necessary one in very warm countries, to face up the sides with a little 
earth or turf, and to strew some earth upon the top, so as to prevent the escape of decomposing matter. When it is wished to hasten the putrefactive process in these heaps, it is better that they be not compressed by the carriages going upon them to unloarl; but where there is no peculiar necessity for hastening the putrefactive process, the carriages and beasts of draught can go upon the heap without injury. When peculiar care is required, as when the dung has been imperfectly fermented in the yards, it should be spread over the heap in layers, so that one layer may undergo a slight fermentation, before it is compressed by that which is to be placed above it.

The mass may be also tumed over in the yards where it lies, and allowed to ferment before it is carried out to the fields for use. In this case the workmen begin at one side of the heap, and with large forks turn it orer, laying: that which was before uppermost underneath, so that the whole may be reversed. If, after this process of turning, no treading of cattle is allowed, the fermentation of the mass will proceed with rapidity, and then the whole may be carried out at once from the yards to the fields for use. This method will not only in certain cases be the most convenient, but will sare some of that waste of rolatile matter of the heap, which takes place under the other system.

Where the dung produced is very rich and well decomposed, as where cattle have been feeding in stalls on juicy and nutritive food, it may not appear to require this turning over to fit it for use : yet even in such a case it is generally beneficial that it be turned orer at least once before being used, the effect being to ferment the mass not only sufficiently but equally, and to mix its different parts together. It may be observed also, that when the mass of vegetable and animal substances is thrown into a common yard, some care should be bestowed in spreading it equally, so that one part of the yard may not be filled with rich dung, and another with poor. The dung of horses, for example, is more susceptible of quick fermentation than 
that of oxen. When the stable, therefore, opens upon a common yard, the horse-dung should not be suffered to accumulate in a mass about the stable, but spread abroad upon the general heap. [Horse-dung is not suitable for dry sandy soils; it is generally kept by itself, and applied to low and cold soils.]

Farm-yard dung is chiefly applied to the soil by being spread upon the land when in tillage, and covered by the plow. Being covered by the earth, the dung soon passes through its course of fermentation, and becomes decomposed and mixed with the matter of the soil.

This valuable substance must be economized in the manner of applying it. The soil must be kept as rich as the means at the farmer's command will allow; but it is an error in practice to saturate it at one time with manures, and to withhold them at another. They ought rather to be applied in limited quantity and frequently, so as to maintain a uniform or increasing fertility in the soil.

Mr. Gaylord recommends, in removing the mass from the yard, to cover the successive deposits of manure with earth from ditches or ponds, peat or muck from swamps, or turf from bogs or plowed lands, as such layers, consisting mostly of vegetable or animal matters, will, by absorbing the drainings of the manure, or by the absorption of the gases, be converted into one of the most effcient of fertilizers.

The question of long or rotted manure the writer just mentioned disposes of in the following judicious manner :

It is a question of considerable importance to the farmer, and one which has been much discussed, whether it was better to apply manure in its long state always, or always allow its full decomposition before using. From his own experience, the writer has been led to doubt the correctness of either of these positions. It seems to be universally admitted that matter, to be efficient as a manure, must be soluble, and it is clear that the more solid parts of farm-yard manure require to be softened by putrefactive fermentation before they can be considered in 
this state. Where, then, the influence of manure is required to be felt at once, as on the turnip, beet and carrot crops, in order to push them forward at the first start beyond the reach of insects, my experience is, that the manure should be in a state reducible to powder, in which condition a large portion of it may be expected to be soluble, and of course at once available by the plant. Where, during the fermentative process, the mass has been reduced to a black carbonaceous matter, it may be inferred that the heat was too great, and the manure seriously damaged; on the contrary, if the mass, while perfectly fine, dry and friable, still retains its dark brown color, it will usually be found that none of the good qualities have been lost by over-fermentation.

But where the manure is to be applied to crops which do not require forcing forward in the early part of their growth, but demand as much or perhaps more nutriment at a late perior of their vegetation to perfect their seeds or roots, then experience has shown that it is best to apply the manure without any considerable fermentation to the soil. Indian corn, potatoes, and the grain crops generally, are of this class; the two first particularly. The time when corn and potatoes require the most nutriment, is at the time when the ears and tubers are forming; and when manures but partially fermented, or used fresh from the yard or stable, are applied, the decomposition is comparatively gradual, and the supply greatest when most needed. I cannot recommend the application of manures of any kind directly to grain crops, as it has a tendency to give straw at the expense of the grain, and wheat so manured is far more apt to suffer from mildew or rust, than when the manure, by application to other and previous crops, has become perfectly incorporated with the soil. In this state, that rapid growth, which is the result of first fermentation, is avoided by the wheat plant; and the substances necessary to perfect the berry are already prepared and within reach of the growing or maturing plant. 
Where the unfermented dung of the yard or stable is applied to the soil, it should be covered at once by the plow, that the gases liberated in fermentation may not be lost, and that the moisture necessary for fermentation may be secured. When rotted or fermented, the covering is not of so much consequence, and it may, without loss, be scattered on the surface and mixed with it. If used without fermenting, it should be applied to hoed or summer crops, such as corn or roots, as these are in that state while the manure is at the height of its fermentation, when forcing manures are the most useful; but if applied to the smaller grains, they are most active when matter for the perfection of the seed, not the enlargement of the straw, is most needed, and the last is increased at the expense of the first.

\section{H A P T E XXIV.}

COMPOSTS AND LIQUIDS.

Mr. Gaylord says, there can be little question that the most economical way of making and using manures, is to convert the stable and barn-yard manure into compost, by the addition of peat, swamp muck, cleansing of ditches, wash of roars, leached ashes, or even common loam or earth, taking care, when the manure is wanted for heavy soils, that the earth used in the compost should be as light or sandy as may be; and where the soil is light, that the compost earth should be marly clay. Into such a compost heap, all weeds, straw, litter, animal matter of all kinds, night soil, \&c., \&c., may be thrown, and upon it all the wash of the yards and urine of the stables may be poured; and if the animal and vegetable matters, as they accumulate, are kept covered and moist, the fermentation will go on successfully; the alkalies and salts of the ani- 
mal matters will act on the vegetable part and saturate the earths used, and the whole will be converted into manure of the most valuable quality. The labor of preparing compost, it is true, is much greater than merely drawing it from the yard, but the quantity is so much increased, and the quality so much improved, that it is the most economical in the end. The only methor that can compare with it is, to place these matters over the yard, and let them be composted or fermented in that place; but there will always be great waste in this way; and where turf or vegetable mould is used for composting with the animal manure, the compost heaps can frequently be made where they are to be used, and the labor of drawing materials greatly lessened. Bommer's patent manure is only compost made in a scientific and accurate manner, every part of the process so managed as to produce a perfect fermentation, without the loss of any of the valuable parts of the constituents used. From a knowledge of the processes employed by him, we are able to say, that where his directions are followed, a powerful and valuable manure cannot fail to be produced. The fundamental principle upon which composts have been made, is that of impregnating the earths used in the process with the soluble salts and the gases, which, in the ordinary methods of rotting, are wholly or partially lost to the farmer.

That well known farmer, W. A. Seeley, of Staten Island, gives the following as his practice:

In the spring and in the fall, immediately after carrying out the supply of manure from my cattle-yards and hogsties, I bottom them anew with turf to the depth of at least a foot, covering it with six inches of sea-weed or drift. To the accumulation of the place during the winter, when little is to be lost in fermentative manures by solar heat or evaporation, I cart around the yard and spread on its upper edges some eight, ten, or more feet wide, the emptyings of my stables and yard-sheds. with the littered surface occasionally of my hing-pens (which are placed in the centre of iny harn-yard). The feeding- 
racks and moveable pens are from time to time shifted, that the turf and sea-weed may, by the tread and droppings of the cattle, and the occasional moisture of the yard, be worked together, and the turf saturated with them as much as practicable. The main part of the manure, being placed on the upper sides of the yard, and settling down to the centre and towards the barn-drain, passes necessarily among the bottoms of the turf and sea-weed, which thus becomes imbued with the substances necessary to prepare for the fermentative decay, which the acid of the one, and the saline impregnation of the other, require for them. In the spring, as soon as solar heat may induce a tendency to fermentation, and consequent evaporation and loss, the yards are turned over with a plow or shovel, that the whole may be so commingled that the turf may attract and absorb the waste which may otherwise ensue. At the lowest part of the barn-yard, and that to which everything from the farm-house, kitchens, farming yards, and stables tends, I have a cemented cistern or tank, capable of containing 250 hogsheads. The windmill and horse-power of the yard is connected with this tank by pulleys, straps, and chain buckets, so that if during the twinter, spring, or summer, I think best to wet my compost heaps, hogsties, or any of the yards with those drainings, the power is conveniently applied, and by leaders the draining is thrown back to settle again through the mass and return to the tank. The compost yard adjoins the barn-yard, and is so graded, that if the drainings from the tank be thrown on to the heaps, after settling through, they return by box under-drains into the yards and tank. If a surplus is still on hand, a cart with a hogshead and sprinkler is used, with which, in a four to one diluted state, I irrigate such grass lands as I think may be benefited by it, or my grain crops in such parts of a field as I apprehend may want it; an excellent method of readily adding to the manure, and of forcing those parts of a field which in the spring are perceived to want manuring; or my garden is fertilized and forced by it to any 
state of productiveness which can be effected by such an application of the most stringent and prompt in its influence, of all manures. The last spring, in spots where my wheat did not thrive comparatively, applying it with a watering-pot, the grain advanced and outstripped the surrounding parts of the crop, which before had afforded better promise of thrift. Pouring a pint of it into a lill of corn, of potatoes, or of vines of any kind, will be found to give an astonishing impulse to them.

The filling and driving of the cart, sprinkling it on the field, or applying it to the hill or garden, is the work of the barn yard power, a boy, horse, cart, sprinkler, and watering-pot. The cart and its sprinkler, in its form and uses, is in all respects like those employed in cities for sprinkling the streets. To irrigate and manure drilled crops, the sprinkler should be taken from the rear of the cart, and two of them should be hung parallel with the shafts and over the drills.

During the heavy rains of the fall and spring, should the drainings of the yard accumulate and fill the tank, and not be otherwise wanted, the surplus is let off into a muck road, embanked on the sides, and filled to the depth of ten to fifteen inches with seaweed, turf, turf-ashes, and a small supply of manure, and made gradually to percolate and settle downward through a distance of from four to six hundred feet in length, and twenty in breadth; and through which muck-road, cattle, carts, and vehicles of every kind, when it is not too wet, are forced to find their way, to break up and mix its contents with the drainings of the yard. Until the drainings of the yard have reached the farthest extent of this road, they should not be applied to agricultural uses. Before driving my cattle from my yards, if it becomes necessary to do so, and always two or three times a day when its surface is moist, a boy, as a standing rule, drives them for exercise several times round the yards, the better to bring the manure in contact with the bottomings. Within the last year I have lost none, absolutely none-of the leachings of my yards and stables. 
To this it will be said by some, it is laborious and expensive. Not so much so as may be apprehended, or as would be the case with others, not assisted with mechanical powers and underdrains as I am; but what I have thus done at some expense may be done, in a great degree, for a mere trifle.

I assume, as a standard, the fact that farmers with us pay one dollar per load for manure, and that this is a criterion by which to form an estimate of the labor or capital which may profitably be bestowed in obtaining it as I do. If this be the true criterion for judging, every day's labor I expend in producing it, is worth twenty-fold the sum I pay my hands to effect it.

Turf affords an invaluable medium for saving the waste of manure and for increasing its amount and usefulness; and it is better than rich mould, earths, or the parings and bottoms of ditches, inasmuch as it is all vegetable, and in itself, strictly speaking, a manure, when properly pre-pared.

The contents of stables, barn-yards, and cattle and hogpens, should never be exposed to the solar heat or to fermentative evaporations, or their drainings lost, when turf, or any inert vegetable substance or surplus farm materials of a vegetable or animal nature abound; nor should animal substances, fish or any other, be suffered to waste their effluvia in the air when such materials can be had. For all useful purposes, enough of the agricultural influence or effect of manure is produced, as soon as vegetable or animal decay is sure to progress. From that moment a compost should be resorted to, and the heat and action of the manure (which is sure and irresistibly powerful) be thus brought to operate on substances to which this propensity has not been sufficiently imparted. In this state, all that is ordinarily wasted, tends to a useful result in augmenting the mass:

It is a common practice to bury fish, preparatory to their use as a manure, in common raw earth. The most soluble of ordinary manures, it is soon dissipated by atmos- 
pheric action, and leaves on the soil to which it has been applied, a raw earth, in its then condition injurious to it. I find it more beneficial to bury the fish in turf or turf ashes, seven loads to one of fish (in Loudon it is said of turf alone, even twenty to one), which the decay of the fish will make an excellent and very powerful manure, and one which will endure long after the fish will have done their office in the soil and disappeared.

For a complete account of the management of the admirable estate of Mr. Seeley, see an editorial notice of "Wheat Sheaf Farm," Vol. I. of American "Agriculturist."

\section{CHAPTER XXV.}

DIFFERENT METHODS FOR THE PREPARATION OR MANUFACTURE OF VEGETABLE MANURE.

IT has been lately announced that an excellent manure can be prepared in 24 hours, by making a bed of green weeds, upon which is spread a thin bed of pulverized quick lime: these beds are continued one upon the other: it is essential to prevent the spontaneous inflammation which would result from the heating of the mass, by covering it with earth and turf.

The following process for the preparation and preservation of manures is according to the method of $M$. $D_{A}$ Otmi. In some suitable and convenient place a square cistern is constructed sufficiently capacious to contain the quantity of dung it is desired to preserve. On one of the sides an easy entrance is made with an opening sufficient to admit a cart; this opening is kept habitually closed by a door or gate. In the neighborhood of the cistern is constructed a pit eight feet deep and three feet wide; a ley is prepared in this pit by putting into it, when filled with water, air-slacked lime and fresh ashes, taking care 
daily to agitate the mixture with a long pole. When the liquid is sufficiently charged with saline principles, which may be known from its greyish milky color and the diminution of its fluidity, the dung is carried into the cistern, making a heap of five or six feet in thickness, which is watered upon its suriace by means of an ordinary watering-pot, with the liquid drawn from the reservoir; this done, the whole is covered with a pretty thick coat of earth. Successive heaps of dung will be added, seasoned and covered with earth in the same manner as the last, upon which will be placed the most compact earth that can be found, giving it a thickness of five or six inches at least. When the dung is taken from the cistern, planks are placed upon each load on the cart, in order to hinder as much as possible the dissipation of the gaseous principles; and when it reaches the field the plowman buries it without delay.

The most approved method, as combining the principles alrearly established, will be found in the following pages.

\section{Improved method for manufacturing vegetable manure.}

1. Form your barn-yard with a gradual descent to one side, so that the liquid formed by the rains will flow gently to that side. Make the bottom as hard and smooth as possible, that there may be little or no waste by soaking into the earth. Arrange your stables, hog-pen, \&c., in such order as to throw all the litter and manure into the yard.

2. Sink a vat or reservoir at the lower side of the yard of sufficient capacity to contain the juice of the yard. The most common form of the vat is six feet wide, by three feet deep, and twelve feet or more in length, according to the size of the yard and the amount of liquor fowing from it. When the vat is more than twelve in length, it will be best to divide it by partitions into two or three parts, so that if at any time you want to use only part of the liquor, you can do so without any inconvenience. It 
will be farther desirable to have the vat so connected with the yard, that when once full, and you have commenced your manufacture, if additional rains come before you shall have completed your heap, of which we will soon speak, you can prevent the liquid so formed from running into your vat, either by keeping it back in the yard, or by turning it in another direction.

3. In this vat mix the following ingredients as nearly as you can without actual measurement or weight: To every barrel of liquid add 4lb. of stone lime just slacked, 4lb. wood ashes of good quality and dry, or an equivalent of leached ashes, or $1-4 \mathrm{lb}$ of potash, $1-4 \mathrm{lb}$. of salt, or its equivalent of old brine; $20 \mathrm{z}$. of saltpetre, $20 \mathrm{lbs}$. of plaster of Paris, or mud, or muck; $10 \mathrm{lbs}$. of excrements from the privy, or $20 \mathrm{lbs}$. of horse manure. Mix these ingredients thoroughly with the liquid in the vat; and if the vat contains one hundred barrels, increase the above ingredients an hundred fold. It will be well to mix these ingredients a few days before you lay up your heap, and stir them every day, but this is not essential.

4. On the upper side of the rat lay the foundation for the heap, by placing poles or rails with one end to the vat and the other extending from it, about two feet apart; on these lay other poles crosswise (precisely as we do the foundation for a stack of hay or grain), to keep the straw from the ground, and that the liquid may flow freely beneath

5. Having everything prepared, commence laying up the heap by placing a layer of straw, weeds, stalks, or whatever you have at hand, on the foundation of poles, to the thickness of a foot. You will find great advantage from throwing the materials, as you collect them, in the yard, and letting the cattle tread on them, until they are thoroughly broken and wet. When the layer is a foot thick, stir up the ingredients in the vat, and with a pail or other vessel thoroughly wet the layer on the poles. Place another layer on the first, and of the same thickness, wet as before; and thus continue until you have raised the heap 
as high as you wish; say, from six to ten feet. Be careful, at every wetting, to stir up the ingredients from the bottom of the vat. The easiest and quickest way to wet the several layers, will be to use a pump or elevaters, with a hose attached, to spread the liquor over the heap. In such case, let one stir, another pump, and a third manage the hose. Only be careful, whatever method you pursue, to wet the sereral layers thoroughly in all their parts. When finished, corer the heap with the settlings in the bottom of the vat, or with anything else at handcommon earth will answer.

6. If the heap consist of straw, weeds, and the like, it will require wetting every fourth day. If you have used much peat, muck, or earth with the straw, water once a week. To water the heap, make holes with an iron bar, or other instrument, in the top of it, from eight to twelve inches apart, and extending downward about to the middle; then stir the liquid in the rat, and pour it into the holes until the whole mass is saturated; finally, close the holes. At every watering make new holes.

7. Give the heap three waterings when made of straw, and it will be fit for use in fifteen days from the time of laying it up; when much mud or muck has been added, in thirty days.

$\mathrm{S}$. When it is desired to manufacture this kind of manure in places where barn-yard liquid cannot be readily obtained, river, spring, or pond water will answer the same purpose for wetting the heaps as the barn-yard liquid, by increasing, in a small proportion, the ingredients for the mixture, as given in section 3, and adding them to it.

\section{Advantages of this mode of manufaciuring manurc.}

1. One great advantage is, the saving of the liquor of the yard by means of the vat or reservoir. With proper arrangement it can all be saved, and used to the best advantage. This juice of the yard is by some called the cooked food of the plants. It certainly must be regarded 
as the essence of the manure; yet this most fertilizing part of the farm-yard is suffered by thousands to be washed away by the rains and lost for ever. Since the writer's attention has been directed to this subject, he has been often surprised and pained to witness the want of economy in this respect. There are very few barn-yards but, after a storm, you may see quite a stream flowing from them, thick and dark, loaded with the most fertilizing properties -in some instances running into the road-in others, mingling with the waters of an adjoining brook or swamp. Even on Long Island, where nothing can be raised without manure, and where hundreds of thousands of dollars are annually expended in the procurement of this indispensable requisite, this shameful waste is still witnessed. The writer has often pointed the farmers to their yards, thus sending forth their fertilizing streams, and addressed them in words like the following :- You will go and expend your money and labor to bring manure from New York, when, at the very time, you are suffering a large quantity already at hand to run to waste. Again and again have they pleaded guilty to the charge; until, at length, some at least show the reproof has not been entirely lost. Some are beginning to sink their reservoirs, and save that which has been too long lost. One gentleman (Garret Kow wenhoven, Esq., of Flatlands) has sunk a vat, 60 feet long by 6 feet wide, and 3 deep, formed with the best white pine plank, by the side of one of his yards; and he is fully satisfied that the saving of the liquor of his yard alone will tenfold pay him for his labor and expense. Turn back to liquid manures, and you will be fully satisfied of the vast saving to be effected.

2. The reservoir will prove a convenient and profitable receptacle for various things which would otherwise be wasted, or worse than wasted-remaining complete nuisances before the disgusted senses. All spoiled meats, fish, dead animals of the smaller kinds, \&c., and even large ones cut in pieces, wash from the kitchen, soap suds, and all collected from the sleeping apartments. It will also 
enable the farmer to use the excrements from the privy in the least offensive manner, and, at the same time, in the most advantageous form. Let him make a box of solid plank and suitable size, with side plank a few inches wider. Let the extra width sink below the bottom of the box-form the ends like a sleigh-runner-fasten straps of iron on the sides, and joined together at the ends with a ring. Place this box under the privy; and as often as full, hook a chain in the ring, and with horse or oxen draw it alongside the reservoir and empty it. If this is carefully attended to it will bring many dollars into the pocket. You need not be afraid of any noxious vapors arising from the reservoir, so long as you keep a proper portion of lime, peat, refuse tanners' bark, charcoal, gypsum, or even turf, mixed in it. With such a reservoir you need let nothing be lost, but save everything.

3. All thistles, mulleins, weeds of every kind, flags, sedge, \&c., now a nuisance, may be converted into a rich and valuable manure. Let them all be gathered and laid up in the heap. Another advantage is the quantity of manure. Every thousand pounds of dry straw will give at least $4000 \mathrm{lbs}$. of manure, if used as soon as thoroughly fermented. Mr. Kowwenhoven (the gentleman mentioned on a preceding page) laid up what was judged to be about one large load of straw; the fifteenth day thereafter it was opened, and on that and the succeeding days his men drew out eleven loads of manure.

The bulk may be very greatly increased by the addition of peat, swamp-muck, or even common soil. The best mode would be, to gather your peat or muck at such times as the ordinary labor of the farm is least urgent; let it lie in heaps of moderate size, or in one continued bed until wanted to lay up in the manufacture. If it lies a year, all the better. In fact, after the first year, the farmer can with all ease collect it one year in advance. In laying up the heap for manure, place equal layers of straw weeds, \&c., and peat or muck; and if necessity require, you can use two parts of peat to one of 
straw which has lain in the yard and mixed with the droppings of the cattle, \&c.

4. You will not fill your land with foul seed from manure made after this plan. The fermentation destroys all seeds in the body of the heap.

5. You have a perfect control over your manure heap. If the fermentation rises too high, so that there is danger of burning or fire-fanging as it is frequently called, watering the heap will prevent it. So long as the heap is sufficiently wet it cannot injure. You have coarse or fine manure at your pleasure. It is fit to use in fifteen days where the heap has been made of straw, weeds, \&c., with but little muck. It is then thoroughly fermented but not decomposed, the best state for plowing in. If you want it fine, let the heap lie, or turn it over, and wet it again.

You can make your manure at such times and in such quantities as you please.

6. And last though not least, the quality of the manure. You can make it by the increase of the ingredients as you please. At the prescribed rate you will have a manure at least as rich as good horse stable dung. 



\section{PART II.}

\section{T I L L A G E.}




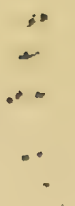




\title{
PRODUCTIVE FARMING:
}

or $A$

\author{
F A M L I R DIGE T
}

OF THE

RECENT DISCOVERIES

of

UIEBIG, DAVY, AND OTHER CELEBRATED WRITERS ON VEGETABLE CHEMISTRY; SHOWING HOW THE RESULTS OF TILLAGE MIGHT BE GREATLY AUGMENTED.

\section{BY JOSEPII A. SMITII.}

REVISED BI.A. B. ALLEIN, EDITOR OF THE AMEIRICAN AGRICULTURIST.

NEW YORK:

1843. 


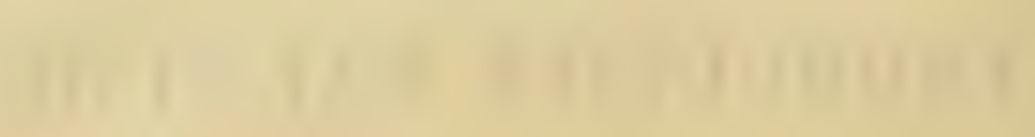




\section{P R E F C E.}

Tris book is a compilation. The object of its compiler has been the simplification of the more strictly scientific and technical writings of the principal agricultural writer's of the present age. Practical farmers require the simplest and most elementary statements. The position of the agricultural interest renders it desirable that the recent views of Professor Liebig, the distinguished chemist, who has effected a complete revolution in the physiology of vegetalion, should be presented in a style free from difficulty, condensed and separated from such portions of his work as would only bewilder ordinary readers. How far the attempt may be successful, the world must judge. The published lectures of the late Sir Humphrey Davy have been freely cited, and such portions selected, as, while they do not clash with later discovery, may prove a useful addition. The writings of Mr. Johnson, whose little elementary book is well known, have been laid under contribution, as well as the lectures of Dr. Mason Good, and such useful statements as have appeared at various 
periods in periodicals devoted to the furtherance of agricultural science. It is to be hoped, that without torturing the sense of previous writers, nothing will be found in these pages inconsistent with the doctrines of the learned German professor, whose writings, though adınirably adapted for the perusal of those who are familiar with chemistry and physiology, are susceptible of being abridged and presented to the industrious farmer in a form less repulsive, because less learned, and, consequently, more generally intelligible. 


\title{
MODERN AGRICULTURE。
}

\author{
CHAPTERI。 \\ INTRODUCTORY OBSERVATIONS.
}

Agriculturat science has for its objects all those changes in the arrangements of matter connected with the growth and nourishment of plants, the constitution of soils, the manner in which lands are enriched by manure, or rendered fertile by the different processes of cultivation; and no rational system of farming can be formed without the practical application of well-understood scientific principles. Such a system must be based on an exact acquaintance with the means of nutrition in vegetables, with the influence of soils, and the action of fertilizing materials upon them. The object of the farmer is, to raise from a given extent of land the largest quantity of the most valuable produce at the least cost, with the least permanent injury to the soil ; and the sciences of chemistry or geology throw light on every step he takes, or ought to take, in order to effect this main object. Whoever reasons upon agriculture is obliged continually to recur to these sciences. He feels that, without such knowledge, it is scarcely possible to advance one step; and, if he be satisfied with insufficient views, it is not because he prefers them to accurate knowlege, but generally because they are more current. It has been said, and undoubtedly with great truth, that a philosopher would most probably make a very unprofitable business of farming; and this, certainly, would be the case if he were a mere philosopher. 
But there is good reason to believe, that he would be a more successful agriculturist than a person equally ignorant of farming but ignorant of chemistry altogether : his science, as far as it went, would be useful to him. The great purpose of chemical investigation in agriculture ought, undoubtedly, to be the discovery of improved methods of cultivation; but to this end, not only practical knowledge but general scientific principles are alike necessary: nor is industry ever so efficacious as when directed by science; as he who, journeying in the night, aided by the most intelligible directions as to the way, is more certain of his footsteps if he carry a lamp to explore his path. Science cannot long be despised by any persons as the mere speculation of theorists, but must soon be considered, by all ranks of men, in its true point of view, -as the refinement of common sense, guided by experience, gradually substituting sound and rational principles for vague popular prejudices. If land be comparatively unproductive, the sure method of determining the cause, is, first to ascertain the exact nature and relative quantities of the ingredients which form the soil (which can only be done by chemical analysis), and then to supply such soil with the deficient materials requisite for the growth of such vegetables as it is best fitted to raise. The preparation of compost will only be of real use when materials, which do not afford singly an efficient or convenient manure, are made to do so by their mixture. Every farmer has it in his power so to compound the best from his store of manuring materials, that the defects of his soil may not only be remedied, but that the crops may receive those substances in sufficient quantity which are required for their vigorous growth. To do this, however, it is requisite to know not only the component parts of the soil, but also those of the crops. If these are not taken into accouut, no clear idea either of the composition, much less of the action of manure, will ever be obtained; and many substances of real value will be tried, and, from misapplication, tend to useless, if not injurious results. Perhaps iron 
may be found in injurious excess, which may be rendered harmless by the addition of lime; or an excess of sand may be neutralized by the addition of clay. Is there a deficiency of lime? The remedy is obvious; or an excess of undecomposed vegetable matter may be removed by the judicious use of lime, by paring and burning.

With the aid of chemistry, the precise value of any variety of limestone may be determined in a few minutes; and so its fitness or unfitness, as one among many substances intended to fertilize the soil, may be determined by a less expensive experiment than waiting to observe its action upon the land. In the same way, peat earth of a certain consistence and composition is an excellent manure ; but there are some varieties of peat which contain so large a quantity of iron as to be absolutely injurious, if not destructive to corn and grasses. Now, nothing can be more necessary, more useful, and fortunately more simple, than the mode of determining whether a metallic substance be present. More especially, it is solely by a reference to the elementary principles of chemistry and the ascertained constitution of manures, vegetables, and the air and soil in which they live and thrive, that we can determine whether it is wiser to plow that manure into the land, to apply it in a fresh, or in a fermented and decomposing state. We know, that as soon as dung begins to decompose, it throws off its volatile or gaseous parts. It is necessary that what is thus lost should be examined. It may be (which is the fact) that such evaporation is not only the escape, but the actual loss of that which forms a most material ingredient in the food of plants: and so, whether this shall be supplied gradually to the growing vegetable, or suddenly, is a question in the mind of an intelligent agriculturist tantamount to the inquiry often agitated among practical farmers, and determined only by individual caprice or fancy, as to whether the produce of the stable or the farm-yard is best, when spread upon the soil in a fresh or in a putrid state. When, for instance, it is considered, that with every pound of the strongly-pungent smelling ammonia lost in 
the air, a loss of at least sixty pounds of grain must cor * respondingly be sustained,-and that with every pound of urine a pound of wheat might be produced,-not only must we feel surprise at the ignorance which prevails as to the fact, but equally so at the indifference manifested by those who are aware of the value of such manure as to the best mode of applying it. On some soils a plant will thrive, on others it will sicken; and the same knowledge which will enable us to correct a faulty or weak vegetation, will enable us also to produce far more abundant results than occur under the most favourable ordinary and natural circumstances. Agriculture has hitherto never fairly sought aid from that science which is based on the knowledge of those substances which plants extract from the soil, and of those restored to the soil on which they grow by means of manure. The application of such principles will be the task of a future generation; for what can be expected from the present, which recoils with seeming distrust and aversion from all means of assistance offered by chemical investigation? A future generation will derive incalculable advantage from these means of help, and make a rational use of philosophical discoveries. A marked and wide difference exists between the progress of manufactures and the history of agricultural operations. We see the steam-engine multiply indefinitely the labor of the human hand-supersede and almost infinitely exceed the united power of brute exertion; invention has lacked no mechanism to produce myriads upon myriads of the same fabric; thousands of piles of manufactured silks and cottons are produced annually, one factory supplying daily as many yards as would encircle the globe-strange advancement on the ancient spinning-wheel; while the sons of the soil still toil on through the long summer months, and brave the winter's cold, to reap the same quantity of produce from the soil as their forefathers of a thousand years ago. We do not say that there is no limit to the capabilities of the earth's surface, but fearlessly maintain, that such limit 
is yet far from realization; and that not until prejudice be silent, and intelligence more universal, can it be hoped that the broad acres of our country will yield to science and skill all the treasures they contain.

Half a century sufficed to Europeans, not only to equal, but to surpass the Chinese in the arts and manufactures; and this was owing merely to the application of correct principles deduced from the study of chemistry. But how infinitely inferior is the agriculture of Europe, even of boasted England, to that of China! The Chinese are the most admirable gardeners and trainers of plants, for each of which they understand how to prepare and apply the best adapted manure. Their agriculture is the most perfect in the world; and there, where the climate in the most fertile districts differs little from the European, very little value is attached to the excrements of animals.* Patient observation of results, and a realy adoption of really useful plans; steady persistance, not in antiquated methods and notions, but in all that has been found by experience to be beneficial, - has raised the agriculture of that country, long ago, to a position which would rapidly, nay, instantly, be ours, if science were permitted to achieve for us that which, with them, has been the slow growth of centuries of experiment.

The soil of England offers inexhaustible resources, which, when properly appreciated and employed, must increase our wealth, our population, and our physical strength. The same energy of character, the same extent of resources which have always distinguished Englishmen, and made them excel in arms, commerce, and learning, only require to be strongly directed to agriculture, to insure the happiest effects. We possess advantages in the use of machinery and the division of labor, peculiar to ourselves;

* This is an error, for no nation equals the Chinese, in not only saving the excrem uts of animals, but those also from the privies and every particle of vegetable and other manures within their reach.AMER. ED. 
and these having been mainly instrumental in aiding one great division of human industry, we are justified in the assertion, that the steam-engine and machinery has not done more for trade, than science and skill, in various ways, may do for land.

Besides chemistry, there is another science which has many relations to practical farming-the science of geology, or that which embodies all ascertained facts in regard to the nature and internal structure, both physical and chemical, of the solid surface of our globe. Though the substances of which soils chiefly consist are so few in number, yet every practical man knows how very diversified they are in character, how very different in value. Thus, in some of the southern English counties, we have a white soil, consisting, apparently, of little more than chalk; in the central parts of the country, a wide plain of darkred land; in the border counties of Wales, and on many of our coal fields, tracts of country almost perfectly black; while yellow, white, and brown lands give the prevailing character to the soils of other districts. These differences arise from the varying proportions in which the sand, lime, clay, and iron, which color the soils, have been mixed together. Now, geology explains the cause why they have been so mixed in different parts of the country-by what natural agency, and for what end ; and by its aid we can predict the general quality of the surface-soil, and, more than this, of the unseen sub-soil, in the several parts of entire kingdoms. We may learn, if the soil be of inferior quality, and yet susceptible of improvement, whether the means of improving it are likely, in any given locality, to be attainable at a reasonable cost.

Whether we attempt to investigate the composition of natural bodies, or, confining our attention to the review of those general diversities so remarkable on the earth's surface, the division of them all into two grand classes, as simple or compound, is an essential preliminary to a correct comprehension of the subject. Those substances are simple, which cannot, by any known method, be separated, 
decomposed, or divided, in such a manner as to produce particles different in their properties from one another. On the other hand, those substances are compound which, by experiment, may be resolved into particles of an unlike nature. Thus, marble is a compound body; for by a strong heat it is converted into lime-an elastic fluid, which is carbonic acid gas (itself also a compound), being disengaged during the process. Vegetable substances, whether in their living or dead state, are mostly of a very compound nature, and consist of a great number of elements. For a period of many centuries, and even till a very late date, there were four substances held to be elementary, or simple. These were Fire, Air, Earth, and Water. Nobody could prove them so; and yet, of these four bodies, all others in nature were supposed to be constituted. This system continued to be orthodox till very lately, when three of these imaginary elements, namely, Air, Water, and Earth, were proved to be compounds; and, as we shall see in the progress of this work, a correct understanding of the properties of the atmosphere, and of its relative agency over vegetation, is indispensable to the adoption of such plans as are intended to increase the fertility of the soil. As to fire, it is still unknown whether it be simple or compound, in what its essence consists, or by what causes its effects are produced. The study of temperature, of the relative dryness or moisture of the air, of the action of the sun's heat over soils and vegetation, is closely identified with the science of agriculture. The influence of the changes of seasons and of the position of the sun on the phenomena of vegetation, demonstrates the effects of heat on the functions of plants. The matter absorbed from the soil can only enter the roots in a fluid state; and when the surface is frozen, this mode of communication is suspended. The activity of chemical changes in living vegetables is likewise increased by a certain increase of temperature, as is evident if a stalk of henbane be partially immersed in hot water: its leaves will, for a time, become erect, and quickly forego their drooping arrangernent, evi$10^{*}$ 
dently referable to the increased rapidity with which fluids, under such circumstances, rise in the minute vessels of the vegetable. Heat, then, is rather to be regarded as an agency by which both compound and simple substances are alike affected. What the ancients considered to be simple bodies, are no longer considered to be such; but, in place of these four assumed substances, the chemists of modern times have elevated to the dignity of elements, or simple bodies, a far more numerous race. No one, however, asserts now-a-days, that even these are all absolutely simple. The term " element," intimates no more than that the body to which it is applied has never, in the opinion of modern chemists, been subject to further division or decomposition: that it has never been divided into particles, different from one another, or from the original substance. The number of simple, or elementary substances, at present known, and constituting visible Nature around us, is fifty-four.

Now, if these elementary, or simple substances, are placed either artificially or, as they are presented in the universe, naturally in contact with each other, they combine, or refuse to combine; and by such combination, when it occurs, a great variety of compound substances are produced. Some combinations are effected instantly, some more slowly and with difficulty, and there are certain elements which can scarcely, by any means, be made to combine. The compounds produced by such combinations possess properties very different from those of the separate elements of which they are composed. Thus, carbonic acid, or the gas which sparkles in fermented liquors, combines very readily with pure caustic lime, and the product of the union is common chalk. So, if the proportions be varied, the same two elements produce the common air we breathe and the strongest aquafortis or nitric acid. The power, in virtue of which simple bodies can combine and produce compounds, is one of which the nature is totally unknown. Chemists have learned no more than that simple bodies, or bodies supposed to be simple, do combine; 
but wHY they combine, or what that is which makes them combine, they have not discovered. To the illustrious Dalton belongs the discovery that they do not unite at random, but always in definite proportions of each; so that, if the elements be represented by numbers, the proportions in which they unite may be expressed either by those numbers, or by some simple multiples of them. Thus, sugar and Indian rubber are compounds resolvable into precisely the same ultimate elements, only in different proportions; and, as the following table will illustrate, nearly one-half the weight of all vegetable productions which are gathered for food for man or beast, in their dry state, are but varying compounds of the same elementary or simple bodies, the names of which are appended over the annexed numbers. What the properties of these elements in their separate state may be, is not our immediate purpose.

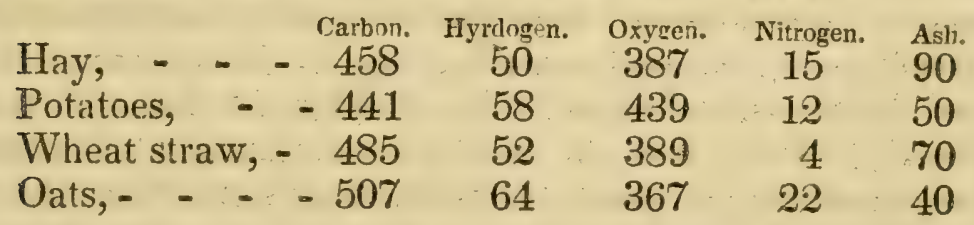

parts by weight in 1000 pounds of each of the above vegetable substances.

If we take the ash left by a known weight of wheat straw, or of hay, and mix it with the proper quantities of the four elementary substances named in the foregoing table, we shall certainly be unable, by this process, to form either the one or the other. The elements, therefore, into which all regetable compounds are ultimately resolvable, are not merely mixed together; they are united in some closer and more intimate manner. To this more intimate state of union the term chemical combination is correctly applied. Again, woody fibre, gum, sap, and the various fluids and substances which form a plant, are themselves mostly resolvable into varying proportions of the same ultimate elements, which, laken together, form the entire vegetable. 'Thus, sugar forms one of the proximate 
principles of the sugar cane, and Indian-rubber is one of the proximate principles of a South American tree, which contains no sugar; yet sugar and Indian-rubber are essentially composed of the same materials. So, if charcoal be burned in the open air, it slowly disappears, and forms a kind of air or gas, known by the name of carbonic acid, an elastic fluid precisely identical with that which forms the froth in ginger beer or common yeast. Now, this carbonic acid is formed by the union of the charcoal or carbon, while burning, with one of the elements composing common air, named oxygen; and in this new form, the elements, carbon and oxygen, are said to be chemically combined. Again, if certain vegetable and animal materials are mixed together, and left to the agency of the atmosphere, they react upon each other-perhaps become heated, as happens in a heap of stable dung, and are sail to become decomposed. New compounds are formed from the union of previously existing elements; perhaps AMmonIA is one of the most common and obvious, as indicated by its effect upon our eyes and nostrils. This, then, is as purely a chemical process as the conversion of wood into vinegar, or into charcoal, or the change that occurs when the flour of grain is converted by the distiller into ardent spirits; and in all well-directed attempts to fertilize the soil, a knowledge of these changes is absolutely necessary: at least, he who proceeds without it has disappointment in prospect, and gropes in the dark, with uncertainty for his guide.

Now, chemical affinity is not only evident in the changes which masses of dead inorganic matter produce upon each other: it is found to be actively at work in the phenomena of vegetation; thus proving that the growth of plants is more completely a chemical process than might have been imagined: and, as our further illustrations will tend to prove, the same law of affinity is equally operative upon animal structure, which, like that of plants, is not more truly alive than they. The sap consists of a number of ingredients dissolved in water by chemical attraction; and it appears to be in consequence of the operation of this 
power that certain principles derived from the sap are united to the vegetable organs. By the laws of chemical attraction, different products of vegetation are changed and formed during the process of growth : vegetable and animal remains are decomposed by the action of air and water, or exert upon those fluids a mutual agency essential to the change ; rocks are broken down and converted into soils, and soils are more finely divided and fitted as receptacles for the roots of plants. The repulsive energy of solar heat, or of that generated during chemical changes of constant occurrence, serves as the only counterbalance to that attraction which pervades the particles of all living or dead matter; and thus the harmonious circle of growth and decay is produced by their mutual operations. The different influence of the different solar rays on vegetation is but partially understood. There are rays transmitfed from the sun which do not impart light, and which yet produce more heat than the risible rays. The effect of these invisible rays is purely chemical and independent of the heat they produce. Thus, potatoes, which sprout in a comparatively dark cellar, send out nearly colorless shoots. Plants kept in the dark in a hot-house grow luxuriantly, but never acquire their natural colors; their leaves are white or pale, and their juices watery and sweet. So the upper surface of most leaves is darker than the lower, upon the same principle that the belly of a fish is whiter than its back.

The most obvious instance of Electrical Agency in external nature occurs in thunder and lightning. Electrical changes are of constant occurrence; but as yet the effects of this power, not as accidental but as essential to healthy vegetation, have not been correctly estimated. No doubt the germination of seeds, as well as the growth of plants, is materially modified by the peculiar electrical condition of the earth and the atmosphere, and by the varying state of each. It is known that grain will sprout more rapidly and readily in water positively electrified - that is, charged with electricity in excess or beyond its natural quantity; and that if, by artificial means, water be deprived of its 
natural amount of electricity, its power of stimulating the growth of seeds is therebydiminished. Experiments made upon the atmosphere show that clouds are usually deficient in electricity; and as when a cloud is in one state of electricity, the surface of the earth beneath that cloud is brought into the opposite state, it is probable that, in common cases, the surface of the earth is charged with the electric fluid in excess.

We have spoken of Chemical Affinity: it is sometimes well named Elective or Chemical Attraction, inasmuch as it is but an exemplification of one form of that law which maintains the order of the universe. It is the expression of the fact, that certain elements of unlike nature combine with each other when placed in contact, or (figuratively speaking) refuse to combine with any other, electing even the proportions in which only such combinations can occur. This affinity is but one division of the great law of attraction. In this aspect, there are five forms in which the relations of all bodies to each other may be arranged. We begin with that which compels the heavenly bodies to rotate round the sun; or a stone when thrown upwards to fall to the ground--in other words, to gravitate tow ards the earth's centre. Next, there is the attraction of cohesion: thus, particles of oil will rise through water, and having reached the range of each other's attraction, will unite into one common and separate bo:ly. It is this form of attraction which gives roundness to the drops of dew, or of the rain as it falls, and is the sole canse of the arched form of the rainbow. In the same way, drops of water or of quicksilver placed upon a dry plate have a tendency to unite, not only when they touch, but to run together when placed near each other. So, perfectly smooth and polished plates of glass or metal have a strong tendency to cohere. It is by the same means that the great number of rocks seem to be produced that enter into the substance of the earth's solid crust. The lowermost rocks are united by an intimate crystallization which is the most perfect form of cohesive or aggregate attraction that can exist among the particles of 
solid bodies. The next form of attraction is observed as occurring between bodies unlike in their nature, solids and fluids, capillary attraction, as when sap rises in the minute vessels forming the stem of a tree against its own weight, or, in other language, overcoming the attraction of gravitation downwards. The Latin word which signifies a hair, is used in this instance to form the word denoting the extreme tenuity and delicacy of these narrow vessels, as only in such could fluids rise : bence the reason and the wistom of this arrangement.

Electrical and Magnetic attraction are important subjects for study, to which, in a practical work, it is not necessary rery minutely to allude. It is well ascertained that the thorns, spines, or prickles that exist on a variety of plants serve not merely for their defence : they have a relation to the electrical condition of the atmosphere; cases having been recorded in which spines have grown more than an inch during a thunder-storm. Some of the acacia tribe are fretted over with formidable spines which will take off a charge of electricity from a prime conductor as rapidly as a brass point-doubtlessly from the presence of a metal in those spines, probably the metallic base of flint. Now it is very unlikely that only the prickly plants require the electric stimulus. We know that, though the torpedo and electrical eel have power to benumb and kill, yet human beings, who have no such powers in health and in disease, are always charged with varying quantities of the electric fluid. So also of all vegetables: oat and wheat straw contain silica, which is metallic; and the firmness of the stem may not be, and is not, the only reason for its presence. Lastly, we have chemical attraction or affinity. A few instances of its operation have been already noted; but some affinities are more powerful than others. Pure lime has a strong affinity for carbonic acid gas, and this is a wise ordination; and it is equally a proof of design that it should form one of the ingredients of the atmosphere. Under this arrangement of things, whole mountains of lime have been crumbled during successive ages into fertile beds 
of chalk. But lime has a still greater affinity for sulphuric acid or oil of vitriol than it has for carbonic acid; and so, if natural or artificial chalk be subjected to the action of vitriol, another decomposition ensues: the carbonic acid flies off, leaving the lime to combine with the acid for which it has a more powerful affinity, the result of the new union being sulphate of lime, better known as alabaster or common gypsum. These transformations may not only be produced artificially, but are of constant occurrence, though of slow operation, in the great laboratory of Nature. To understand them is essential to the slightest knowledge of those chemical changes which are identical with the processes of growth in the vegetable world, and indeed in all living organized bodies, - and there are sufficient motives connected both with pleasure and profit to encourage ingenious men to pursue this new path of investigation.

\section{CHAPTER II.}

Sume Account of the Simple or Elementary Bodies found (combined or uncombined) in Animals, Plants, and Soils.

IT is absolutely necessary, in order to a right apprehension of the changes that occur during vegetable growth, and of course to a correct estimation of the most rational methods of forcing or favoring healthy vegetation, that we should become familiar with some of the most common properties of those simple bodies or elements, of which all nature around us is compounded.

Four of them, by combining with other simple bodies that will burn, form acids; eight of them are inflammable; and there are upwards of forty metals.

First, let us speak of Oxygen. Oxygen, in union with latent heat, forms oxygen gas, constituting about one-fifth of the air of our atmosphere. It is an elastic fluid at all 
known temperatures. It is heavier than the air, and supports combustion with much more vividness than common air; so that if a small steel wire, or a watch spring, having a bit of burning wood attached to it,-or, better still, a bit of phosphorus or brimstone, be introduced into a bottle filled with this gas, it burns with surprising splendor. Oxygen is a substance very extensively diffused throughout the material world: it forms with nitrogen the air we breathe; united with another element, named hydrogen, it forms water. It exists as a constituent of all animal and vegetable matter; and is found also naturally in combination with most mineral productions; from some of which, for experimental purposes, it may with great ease be prepared. Oxygen gas, when suddenly compressed, evolves both light and heat; is sparingly dissolved by water, 100 cubic inches taking up only three or four of the gas. If a mouse, or a bird, were confined under a large bell-glass, filled with common air, it would live until it had consumed all the oxygen contained in that portion of air, and no longer. If, instead of the bird, a bit of burning brimstone, or a candle, were placed there, it would burn until it had absorbed all the oxygen, and then become extinguished.

2. Hydrogen.-Hydrogen, or inflammable air, is the lightest known substance, being about sixteen times lighter than common air. For this reason it is used in filling balloons. The common gas in the streets and shops is mostly used for this purpose, instead of pure hydrogen, - the carbon it contains not materially destroying its lightness. Not only is pure hydrogen the lightest of gases, but it is highly inflammable; it will neither support combustion nor respiration; - in other words, if a lighted taper or a living animal be immersed in pure hydrogen gas, it would cease to burn, or die. Hydrogen and oxygen are the two elements which form pure water, of which we must say more in another place. When these gases are mixed in certain proportions, they unite and explode with great violence if a lighted candle be brought in contact with them; for experiment's sake, one part of hydrogen, 
and six of oxygen or even atmospheric air, will form a very powerfully explosive mixture. When a stream of hydrogen gas issuing from one ressel, and a jet of oxygen from another, are made to inflame as they unite, a most intense heat will be generated, sufficient to melt the clay of a common tobacco-pipe, and render lime perfectly fluid. Neither hydrogen nor oxygen are known to occur anywhere in nature in any sensible separate quantity. They are abundant enough in combination with other matters.

3. Nitrogen, sometimes called Azote, is another elementary substance, entering most largely into the constitution of universal nature. United with the matter of heat, it may be artificially produced and presented as a transparent, colorless, insipid, incombustible gas, incapable of supporting flame or breathing. It may be made to unite with oxygen (but of course only in certain definite proportions) by the agency of electrical fire. It may easily be procured by burning a bit of phosphorus in a confined portion of air over water. The inflamed phosphorus rapidly unites with the oxygen until it has exhausted all that the air contains, then combustion stops, and the remaining gas is nearly pure nitrogen. Small creatures soon die in it for want of oxygen. It combines in five different proportions with oxygen, forming, in one instance, nitric acid oraquafortis; and mixed, rather than chemically combined, with one-fifth its bulk of oxygen, it forms the air we breathe. Though ammonia is not a simple body, and, therefore, not to be classed with the present list, it may not be inappropriate, after the mention of hydrogen and nitrogen, to say that it results from the union of the two. Ammonia exists in rain water, and, as we shall subsequently show, is an important auxiliary to vegetable growth; it becomes developed in putrid urine or stable compost ; it is a colorless gas, with a strong pungent odor. It dissolves easily in water, and is then called hartshorn. It is very volatile; has all the common properties of solla and potash, combining readily with acids. Sulphate of ammonia exists 
largely in the soot from coals. From this source the "sal ammoniac" of commerce is procured.

Carbon.-Charcoal is the most usual and best known variety of carbon. It is black, soils the fingers, and is more or less porous according to the kind of wond from which it has been formed. Coke, obtained by charring, or distilling coal, is another variety. It is generally heavier or denser than the former, though less pure. Black-lead, or carburet of iron, there being in reality no lead in its composition, is a third variety still heavier and more impure. The diamond is the only form in which carbon occurs in nature in a state of perfect purity. That the diamond is essentially the same substance with pure lampblack is a very remarkable circumstance. Charcoal, the diamond, lamp-black, and all the other forms of carbon, burn away more or less slowly when heated in the air; and, combining with the oxygen of the atmosphere, form carbonic acid:

Oxygen, hydrogen, nitrogen, and carbon, form the ultimate elements into which all the organized part of all vegetable and animal substances is resolvable. We say organized: bones contain lime, and vegetables contain earthy and saline matters; but these are not organized, they are deposited in cells or in a structure so arranged as to contain them.

Chlorine, or Oxymuriatic gas, is, like oxygen gas, a permanently elastic fluid. When pure it has a greenish yellow color, and a very disagreeable odor and acid taste. It may not be breathed, and burning bodies are extinguished by it. It destroys all vegetable anil animal coloring substances, as also the effurium arising from the putrefaction of dead animal matter. It does not exist separately in nature, but is one of the components of common salt.

Fluorine.-This substance has such strong tendencies to combination, that as yet no vessels have been found capable of containing it in its pure form. It is one of the elements composing the Derbyshire fluor spar or blue john. 
This mineral is a fluate of lime, in other words, a compound of fluoric acid and lime. Now, fluoric acid is itself a compound of fluorine and hydrogen; and lime is not a simple body, but in reality the oxide or rust of a metal named Calcium, from the Latin word "Calx," signifying lime. Fluoric acid may be obtained from the Derbyshire spar by the action of sulphuric acid, which combines with the lime in consequence of the greater affinity of the two than exists between lime and fluoric acid, which by such process may be separated.

Having disposed of these, we proceed to notice (not the whole range) but a few other simple substances found in nature, and chiefly in the animal, vegetable and mineral world.

Sulphur.-This is a solid substance of a light yellow color, brittle and tasteless, and when rubbed emitting a peculiar odor. Melted and poured into cylindrical moulds it forms the roll brimstone of commerce. It burns with a pale blue flame in the open air, during which process it combines with the oxygen of the atmosphere, and forms sulphuric acid or oil of vitriol. Sulphur is found native in Sicily, Italy, and Iceland, and in combination with metals and earths in greater or less quantity throughout the mineral kingdom. It is a constituent of many vegetable and nearly all animal structures.

Phosphorus.-Phosphorus is most easily obtained by burning bones to whiteness in an open fire. In this way the animal matter is driven off and nearly pure phosphate of lime (or a salt composed of phosphoric acid and lime) remains. This phosphate of lime, reduced to powder, is next mixed with oil of vitriol and water; decomposition ensues in consequence of the greater affinity which oil of vitriol or sulphuric acid has for lime than the phosphoric acid already in combination with it. Next, by evaporation, the addition of powdered charcoal, and exposure of the mixed mass to distillation, the liberated phosphorus is separated into its two elements (phosphorus and oxygen), the former of which distils over, and at a low temperature 
becomes solid. Phosphorus may also be prepared from urine. It takes fire at a heat considerably lower than that of boiling water. Phosphorus has a waxy consistence; when burned in oxygen gas, a rery dazzling light is produced; and the result of the combination is phosphoric acid, just as sulphur or brimstone, burnt in oxygen gas, produces sulphuric acid. Phosphoric acid combined with lime, forms phosphate of lime, the solid inorganic constituent of bones. Phosphate of lime is easily obtained by exposing bones to a red heat in an open fire. Its first action is to blacken the bones, converting its animal carbonaceous matter into charcoal: if the heat be continued, the charcoal or carbon unites with the oxygen of the atmosphere in the form of carbonic acid gas, and the phosphate of lime remains beautifully white, left in the shape and arrangement of the organized cells it lately filled. Phosphate of lime is found as a native mineral production in some parts of Ireland and elsewhere. Phosphorus will dissolve in spirit of wine or in oil, but is insoluble in water, under which fluid it is always preserved.

Iodine.-This simple substance is found existing as an undecompounded element in the ashes of marine plants after the extraction of the soda they contain. Sea-weed is largely used on the coasts of England and Scotland as a manure. Iodine is a dark-colored solid, having somewhat the appearance of black-lead. It unites with all the metals upon which its action has been examined, and combines with oxygen, forming an acid.

Next, let us allude to earths and metals, or such forms of them as fall within the range of simple elementary bodies. We have already said that lime, ordinarily considered as an earth, is in reality a metallic oxide; pure soda, pure potash, calcined magnesia, pipe-clay, the base of flint, and some other similar substances, are, in truth, metals, united to oxygen in the same way as rust of iron is a compound of iron and oxygen. Lime, then, or, in chemical language, " oxide of calcium," combined with various acids, is a very abundant natural production, found widely diffused 
over every part of the habitable globe, as limestone, marble, chalk, fluor spar, plaster of Paris, gypsum, or alabaster; these, under various names, being all of them compounds of lime with the carbonic, fluoric, or sulphuric acid. Besides these, lime, in combination with phosphoric acid, enters very largely into the composition of the solid skeleton or shell of animals. Pure lime is more soluble in cold than in hot water, a fact not without its interest nor intention. If chalk be exposed to a red heat, the carbonic acid, one of its constituents, is expelled, and pure lime remains. Pure, or caustic quick-lime, corrodes animal and vegetable substances, and is never found in them in an unmixel state. Lime is one of the most infusible bodies known, but may be made to melt by the joint action of the combustion of oxygen and hydrogen gases. Lime has a powerful affinity for water, and the combination is attended with the extrication of great heat, as when lime is slacked for the builder. In this process the water becomes solid, unites, not mixes, with the lime, and in passing from the fluid to the solid state, gives out the latent heat necessary to maintain fluidity. This heat becoming suddenly sensible, is sufficient to carry off a portion of the water in vapor, the union of the lime and the water producing a dry solid. The same chemical union occurs when plaster of Paris, or dry sulphate of lime, is mixed in certain proportions with water: the fluid solidifies, and unites with the lime into the hard substance which forms the common plaster images or casts hawked about the streets by the Italians. Lime combines freely with many acids, existing in this form as " muriate of lime" in the water of the ocean. Of the application of earthy minerals to the land, we will speak in its proper place.

Sodium.-This is the metallic base of common table or rock salt, which is a compound of two elements, chlorine, already alluded to, and sodium, with water. The metal sodium has a lustre and color very similar to silver, and is so soft as to be pressed into leaves between the fingers. It may be obtained through the agency of the galvanic appa- 
ratus. When thrown upon water, it decomposes that fluil, it soon becomes oxidized, or robs the water of oxygen, setting its other constituent, hydrogen, at liberty, the action being accoinpanied with a hissing noise. Chloride of sodium, or common salt, is abundantly diffused over the world, both as a solid mineral production, and as the principal ingredient in sea-water ; it is essential to healthy action, as well in animal as in vegetable nutrition. If thrown upon hot coals, salt crackles, because the water it contains is not chemically combined but merely mixed or interposed between its particles, and so expanding by heat causes the separation of those particles and the resulting sound. Sodium united to oxygen, forms pure soda; pure soda united to sulphuric acid, forms the Glauber sait, so commonly given to cattle; pure soda united to carbonic acid, forms the substance sold in the shops as "soda," and bought for the purposes of the washerwoman.

Potassium.-This is the metallic base of common pearl ashes. If the pure metal be thrown upon water, like sodium it swims on the surface, and darts violently hither and thither, with the sudden extrication of flame. This flame is burning hydrogen, and the phenomenon arises from the great affinity of potassium for oxygen, abstracting it from water, or all bodies that contain it. If the metal potassium be united with oxygen, it forms pure, or caustic potash, or oxide of potassium; if pure potash be united with carbonic acid, the result is carbonate of potash, of which pearl ashes is an impure variety. United with nitric acid, potash forms saltpetre, which is found very abundantly as a natural product. Potash, combined with oxalic acid, is found in sorrel and other sour plants. Impure carbonate of potash remains in the ashes of most vegetables, and so largely in some of them, as to yield the immense supply for trade. Potash, united with fatty or oily substances, forms the various kinds of soap.

Silicon is another metal which, in union with oxygen, forms silica, or siliceous earth, existing native in great abundance, and forming the chief ingredient in fint, quartz, 
and rock-crystal. From these substances silica may easily be obtained, by first heating them to redness, and then throwing them into water. For all common purposes, sand from the glass-house will answer. It unites with potash and forms glass, and is insoluble in all acids, except the fluoric acid, for which reason this acid is kept in leaden bottles. Silica exists very largely in the hard coating of the sugar-cane. In the stem of wheat straw, silica is essential to the firm, erect position of the plant; consequently, if the soil be deficient of silica (a fact which is easily determined), the ear of corn will droop, upon a slender, short, and lanky straw.

Aluminium.-This metal, in combination with oxygen, forms pure alumina. Alumina, more or less pure, exists as a most abundant natural production, being found as a chief constituent of clay, for pottery and bricks. Crystallized, it forms those precious gems, the ruby and sapphire; so that the difference between a bit of charcoal and a diamond, is a similar difference to that which exists between a bit of clay and a precious jewel-merely a diversity in the arrangement of particles of the same matter.

Barium.-A metal forming the base of the earth baryta, and of the various acids in combination with that earth. Carbonate of baryta is found native in Derbyshire. Pure baryta, like lime, slacks when in contact with water; for which it has so strong an affinity, that the heat of a forge will not drive it off.

Magnesium.-The metallic base of the earth magnesia, the calcined magnesia of the shops. In combination with muriatic acid, it exists largely in sea-water. With sulphuric acid, magnesia forms the common Epsom salt, and is found as a native magnesian limestone in combination with lime and carbonic acid.

Iron.--Iron is found native in many parts of the world, and is also very abundant in combination with sulphur, and many other substances, such as oxygen, forming oxides; also in further union with acids, forming carbonates, sulphates, and phosphates. Green copperas is a sulphate of 
iron. Rust of iron, produced by the action of the atmosphere, arises from the combination of the iron with oxygen, derived from the air, and also with a portion of carbonic acid from the same source, and so may be correctly named carbonate of iron.

Lead.-Metallic lead is rarely found native, but is obtained in large quantities by smelting the sulphuret, a mineral known by the name of galena. Lead is found also in combination with oxygen and acids.

Copper.-This metal occurs very commonly native in a state of perfect purity, sometimes in large masses, at other times in a crystalline form. It is commonly found in combination with sulphur, from which it is generally obtained. Blue stone, used by the farrier, is a sulphate of copper.

Zinc.-Metallic zinc, sometimes named spelter, is obtained either from the impure carbonate, a native production called "calamine," or from another natural compound, the "sulphuret," or zinc blende. White vitriol, used in veterinary medicine, is a sulphate of zinc. The ores from which it is smelted, exist largely in some districts.--Tin, bismuth, antimony, arsenic, nickel, cobalt, and many other metallic substances, might similarly be enumerated; but these, existing in comparatively minute quantities, may be safely passed over. The elements found in vegetables are but few. Oxygen, hydrogen and carbon, form the greatest part of their organized matter. Nitrogen, phosphorus, sulphur, manganesum, iron, silicum, calcium, aluminum, and magnesium, enter into their composition, or are found in the agents to which they are exposed; and these twelve, out of nearly sixty undecompounded elements, require to be familiarly understood by the agricultural chemist. Life gives a peculiar character to all its productions : the power of attraction and repulsion, combination and decomposition, are subservient to it. A few elements, by the diversity of their arrangement, are made to form the most different substances; and similar substances are produced from compounds which, when superficially examined, appear entirely different. 


\section{CHAPTER III.}

Plants and Animals are both alike endowed with Life; the Eleme:ttary Materials and many of the Proximate Principles of Animal and Vegetable matter are precisely identical-they have similar Organs essential to their growth and reproduction, and are nourished or destroyed by the same agencies.

IF I dig up a stone, and remore it from one place to another, the stone will suffer no alteration by the change of place; but if I dig up a plant, and remove it, strip its leaves, and leave the stem standing, or mutilate an animal,- - that plant or animal will instantly sicken, and perhaps die. What is the reason of this? Both have been perfected in connection with the same common soil. If I break the stone to pieces, though chemically, it may consist of several elements, yet every individual fragment will be found possessed of the original character of the whole mass; it is only altered in shape and magnitude: but if I tear off a branch from a plant, it will wither and lose the properties of its parent stock. The mineral can only be destroyed or changed by mechanical or chemical force; while the plant, like all animals, has been produced by generation, has grown by nutrition, and been destroyed by death, -in fact, it has been actuated by an internal power.

In what this internal power consists, we know not. Differently modified, we meet with it in both plants and animals. Wherever we find it, we denominate it the "PRINCIPLE OF LIFE ;" its presence forming a clear distinction and boundary between the two great families of animals and plants, and all else besides in the universe. A cabbage is not less truly alive than the ox which feeds upon it. The superiority of the animal over the plant 
consists chiefly in this-the existence of mind or intellect, and correspondingly, a brain and nerves, of which the plant is deficient. Now, all living things are said to be organized,- that is, made up of various structures, evidently destined to answer certain ends; and these, taken together, compose the entire plant or animal: as the root, sap ressels, bark, leaves, and other organs of a tree; and, correspondingly, the bones, muscles, blood-vessels, skin, and lungs of a horse, a man, or a sheep. But this description is not true of a piece of limestone, or a lump of clay, and, therefore, it is said to be inorganized. Hence, all the various bodies in nature arrange themselves naturally under the two great divisions of organized and vital, or inorganized and dead, without a single exception.

In their more perfect forms, the distinctions between animal and regetable life are obvious enough. There is a wide distinction between a horse chestnut and a chestnut horse; but as we approach the contiguous extremities of the animal and vegetable kingdoms, the distinction is not so easy. There are some natural productions which have been originally considered as minerals, afterwards as vegetables, and have at last been regarded as belonging to the animal kingdom-less on account of any other property they possess than their similarity of chemical and elementary constitution to the well-known ingredients of animal matter. Sponges, and many fungous growths, are of this character.

In what part of a plant the living principle chiefly exists, or to what quarter it retires during the winter, we know not; but we are just as ignorunt in relation to animal life. In both, it operates towards every point: it consists in the whole, and resides in the whole; and its proof of existence is drawn from its resisting those putrefactive or chemical agencies which instantly begin to operate as soon as the plant or animal is dead. While life exists, a vegetable or animal thrives and increases in its bulk; a tree puts forth annually a new progeny of buds, and becomes 
clothed with a beautiful foliage of lungs, (every leaf being in itself a distinct lung), for the respiration of the rising brood, and with an harmonious circle of action, that can never be too much admired, a perpetual supply of nourishment is furnished first for its own growth, next for the growth and perfection of animal life; while, from its own decay, as well as from the death of animal matter, there is formed, in rich abundance, the means of new births, new buds, and new harvests. In fact, everything is formed for everything, and subsists (if we may speak figuratively) by the kind intercourse of giving and receiving benefits. Such is the simple, but beautiful, circle of nature. That which lives, flourishes, decays, and dies, is not lost ; the great principle of life only changes its form; and the destruction of one generation of plants or animals is but the necessary requisite to the support or existence of the next.

Carbonic acid, Ammonia, and Water, yield elements out of which are built up all the organized parts of plants; and it is no less true that these elements form the entire organized structure of animals. This being the fact, we should naturally suppose the conditions essential to the growth of each are the same-in fact, that the food consumed by vegetables and animals would prove essentially similar: and such is actually the case. The process of digestion in an animal is precisely identical with the process of appropriation or nourishment in a plant. Certain inorganic substances, salts and metallic oxides, serve peculiar uses-as lime to give solidity to the bones of an ox ; and silica, or the earth of flints, to serve the same end in wheat straw.

We have already spoken of the elementary or ultimate constituents of vegetables. Out of these are formed the various immediate compounds which are found in them. The compound substances found in vegetables are,-1. Albumen; 2. Gum; 3. Sugar; 4. Gluten; 5. Woody fibre; 6. Starch ; 7. Extractive; 8. Tannin; 9. Resin ; 10. Wax; 11. Fixed and volatile oils; 12. Bitter prin- 
ciple; 13. Free acids; and a few others; to which must be added the mineral, saline, or metallic substances they contain.

Out of the same elementary constituents of vegetable and animal structure are formed the materials composing the blood and all the secretions-fibrin, gelatin, mucus, albumen; all the animal acids-spermaceti, hog's lard, train oil, and other fatty substances; ozmazome, urea, sugar of milk; together with many other matters enumerated by chemists, only some of which are peculiar to the animal kingdom;-so that there is no difference between albumen obtained from a vegetable and that which forms, in nearly a pure state, the white of an egg. Albumen, in a solid form, constitutes the principal part of the almond, and of the kernels of nuts. The juice of a West Indian plant (Hibiscus esculentus) contains liquid albumen in such quantities, that it is employed in Dominica as a substitute for the white of eggs in clarifying the juice of the sugar-cane. Albumen is common to the vegetable as well as the animal kingdom, and may be easily distinguished from other substances by its property of coagulating or becoming hard and permanently solid by the action of moderate heat, or of acids. It forms a constituent of the serum of blood, of several of the animal secretions, and in a solid form of some of the organized structures of the body. Its composition, from whatever source it may be obtained, is Carbon, 52; Hydrogen, 7; Oxygen, 23; and Nitrogen 15 parts, (rejecting fractions), in every 100.

Let us trace a few more of these comparisons, bearing in mind that nitrogen, as one of the elements into which both vegetable and animal compounds are ultimately resolvable, exists always in greater proportion in flesh, than in grasses. All animal matters do not contain nitrogen; nor are all vegetable substances devoid of it.

Vegetable gum is analogous to animal mucus. Gum is a substance which exudes from certain trees; it appears in the form of a thick fluid, but soon hardens in the air, and becomes solid, when it appears white, or yellowish white, 
and somewhat brittle. The characteristic properties of gum are its easy solubility in water, and its insolubility in spirit of wine. All the varieties of gum are nutritious as food. Gum is composed of 43 carbon, 51 oxygen, and 6 hydrogen, in 100 parts, or nearly. Mucus, a secretion found on the surfaces of the lining membrane of the intestines, possesses the same characters ; and its composition is nearly the same. It may be obtained by evaporating the saliva to dryness; and is then similar to gum-arabic in its general appearance, but rather more opaque. It may be procured also by evaporating to dryness the fluid found in the shell of the oyster, or water in which that animal has been macerated.

Sugar is essentially the same, whether derived from the maple-tree, the sugar-cane, the milk of animals, or even from the urine in the disease known by the name diabetes. Its composition is 28 carbon, 8 hydrogen, and 64 oxygen, in 100 parts, differing not very widely from gum. Sugar exists, naturally formed, in many plants and fruits, especially the sugar-cane. During the Peninsular war, it was largely manufactured from the juice of the beet-root, both in France and Germany. It has also been obtained from grapes, from manna, from carrots, and from honey.

Let us compare vegetable gluten with animal gelatin. First, of gluten. It may readily be prepared from wheat, or from flour, by the agency of cold water, and pressing out the starch. It has a grey color; is elastic, ductile, and tenacious; soon decomposing when kept long in contact with the air, emitting an offensive odor similar to that of putrid animal matter. Gluten, when burnt, affords similar products to albumen, or white of egg, and differs little from it in composition. It is found in a great number of plants : in acorns, chestnuts, apples, rye, barley, wheat, peas, and beans ; in the berries of the elder, and in grapes. Gluten appears to be one of the most nutritive of the vegetable substances; and wheat seems to owe its superiority to other grain, from the circumstance of containing it in larger quantities. Animal gelatin, its counterpart from 
the animal kingdom, enters largely into the composition of many of the animal solids; such as horns, hoofs, and skin, the organized structure of bone, cartilage, and tendon. Isinglass and common joiner's-glue are forms of gelatin, it being readily distinguished from all animal principles by its easy solubility in boiling water. Gluten and albumen, derived from vegetables, differ from other vegetable products, principally in containing nitrogen, and thus assimilating very closely to the chemical character of animal matter. Its composition is 47 parts of carbon, 8 of hydrogen, 27 of oxygen, and 18 nitrogen, in 100 parts, or pounds.

Woody fibre is a substance remaining after the plant subjected to analysis has been exhausted of all its soluble materials by repeated boiling in water and spirit of wine. It forms the bulk of vegetables. Its composition is 52 parts of carbon, and $4 S$ of hydrogen and oxygen, in such proportions as form water, in 100 parts. Animal fibrin is a principal constituent of the muscular, red or fleshy parts of animals, and of the blood. It may conveniently be procured by stirring blond recently abstracted, during its coagulation; then washing the fibres till they become colorless, or by digesting small pieces of lean meat in repeated portions of water. As vegetable charcoal is made largely from woolly fibre subjected to the action of a close fire, so animal charcoal may be similarly prepared from the muscular parts of animals by the same agency; or, indeed, from any organized structure containing carbon. In animal fibrin, as it exists in muscle or in blood, onehalf the weight is carbon. Fibrin is white, inodorous, and insipid; when dry, it is hard, brittle, and slightly transparent. Strong sulphuric acid blackens it, converting it into charcoal precisely as it does wood. In the ronts of plants, in the trunk and branches of trees, the bark and heartwood, the leares and flowers, the great basis of the solid parts is wrodly fibre. it forms by far the greatest part of the heart-wood and bark; there is less in the alburnum, still less in the leaves and flowers. Fibrin holds a similar 
relation to animal bodies. In 100 parts of fibrin there are 53 1-2 of carbon, hydrogen 7, oxygen 19 , and 19 of nitrogen; the presence of nitrogen, or its addition, constituting. the peculiarity which distinguishes fibrin from woody fibre.

We have run the parallel far enough for ordinary pulposes. Of course, there are some proximate compounds in animals and regetables which are not common to both, though, with the usual addition of another element, nitrogen, the most varying and unlike substances derivable from the animal and vegetable world are compounded from the same ultimate elements. Let us next briefly glance at a few of these.

Starch.-Starch is procured from different vegetables, but particularly from wheat, or from potatoes. To make starch from wheat, the grain is steeped in cold water till it becomes soft, and yields a milky juice by pressure; it is then put into sacks of linen, and pressed in a vat filled with water; as long as any milky juice exudes, the pressure is continued, the fluid becomes gradually clear, and a white powder subsides, which is starch. Arrow-root, tapioca, and sago, are nearly pure starch. Starch, or, in its absence, coagulated mucilage, forms the greatest part of the seeds and grains used for food; and they are generally combined with gluten, oil, or albumen; in corn with gluten, in peas and beans with albumen, and in rapeseed, hemp-seed, linseed, and the kernels of most nuts, with oils. Its characteristic property is its easy solubility in boiling-water, and its insolubility in that fluid when cold. The ultimate composition of starch is, carbon 43 1-2, oxygen 50, hydrogen $61-2$; or, in other words, carbon $431-2$, and oxygen and hydrogen in such proportions as form water; differing, chemically, from gum, only in a very slight variation in these quantities.

Extract, or the Extractive principle, exists in almost all plants. It may be procured in a state of tolerable purity from saffron, by merely infusing it in water, and evaporating the solution. It may likewise be obtained from catechu, or terra Japonica, a substance now imported in immense quantities from India, and used in calico-printing. 
This substance consists principally of astringent matter and extract. By the action of water upon it, the astringent matter is first dissolved, and may be separated from the extract. There are almost as many varieties of extract as there are species of plants. It is not, nor can it be, used singly as an article of fond; but is probably nutritive when united to starch, mucilage, or sugar. Its composition is carbon, hydrogen, oxygen, and a little nitrogen.

Tannin, or the tanning principle, may be procured by the action of cold water on bruised grape-seeds, or pounded gall-nuts, and by the evaporation of the solution to dryness. It is a yellow, highly-astringent substance. If tannin be distilled in close vessels, the principal products are charcoal, carbonic acid, and inflammable gases, with a minute quantity of volatile alkali. Hence its ultimate elements seem the same as those of extract, but probably in different proportions. Tannin is not a nutritive substance, but is of great importance in its application to the art of tanning. When skins (which are composed almost entirely of gelatin or jelly) are exposed to solutions containing tannin, they slowly combine with that principle; their fibrous texture and coherence are preserved; they are insoluble in water, and no longer liable to putrefaction; and, by subsequent processes of rolling and drying, form leather. In general, in this country, the requisite tannin is made from the bark of the oak; but the barks of other trees, and the wood and leaves of many shrubs, yield it abundantly.

Resin is very common in the vegetable kingdom. One of the most usual species is that afforded by the different kinds of fir. When a portion of the bark is removed from a fir-tree in spring, a matter exudes, which is called turpentine. By heating this turpentine gently, a volatile oil rises from it, known familiarly as "spirit of turpentine." A more fixed substance remains, which is common yellow resin. Resins are insoluble in water, but very soluble in spirit of wine; in this respect reversing the character of gum. Sandarac, copal, mastic, elemi, are resins obtained $11^{*}$ 
from various trees; and the list is very numerous Tar and pitch principally consist of resin in a partially decomposed state. Tar is made by slowly burning the fir ; and pitch, by the evaporation of the more volatile parts of tar. One hundred parts of common resin contain 76 of carbon, 13 3-10ths of oxygen, and $107-10$ ths of hydrogen.

Wax is found in a number of vegetables, from their berries and the surfaces of their leaves. Its combustible property, like that of resins, is well known. The wax of the vegetable kingdom seems to be precisely of the same nature as that afforded by the bee. Its constituents are, carbon 81 7-10ths, oxygen 5 1-2, hydrogen 12 6-10ths, in 100 parts.

Fixed oil is obtained by expression from seeds and fruits. The olive, the almond, linseed, and rape-seed, afford the most common vegetable fixed oils. Their common properties are well known. They are lighter than water; and many of them congeal at a lower temperature than that at which water freezes. They all require, for their evaporation, a higher temperature than that at which water boils. The products of the combustion of oil are, water and carbonic acid gas. The fixed oils are very nutritive substances : they are of great importance in their applications to the purposes of life. Fixed oil, in combination with soda, forms the finest kind of hard soap. Let us compare the ultimate analysis of olive or vcgetable oil with that of spermaceti oil which is of animal origin;-

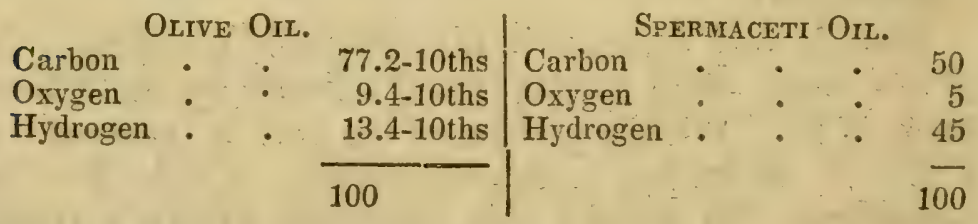

The greater proportion of hydrogen in spermaceti oil renders it a fitter fluid for combustion in lamps than vegetable fixed oils; but the ultimate composition of the two, as far as the list of ingredients is concerned, is evidently the same. 
Hog's lard, butter, spermaceti, may be regarded as animal fixed oils.

Volatile, or essential oils, differ from fixed oils, in being capable of evaporation by a much lower degree of heat. Volatile oils give the peculiarity of odour to the peppermint plant, to camomile, and numberless other shrubs and trees ; existing in the flowers of some of them, and in the leaves and inner bark of others. Thousands of minute insects may usually be seen in the stalk and leaves of the rose; but none of them are ever observed on the flower. One reason for the existence of fragrant volatile oil in plants may be, the preservation of the parts destined to the propagation of the species from the destructive ravages of insects and animalculæ which feed on the bodies of plants. So, those woods that contain aromatic oils are remarkable for their indestructibility, as cedar, rose-wood, and cypress. The volatile oils inflame with more facility than fixed oils; and afford, by their combustion, different proportions of the same substances-namely, water, carbonic acid, and charcoal or carbon. Volatile oils consist of carbon, hydrogen, and oxygen ; but, as yet, no accurate experiments have decided their relative proportions.

The bitter principle is very extensively diffused in the vegetable kingdom. It is found abundantly in the hop, in the common broom, in camomile, and in quassia. The natural bitter principle is of great importance in the art of brewing. It checks fermentation, and preserves fermented liquors, and doubtlessly plays an important part in the healthy nutrition of the living regetable. An intensivelybitter substance is found in bile, or the fluid secreted by the liver of animals. The gastric juice, or fluid secreted by the stomach, is not only the principal solvent in digestion, but has the same antiseptic property, or resists putrefaction as strongly as the vegetable bitter principle.

Systematic writers on chemistry have enumerated a long list of proximate constiments, both of animal and vegetable structure. Mainy of them, as we have seen, are but the counterparts of each other. It is needless to specify them all. 
The earths found in plants are four, all of them, as previously related, of metallic origin. These are, $1 s t$, Silica, or the earth of flints, the base of which is the metal silicon; $2 d$, Alumina, or pure clay, the base of which is the metal aluminum; $3 d$, Lime, the metallic base of which is calcium; and, $4 t h l y$, Magnesia, the metallic base of which is magnesium. All of these are similarly found in animals; among them, lime, most largely in their bones and shells. Some insects are almost entirely composed of silica : iron, existing in peat-mosses and in many vegetables, gives the red color to the blood. None of these exist in a free or uncombined state, in either the vegetable or animal world; most commonly in combination with acids, of which we may observe, that some plants contain free vegetable acids in large proportion, as the common sorrel or sour-leaf. The applications of the vegetable acids are well known. The agreeable taste and wholesomeness of various vegetable substances used as fond, materially depend upon the regetable acid they contain. Phosphoric acid (united to lime in bones) is found free in the onion; and the sulphuric, muriatic, and nitric acids, though they cannot with propriety be considered as vegetable products, exist in many saline compounds, as part of the inorganic constituents of plants as well as animals. They are all variously compounded of carbon, hydrogen, and oxygen. Then, too, the saline compounds found in plants correspond with many similar compounds found in animals. Potash and soda, blended with acids, are found in blood, in the various animal secretions, in the leaves and stalks of vegetables; sparingly in animal matter, very largely in sea-weed yielding soda, and in the ashes of burnt wood yielding potash.

Plants, like animals, are produced by ordinary generation; and though we meet with various instances of production by the generation of buds, and bulbs, or of slips and offsets, the similarity, instead of being hereby diminished, is only drawn the closer ; for we meet with just as many instances of the same variety of propagation among 
animals. Many species of worms are capable of increase by buds, bulbs, or offsets; and some of these animals, like the house-leek and various grasses, by spontaneous separation. A twig of myrtle will live and grow, if placed in the ground, because it contains in itself all the parts of a perfect plant; but that is independent of the provision nature has made for the propagation of the plant naturally, from the seed buried in the earth. Something approaching very closely to the character of a sexual, or reproductive system of organs, is visible in the flowers of plants. The pistil is the organ which contains the rudiments of the seed; but the seed is never formed, as a reproductive germ, without the influence of the pollen, or dust on the anthers. This mysterious impression is necessary to the continued succession of the different regetable tribes. It is a feature which extends the resemblances of animal and vegetable existence, and establishes, on a great scale, the beautiful analogy of nature. Seeds which are shed devoid of this fructifying dust, are precisely analogous to eggs over which the influence of the male bird has neverbeen exerted. Vitality is therefore essential to the germination of seeds: life will remain dormant, inert for an indefinite period,- - and then change its form into that of active vitality, if that seed be placed under the action of moisture, heat, and air. So that the scriptural inquiry, "How can a seed quicken, unless it die?" is not to be talken as the enunciation of a scientific truth, but as an illustration drawn from the ordinary apprehensions of mankind.

The utmost period of time to which seeds may be kept, and be enabled to retain their life, and, consequently, their power of growth, has not been accurately determined; but we have proofs enough to show that the duration may be very long. A paper of melon seeds, found in the year 1762 in a cabinet of Lord Mortimer, and apparently collected in 1660, were then sown, and produced excellent fruit; and, more latterly, seeds buried in the ruins of Herculaneum, and others brought from Egypt,-found in 
the tombs that are more ancient than the time of Moses, - have been proved to retain their vitality. Animal seeds, or, more properly, EGGS, when perfectly impregnated, appear capable of preservation quite as long. This inert condition of seeds is not unlike what occurs in the hollows of our waste lands, in reference to animal matter. When those have been for some time filled with stagnant water, we not unfrequently find minute eels, minnows, and waterinsects there, and wonter how they could get into such a situation. But the mud which has been emptied out of a fish-pond has been, perhaps, thrown into these very hollows; or the eggs of the animals or insects have been carried, mixed with other materials, into the same place, and then waiting, it may be, year after year, the accidental, yet necessary, circumstances of warmth, water, light, and air, they have been stimulated to active life. One species of locust appears, in numbers, only once in seventeen years: and the paliner-worm once only, in similar numbers, in thirty years. Something analogous to this occurs in reference to various species of grub and fly, as observed by practical farmers; and the reason of it is, that the integument, or outer covering, of many minute ova, ensures their protection and their vitality dyring long periods. The eggs of the gad-ffy could never be hatched on the horse's back: their covering preserves them entire aud vital, till, by the itching sensation their presence excites, the animal is tempted to lick the spot, and so convey them to his stomach, the only place where it is destined they should come to maturity. Numberless small fish are seen in the salt-pans at a village in Hesse Darmstadt : the ova of these fish have been conveyed there by birds, and, it so happens, are deposited in a place where the necessary conditions exist for their development.

The essential difference between the egg of a barndoor fowl, and the ovum, or egg, which ultimately becomes a calf, a foal, or a human being, is, that the one, after the stimulus of impregnation has been applied to it by the male, comes to maturity within the body of its parent; in the 
other instance, it is hatched after its expulsion. In fish and in frogs, the spawn, or ova, is first expelled, then the male passes over it. The seeds of plants are exactly analogous to eggs; in ordinary instances the germs and the fecundating material which ensures reproduction, being both found in the same flower, and, of course, attached to the same stalk. The various species of fruit are but contrivances for the shelter and preservation of seeds, as the pippins of the apple, or of the orange and lemon; these, when fully ripe, left to themselves, would fall, become rotten, or, in other words, subjected to common chemical agencies and exposing the seed within, form, in the first instance, a manuring material for the perpetuation of the plant or tree which had yielded it.

Plants derive all their sustenance from the spot on which they are placed; and, solely for this reason, are not provided with a peculiarity which distinguishes animals, namely, a set of moveable levers or bones, destined to carry them about from place to place in quest of food, and of muscles, or red, fleshy, contractile organs, intended to act upon those passive levers: and yet there are some plants that seem fairly entitled to the character of locornotive or migratory. A familiar instance of this occurs in the strawberry genus: such plants grow from a new bulb, or knob, or radicle, while the old root dies away; in consequence of which, we can only conclude, that the living principle of the plant has quitted an old, decayed, and ruinous mansion, to take possession of a new one; so much so, that were a person to plant the orchis, or the devil's-bit, in his garden, and to search for it in the same spot, after an interval of seven years, he would find it several hundred yards from the spot where he had planted it.

There are some creatures that throw off their outer covering annually: so the shrubby cinquefoil, indigenous to Yorkshire; and other plants and trees, which, sending: forth, every spring, new colonies, by means of runners (as we call them), shortly obtain a settlement for 
themselves, and break off all connection with the parent stock.

The blood of plants, like that of animals, is of an extremely compound character. If blood be allowed to stand in a vessel, it soon separates into a clot, and a fluid in which that clot floats. Each of these is, again, divisible into several other matters. So with the fluid that circulates in the vessels of a tree. And, as from blood the various dissimilar solid and fluid secretions and excretions are formed, building up the animal fabric,-as bone, muscle, bile, urine, jelly,-so, from this common current of vitality, the sap, plants, like animals, secrete a variety of substances of different, and frequently of opposite powers and qualities-substances rutritive, medicinal, or destructive. The flesh of the viper is healthful, his poison is deadly; the root of the Indian cassara is poisonous, its leaves are eaten as ordinary food. Every one is familiar with the fact, that some of our domesticated animals will eat with impunity regetables that would be poisonous to others. Then, too, how close is the analogy between the torpidity of the squirrel, or the dormouse, or the swallow, ${ }^{*}$ during the winter, and that of deciduous plants during the same season: we know, that if proper care be exercised, they may be removed in that state without endangering their vitality. Many animals are amphibious-they can live equally well on land or in the water; and the regetable world is not without illustrations of a similar power. Indeed, the instances of resemblance between animal and vegetable life are innumerable. Some vegetables, like a few birds, more insects, and most of our forest beasts, appear to sleep through the day, and become active at night; while the greater number of them, like the great

* It is a mere fable that the squirrel and swallow become torpid during the winter. We have seen the former, hundreds of times frolicking in the liveliest manner in the forests, in the coldest weather in winter, as high up as the latitude of $43^{\circ}$; and as to the latter, it migrates to the south in the autumn like our other summer birds.AMER. ED. 
majority of animals, fold or hang their leaves at sunset, and appear invigorated with the return of morning. Like animals, the duration of their existence is equally various.

We have already observed, that plants and animals convert the materials of nutriment they receive into their own substance precisely by the same agency, and that there is no essential difference between the ultimate composition of the requisite materials in either instance. If this be so, as in the further progress of this inquiry we shall unquestionably prove, it would be fair to expect that the digestive organs of animals, -in fart, all that is connected with reproduction and growth, - have their counterpart in plants; and such is actually the case. Let us briefly review the anatomy, or organized structure, of a plant, and compare that structure with the anatomy of a horse.

Every plant, examined as to external structure, displays, at least, four systems of organs, or some analogous part. First, the Root; Secondly, the Trunle and Branches, or Stem; Thirdly, the Leaves; and, Fourthly, the Flowers or Seeds.

The stem of any tree consists of the pith in the centre, the wood surrounding the pith, and the bark which covers the whole. A tree completely divested of bark, is precistly in the predicament of an animal deprived of its hide. The pith consists of bundles of minute hollow tubes, or vessels arranged horizontally; the wood and inner bark, of long tubes or vessels bound together in a rertical position, so as to be capable of carrying vegetable blood up and down between the roots and leaves. When a piece of wood is sawn across, the cut ends of these tubes are as distinctly perceptible as the divided arteries and veins in the stump of an amputated limb. Branches are only prolongations of the stem, and have the same character.

The bark of the stem and root is divisible, like the covering of animals, into epidermis (analogous to the scarf skin which rises over a blister), and true skin, or inner bark, which alone is vascular and vital. In forest 
trees, and in the larger shrubs, the bodies of which are firm, the outer bark, epidermis, or scarf skin, is a part of little importance; but in reeds, grasses, and plants having hollow stalks, as wheat and oats, it is of great use, and is exceedingly strong, from the provision of its containing siliceous earth, or the oxide of a metal, as already stated. The analogy between this contrivance and the shell of the lobster, or the covering of insects, is very obvious.

As the root tapers away, the pith gradually disappears, the bark thins out, the wood softens, till the white tendrils, of which its extremities are composed, consist only of a colorless, spongy mass, in which the vessels or tubes that carry on the circulation lose themselves.

The leaf is an expansion of the twig. Each separate leaf is precisely analogous in its action to the gills of a fish, or the lungs of an ox, or of a human being. The fibres which are seen to branch out from the base over the inner surface of the leaf, are prolongations of the vessels of the wood, precisely as the lung of an animal is but an outspread division of blood-vessels. A powerful sucking and forcing pump called the heart, is essential to drive human blood along large vessels to its ultimate division; but the vessels of plants are capillary, that is, hair-like, exceedingly minute, and therefore a central power or heart is not necessary. So there are capillary ressels in animals, and there the action of the heart is not so sensibly felt. Their minuter blood-ressels are believed by some to be contractile. The green exterior portion of the leaf is a continuation of the inner bark, and communicates directly with its vessels. Most of the vessels of the living plant are full of sap or vegetable blood in almost continual motion. In spring and autumn the motion is more rapid; in winter it is sometimes scarcely perceptible. From the spongy part of the root the sap ascends through the ressels of the wood in virtue of that capillary attraction already adverted to, until it is diffused over the inner surface of the leaf. By the ressels in the green of the leaf it is returned to the bark, and through the vessels of the inner bark it is 
returned to the root. In man and four-footed animals the blood is driven from the heart along the arteries, and returns back by the veins; but previously to being sent along the circulation a second time, it is driven into the lungs, is there subjected to the action of the air, (whence the necessity for breathing), and then, returned to the other side of the heart, is again fitted to recommence its journey. Animals derive a considerable portion of their nutriment from the change effected on the air by the action of the lungs: something is absorbed as well as given out. The leaves of plants perform the same office. In the sunshine, the leaves are continually absorbing carbonic acid as well as other matters from the air, and giving out oxygen gas. In breathing, carbonic acid is given off, and not triffingly. The air becomes instantly poisonous, if that gas accumulate as rapidly as it did when some hundreds of our brave countrymen were pent up in the confined space of the "black-hole" at Calcutta. The leaves, then, are continually appropriating carbon, the basis of charcoal, from the atmosphere. When night comes, this process ceases, and they begin to absorb oxygen and give off carbonic acid. Hence the mischief of placing large plants, in great numbers, in bedrooms. It would result from the above arrangement, that plants grow very little, perhaps not at all, during the night. Now, during the summer months when they are provided with leaves, the days are long, the nights short : in winter, when plants are torpid or stationary, the nights are long, and the day comparatively brief. Sunshine is necessary, in order to enable plants to decompose carbonic acid and appropriate the carbon. It is owing to this law, that in the cold northern regions where, in their highest latitudes, the sun once risen never sets again during the whole of their short summer, vegetation almost rushes up from the soil ; almost literally, plants may be seen to grow. The green leaves are continually gaining from the air and never losing; ever taking in and never giving off carbon, since no darkness interrupts or suspends their labors. 
Every child is led to regard the root of a plant as the organ from which the vegetable grows; not merely as attaching it in the erect position to the spot, but as forming the medium of communication between all that is above ground, and the food the soil is supposed to yield. But it is not so obvious to us, who, in many senses, are but children of a larger growth, that the leaves of an oak or an ash spread their broad leaves into the air for the very same purpose as the roots diffuse their fibres through the soil. The only difference is, that while the roots absorb chiefly liquid, the leaves inhale almost solely gaseous food. The human lungs expose the blood to air just as, in the leaf, the sap is submitted to the same agency; and in each instance there is a double use to which these organs are destined: they not only change the character of the circulating fluid, but permit, by the decomposition of air, the absorption of some of its elements as food for the animal or plant. So that, in truth, we live and are nourished partly upon the air we breathe, and so is a cabbage upon the atmosphere it decomposes. If the experiment be repeated-it has often succeeded-that of burying the branches of certain trees in the soil and elevating the roots in the atmosphere, turning the vegetable upside downthere is as it were an inversion of its functions-the roots will produce buds and leaves, and the branches shoot out into root-like fibres and tubes. The experiment succeeds well with the willow.

Though plants give out in the night carbonic acid, this process does not go on so rapidly, or to such an extent, as to destroy the balance in their favor of what has been absorbed during the day. The quantity absorbed through the leaves varies with the season, the climate, and the lsind of tree; it is also modified by the nature of the soil. It has been ascertained, however, that in our climate, on an average not less than from one-third to three-fourths of the entire quantity of carbon contained in the crops we reap from land of average fertility, or (pretty nearly) the 
amount of charcoal a burnt hay-stack would yield, is really obtained from the air.

The varied and equally important uses of a leaf appear, to the contemplative mind, singularly beautiful.

"In human works, though labored on with pain,

A thousand movements scarce one purpose gain;

In God's, one, single, can its ends produce,

Yet serves to second, too, some other use."?

Then, too, the contrivance of so many expanded leaves! The air contains only one gallon of carbonic acid in every 2500 ; and this fortunately, rather we ought to say design$e d l y$, only in a state of mixture, not of combination, with the elements of the atmosphere, and therefore more easily separable; were the proportion larger, it would prove poisonous to the animals that live in it, deriving also a portion of their nourishment from another element of the atmosphere equally essential to plants. Now, in order to catch this minute quantity of carbonic acid, the tree hangs out thousands of square feet of leaf, in perpetual motion through the ever-moving air ; and thus by the conjoined labors of millions of pores, the substance of whole forests of solid wood is slowly extracted from the fleeting winds. Is not this wonderful! Green stems, and stalks of grasses, absorb carbonic acid as the leaf does; and thus a larger supply is afforled when the growth is most rapid, or when the short life of the annual plant demands much nourishment in a limited time. The slender and comparatively dry leaves of the pine and the cedar perform the same functions as the large and juicy leaves of the fig-tree, the cabbage, the walnut, or the rhubarb plant. That plants derive so large a proportion of their nutriment not from the soil, but from the air, is evident from observing the habitudes of many found in hot climates, which refuse to vegetate except in a soil so dusty that no moisture can be extracted from it, and perish if water be ignorantly supplied to them. A well-known Jamaica shrub was long propagated in our own stoves by cuttings, which though freely watered, could never be made to produce any signs of 
flowers or fruit, notwithstanding that the cuttings were several feet in length every season. By accident, a pot with young cuttings was mislaid and forgotten in the royal garden, and having no water given it, it was thereby reduced to its healthy dryness, and then every extremity was seen to produce a flower. It is an opinion common to many able men of the present day, that many plants derive the whole of their support from the surrounding atmosphere; if this be true of some, it is partially true of all, and must very materially modify all our plans intended to increase the product of the soil. There are, we say, some plants which have no root whatever, as in the prickly-pear or Indian fig ; many are attached only to the hard surface of a stone, and propagate their kinds by off-sets, without any other regetable organs. Now, there are some. quadrupeds that appear to derive nourishment in the same way. The sloth never drinks : it imbibes moisture by its skin, it trembles at the feeling of rain; so the olive cavy, and the ostrich, are noted by the Arabs as avoiding water, and yet these creatures are as juicy and well supplied with fluids as any with which we are acquainted.

If leaves are necessary for the existence of the individual tree, the FLowERs are necessary as generative organs for the continuation of the species. Even in that class of plants where no flowers are distinct, still there is every reason to believe that the production of the seed is effected in the same way as in other plants. Mosses and lichens, which belong to this family, have no distinct roots, but they are furnished with filaments which perform the same functions; and even in mushrooms there is a system for the absorption and exposure of the sap to the air. Of all parts of plants the flowers are most refined, the most beautiful in their structure, and appear as the master-work of nature in the vegetable kingdom. The elegance of their tints, the variety of their forms, the delicacy of their organization, and the adaptation of their parts, are all calculated to awaken our curiosity and excite our admiration. The ancients had observed, that different date-trees bore 
different flowers; and that those trees producing flowers, containing in their centre organs termed by botanists "pistils," bore no fruit unless in the immediate neighborhood of such trees as produced flowers differently arranged in their central structure, and containing "stamens." The great naturalist, Linnæus, has arranged the whole Vegetable Kingdom into twenty-four classes, as deducible from the numbers of these sexual organs in each fower. The numbers of the stamens and pistils in each, their arrangements, or their division, are the circumstances which guided him, and enabled him to form a system of botany admirably adapted to assist the memory, and denoting well the analogies of all the essential parts of plants.

The SEED, the last production of vigorous vegetation, is wonderfully diversified in form. Being that part which is of the highest importance, it is found defended above all other parts of the plant; sometimes by soft pulpy substances, in addition to a hard shell, as in apricots and plums; by thick membranes, as in common garden peas and beans; by hard shells, or a thick coating, as in corn and grasses. So, similarly, the eggs of the ostrich, which are destined to be hatched by the sun in the sand where they are deposited, are invested with a strong shell, not firmer, comparatively, than the encasement surrounding every one of the myriads of ova or eggs in the roe of a codfish or herring. If we were to pursue the analogy more closely still, between the structure of a grain of wheat and that of the egg of a bird or the ovum of a quadruped, we should find the parallelism singularly minute and exact; but this is the province of the physiologist: it is enough for our purpose to cite a familiar illustration. When potatoes are cut in pieces for seed, every gardener knows that, if each separate piece have not an "eye" upon it, the fragment will not grow. If it vegetate, it will be from that living spot or "eye:" the remainder will serve to minister nutriment to the infant plant before it can pierce the soil; it will strike upwards and downwards; the original bit of potato will be absorbed, or 
perish. So, a common garden bean is divisible into two equal halves or lobes, which form the organ of nourishment; but the young plant springs not from these, but from the plume or small white point between their upper parts, and the young root is found like a small curved cone at the other end of the seed. In wheat, and many grasses, the organ of nourishment is not divisible as in a bean; but the same principle holds true not only of all seeds, but of bird eggs, and the rudimentary ova of all animals.

\section{H A P T E R I V.}

Of the Elementary Composition of WATER; of the Composition of the Aturosphere; and of the artificial Application of Water to Grass Lands.

$W_{E}$ have already traced some of the more prominent analogies obviously existing between vegetables regarded as alive, and animals. We have shown that the ultimate, and many of the proximate, elements of both are the same - that they are nourished or destroyed by the same agencies. Before we describe minutely the nature of the process of nutrition and growth, it is necessary to understand the chemical composition of the ATMOSPHERE, which is related similarly to lungs as to leaves; and of WATER, necessary alike to plants as to animals.

If one measure of hydrogen gas, and half as much oxygen gas, or, by weight, eight grains of oxygen gas, and one grain of hydrogen, be mixed in a dry glass over mercury, and the mixture set on fire, the result will be the formation of pure water. So water is formed, and is sometimes seen collected, from the burning of the common carburetted hydrogen, in the street or shop gas-lamps: the effect being nothing more nor less than the combination of the oxygen of the air with the burning hydrngen. Water 
is the result of their union, and combustion, or burning, EFFECTs that union. The gas in the pipes would not, could not, burn, if a free supply of air, or rather of oxygen, contained in that air, were cut off; and water is the ProDUC'T of their union. So that perfectly pure water is, chemically speaking, not a simple undecompounded element, but a compound of two elements-oxygen and hydrogen; both of which, as elements, enter largely into the composition of both animal and vegetable matter. Oil and fat owe their utility in yielding light in lamps to the presence of hydrogen. Its presence causes turpentine and resin to blaze and burn readily; while oxygen is equally an ultimate ingredient in all vegetable and animal substances. These details may appear scientific; but the action of manure is not to be understood without them, or rather, the nature of vegetable and animal growth, and all that favors or retards it.

The purest NaTURAL water we can obtain is procured by melting snow, or collecting rain-water, in stations distant from the smoke of a town. If pure water be requisite for the experiments of a chemist, it is generally obtained by distilling rain-water in glass vessels, - that is, raising it into steam by heat, then allowing that steam to condense, by passing it through cold pipes. The characters of absolutely pure water are-that it is perfectly transparent and colorless, limpid, not sparkling, insipid, unpleasant, and sickly to the taste, and is lighter than common river or spring water. One hundred cubic inches of water weigh $252 \frac{1}{2}$ grains; it is 828 times heavier than air; and when expanded into steam, occupies 1700 times its previous space. Steam is not nearly so heavy as the air. Water readily absorbs many gases: what is called soda-water, is water impregnated with fixed air, or carbonic acid gas. It absorbs ammoniacal gas readily in large quantities, forming what is sold in the shops as spirit of hartshorn.

Of the constitution of SEA WATER, the proportions and nature of its saline ingredients, one of their final uses in vegetation, and especially the relatively large proportion 
of carbonic acid it contains, we will speak, when adverling to the necessity and wisdom of such arrangement.

Neither is the ATnosphere animals breathe and decompose, and in which living plants carry on analogous operations, a simple element. Air is a compound of two gases, oxygen and nitrogen, in the proportion of two parts of nitrogen to one of oxygen. 100 cubic inches of air weigh 30 grains. The atmospheric pressure of the air upon the earth's surface, at the level of the sea, is equal to a weight of 15 pounds upon every square inch, and is capable of supporting a column of water 34 feet high, or of mercury, 30 inches. For this reason, a pump will not work if the depth of the shaft be greater than 34 feet; and the height to which the quicksilver will rise in the weatherglass, always corresponds to the pressure of the atmosphere; that is to say, the weight of the mercury in the tube is exactly equal to the weight of a column of air the same thickness, only the height of the atmosphere. The air receives its heat entirely from the earth: hence the phenomena of cold which we perceive the higher we ascend from the earth's surface.

If water be passed through a red-hot gun-barrel, it will be decomposed; its oxygen will unite with the metal, its hydrogen will escape, and may be collected in the form of a gas, and preserved in a bladder. Many similar experiments demonstrate the composition of water. It may be made, in fact is made, in almost every instance where a combustible body unites with the oxygen of the air: it may be separated into its elements,-unmade, so to speak, by a variety of processes. Synthesis is the term chemists apply to the former, analysis, to the latter mode of demonstrating its composition.

Now, it is most materially important, in connecion with our future inquiries, to observe, that there are other maiters, not essential to the composition either of AIR or WATER, that IN NATURE are always found mechanically mixed up or associated with each, and this as an express provision for the sustenance of animals and plants. 
The atmosphere is not compounded purely of oxygen and nitrogen: it contains carbonic acid and watery vapor.

The proportion of carbonic acid in the atmosphere may be regarded as equal nearly to one part in a thousand, estimated by weight. The quantity varies according to the seasons, but the yearly average remains continually the same.

And the rain that descends from the clouds contains ammonia, one of the elements of which, as previously stated, is nitrogen. Experiments confirm the theory upon which the presence of ammonia in rain-water might reasonably be expected. If a few hundred pounds of rainwater be carefully subjected to distillation, and the first two or three pounds evaporated, with the addition of a little muriatic acid, a very distinct crystallization of muriate of ammonia, or sal anmoniac, may be obtained, which crystals have a brownish-yellow color. If a little sulphuric or muriatic acid be added to a quantity of rainwater, and the mixture boiled to dryness, the ammonia remains as the residue, in combination with the acid employed; and it may be detected by the addition of a little powdered lime, which, combining with the acid, sets the ammonia free, and is recognized by its pungent smell. The sensation which is perceived upon moistening the hand with rain-water, so different from that produced by washing it in pure distilled water, and to which the term softness is applied, is owing to the presence of carbonate of ammonia in rain water.

How this ammonia is generated in rain-water, the importance and utility of the fact, and the uses of carbonic acid in the atmosphere, are matters so closely identified with living processes in anirnals and plants, that we must here simply confine ourselves to the statement. We have now the preliminary materials for the examination of nutritive actions. When these, as they exist naturally, are understood, we shall be able to say what are those substances called FERTILIzING, which may be useful in given instances as manure, whether their application may be 
suitable or injurious; just as a knowledge of anatomy and physiology is necessary to the physician who would amend the diseased conditions of the body. He must know what is the nature of healthy and ordinary action in the living frame, before he can understand and alter diseased action.

The artificial application of water in large quantities to the land, is a subject well understood, and its effects accurately marked and recognized in many parts of the world that have been regarded as strictly agricultural localities during a long succession of ages. Irrigation is, in truth, a mode of applying the weakest of liquid manures, on a very bold scale, to grass-lands. Almost every farmer has a mode of accounting for the highly-fertilizing effects of irrigation. Davy added another to the list of explanations. He thought that a winter-flooding protected the grass from the injurious effects of the frost. He examined, with a thermometer, and with his usual address, the water-meadows near Hungerford, in Berkshire, and ascertained that the temperature of the soil was ten degrees higher than the surface of the water, and that, too, on a frosty March morning. He remarked, also, a fact that most farmers will confirm, that those waters which breed the best fish are ever the best fitted for watering meadows. He appears, however, never to have steadily investigated the chemical composition of river-water with regard to its uses in irrigation; and in consequence, he knew little of the value of some of its impurities to vegetation. Thus, if the river-water contains gypsum (sulphate of lime), which it certainly does if the water is hard, it must, under ordinary circumstances, on this account alone, be highly fertilizing to mearlows, since the grasses contain this salt in very sensible proportions. Calculating that one part of sulphate of lime is contained in every two thousand parts of the river-water, and that every square yard of dry meadow-soil absorbs only eight gallons of water, then it will be found, that by every flooding, more than one hundred weight and a half of gypsum per acre is diffused through the soil in the water; a quantity equal to that generally adopted by those who spread gypsum on their clover, lucern, and sainfoin crops 
as a manure, either in a state of powder, or as it exists in peat-ashes.

And, if we apply the same calculation to the organic substances ever more or less contained in flood waters, and if we allow only 25 parts of animal and regetable remains to be present in a thousand parts of river-water, then we shall find, taking the same data, that every soaking with such water will add to the meadow nearly two tons per acre of animal and vegetable matters; which, allowing in the case of water meadows five floodings per annum, is equal to a yearly application of ten tons of organic matter. The quantity of foreign substances present in river-water, although commonly less, yet very often exceeds the proportion we have calculated to exist.*

- As the introduction of water meadows would be of inestimable value to our country, we here give an extract from Vol. I. of the American Agriculturist on this subject :-

"All who have ever heard of the overflowings of the Nile, or passed up the magnificent valley of the Connecticut, along the banks of the Genesee, and the wide-spread delta of the Mississippi, and hundreds of others of our rivers, cannot but have noticed the surprising fertility given to the land, in consequence of the annual rise of their waters, and the deposite from the enriching sediment; it is to avail themselves of something like the advantages of these great overflowings, on a small scale, from their own little rivers, that the English landholders have constructed their water meadows, and in some instances have gone to a very great expense in so doing. It is computed that there are at least 70,000 acres of water meadows in Gloucestershire, Berks, Wilts and Hants, which have been made at an expense of from $5 l$. to $45 l$. per acre, the average not being less perhaps than $15 l$. or say $\$ 75$ per acre. Johnson asserts, that in 1821 forty acres of the Freegate Whins, ten of which were made from a poor sandy soil, thrown up by the sea in the vicinity of Edinburgh, cost $1000 l$., and let for about $600 l$. per annum, and are in a constant state of improvement. The Craigintinny meadows, near the same place, let for $20 l$. to $30 l$. per acre per annum, while "in 1826, part of the Earl of Moray's meadow fetched $57 l$. (\$275) per acre per annum." But it must be recollected that these are in the vicinity of a large town, where the grass is cut daily, and carried in fresh, and retailed at high prices for soiling. In no other way could these meadows command such exorbitant rents. They yield four to five crops of grass every season, which, if dried, it is estimated would nearly equal two tons in weight at each cutting. But the water used here for overflowing is unusually rich, it receiving the wash of all the sewers of this large town, and hence their greatly increased fertilizing effects."--AM. ED. 
There is no stream more celebrated for its prolific water meadows than the Itchen in Hampshire; and in no part of England is the system of irrigation better understood and more zealously followed. The water of this river, taken from above the city of Winchester, contains in 10,000 parts, after all its mechanically suspended matters bave subsided, about 2.2-3d parts, namely-

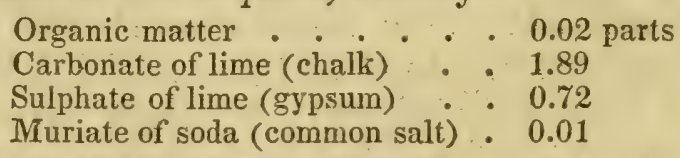

The water of lakes is usually still more surcharged with foreign substances than those of rivers; and, from the use of such waters, especially if an occasional or winter stream of water passes through them, we have witnessed great fertilizing effects produced on meadow land.

\section{H A P T E R V:}

Of the Nature of Vegetable Growth; the true use of Vegetable Mould or Humus; and of the Sources of the Elementary Constituents of Plants.

From the facts detailed in the foregoing chapters, the development or nutrition and growth of a plant requires the presence, first, of substances yielding carbon and nitrogen as elements to the growing structure; secondly, of water, furnishing in itself two very important elements, namely, oxygen and hydrogen, besides adventitious matters; and lastly, a soil, to yield the saline, earthy, metallic, or other inorganic materials essential to vegetable life.

The fertility of every soil is generally supposed to depend on the presence in it of a peculiar substance, named " $h u$ mus." This substance, incorrectly supposed to form the principal nutriment of plants, and to be extracted from them by the soil in which they grow, is nothing more than vegetable mould, the product of the decay of other plants. 
Adherence to the above incorrect opinion, has hitherto rendered it impossible for the true theory of the nutritive process in vegetables to become known, and has thus deprived us of our best guide to a rational practice in agriculture. Any great improvement in that most important of all arts, is inconceivable without a deeper and more perfect acquaintance with the substances which really nourish plants, and with the sources whence they are derived. It was supposed that by the aid of water "humus" is renderel capable of being absorbed by the roots of plants. If it be, it must be in some altered form; for if a portion of good mould be long subjected to the action of water, that fluid will not dissolve more than a hundred-thousandth part of its weight, and contain only soluble organic matters, and the salts which are contained in the rain-water which has fallen upon it. Decayed oak wood, beech, and fir, yield the same results.

Let us inquire whence the grass in a meadow, or the wood in a forest, receives the carbon essential to the formation of that WOODY FIBRE constituting the principal weight and solid bulk of the tree or plant. Whole tracts of open country in the green wilds of America, immense woods and forests in all parts of the world, receive no carbon in the form of manure; how does it happen that the soil, instead of being exhausted through the annual production of regetation for ages, becomes every year richer in carbon? In other words, a certain quantity of carbon is taken every year from an unmanured forest or meadow, in the form of growing wood or grasses; and in spite of this, the quantity of carbon in the soil augments; it becomes richer in vegetable mould, in humus-so much so, that in process of time it will not support the trees which stood upon it: they fall, and the surface becomes a peat moss, burying huge trunks in its bosom.* Plants

* This is a great mistake on the part of the author in regard to American forests. We scarcely know of a single instance of their becoming a peat moss; on the contrary, they almost universally retain their original character.-AMER. ED. 
give back more carbon to the soil than they take from it; it is evident, then, that their growth must depend on the reception of carbon as food from another quarter. It is not denied that manure, rightly chosen and applied, exerts an influence upon the growth of plants; but it neither serves for the production of the carbonaceous woody fibre, nor has any influence upon it, because we find that the quantity of carbon produced by manured land is not greater than that yielded by lands which are not manured. The discussion as to what manure really produces, has nothing to do with the present question, which is, the origin of the carbon as the principal element of the woody fibre. It must be derived from other sources; and as the soil does not yield it, we are driven to look for it in the atmosphere.

Now, we have already stated that the air contains carbonic acid; and if the reason of its presence there be not, that it may yield carbon to plants, what other use can be assigned to it? Animals do not derive their chief sustenance from the air : to them pure and unmixed carbonic acid is poisonous; though taken into the stomach it is grateful. Besides, we know it to be a fact, that during the sunshine of day the leaves of plants are continually absorbing this very gas, and giving out oxygen; and if not for their nutrition and growth, for what other purpose? Carbonic acid being a compound of carbon and oxygen, they retain the carbon and give out the oxygen. This has been long known; but it is only a recent discovery, that the sole source of woody fibre is the atmosphere.

Mould, or humus, can only arise from the decay of plants. No primitive mould can have existed; for plants must have preceded the mould, which this theory assumes as necessary to their existence. Whence, then, did the first vegetables derive their carbon, if not, as now, from the surrounding air? We shall arrive at satisfactory conclusions respecting the mode in which animal, as well as vegetable, life and nutrition are maintained, by observing how the uninterrupted uniformity of proportion is secured in the quantities of the elements composing the atmosphere. 
How does it happen that, with such an immense expenditure of oxygen as occurs in the combustion of countless millions of tons of coal, and in the consumption of that gas in the lungs of the myriads of creatures that live on the earth's surface, still the composition of the atmosphere is invariably the same?

The answer to this question depends upon another. What becomes of the carbonic acid which is produced by the breathing of animals, and in every instance where a combustible body is burnt? There is no change of volume; for the oxygen extracted from the atmosphere by a coal fire is replaced by the same bulk of carbonic acid, and similarly in every breath we draw. The immense masses of carbonic acid which flow into the atmosphere from so many causes ought perceptibly, after 6000 years, to increase its quantity.

A cause must exist which prevents the increase of carbonic acid, by removing that which is continually forming; and there must be some means of replacing the oxygen which is removed from the air by combustion, breathing, and putrefaction.

Both these causes are united and displayed in the process of vegetable as well as of animal life. The facts we have already stated prove that the woody fibre, or carbon of plants, must be derived exclusively from the atmosphere. Now carbon exists in the air only in the form of carbonic acid, and, therefore, in a state of combination with oxygen.

Besides, as already stated, carbon and the elements of water form the principal constituents of vegetables. Now, the proportion of oxygen in the whole mass of a plant is less than in carbonic acid. It is, therefore, certain that plants must possess the power of decomposing carbonic acid, since they appropriate the carbon for their own use. The formation of woody fibre, gum, starch, and the various substances containing carbon-that taken together compose a plant-must necessarily be attended with the separation of the carbon of the carbonic acid in the air from the oxygen of that acid. This oxygen is returned to the 
atmosphere, as experiment and observation prove, though its source is only just understood. And the carbon enters into composition with water, or its elements in the plant. The atmosphere must thus receive a volume of oxygen for every volume of carbonic acid which has been abstracted from it and decomposed. The leaves and green parts of a plant emit an equal quantity of oxygen in exchange for the carbonic acid they absorb, and they will do this even when torn from the stem on which they were just growing. Each acre of land which produces eight hundred weight of carbon (say woody fibre) gives annually to the atmosphere about two thousand six hundred pounds of free oxygen gas; so that an acre of meadow, wood, or cultivated land, replaces, therefore, in the atmosphere as much oxygen as is exhausted by eight hundred weight of carbon, either in its ordinary destruction by burning, or in the action of the lungs of animals.

Plants not only separate all noxious matters from the air,-they form, by this arrangement, an inexhaustible source of pure oxygen to supply that loss the air is constantly sustaining. Animals, on the other hand, throw off carbon from their lungs, which plants take in by their leaves; and thus the composition, or the relative proportions of the elements forming that medium in which they both exist, is maintained constantly unchanged.

Many conditions are necessary for the life and growth of plants. Each kind requires special conditions; and should but one of these be wanting, although all the rest be supplied, the plants will not be brought to maturity. It is in vegetable as in animal life: a mother crams her child exclusively with arrow-root; it becomes fat, it is true; but alas! it is ricketty, and gets its teeth very slowly and with difficulty. Mamma is ignorant, or never thinks that her offspring cannot make bone, or what is the same thing, phosphate of lime, the principal bulk of bone, out of starch. It does its best; and were it not for a little milk and bread, perhaps now and then a little meat and soup, it would have no bones and no teeth at all. Farmers 
keep poultry; and what is true of fowls, is true of a cabbage, a turnip, or an ear of wheat. If we mix with the food of fowls a sufficient quantity of egg-shells, or chalk, which they eat greedily, they will lay many more eggs than before. A well-fed fowl is disposed to lay a vast number of eggs; but cannot do so without the materials for the shells, however nourishing in other respects her food may be. A fowl, with the best will in the world, not finding any lime in the soil, nor mortar from walls, nor calcareous matter in her food, is incapacitated from laying any eggs at all. Let farmers lay such facts as these, which are matter of common observation, to heart, and transfer the analogy, as they justly may do, to the habits of plants, which are as truly alive, and answer as closely to evil or judicious treatment as their own horses. The organs of plants, like those of animals, contain substances of the most different kinds. Some are formed solely of carbon and the elements of water : as, for instance, woody fibre, resin, gum, and starch; some contain nitrogen: as, for instance, the gluten of wheat; and in all plants we find metals in a state of combination with oxygen. The food which can serve for the production or increase of any, or of all the organs of a plant, must necessarily contain the elements of that part, or set of parts. Dogs die although fed with jelly, which contains nitrogen in abundance: they cannot live upon white bread, sugar, or starch, if these are given as food to the exclusion of other substances. Can it be concluded from this, that these things contain no elements suited for nutrition? Certainly not.

Because a regetable is alive, it has the power of constantly reproducing itself ; for this it requires a supply of substances which contain the constituent elements of its own substance, and which are susceptible of undergoing the necessary transformation. All the organs together, whether of animal or vegetable life, have not the power to generate, that is, to produce out of nothing a single element. A dog would die in the vacuum of an air-pump, even though supplied with a superabundance of food ; it 
will die in the air if no food be given to it; it will die in oxygen gas, however freely it may be supplied with nourishment. But it is not hence to be concluded, that neither flesh, nor air, nor oxygen, is fitted to support life. They are all admirably calculated to do so ; so it is just as reasonable to expect to bring a plant to perfection,-wheat, for instance, - which, in its healthy and natural state, contains silica or potash, if it be planted in a soil destitute of such inorganic materials, or to which they have not been added. When we are acquainted with the nature of a single cubic inch of that soil, and know the composition of air and rain-water, we are in possession of all the conditions necessary to their life. The source of the different elements entering into the composition of plants, cannot possibly escape us, if we know in what form they take up their nourishment, and compare its composition with that of the vegetable substances which compose their structure.

Vegetables undergo, after death, two processes of decomposition : one of these is fermentation, the other is putrefaction. Decaying leaves, stalks, or roots, are, in fact, undergoing a slow process, analogous to combustion; inasmuch as it is the combination of the combustible parts of a plant (structures that will burn) with the oxygen of the atmosphere.

The decay of woody fibre (the principal constituent of all plants) is accompanied by appearances of a peculiar kind. This substance, in contact with air or oxygen gas, and no longer preserved from chemical decomposition by the living principle which has now left it, unites with that gas, and the product is an equal volume of carbonic acid. The property which woody fibre in a state of decay has to form carbonic acid with the surrounding oxygen of the atmosphere, diminishes as the decay advances, till it is complete, and ceases. Mould constitutes the principal part of brown coal and peat. An atmosphere of carbonic acid, formed at the expense of the oxygen of the air, surrounds every particle of decaying vegetable matter; hence the value of plowing, digging, and otherwise loos- 
ening the soil: it permits the access of air. An atmosphere of carbonic acid is therefore contained in every fertile soil, and is the first and most important food for the young plants before they reach the surface. The leares of trees which fall in the forest in autumn, and old roots of grass in a meadow, are converted into what is termed humus by the same agency; but humus does not nourish plants directly, by being taken up in its unaltered state, but by presenting a slow and lasting source of carbonic acid, which is absorbed by the roots of plants, and forms their principal nutriment at a time when, being destitute of leaves, they cannot, as yet, extract food from the atmosphere: hence one reason of the value of plowing; digging, and otherwise lightening the soil, by permitting the access of air, and, consequently, of carbonic acid to the seeds and roots. Seeds should always be sown, so as to be fully exposed to the influence of the air; and one cause of the unproductiveness of cold, clayey, adhesive soils is, that the seed is coated with matter which the air cannot get at. In sandy soils, the earth is mostly sufficiently penetrable by the atmosphere; but in clayey soils, there can scarcely be too great a mechanical tearing up and division, in the process of tillage. Many plowmen know the fact, without knowing the reason of it : however, any seed not fully supplied with air, always produces a weak and diseased plant. In this way, then, we see the true uses of the vegetable decaying mould, when well torn up by the plow. The roots perform the after-functions of the leaves: they extract from the soil the carbonic acid generated from the humus, or vegetable mould: they decompose that acid, and absorb the carbon. When a plant is quite matured, and when the organs by which it obtains food from the air are fully formed, the carbonic acid of the soil is no longer required.

If turnips be sown in a soil capable of yielding as much nourishment as they will take up, they will attain a much larger size than under the reverse circumstances. The size of a plant is always proportioned to the SURFACE of 
the organs which are destined to convey food to it. A plant gains another mouth and stomach with every new fibre of root, and every new leaf.

Let us suppose a plant fully grown. All the necessary amount of woody fibre has been formed by the leaves. But the action of the leaf does not cease. Carbon is still absorbed; the expenditure of nutriment, the supply of which continues the same, takes a new direction. The leaves now produce sugar, starch, gum, or acids, which were previously formed by the ronts when these substances were necessary for the development of the stem, buds, leaves, and branches of the rising plant. The direction of the nutriment again changes, and blossnms are produced. The functions of most plants cease upon the ripening of their fruit, because the products of their action are no longer needed. They now yield to the chemical influence of the oxygen of the air: their feeble vitality weakly opposes the decomposition which awaits all dead matter; they change color, fall off, and become converted into the mould of which we have been-speaking.

A cubic inch of sulphuretted hydrogen gas introduced into the human lungs would cause insiant death; but it is often formed, under a variety of circumstances, in the bowels without injurious effects. Each organ, whether of an animal or a regetable, extracts from the food presented to it what it requires for its own action and sustenance; while the remaining absorbed matters, which are not nutritive, combine together, and are separated as excrement. The excrementitious matters of one organ come in contact with another during their passage through the plant or animal, and, in consequence, suffer new transformations: the useless matters rejected by one organ contain the elements for the nourishment of another, till what is utterly useless is expelled from the system, by contrivances for that purpose. So the kidneys, liver, and lungs, are organs of excretion: the first separate from the body substances in which a large proportion of nitrogen is contained; the second, those with an excess of carbon; and 
the third, such as are composed, principally, of more oxyger and hydrogen than is wanted. All superabundant nitrogen is thrown out from the body as a LiQuid excrement through the urinary passages : all solid substances, incapable of further useful transformation, pass out by the intestinal canal; and all gaseous matters by the lungs.

The presence of life prerents common chemical decomposition or putrefaction : the power to effect the transformations essential to nutrition and growth does not belong to it. Each such transformation is owing to a disturbance in the attraction of the elements of a given compound, and is, consequently, a purely chemical process. Similar changes of existing compounds are in constant progress during the whole life of a plant; in consequence of which there are produced gaseous matters, thrown off by the leaves and blossoms, solid excrements deposited in the bark, and fluid soluble substances which are excreted by the roots. Through the expulsion of these matters unfitted for nutrition, the soil receives back again the greatest part of the carbon, which it had at first yielded to the young plants as foor in the shape of carbonic acid, from the decaying mould.

Having disposed of the question as to the origin of carbon in plants, and examined the relation between vegetable mould and the springing vegetable, we must next trace the source of the hydrogen and nitrogen they contain.

All the hydrogen necessary for the formation of a plant or animal is supplied by the decomposition of water. From their generating wax, fats, and volatile oils, containing hydrogen in large quantity, and no oxygen, we may be certain that plants possess the property of decomposing water; because from no other body, with which they are placed in contact, could they obtain the hydrogen which exists as an element in those matters. The process of vegetable growth, in its simplest form, consists in the extraction of hydrogen from water, and carbon from carbonic acid. The green resinous principle of the leaf 
diminishes in quantity while oxygen is absorbed. We can explain in a similar manner, the formation of all the component substances of plants which contain no nitrogen. During the progress of growth, plants appropriate carbon from the carbonic acid found in the air, and hydrogen from the decomposition of water; the oxygen of which fluid is set at liberty, together with a part, or all of that contained in the carbonic acid. Decay, then, or vegetable putrefaction, is that great operation of Nature by which that oxygen which was consumed by plants during life is again returned to the atmosphere; for water is essential to such putrefaction.

As to the origin of nitrogen in plants, we may observe, that it exists in every part of the regetable structure. No plant would attain maturity, even in the richest vegetable mould, unless nitrogen were supplied to it. How, it may be asked then, and in what form, does Nature furnish nitrogen to assist in the formation of regetable albumen and gluten, to fruits and seeds?

This question is susceptible of a very simple solution. Plants, as we know, grow perfectly well in pure charcoal, if supplied at the same time-not with river or spring, or perfectly pure water, but with rain-water. Now, rainwater can contain nitrogen only in two forms-either as dissolved atmospheric air (which, of course, contains nitrogen), or as AMNONIA, of which nitrogen is one element. We have obserred, in speaking of the composition of water, that rain-water is found to contain ammonia; and this is the practical application of the fact. Pure air may, for our present purpose, be considered as oxygen and nitrogen in certain unalterable proportions, in a state of mixture; the carbonic acid and ammonia which foat in the atmosphere may be regarded as accidental ingredients. If we were to suppose that plants derived their nitrogen directly from the atmosphere,- that is, by depriving the air of a portion of that nitrogen which is essential to its constitution-we are met by many difficulties. Rain-water does not yield nitrogen from pure air, which it may 
hold in solution or suspension, but from ammonia, which, rising from putrefied animal remains, becomes readily dissolved in the first mass of watery vapor that may present itself. We have no reason to believe that the nitrogen of the air takes part in the processes of nutrition in plants and animals; on the contrary, we know that many vegetables emit, or give off the nitrogen which is absorbed by their roots. But, on the other hand, there are numerous facts, showing that the formation in plants of substances containing nitrogen, as gluten, for instance, in corn, takes place in proportion to the quantity of this element, which is conveyed то THEIR ROOTS in the state of soluble salts of ammonia, derived from the putrefaction of animal matter.

All animal bodies, during their decay, yield the nitrogen, which they abundantly contain, to the atmosphere in the form of ammonia. A generation of a thousand millions of human beings is renewed every thirty years: countless millions of animals have, during that period, ceased to live. Where, but floating in the atmosphere, is the nitrogen their bodies contained during life ? Without the occurrence of putridity and the generation of ammonia, and its diffusion in the dir, the wheels of nature would soon stop-vegetable and animal life could go on no longer. Ammonia is the simplest of all the compounds of nitrogen : the reader will remember our previous statement, that hydrogen and nitrogen combine to form ammonia. Hydrogen is that element for which nitrogen possesses the most powerful affinity.

The nitrogen, then, of putrefier animals is contained in the atmosphere (combined with hydrogen) as ammonia, in the form of a gas which is capable of entering into combination with carbonic acid, and of forming a volatile salt very soluble in water. Ammonia, therefore, cannot remain long in the air, as every shower of rain must dissolve it and convey it to the earth's surface, to be absorbed and decomposed by the roots of plants. We ought to expect, and such is the fact, that rain-water must at all times 
contain ammonia, though not always in equal quantity. If a pint of rain-water contain only a quarter of a grain of ammonia, then a field of forty thousand square feet must receive yearly upwards of eighty pounds of ammonia, or sixty-five pounds of nitrogen; for it is ascertained that the annual fall of rain water over this extent of surface is at least 2,500,000 pounds. This is much more nitrogen than is contained in the fnrm of vegetable alburnen and gluten in 2650 pounds of wood, 2500 pounds of hay, or 200 cwt. of beet-root, which would be the yearly produce of such a field; but it is less than the straw, roots, and grain of corn which might grow on the same surface would contain. Animal manure, as we shall presently show, acts only by the formation of ammonia. Its employment in the cultivation of grain, and of fodder for cattle, furnishes convincing proof that the nitrogen of vegetables is derived from ammonia. The quantity of gluten in wheat, rye, and barley, is very different; and they contain nitrogen in varying proportions. Even in samples of the same seed the quantity varies; and why? Evidently because one variety has been better fed with its own appropriate fertilizer, than another which has been reared on a soil less accurately alapted by artificial means for its growth. French wheat contains 12 per cent. of gluten; Bavarian, 24 per cent. Sir H. Davy obtained 19 per cent. from winter, and 24 from summer wheat; from Sicilian 21, from Barbary wheat 19 per cent. Such Great differences MUST BE OWING TO SOME CAUSE, AND THIS WE FIND IN THE DifFERENT METHODS OF CULTIVATION. An increase of animal manure gives rise not only to an increase in the number of seeds, but also to a remarkable difference in the proportion of gluten which those seeds contain. Among manures of animal origin there is great diversity. Cow dung contains but a small proportion of nitrogen. One hundred parts of wheat, grown on a soil to which this material was applied, afforded unly 11 parts of gluten, and 64 of starch ; while the same quantity of wheat, grown on a soil fertilized with human urine, yielded 35 per cent. of 
gluten, and of course a smaller proportion of less valuable ingredients. During the putrefaction of urine, ammoniacal salts are formed in large quantity, it may be said, exclusively: for under the influence of warmth and moisture, urea, the most prominent ingredient of urine, is converted into carbonate of ammonia. Putrid urine is employed in Flanders as a manure with the best results. The barren soil on the coast of Peru is rendered fertile by means of a manure called guano, which is collected from several islands in the South Sea. It forms a layer several feet in thickness upon the surface of these islands, and consists of the putrid excrements of innumerable sea-fowl that remain on them during the breeding season. This substance has recently been imported in large quantities into England; and its fertilizing powers are very extraordinary. Its price, about $£ 18(\$ 90)$ per ton, is a serious objection; and since the nitrogen it contains forms its principal recommendation, doubtlessly other matters nearer home will not be wasted, or their value unknown and disregarded, as to a great extent they have been. As to the practical results of the application of guano, an intelligent agriculturist in the neighborhood of Hamburg has forwarded the annexed remarks to the Editor of the Gardener's Chronicle. He observes that "Most of the experiments with guano in the vicinity of this city have been made on meadows and lawns. On these it has produced the best possible effects; so that, for instance, at Flottbeck, the patches manured with guano presented not only a finer and darker green, but the grass was closer and more rich; so that, comparing it with patches not guanised, the produce of the former may, without exaggeration, be stated to be double. To give an idea of the extraordinary forcing qualities of guano, we may mention that at Flottbeck, on a plot of grass managed after the English fashion, the second cutting of the grass was necessarily five days after the first, while the grass growing close by (which had not been guanised), although healthy and vigorous, required double the time to arrive at the same state of progress. It deserves to be stated as some- 
thing remarkable, that, n the guanised spot, the dew appeared in the morning much stronger on the tops of the leaves, than on the part unguanised. In an experiment made by M. Staudinger on a barren hill, composed of granite or quartz, the guanised spot exhibited a dark bluish green sward, while round about nothing but barrenness was to be seen. If, therefore, a land-owner wishes to cover bleak hungry pasture in a short time with nutritious grass for cattle or sheep, the guano certainly is the thing to do it. It would not only produce a plentiful fodder in the autumn, where cattle can be well nourished and prepared for the winter, but such guanised pasture will bring a heavy crop early in the spring. Guano has also been used advantageously on a sour meadow, overgrown with horsetails; and it produced, instead of reeds and bullrushes, a dense turf of sweet grass, and the horsetail alınost disappeared. Thus, in the first place, more grass is obtained, which may be put down as double the former crops; and then the grass is very much improved in quality. Of course good drainage must be attended to on each meadow, if the result is expected to be complete. In using guano we must be careful to pulverise it well; because, on account of its tenacity, it will form into lumps, and on places where it lies too thick, it will burn the grass, although, subsequently, even on such places a luxuriant herbage will spring up. Experiments with guano on spring crops have been as successful at Flottbeck, with both wheat and rye, as on the above meadow. The wheat manured in the spring with guano is much superior to that manured in the ordinary way, both in grain and straw. The following experiment was tried on a spot of almost blowing sand:- ' On the 18th March, several square rods in the above locality, planted with winter rye, were strewed with guano. The spot thus manured was in a short time not only conspicuous for its dark green color, but the tiller became so luxuriant as to cover the whole surface. Notwithstanding a drought of two months, the guanised crops remained in the same flourishing condition; whilst the 
other rye standing close by had a weak and sickly appearance. Subsequently the former attained the height of five or six feet, with ears five inches long, with strong plump grain; whilst the latter were scarcely half that height in straw, and their ears were barren and empty.' This experiment speaks in favor of guano in preference to other manure in another respect. If a light sandy soil like the above is manured too much with common dung, and if there follows a luxuriant vegetation, with dark green foliage, we may be sure that, if there be subsequently any long drought, or sudden change of temperature from great heat to intense cold, rust will follow as a matter of course ; whilst in the above experiment, notwithstanding a nineweeks' drought, and some intervening night frosts, the growth of the guanised rye was uniformly good up to the ripening of grain - a sufficient proof that the guano must possess the property of attracting and retaining the fine vapor contained in the air. Hence the fact is to be explained why dew was more apparent on the guanised turf than on that not subjected to that process. As we know that in general, during long drought, the action of dung-in fact of every manure-ceases; and as it is light sandy soil which first suffers from drought, it must be evident what valuable manure guano is, not only on pastures, but for winter rye, our chief crop on light land. If an acre of land is dressed with 125 lbs. of guano, an abundant crop of grain and straw will fully repay the expenses incurred. If such a rye-field is laid down in spring with meadow catstail grass (Phleum pratense) and white clover, a heavy grass crop in the autumn would still increase the advantages already mentioned. As rape can by no means be too luxuriant, guano would produce an extraordinary result on it."

If a soil consist only of sand and clay, and be deficient of organic matter or the decaying remnants of animal or vegetable life, it is sufficient, and chemically correct, to add to it guano, in order to ensure a plentiful crop. Guano consists of ammonia in separate combination with uric, 
phosphoric, oxalic, and carbonic acids, together with a few earthy salts and some impurities. If guano be the fertilizer employed, it is valuable, chiefly from the ammonia it contains, and ammonia is valuable because one of its elements is nitrogen, which is yielded to the plants. Ammonia assists not only in the formation of gluten in wheat, but also in the production of vegetable albumen, one of the principal constituents of plants, and it is ammonia which forms the red and blue coloring of flowers. Nitrates, that is, earthy or metallic substances, combined with nitric acid (which nitric acid is itself a compound of nitrogen and oxygen), are necessary constituents of several plants which thrive only when ammonia is present,--hence the value of nitrate of soda. The influence of the rays of the sun is to effect the disengagement of oxygen from the stem and leaves of plants (as previously stated), which oxygen, seizing upon the nitrogen contained in ammnniacal matters, forms nitric acid, found in union with certain bases in many vegetables. In this way ammonia, by its transformation, furnishes nitric acid to the tobacco plant, that is, if it be found growing in a soil completely free from nitre or saltpetre, which is not nitrate of soda, but, in chemical language, nitrate of potass. The urine of man and of animals living upon flesh contains a large quantity of nitrogen, partly in the form of phosphates, partly as urea, a substance naturally peculiar to urine. Urea is transformed by the putrefactive process into carbonate of ammonia; that is to say, it trkes the form of the identical salt which is always present in rain-water. Human urine is the most powerful manure for all vegetables which contain nitrogen; that of horses and horned cattle contains less of this element, but infinitely more than the solid excrements of these animals.

In the face of such facts as these, is it not pitiable to observe how the urine of the stable or cow-shed is often permitted to run off, to sink uselessly into the earth, or to form a pool in the middle of a farm-yard, from which, as it putrefies, the ammonia formed in it is rapidly and com- 
pletely escaping into the atmosphere, to be of as great utility in that volatile form to a neighbor's acres as to those nearer home?

It should be the care of the farmer so to employ all the substances containing nitrogen which his farm affords in the shape of animal excrements, that they shall serve as nutriment to his own fields. This will not be the case, unless they are properly preserved and distributed over the soil. A heap of manure lying unemployed would serve him no more than other people, if the nitrogen it contains be allowed to form ammonia, by combining with hydrogen. All animal matters emit carbonic acid and ammonia as long as any nitrogen remains in them. The residue is a nearly worthless carbonaceous mass. All animal excrements emit carbonic acid and ammonia as long as nitrogen exists in them. In every stage of their putrefaction an escape of ammonia from them may be induced by moistening them with pearl-ashes dissolved in water, the ammonia being apparent to the senses by its pungent effect on the nostrils. This ammonia, evolved from manure, is imbibed by the soil either in solution in water, or in the form of gas; and thus it is that plants may artificially be made to receive a larger supply of nitrogen than is naturally afforded to them by the surrounding atmosphere. Cultivated plants receive, of course, the same quantity of nitrogen from the air as trees, shrubs, and wild plants; but this, of course, is not enough for the purposes of agricultuie; cabbages, wheat, potatoes, and apples being very different things in their wild, or, more properly, their natural state. The object of forest culture is, the production of carbon or woody fibre; of garden or field culture, chiefly the addition of as much nitrogen as the plant can ke made to take up.

The solid excrements of animals do not contain as much nitrogen as those which are voided in a liquid form; and, for this reason, do not constitute so powerful a fertilizing material. This could not be otherwise. The quantity of food which animals take diminishes or increases in pro- 
portion as it contains more or less of the substances containing nitrogen. The bowels of the cow are relatively much longer than those of the tiger; the bulk of food consumed by the former animal is greater, and it requires to be retained longer, to traverse a greater extent of surface, before it can yield all its nutriment, than occurs in animals feeding on flesh which contains so much nitrogen. A horse may be kept alive upon potatoes, which contain very little nitrogen; but life thus supported is gradual starvation. So the quantity of rice which an inhabitant of the East Indies will eat astonishes an Englishman; but the fact that rice contains less nitrogen than any other kind of grain, at once explains the circumstance. In hot countries human beings live sparingly on vegetables which contain little of this principle; in very cold countries, human beings require very fat substances, in order to support existence, and to enable them to generate as much animal heat as is necessary. The Esquimaux will devour amazing quantities of whale's blubber, and would speedily die (in that climate) without a free supply of food containing large quantities of nitrogen. Hence vegetation is scanty --for food it is scarcely necessary : they live upon fish, or animals caught in the chase. In tropical climates, on the contrary, where animal food is not so necessary, a luxuriant vegetation is provided to satisfy the natural wants of man.

By means of manure an addition only is made to the nourishment supplied from the air ; for the excrements of all animals contain less nitrogen than their food, and consequently a smaller quantity of matter containing nitrogen is given to the soil than has been abstracted in the form of grass, hay, or seeds.

Another reason why liquid excrements containing ammonia (or that which, by further spontaneous chemical action, yields ammonia, and consequently nitrogen) are more useful than solid excrements, is to be found in the fact, that the former contain the greatest part of their ammonia in the state of salts: in a form, therefore, in 
which it has lost its volatility when presented in this condition, not the smallest quantity of ammonia, in such a shape, is lost to the plants -it is all dissolved by water and imbibed by their roots. Practical farmers see the results: they know that plaster of Paris or gypsum, the insoluble sulphate of lime, strikingly increases the luxuriance of meadow-grass upon which it is strewed. But why? Because it fixes in the soil all the ammonia of the atmosphere, which would otherwise be partially volatilized with the water that constantly evaporates from the surface of the soil. The sulphuric acid of the sulphate of lime has a stronger affinity for ammonia than it has for lime; so sulphate of ammonia is formed, which is not volatile, does not escape into a neighbor's pastures. In such an instance, the carbonate of ammonia naturally contained in rainwater is decomposed by the gypsum, in precisely the same manner as occurs in the manufacture of sal-ammoniac. Soluble (but not volatile) sulphate of ammonia, and carbonate of lime or chalk, are formed by double decomposition; so that the beneficial effects of gypsum as a manure are not direct, but indirect, by fixing the ammonia either of rain-water or of manure with which it may have been mixed, and thus presenting that ammonia, or its valuable element nitrogen, to the roots of plants in a form susceptible of absorption. All the gypsum gradually disappears, but its action upon the carbonate of ammonia continues as long as a trace of it exists.

It is quite evident, therefore, that science alone can truly explain the mode in which certain matters exert their beneficial agency; and, consequently, science alone can rationally direct the practical farmer. All else beside is mere experiment-hazardous, expensive, and conjectural.

In order to form an idea of the effect of gypsum, it may be sufficient to remark, that 100 pounds of burnt gypsum $f i x$ as much ammonia in the soil as 6,250 pounds of horse's urine would yield to it. The decomposition of gypsum does not take place instantameously; it proceeds very gradually, and this explains why the action of gyp13 
sum lasts for several years; the supply of armmonia from the air, of course, remaining steady and unfailing.

All rust of iron (or iron in combination with oxygen) contains a certain quantity of ammonia : the advantage of manuring fields with burned clay depends upon the presence of oxide of iron. Now, all minerals containing alumina, or oxide of iron, possess, in a remarkable degree, the property of attracting ammonia from the atmospliere, and of retaining it in the soil. Pipe-clay (which is aluminous earth), when moistened with a solution of caustic potash, emits ammonia, which it has absorbed from the atmosphere. Soils, therefore, containing oxides of iron and burnt clay, must absorb ammonia, which is separated by every shower of rain, and conveyed, in a dissolved state, to the roots of vegetables. Charcoal possesses a similar action; it will absorb ninety times its volume of ammoniacal gas, which may again be separated simply by moistening it with water, in which ammonia is extremely soluble. This explains why plants will grow in pure charcoal moistened with Rain-water. We have here another easy and satisfactory method of explaining still further the properties of humus, or of wood in a decaying state. Decayed oak wood absorbs 72 times its weight of ammonia; humus, then, is not only a slow and constant source of carbonic acid, (repairing the loss of that which is constantly decomposed and absorbed by the leaves of regetables, as before stated), but it is a means by which the necessary nitrogen is mechanically conveyed to plants.

No conclusion can have a better foundation than this, that it is the ammonia of the atmosphere which furnishes all the nitrogen to plants they receive while uncultivated. All the innumerable products of vitality resume, after death, the original form from which they sprung; and thus death, the complete dissolution of an existing generation of animals and plants, becomes the source of life for a new one, and of that artificial and forced amount of nutriment which plants may be compelled to receive, if judiciously fed, or, in other words, manured. 


\section{CHAPTER VI.}

Of the Sources of the Saline, Earthy, and other Unorganized Constituents of Vegetables.

A further question arises: Are the conditions already considered all that is necessary for the life and growth of plants? It will now be shown that they are not.

Carbonic acid, water, and ammonia, are necessary for the existence of vegetation, because they contain the elements from which their organs are formed; but other substances are requisite (as silica in straw) for the formation of certain organs destined for special functions peculiar to each family of plants. Plants obtain these substances from inorganic nature. In the ashes of burnt vegetables the same substances are found, although in an altered condition. Many of these inorganic constituents vary according to the soil in which the plants grow; but without a certain number of them, according to the nature of such plant, they never arrive at maturity. All substances that water will dissolve in a soil are absorbed by the roots of plants exactly as a sponge imbibes a liquid indiscriminately. The substances thus conveyed to plants, are either retained in greater or less quantity, or are entirely separated when not suited for nutritive purposes.

Phosphate of magnesia, in combination with ammonia, is an invariable constituent of the seeds of all kinds of grasses. It is contained in the outer husk, and is introduced into bread, along with the flour, as part of the bran. When ammonia is mixed with beer, this salt is precipitated.

Most plants contain acins of very different composition and properties, all of which are in combination with bases, such as potash, soda, lime, or magnesia. These bases 
evidently regulate the formation of the acids ; for example, the quantity of potash contained in the juice of the grape is less when it is ripe than when unripe; and the acids, under the same circumstances, are found to vary in a similar manner. We glanced, in a former chapter, at the existence of inorganic acids and bases in vegetables: we have now to investigate their source.

The acids found in the different families of plants are very various. It cannot be supposed their presence and peculiarities are the result of chance or accident. They must serve some end in vegetable life, independently of their utility to the animals for whose healthful use some, if not all, of them are ultimately destined. Acids constantly exist in vegetables; and it is incontestable that they are necessary to their life. And it is equally certain, that some alkaline, earthy, or metallic base, is also indispensable, in order to enter into combination with such acids which are always found in the state of salts, as oxalate of potash in the sour-leaf or sorrel.

The nature of a soil exercises a decided influence on the quantity of the different metallic oxides contained in the plants which grow on it. It is not known in what form silica, manganese, and oxide of iron, are contained in vegetables; but we know that potash, soda, and magnesia, can be extracted from all parts of their structure, in the form of salts of organic acids. As these acids and bases are never absent from plants, and as even the form in which they present themselves is subject to no deriation, it may be affirmed that they are necessary, as exercising an important influence over the development of fruits and seeds, and also on many other functions, of the nature of which we are at present ignorant. The perfect development of a plant is dependent, then, on the presence of alkalies, or alkaline earths; when these substances are totally wanting, its growth will be stoppea ; when they are only deficient, it must be correspondingly impeded. Firs and pines find a sufficient quantity of alkalies in barrer, sandy soil; and wheat thrives in another kind of soil: 
because the bases necessary to bring each to maturity exist there in sufficient quantity. The proportion of silicate of potash (necessary for the firmness of wheat straw) does not vary perceptibly in the soil of corn-fields, because what is removed by the reaper, is again replaced in putrefying straw. But this is not the case with meadow-land. Hence we never find a luxuriant crop of grass on sandy and limestone soils which contain little potash, evidently because one of the constituents indispensable to the growth of the plants is wanting. If a meadow be well manured, we remove, with the increased crop of grass, a greater quantity of potash than can, by a repetition of the same manure, be restored to it. So, grass-land manured with gypsum soon ceases to feel its agency. But if the meadow be strewed from time to time with wood ashes, or soap-boilers' ley made from wood ashes, then the grass thrives as luxuriantly as before. And why? The ashes are only a means of restoring the necessary potash for the grass stalks. So oats, barley, and rye, may be made for once to grow upon a sandy heath, by mixing with the scarity soil the ashes of the heath-plants that grow upon it. Those ashes contain soda and potash, conveyed to the growing furze or gorse by rain-water. The soil of one district consists of sandstone; certain trees find in it a quantity of alkaline earths sufficient for their own sustenance. When felled, and burnt, and sprinkled upon the soil, oats grow and thrive that without such aid would not vegetate.

The most decisive proof of the absurdity of the indiscriminate use of any strong manure was obtained at Bingen, a town on the Rhine, where the produce and development of vines were highly increased by manuring them with animal matters, such as shavings of horn. After some years, the formation of the wood and leaves decreased perceptibly.* Such manure had too much hastened

* It is said that this would be obviated, by burying the cuttings round the roots of the vines when pruned.-AMFr. ED. 
the growth of the vines: in two or three years they had exhausted the potash in the formation of their fruit leaves and wood; so that none remained for the future crops, as shavings of horn contain no potash. Cow-dung would have been better, and is known to be better. A knowledge of chemistry furnished the reason which is found in the fact, that it contains a large proportion of potash, though very little nitrogen. Hence, if nitrogen be the element in demand, cow-dung is not the material that will yield it. All the potash contained in the food consumed by a cow, is again immediately discharged in its excrements.

A landed proprietor, in order to obtain more potash for his soil, planted it with wormwood, the ashes of which are well known to contain a large quantity of that alkali. The consequence was, that he rendered his land quite incapable of bearing grain for many years. He had entirely deprived the soil of its potash. Had he sown wheat upon it instead of wormwood, he would have found the soil contained as much potash as was necessary for the nutrition of that vegetable. The supposition that alkalies, metallic oxides, or inorganic matter in general, are produced by plants, is refuted by such facts as these: they are absorbed by plants, not generated.

Those grasses, the seeds of which furnish food for man, follow him like the domestic animals. Saline plants require common salt, and seek the sea-shore. The plants which grow on dung-hills need ammonia and the nitrates, and are attracted whither these can be found just as the dung-fly is to animal excrements. So, likewise, none of our grain plants can bear plump seeds, yielding good and plentiful flour, without a large supply of phosphate of magnesia and ammonia, substances which they require for their maturity. No soil is richer in them than those where men and animals dwell together. Where the urine and excrements of these are found, grain plants appear ; because their seeds cannot attain maturity unless supplied with the constituents of these matters. 
During the boiling or evaporation of saltpetre ley, the salt volatilizes with the water, causing a loss which otherwise could not be explained. In sea storms, leaves, in the direction of the wind, are covered with crystals of salt, twenty or thirty miles from the sea. The great storm which occurred in England a few winters ago, verifies this statement. But it does not require a storm to cause the volatilization of the salt : every breeze must carry it away. The sea-air is always sufficient to make a solution of nitrate of silver turbid and milky. Now, as millions of tons of sea-water annually evaporate into the atmosphere, a corresponding quantity of the saline matters dissolved in it, common salt, muriate of potash, muriate of magnesia, and other matters, will be conveyed by the wind to the land. This volatilization is a source of considerable loss in salt-works where the quantity of salt in the liquor is not large.

According to Marcel, sea-water contains in every 1000 parts 26 of common salt, 4 of sulphate of soda or glauber salt, $1 \frac{1}{2}$ of muriate of potash, $5 \frac{1}{4}$ muriate of magnesia, and $1 \frac{1}{2}$ of sulphate of lime or gypsum. If it be asked, whether there be any peculiarities in the morle of existence of seaplants and fish, we know that ammonia is found in sea water; and that, while air contains only from four to six ten-thousandth parts of its volume of carbonic acid, seawater contains 100 times more, or 620 parts in every ten thousand; so that the same conditions which sustain living beings on the land, are combined in the ocean, in which a separate world of other plants and animals exists.

By the continual evaporation of the sea, its salts are spread over the whole surface of the earth, subsequently to be carried down by the rain, and furnishing to vegetables, through the medium of the soil, those saline matters essential to their existence. The salts of potash, magnesia, and soda, are not peculiar to the ocean: they are found naturally existing on the land as in the water; but the above explanation accounts for the ori- 
gin of alkalies in the ashes of plants in those cases where the soil could not have yielded them. Nor must we overlook the fact, that whatever be the nature of the soil, or however impoverished by successive crops of alkaline vegetables, upon that surface the distant ocean is for ever, unchangingly and silently, pouring the saline treasures of the great deep. Were the proportions of land and ocean reversed as to their extent, it is easy to predict the effect upon vegetation; as it is, the existing quantity of saline material in the ocean (which could not be increased without detriment to its inhabitants) is amply sufficient for the more than single purpose that wise arrangement was destined to answer. The atmosphere contains only a thousandth part of its weight of carbonic acid; and yet small as this proportion appears, it is quite sufficient to supply the whole of the present generation of living beings with carbon for a thousand years, even if it were not renewed. Navigators have sailed for hundreds of miles along the unbroken edge of a coral reef : the clustering islands of the Pacific are many of them exclusively of coraline origin. Seawater contains one twelve-thousandth part of its weight of lime; and yet, from this apparently minute quantity, insect agency has raised those very reefs upon which many a huge ship has been dashed into shapeless fragments. 


\section{CHAPTER VII.}

OS the necessary Relation between the Composition of a Soil and the Vegetables it is fitted to raise. Fallowing and Green Crops considered as Vegetable Manure.

The methols employed in the cultivation of land are different in every country; and when we inquire the cause of these differences, we are told that they "depend upon circumstances." Now, as few people have endeavored to ascertain these circumstances, to reason correctly, and act from rational principle, no answer could show ignorance more plainly. So, when we inquire how manure acts, we are either met with a reply that is figurative and incorrect, or, with the admission that the result is all that is lnown or cared about. We are told that the excrements of man and animals, or that certain mineral matters, are supposed to contain an incomprehensible something, which assists in the nourisiment of plants, and increases their size. No attempt is made to ascertain the component parts of the different species of manure, much less to ascertain whether it be precisely fitted to supply a known deficiency in the soil.

Besides heat, light, moisture, and the component elements of the atmosphere, which are necessary for the mere existence of all plants, certain fertilizing substances are seen to exercise a peculiar influence over the devclopment either of whole plants, or of particular parts of them. Such substances are either already contained in soil, or may be artificially supplied in the form of manure.

The rules of a rational system of agriculture should enable us, therefore, to give to each plant that which it requires for the atlainment of the special object in viewnamely, an artificial increase of certain parts which are employed as food for man and animals. 
The means employed for the production of fine pliable straw for hats and bonnets is the very opposite to the mode which must be adopted, in order to produce the largest possible quantity of corn from the same plant. Peculiar methods must be used for the production of nitrogen in the seeds; others for giving strength to the straw; and others again, when we wish to give such qualities to the straw as will enable it to bear the weight of the ears.

We must proceed in the artificial rearing and forcing of plants precisely as we do in the fattening of animals. The flesh of wild animals is devoid of fat, or nearly so. The production of flesh and fat may be artificially increased: all domesticaterl animals are easily fattened. To do this, we add to the quantity of food, and lessen (as in the stallfed ox) the waste occasioned by the increased action of the lungs, (as consequent upon motion), together with the waste which such muscular exertion would produce by increased action of the skin.

Arable land is originally formed by the crumbling of rocks ; and its properties depend on the nature of its comporient parts.

Sand, clay, and lime, are the names given to the principal constituents of the different kinds of soil.

Pure sand, and pure limestone, in which there are no other unorganized substances except the earth of flint, chalk, or silicic acid combined with lime, form absolutely: barren soils. But clay always forms a part of fertile soils. Whence is the origin of clay earths in arable land? What are their constituents? and what part do they play in favoring vegetation? They are produced by the breaking down of aluminous minerals by the action of the weather. These minerals are found, mixed with other substances, in granite, mica-slate, porphyry, clay-slate, the volcanic rocks, and others. Mountain linestone is remarkable for the quantity of clayey earths which it contains. In grauwacke we find pure quartz, clay slate, and lime; in the sandstones, quartz and loam; and in the transition 
limestone there is an intermixture of clay, felspar, and clay slate. These examples may be sufficient.

It is known that aluminous minerals (that is to say, minerals containing the metal "aluminium," which combined with oxygen, forms "alumina," or the pure earth of clay) are the most widely diffused on the surface of the earth ; and all fertile soils, cr suils capable of culture, invariably contain alumina.

There must, therefore, be something in aluminous earth which causes it to exercise an influence on the life of plants, and to assist in their growth. The property on which this depends is, that clay imariably contains potash and soda. Besides which, alumina attracts and retains water and ammonia from the atmosphere. Alumina is itself very rarely found in the ashes of plants; but silica (or the earth of flints) is always present, having, in most places, entered the plants by means of alkalies. Among aluminons minerals, felspar, which is one of them, contains 17 per cent. of potash; mica from 3 to 5 per cent. of soda; clay slate contains from 2 to 3 per cent. of potash; and loam from $1 \frac{1}{2}$ to 4 per cent. of the same alkali.

So that, in a layer of soil formed by the breaking down of 40,000 square feet of one of these rocks, to the depth of twenty inches, we should find that so much felspar would contain more than a million pounds of potash; if the soil were formed by the disintegration of clay slate, about 200,000 ; if loam were the material, from 87,000 to 300,000 ; and similarly of other rocks of partially aluminous character.

Potash is present in all clays, and in marl; it has been found in all aluminous earths in which it has been sought. Alum (which is a sulphate of alumina, combined with sulphate of potash) may be procured by digesting clay in sulphuric acid, which takes up both the alumina and the potash.

A thousandth part of loam mixed with the quartz in red sandstone, or with the lime in the different limestone 
formations, affords as much potash to a soil 20 inches in depth, as is sufficient to supply a forest of pines growing upon it with potash for a hundred years.

Water, impregnated with the carbonic acir of the atmosphere, decomposes rocks which contain alkalies, and then dissolves a part of the alkaline carbonates formed in the process. Plants, also, by producing carbonic acid during their decay, and by means of the acids emitted by their living roots, contribute no less powerfully to destroy the coherence of solid minerals. Air, water, and changing temperature prepare the different species of rocks for yielding to plants the potash or soda they contain. Mrs. Ellis relates, that among the mountains which divide France from Spain, the rocks actually smole after rain, under the influence of the summer sun, and become so hot that it is uncomfortable to sit down upon them. Changing temperature is a most important agent in nature. It not only assists in the original formation of soils, but exerts a most powerful influence over those already in existence. In wet soils the temperature rises slowly, and never attains the same height as in one that is sandy and dry. When the heat of the atmosphere rises no higher in the shade than 60 or 70 degrees, a $d r y$ soil may become so warm as to raise the thermometer to 90 or 100 . Hence, though the expression be used figuratively, it is in this instance strictly c rreet to say that wet soils are cold.

The exhausition of allatie in a soil by successive crops is the true reason why practical farmers suppose themselves compelled to suffer land to lie in fallow. It is the greatest possible mistake to think that the temporary diminution of fertility in a field is chiefly owing to the loss of the decaying vegetable matter it previously contained: it is principally the consequence of the exhaustion of potash and soda, which are restored by the slow process of the more complete disintegration of the materials of the soil. It is evident that the careful tilling of fallow land must accelerate and increase this further breaking up of its 
mineral ingredients. Nor is this repose of the soil always necessary. A field, which has become unfitted for a certain kind of produce, may not, on that account, be unsuitable for another; and upon this observation, a system of agriculture has been gradually formed, the principal object of which is to obtain the greatest possible produce in a succession of years, with the least outlay for manure. Because plants require for their growth different constituents of soil, changing the crop from year to year will maintain the fertility of that soil (provided it be done with judgment) quite as well as leaving it at rest or fallow. In this we but imitate nature. The oak, after thriving for long generations on a particular spot, gradually sickens; its entire race dies out; other trees and shrubs succeed it, till, at length, the surface becomes so charged with an excess of dead vegetable matter, that the forest becomes a peat moss, * or a surface upon which no large tree will grow. Generally long before this can occur, the opcration of natural causes has gradually removed from the soil substances essential to the growth of oak, leaving others favorable and necessary to the growth of beech or pine. So, in practical farming, one crop in artificial rotation with others, extracts from the soil a certain quantity of necessary inorganic matters; a second carries off, in preference, those which the former had left, and neither could nor would take up.

Experience proves that wheat should not be attempted to be raised after wheat on the same soil ; for, like tobacco, it exhausts the soil. But, if " humus," decaying vegetable matter, gives it the power of producing corn, how happens it that, in soils formed in large proportion of mouldered wood, the corn-stalk attains no strength, and droops permanently? The cause is this: the strength of the stalk is due to silicate of potash, and the corn requires phosphate of magnesia; neither of which substances a soil

* This does not happen in American forests, but when oak and other deciduous trees are cut off, they will be succeeded frequently by a growth of pine, and so vice versâ.-AMER. ED. 
of decaying regetable matter can afford, since it does not contain them: the plant may, indeed, under such circumstances, become a herb, but will bear no seeds. We say phosphate of magnesia is necessary; - the small quantities of the phosphates found in peas and beans is the cause of their comparatively small value as articles of nourishment, since they surpass all other vegetable food in the quantity of nitrogen they contain. But as the component parts of bone, namely, phosphate of lime and magnesia, are absent in beans and peas, they satisfy appetite without increasing the strength.

Again, how does it happen that wheat does not flourish on a sandy soil, and that a limestone soil is also unsuitable, unless mixed with a considerable quantity of clay? Evidently because these soils do not contain potash and soda (always found in clay); the growth of wheat being arrested by this circumstance, even should all other requisite substances be presented in abundance. It is because they are mutually prejudicial by appropriating the alkalies of the soil, that wormwood will not thrive where wheat has grown, nor wheat where wormwood has been.

One hundred parts of wheat straw yield $15 \frac{1}{2}$ of ashes; the same quantity of barley straw, $\$ \frac{1}{2}$; of oat straw, only 4: the ashes of the three are, chemically, of the same composition. Upon the same field which will yield only one harvest of wheat, two successive crops of barley may be raised, and three of oats. We have, in these facts, a clear proof of what is abstracted from the soil, and, consequently, what plants require for their growth-a key to the rational mode of supplying the deficiency.

Potash is not the only substance requisite for the existence of most plants; indeed it may be replaced, in some cases, by soda, magnesia, or lime; but other substances are required also.

Plants obtain phosphoric acid (found in combination with lime or magnesia) from the soil, and they, in their turn, yield it to animals, to assist in the formation of their bones. Creatures that feed upon flesh, bread, fruit, and 
husks of grain, take in much more phosphorus than is required for the building up of the animal fabric; and this excess is again usefully thrown out by them, chiefly in their liquid excrements. Some plants, however, extract other matters from the soil besides silica, potash, and phosphoric acid, which are essential constituents of the plants ordinarily cultivated.

English farming presents us with varied instances of plants sown, and growing together in the same field. Two such vegetables will mutually injure each other, if they withdraw the same food from the soil. Plants will thrive beside each other, either when the substances necessary for their growth, extracted from the soil, are of different kinds, or when they themselves are not both in the same stage of growth at the same time. On a soil containing potash, wheat and tobacco may be reared in succession, because the latter plant does not require the phosphates which the wheat has appropriated to itself. Now, tobacco requires only alkalies, and food containing nitrogen. When we grow different plants in the same soil, for several years in succession, the first of which leaves behind that which the second, and the second that which the third may require, the soil will be a fruitful one for all the three kinds of produce. If the first plant, for example, be wheat, which consumes the greatest part of the silicate of potash in the soil, the plants which succeed it should be such as require little potash, as turnips or potatoes. The wheat lands may be sown again with wheat, advantageously, after the fourth year. The reason of this is, that during the interval of three years, the soil will, by the action of ihe atmosphere, be rendered capable of again yielding silicate of potash in sufficient quantity for wheat. Whether this process can be artificially anticipated, by supplying the exhausted ingredient to the soil, is a further and most interesting inquiry.

In a four-years' course of cropping, the crops gathered amounted, per acre, to- 
1st year, Turnips, 25 tons of bulbs, and 7 tons of tops.

$2 d$ year, Barley, 38 bushels, and a ton of straw.

$3 d$ year, Clover and Rye Grass, 1 ton of each in hay:

4th year, Wheat, 25 bushels, and 2 torss of straw.

Supposing none of the crops to be eaten upon the land, the quantity of inorganic matter contained in the above would be as follows :-

\begin{tabular}{|c|c|c|c|}
\hline & lbs. & & lbs. \\
\hline Potash & $\begin{array}{l}281 \\
130\end{array}$ & Silica, & 318 in combination \\
\hline Lime, & 242 & Phosphoric acid, & 61 with the earths \\
\hline Magnesia, & 42 & Chlorine, & 39 and alkalies; \\
\hline & 11 & & \\
\hline
\end{tabular}

making a gross weight of 1,240 pounds, or about elcren hundred weight.

A still clearer idea of the importance and quantities of these inorganic matters may be obtained by a consideration of the fact, that if we were to carry off the entire of the above produce, and return none of it again in the shape of manure, (supposing also that we could stop the beneficial ag"ency of the atmosphere during that period), we must, or ought, instead of that produce-if the land is to be restored to its original condition - add to each acre, every four years, 300 pounds of pearl ashes, or potash; 440 of carbonate of soda; 65 of common salt; 240 of quick lime; 250 of sulphate of magnesia, that is, Epsom salts; 84 of alum; and 260 of bone dust: making; 1,729 pounds of solid saline matter, at an expense of nearly £9. The fertility of a soil cannot remain long unimpaired, unless we replace in it all those substances of which it has been deprived. We could keep our fields in a constant state of fertility, by replacing, every year, as much as we remove from them in the form of produce; and, be it remembered, that our cultivated corn plants and bulbous roots are not like forest plants and trees: the quantity of nutriment they require, and take up, to bring them to perfection and perpetuate the race, is far more than the unaided elements around them could supply. Wheat, for instance, as a natural production of the 
soil, appears to have been a very small grass: and the case is still more remarkable with the apple and the plum. The common crab seems to have been the parent of all our apples. Potatoes and turnips, in their wild or natural state, are unfit for food; and two fruits can scarcely be conceived more different in color, size, and appearance. than the wild plum and the rich magnum bonum. We have to contend, then, with two important differences: First, That wheat or turnips are not natural productions; and, secondly, That because they are not, they drain or exhaust unassisted soil faster than the wild plants of the forest; nor will they thrive long, if denied that assistance from artificial nutriment, which nature cannot supply in sufficient quantity.

It is evident, then, that an increase of fertility, and consequent increase of crop, can only he expected when we add more to the soil of the proper material (and no other), than we take away. Any soil will partially regain itself by lying fallow : this is owing to atmospheric action, and the conversion of the roots and stalks into humus. But though the quantity of decaying vegetable humus in a soil may be increased to a certain degree by cultivation and alternate cropping, still, there cannot be the smallest doubt, that a soil must (without help) ultimately lose those of its constituents, which are removed in the seeds, roots, and leaves of the plants raised upon it.

To prevent this loss, and, as a further object, to enable us to raise increased quantities of productions, demanding more sustenance than land will naturally yield, is the object of the application of the various substances used as ManUres. They will prove useless, injurious, or valuable, precisely as they are accurately or inaccurately adlapted to meet the deficiency.

Land, when not employed in raising food for animals or man, should at least be applied to the purpose of raising manure for itself; and this, to a certain extent, may be effected by means of GREEN CROPS, which, by their decomposition, not only add to the amount of vegetable mould 
contained in the soil, but supply the allalies that would be found in their ashes. That the soil should become richer by this burial of a crop, than it was before the seed of that crop was sown, will be understood, by recollecting that three-fourths of the whole organic matter we bury has been derived from the air : that by this process of plowing in, the vegetable matter is more equally diffused through the whole soil, and therefore more easily and rapidly decomposed; and that by its gradual decomposition, ammonia and nitric acid are certainly generated, though not so largely as when animal matters are employed. He who neglects the green sods, and crops of weeds that flourish by his hedgerows and ditches, overlooks an important natural means of wealth. Left to themselves, they ripen their seeds, exhausting the soil, and sowing them annually in his fields: collected in compost heaps, they add materially to his yearly crops of corn. We have said that absolute repose of the soil is not frequently neerled; and, with some practical illustrations of the system of alternate cropping, we will close this section.

In Flanders, two crops of clover are cut, and the third is plowed in. In Sussex, turnip seed has been sown at the end of larvest, and, after two months, again plowed in with great benefit to the land. So turnip leaves and potato tops decay rapidly, and are more enriching when buried in the green state. In the Earl of Leicester's course of cropping, the land is never idle. The turnip is the first in the order of succession. This crop is manured with recent dung, which immediately affords sufficient matter for its nourishment; the heat produced in its decomposition assisting in the extrication of ammonia, the liberation of nitrogen, and the consequent germination of the seed, and growth of the plant. Next after turnips, barley, with grass seeds, is sown; and the land having been little exhausted by the previous crop of turnips, affords the soluble parts of the decomposing tops and manure to the barley. The barley is gathered ; the grasses, rye-grass and clover, remain, which derive a small part only of 
their organized matter from the soil, and probably consume the gypsum which would be useless to previous and succeeding crops. These grasses, by their large system of leaves, absorb mainly their nutriment from the atmosphere; and, when PLOWED IN at the end of two years, their decomposed roots and leaves are useful to the wheat crop, which is next, and last in succession. At this period of the course, the woody fibre of the farm-yard manure, containing phosphate of lime, is sufficiently decomposed ; and as soon as the most exhausting crop is taken off the land, recent animal manure is again applied. Peas and beans, in all instances, seem well adapted to prepare the ground for wheat; and in some parts of the country they are raised, alternately with wheat, for years together. Mr. Gregg,-whose ingenious system of cultivation has been published by the Board of Agriculture, and who adopts, upon strong clays, a plan similar to that of the Earl of Leicester (better known as Mr. Coke of Holkham),suffers the ground, after barley, to remain at rest for two years in grass; sows peas and beans on the leys; plows in the pea or bean stubble for wheat ; and, in some instances, follows his wheat crops by a course of winter tares and winter barley, which is eaten off in the spring, before the land is sown for turnips.

It is a great advantage, in the convertible system of cultivation, that the whole of the manure is employed, as well as the entire resources of the land, in their proper order; those materials which are not fitted for one crop, remaining as nutriment, or essential requisites for the next, or for another. 


\section{CHAPTER VIII.}

Of the Nature and correct Use of the Excrements of Animals considered as Manure; the Mode of its Action and Preservation.Bone Dust, and dead Animal Matter.

CALICo printers for a long time have used the solid excrements of the cow in order to brighten and fasten colors on cotten cloth. This material appeared quite necessary, and its action was ascribed to some latent principle or material derivable from the living animal. But since the action of cow-dung was known to depend on the phosphates contained in it, it has been completely replaced by a more cleanly mixture of certain salts, of which the most prominent is phosphate of soda.

So, similarly, in medicine, for many centuries the mode of action, or the active principle of all remedies, was veiled in obscurity. But now these principles have been presented to the world in an extremely active and concentrated form. The extraordinary efficacy of Peruvian bark in the cure of fever, is found to depend on the admixture of a minute quantity of a crystalline substance termed quinine, with the useless woody fibre; and the causes of the various effects of opium, in as many equally minute yet powerful ingredients in that drug. The inhabitants of Savoy are much infested with the disease known amongst us as "Derbyshire neck." They have springs which are famous for its cure; we derive benefit from the use of burnt sponge. Now, burnt sponge contains iodine; and upon examination these springs contain iodine in small quantities. The action of the sponge, or of the water, must depend upon some definite cause common to both; by ascertaining which we place the action and result completely at our command. 
Apply this reasoning to agricultural operations. One practical farmer applies, indiscriminately, any fertilizing material to his land in any state; another, more partial to what is technically termed "short muck," allows violent fermentation to reduce his mixture of straw and dung to one half its weight; during which operation much gaseous ammonia is disengaged and lost, which, if retained, or supplied to the soil, would have proved extremely serviceable. Both methods cannot be right in all cases.

Besides the dissipation of gaseous matter when fermentation is pushed to the extreme, there is another disadvantage in the loss of heat, which, if exciterl in the soil instead of the dunghill, is useful in promoting the springing of the seed and in assisting the plant in the first stage of its growth, when it is most feeble and most liable to disease: and the decomposition of manure in the soil must be particularly favorable to the wheat crop, in preserving a genial temperature beneath the surface late in autumn and during the winter. These views are in accordance with a well-known principle in chemistry-that, in all cases of decomposition, substances combine much more readily at the moment of their disengagement than after they have been some time perfectly formed and set at liberty. And in fermentation beneath the soil, the fluid matter produced is applied instantly, even whilst it is warm, to the young organs of the rising plant; and, consequent$\mathrm{ly}$, is more likely to be efficient, than in manure that has gone through the process, and of which all the principles have entered into new combinations.

It is certainly a matter of indifference whether we employ excrements, ashes, or bones, in carrying out the principle of restoring to the soil those substances which have been taken from it by the previous crop. But, unless we know accurately what are those matters that have been actually removed, how is it possible to supply, otherwise than at random guess, the deficiency ? Fermented dung may be really useful, if no nitrogen be demanded. A time 
will come when fields will be manured with saline soltltions, with the ashes of burnt straw, or with salts of phosphoric acid prepared in chemical manufactories, with as much certainty as now, in medicine, iodine cures the Derbyshire neck, or as quinine is substituted for the bulky powdered bark in fever. The same mixed mass of materials may be useful in one state, less so in another and under other circumstances. A knowledge of the actual wants of the land, and of the exact composition of the proposed manure, is obriously necessary to enable the farmer to adapt the one to the other as a requisite and fitting remedy. If our object be the development of the seeds of plants, we know they contain nitrogen. Our manure then must be rich in this material. If by fermentation ammonia be formed in the manure, if it become dry, rotten, and nearly devoid of smell, having lost its previous heat; although it may cut better with the spade, we may be sure it has lost its nitrogen, and, consequently, as far as our object is concerned (the nutriment of the seed), nearly lost its utility. The leaves, which by their action on the air nourish the stem and woody fibre; the roots, from which the leaves are formed; in short, every part of the structure of a plant contains nitrogen in small and varying proportions. But the seeds are always rich in nitrogen.

The most important object, then, of farming operations, at least as far as corn is concerned, is the supply of nitrogen to corn plants in a state capable of being taken up by them-the production, therefore, of manures containing the most of this element. Gypsum and nitrate of soda are as properly termed manures as farm-yard dung, bone-dust, or night-soil; but our present inquiry is, what class of substances contain and yield to corn-plants most NiTroGEN? Nature, by the ordinary action of the atmosphere, furnishes as much nitrogen to a plant as is necessary to its bare existence. But plants do not exist for themselves alone-the greater number of animals depend upon the 
regetable world for food; and, by a wise adjustment of nature, plants have the remarkable power of converting, to a certain degree, all the nitrogen offered to them into nutriment for animals. We may furnish a PLANT with carbonic acid, and all the materials which it may require for its mere life; we may supply it with vegetable matter in a state of decay in the most abundant quantity; but it will not attain complete development unless nitrogen be afforded to it by the supply of suitable manure: a herb will, indeed, be formed, but its seeds or grain will be imperfect and feeble.

But when, with proper manure, we supply nitrogen in addition to what the plant would derive from natural sources, we enable it to attrict from the air the carbon which is necessary for its nutrition-that is, when that in the soil is not sufficient, we afford it a means of fixing the atmospheric carbon.

There are two principal descriptions of manure, the beneficial agency of which is derivable, almost exclusirely, from the large quantity of nitrogen they yield.

These are the solid as well as fluid excrements of man and animals, their dung and urine.

URINE is employed as manure, either singly, in its liquid state, or with the fæces which are impregnated with it. It is the urine contained in night-soil which gives it the property of giving off ammonia, a property which the discharges from the bowels possess only in a very slight degree. Liquid manures act chiefly through the saline substances they hold in solution; while the solid manures, even of animal origin, contain insoluble matters, which decay slowly in the soil, and there become useful only after a time. When we examine what substances we add to a soil by supplying it with urine, we find that this liquid contains in solution ammoniacal salts, uric acid (a substance itself containing much nitrogen), and salts of phosphoric acid.

Human urine consists in 1000 parts of 
Water, - - - - - - - _ - 932

Urea, and other organic matters containing nitrogen, 49

Phosphates of ammonia, soda, lime, and magnesia, - 6

Sulphates of soda and ammonia, - $-\quad-\quad-7$

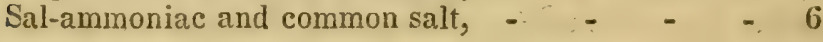

1000

In dung reservoirs, well constructed and protecter from evaporation, the carbonate of ammonia, which forms in consequence of putrefaction, is retained in solution; and when the putrefied urine is spread over the land, a part of this ammonia will escape with the water which evaporates. On account of the formation of carbonate of ammonia in putrid urine, it becomes alkaline, though naturally acid in its recent state; and when this carbonate of ammonia is lost by being volatilized in the air (which happens in most cases), the loss suffered is nearly equal to one half of the urine employed. So that, if we fix the ammonia (by combining it with some acid which forms with it a compound not volatile) we increase its action two-fold. Now the carbonate of ammonia formed by the putrefaction of urine can be fixed, or deprived of its volatility, in many ways.

If, for instance, a field be strewed with gypsum, or plaster of Paris (in chemical language, sulphate of lime), and then sprinkled with urine, or the drainings of the cowshed, a double exchange or decomposition takes place. Sulphate of lime and carbonate of ammonia become converted into carbonate of lime (that is, chalk) and sulphate of ammonia; and this because sulphuric acid has a greater affinity for ammonia than it has for lime. This sulphate of ammonia will remain in the soil-it will not evaporate.

If a basin containing spirit of salt, or muriatic acid, be left a few weeks in a close stable or privy, so that its surface is in free communication with the ammoniacal vapors that rise from below, crystals of muriate of ammonia, or common sal-ammoniac, will soon be visible, as an incrustation about its edges. The ammonia that escapes 
in this way is not only entirely lost as far as vegetation is concerned; it works also a slow but not less certain destruction of the mortar and plaster of the building. For when in contact with the lime of the mortar, ammonia is converted into nitric acid, which gradually dissolves the lime. There are few schoolboys who have not picked out crystals of nitrate of potass, or saltpetre, from an old brick wall; and in this instance the atmosphere has yielded the ammonia.

The offensive carbonate of ammonia in close stables is very injurious to the eyes and lung's of horses, as the army veterinary surgeons are well able to testify. They adopt measures to carry it off by rentilation and cleanliness. If the floors of stables or cow-sheds were strewed with common gypsum, they would lose all their offensive and injurious smell, and none of the ammonia which forms could be lost, but would be retained in a condition serviceable as manure. This composition, swept from the stable floor, nearly constitutes what is sold under the denomination of urate. Manufacturers of this material state, that three or four hundred weight of urate form sufficient manure for an acre; a far more promising adventure for a practical farmer will be to go to some expense in saving his own liquid manure, and, after mixing it with burnt gypsum, to lay it abundantly upon his corn-lands. For, in this way, he may use as much gypsum as will absorb the whole of the urine. Now, in the manufacture of urate, the proportion of 10 pounds is employed to every 7 gallons,allowing the mixture, occasicnally stirred, to stand some time, pouring off the liquid, and with it nearly all its saline contents, except the ammonia. Urate, therefore, can never present all the virtues of the urine - 100 pounds of urate containing no greater weight of saline and organic matter than 10 gallons of urine.

From the foregoing analysis it would appear, that 1000 pounds of human urine contain no less than 68 pounds of $d r y$ fertilizing matter of the richest quality, worth, at the present rate of selling artificial manures in this country, at 
least 20 shillings $(\$ 5)$ per hundred weight. Suppose we say that the liquid and solid excrements of one human being amount on an average to a pound and a half daily, then in one year they will amount to 547 pounds; which, at the rate of 3 per cent. of contained nitrogen, would yield 16 pounds of that material for the land, a quantity sufficient to supply enough for 800 pounds of wheat, rye, or oats, or for 900 pounds of barley. As each person in reality voids at least 1000 pounds or pints of urine in a year, the national waste incurred in this form amounts, at the above valuation, to twelve shillings a head upon every individual of the whole population of England and Wales. And if five tons of farm-yard manure per acre, added yearly, will keep a farm in good order, four hundred weight of the solid matter of urine would probably have an equal effect-in other words, the excrements of a single individual are more than sufficient to yield the requisite nitrogen to an acre of land, in order to enable it (with the assistance of the nitrogen absorbed naturally from the atmosphere) to produce the richest possible yearly crop. Every town and farm might thus supply itself with the manure, which, besides containing the most nitrogen, contains also the most phosphates; and if an alternation of the crops were adopted, they would be most abundant. By using at the same time bones and wood ashes, the excrements of animals might be completely dispensed with; so that artificial, mineral, or chemical manures are no imperfect substitutes, if applied judiciously.

The urine alone discharged into rivers or sewers by a town population of 10,000 inhabitants would supply manure to a farm of 1500 acres, yielding a return of 4500 quarters (36,000 bushels) of wheat, or an equivalent produce of other crops. The powerful agency of urine as a manure is well known on the continent of Europe, and the Chinese justly consider it as invaluable ; and they are the oldest as well as the best agriculturists in the world. Indeed so much value is attached to human excrements by the Chinese, that the laws of the country forbid that any 
of them should be thrown away; and reservoirs are placed in every house, where they are collected with the utmost care. No other kind of manure is used for their grain fields.

Human urire contains a greater variety of constituents than any otker species examined. Urea, uric acid, and another acid similar to it in nature, called rosacic acid, acetic acid, albumen, gelatine, a resinous matter, and its various salts, are all valuable to the land, inasmuch as from the land they or their elements have been originally derived. The urine of animals that feed exclusively on flesh contains more animal matter, and consequently more nitrogen, than that of vegetable feeders, whence it is more apt to run into the putrefactive process and disengage ammonia. In proportion as there are more gelatine and albumen in urine, so in proportion does it putrefy more rapidly. Thus, then, all urine contains the essential elements of vegetables in a state of solution; and that will be the best for manure which contains most albumen, gelatine, and urea. Putrid urine abounds in ammoniacal salts, and is only less active as a manure than fresh urine, because of the portion of ammonia which is continually exhaling into the atmosphere.

As to the urine of cattle, it contains less water than that of man, varying with the kind of food on which the animal is fed. A cow will secrete and discharge from two thousand to three thousand gallons of urine a year'; and this quantity will contain at least from 1200 to 1500 pounds of dry solid saline matters, worth from ten to twelve pounds sterling ( $\$ 50$ to $\$ 60)$. Even in the liquid state, the urine of one cow, collected and preserved as it is in Flanders, is valued at $£ 2(\$ 10)$ a year. Any practical farmer may easily make the calculation for himself, how much real wealth is lost in his own farm-yard, how much of the natural means of reproductive industry passes into his drains or evaporates in the air.

The urine of the cow is particularly rich in salts of potash, but contains very little soda. The urine of swine 
contains a large quantity of the phosphates of ammonia and magnesia. That of the horse contains less nitrogen and phosphates than that of man.

The fertilizing power of animal manures, whether fluid or solid, is dependent, like that of the soil itself, upon the happy admixture of a great number, if not of all, those substances which are required by plants in the universal cultivation they receive from the industry and skill of man, more especially upon the large proportion of nitrogen they contain. The amount of this latter material affords the readiest test by which their agricultural value, compared with other matters and with that of each other, can be tolerably well estimated.

Ordinary farm-yard manure, in its recent state, contains a given proportion of nitrogen; but fifteen pounds of blood would yield as much nitrogen as one hundred pounds of farm-yard compost. If dried blood were taken, four pounds would be sufficient; three pounds of feathers, three of horn-shavings, five of pigeons' dung, or even two and-ahalf of woollen rags, would counterpoise one hundred of the first named materia!. Sixteen would be the equivalent number for the urine of the horse, ninety-one that of the cow, seventy-three for horse-dung, one hundred and twenty-five for cow-dung; while the mixed excrements of either animals would correspond with the fact, that the discharges of the cow offer no resemblance to those of the horse.

Besides their general relative value, namely, is to the proportions of nitrogen they contain, the above matters have a further special value, dependent upon the dirersity of saline, and other organic matters which they severally contain. Thus, three of dried flesh are equal to five of pigeons' dung, as far as nitrogen is concerned; but then pigeons' dung contains a quantity of bone, earth, and saline matter, scarcely present in the former. Hence, the dung of fowls will benefit vegetation in some instances where even horse-flesh, ordinarily regarded as a strong manure, would fail. And why? Evidently because, if 
saline matlers are deficient in the soil, an excessive supply of nitrogen will not serve as their substitute. So the liquid excretions contain much important saline matter not present in solid dung, nor in such substances as horn, hair, or wool; and therefore each must be capable of exercising its own peculiar influence, and be comparatively useless if deficient of those matters which are also found wanting, deficient, yet necessary in the soil. This affords the reason why no one manure can long answer on the same land: it can only supply the materials it contains. When all the silicate of potash in corn-fields is exhausted, urine will not, cannot, supply the deficiency; because it contains no silicate of potash. So long as the land remained rich in this material, urine or blood would supply the requisite nitrogen. Hence, in all ages and countries, the habit of employing mixed manures and artificial composts has been universally diffused. What is wanting is, a more accurate knowledge of the precise deficiency at any given moment, and a consequent saving of capital from unnecessary waste, together with an immense increase in fertility, as the reward of so accurate an adaptation of means and ends. The knowledge of a disease is essential to the correct application of a remedy.

A high degree of culture requires an increased supply of manure. With its abundance, the produce in corn and cattle will augment, but must diminish with its deficiency.

From the foregoing remarks, it must be evident, that the greatest value should be attached to the liquid excrements of man and animals when a manure is desired which shall supply nitrogen to the soil. And as nitrogen is seldom wanted alone,-and as, generally, in practice, both liquid and solid excrements are found associated, containing, besides nitrogen, many other essential and invaluable ingredients, - too much care cannot be taken, not only in preserving them, but which is equally important, in securing to the land the full value of their operation, by applying them in the best possible condition for the development of their powers. 
We have already alluded to the loss sustained by the fermentation of dung-heaps. As we observed, in an earlier chapter when it is considered that, with every pound of ammonia which evaporates, a loss of sixty pounds of grain is sustained, and that, with every pound of urine, a pound of wheat might be produced, the indifference with which liquid refuse is allowed to run to waste is quite incomprehensible. That it should be allowed to expend its ammonia by fermentation in the dung-heap, and evaporation into the atmosphere, is ascribable solely to ignorance of the elementary outlines of that science which hitherto the practical farmer has thought it no disgrace, but rather an honor to publish, glorying in his utter disregard of all bookish knowledge! and substituting his own notions of wasteful and vague experience for the calm deductions of sound and rational investigation. In most places, only the solid excrements impregnated with the liquid are used ; and the dunghills containing them are protected neither from evaporation, nor from rain. The solid excrements contain the insoluble, the liquid excrements all the soluble phosphates ; and the latter contain, likewise, all the potash which existed as organic salts in the plants consumed by the animals which fed upon them.

It is by no means difficult to prevent the destructive fermentation and heating of farm-yard compost. The surface should be defended from the oxygen of the atmosphere. A compact marl, or a tenacious clay, offers the best protection against the air; and before the dung is covered over, or, as it were, sealed up, it should be dried as muck as possible. If the dung be found at any time to heat strongly, it should be turned over, and cooled by exposure to air. Watering dung-hills is sometimes recommended for checking the process of putrefaction, and the consequent escape of ammonia; but this practice is not consistent with correct chemistry. It may cool the dung for a short time; but moisture is a principal agent in all processes of decomposition. Water, or moisture, is as necessary to the change as air; and to supply it to reek- 
ing duug, is to supply an agent which will hasten its decay.

If a thermometer, plunged into the dung, does not rise much above blood-heat, there is little danger of the escape of ammonia. When a piece of paper, moistened with spirit of salt, or muriatic acid, held over the steams arising from a dung-hill, gives dense fumes, it is a certain test that decomposition is going too far; for this indicates that ammonia is not only formed, but is escaping to unite with the acid in the shape of sal-ammoniac.

When clung is to be preserved for any time, the situation in which it is kept is of importance. It should, if possible, be defended from the sun. To preserve it under sheds would be of great use, or to make the site of a dung-hill on the north side of a wall. The floor on which the dung is heaped, should, if possible, be paved with flat stones; and there should be a little inclination from each side towards the centre, in which there should be drains, connected with a small well, furnished with a pump, by which any fluid matter may be collected for the use of the land. It too often happens, that a heavy, thick, extractive fluid is suffered to drain away from the dung-hill, so as to be entirely lost to the farm.

Night-soil, it is well known, is a very powerful manure, and very liable to decompose. Human excrements differ in their composition, but always abound in nitrogen, hydrogen, carbon, and oxygen. From the analysis of Berzelins, it appears that a part of it is always soluble in water; and in whatever state it is used, whether recent or decomposed, it supplies abundant food to plants. But this affords no excuse for its misapplication in any other condition than that which is most profitable. It varies, no doubt, in richness with the food of the inhabitants of each district,-chiefly with the quantity of animal food they consume,-but, when dry, no other solid manure, weight for weight, can probably be compared with it in general efficacy. The soluble and saline matters it contains are made up from the constituents of the food we 
eat; of course, it contains most of those elementary substances which are necessary to the growth of the plants on which we live. The disagreeable smell of night-soil may be destroyed by quick lime. If exposed to the air in thin layers strewed over with lime, in fine weather, it speedily dries, is easily pulverised, and, in this state, may be used in the same manner as rape-cake, and delivered into the furrow with the seed. If night-soil be treated in a proper manner, so as to remove the moisture it contains, without permitting the escape of its ammonia, it may be put into such a form as will allow it to be transported even to great distances. This is already attempted in many places; and the preparation of human excrements for exportation constitutes not an unimportant branch of industry. But the manner in which this is done, is not always the most judicious. In Paris, the excrements are preserved in the houses in open casks, from which they are collected and placed in deep pits at Montfaucon; but they are not sold until they have attained a certain degree of dryness by evaporation in the air. But whilst lying in the receptacles appropriated for them in the houses, the greatest part of their urea is converted into carbonate of ammonia; lactate and phosphate of ammonia are also formed, and the regetable matters contained in them putrefy; all their sulphates are decomposed, whilst their sulphur forms sulphuretted hydrogen. The mass, when dried by exposure to the air, has lost more than half of the nitrogen which the excrements originally contained; for the ammonia escapes into the atmosphere along with the water which evaporates; and the residue now consists principally of phosphate and lactate of ammonia, and small quantities of urate of magnesia and fatty matter. Nevertheless, it is still a very powerful manure; but its value as such would be twice or four times as great, if the excrements, before being dried, were neutralized with a cheap mineral acid.

In other manufactories of manure, the excrements, whilst still soft, are mixed with the ashes of wood, or with 
earth; both of which substances contain a large quantity of caustic lime, by means of which a complete expulsion of all their ammonia is effected, and they are completely deprived of smell. But such a residue applied as manure, can act only by the phosphates which it still contains; for all the ammoniacal salts have been decomposed, and their ammonia expelled. In London, night-soil is dried with various mixtures; while, in other of our large towns, what is called "animalized charcoal" is prepared by mixing and drying night-soil with gypsum and ordinary wood charcoal in fine powder. In all cases, the excrements of human beings contain more nitrogen than those of any other animal. Berzelius obtained, by the burning of 100 parts of dried excrements, 15 parts of ashes, principally composed of the phosphates of lime and magnesia.

It is quite certain that the vegetable constituents of the excrements with which we manure our fields, cannot be entirely without influence upon the growth of the crops on them; for they will decay, and thus furnish carbonic acid to the young plants. But it cannot be imagined that their influence is very great, when it is considered that a good soil is manured only once every six or seven years; that the quantity of carbon thus given to the land corresponds only to 5 per cent. of what is removed in the form of herbs, straw, or grain ; and further, that the rain-water received by a soil contains much more carbon in the form of carbonic acid than these vegetable constituents of animal excrement.

The peculiar action, then, of solid, as opposed to fluid, animal excrements, is limited to their inorganic constituents,rather than to the presence of the partially changed vegetable or organized matter which they contain. Horsedung contains a large proportion of such partially altered vegetable matter; and the reason why night-soil is a more powerful manure, is that, relatively, it contains less vegetable matter, while nitrogen is more abundant; and this, principally, because its weight is materially made up by the liquid excrement, or urine, always forming part of its 
composition. Now, urine easily putrefies, and yields ammonia largely; and this because of its containing more animal matter than is contained in dung. A horse lives exclusively on vegetables; and 100 pounds of the urine of a healthy man (living, of course, partially upon flesh, and partly upon those seeds and parts of plants containing nitrogen, in quantity) will yield as much nitrogen as 1300 pounds of fresh horse-dung, or 600 of cow-dung. We cannot ascribe much of the power of the excrements of cattle, sheep, and horses, to the nitrogen which they contain, for the quantity derivable from these vegetable feeders is too minute. The restoration of inorganic matter to the land, is the chief value arising from the application of the dung of cattle. A certain amount of inorganic matter is removed with every crop. If we manure that land with the dung of the cow or sheep, we restore to the surface silicate of potash, and some salts of phosphoric acid. If we use horse-dung, we supply, chiefly, phosphate of magnesia and silicate of potash. In the straw which has served as litter, we add a further quantity of silicate of potash, and phosphates, which, if the straw be already putrefied, are exactly in the same state as before they formed part of the crop which yielded them.

But, if we use human excrements, in addition to the phosphates of lime and magnesia, we supply a larger proportion of compounds of nitrogen, essential to the development of those parts of plants upon which human beings are accustomed to feed: and, by a wise ordination, cereal-plants are found associated with human dwellings, -in other words, the farnily of man having selected such spots on the earth's surface as are fitted for the growth of grain, animal manure is always at hand in quantity for its artificial cultivation; thus restoring, through the feculent discharges of man and animals resident on the spot, precisely those materials which the process of growth has removed from the soil.

* Cow-dung is not incorrectly said to be "cold :" so much of the saline, nutritive, and other organic matters from the 
cow, pass off almost exclusively with her urine, that her dung does not readily heat and run into putrefaction. Still, mixed with other manures, or well diffused through the soil, its vegetable matter is not useless. It loses more than any other similar substance in drying. The dung of pigs is soft and cold, like that of the cow ; containing, like it, nearly 80 per cent. of water. Mixed with other manures, it may be applied to any crop; but is of very variable quality, owing to the variety of food of the animal.

The horse is fed, generally, on less liquid food, less succulent and watery, than that of oxen. He discharges less urine,-hence his dung is richer in animalized matter ; or, adopting the figurative language of the farmer, it is hotter, and, indeed, runs more readily into the putrefactive fermentation.

If the solid excrements of animals are chiefiy valuable for the saline, earthy, and inorganic constituents they restore to the soil which has yielded them, it will be readily inferred, that instead of dung or night-soil, other substances, containing their peculiar ingredients, may be substituted. One hundred tons of fresh horse-dung, if dried, would leave only from 25 to 30 tons of solid matter, the rest being only water; and if this dried matter (itself only one-fourth of the original weight) were burnt, so as to decompose its regetable ingredients, we should obtain, perhaps, 10 per cent. of really useful saline and earthy matters (one-fortieth of the original weight), according to the richness or poverty of the food the horse had taken.

Now, this minute proportion of saline and earthy matters, and its relative quantily, in the various kinds of dung or excrement, forms, evidently, the chief topic of interest to which our attention should be directed; inasmuch as what is left upon such examination and analysis, is exactly what has made up the component inorganic parts of the hay, straw, grass, or oats, on which the animal has been fed; or, in other words, exactly what has been removed from the soil, and requires to be replaced, if the next crop is to equal the last. If our object is increased fertility, 
more must be added than has been taken away. Hay, straw, and oats, form (for illustration' sake) the food of a horse. Their principal constituents are the phosphates of lime and magnesia, carbonate of lime, and silicate of potash; the first three of these preponderated in the corn, the latter in the hay; and these, removed from the soil with the crop, are precisely the saline matters which would be found in the excrement of the animal for whose support that crop was intended.

In order, then, to atone for the absence of that excrement which derives its value from the soil which has produced it, and for which it is peculiarly fitted, as containing what that soil has lost, the askes of wood or bones may often be judiciously substituted; and for this reason: woodashes contain silicate of potash, exactly in the same proportion as that salt is found to exist in the straw of the last crop ; and as to bones, the greatest part of their bulk consists of the phosphates of lime and magnesia. Ashes obtained from varions trees are of unequal value: those from oak-wood are the least, those from beech most serviceable. With every 100 pounds of the ashes of the beech spread over a soil, we furnish as much phosphates as 460 pounds of fresh night-soil could yield. But nightsoil contains other useful matters besides phosphates; hence the utility of mixed composts, as, evidently, the ashes of the beech would not alone secure fertility.

Bone manure possesses still greater importance than wood ashes as a substitute for an indefinite and large supply of animal excrement. The primary sources from which the bones of animals are derived are, - the hiay, straw, or other substances which they take as food. Now, bones contain more than half their weight of the phosphates of lime and magnesia ; and hay contains as much of these salts as wheat straw. It follows then, that 8 pounds of bones contain as much phosphate of lime as 1000 pounds of hay or wheat straw ; and 2 pounds of bones as much as is found in 1000 of the grain of wheat or oats. These numbers express pretty exactly the quantity of 
phosphates which a soil yields annually on the growth of hay and corn. Upon every acre of land appropriated to the growth of wheat, clover, potatoes, or turnips, forty pounds of bone-dust will be found sufficient to furnish an adequate supply of phosphates for three successive crops.

To secure the best application of bones, they should be reduced to powder; and the more intimately they are mixed with the soil, the more easily are they taken up and assimilated. The most easy and practical mode of effecting this, is to pour over the bones, in powder, half their weight of sulphuric acirl (or oil of vitriol), diluted with three or four parts of water; and after they have remained in contact for some time, say a fortnight, to add one hundred parts of water, and sprinkle this mixture over the field before the plow. Bones may be preserved unchanged, for thousands of years, in dry, or even in moist soils, provided the access of rain be preventerl, as is exemplified by the bones of animals, burier previous to the Flood, found in loam or gypsum; the interior parts being protected by the exterior from the action of water. But they become warm when reduced to a fine powder; and moistened bones generate heat, and enter into putrefaction - the gelatine which they contain is decomposed, and its nitrogen converted into carbonate of ammonia, and other ammoniacal salts, which are retained, in a great measure, by the powder itself. Bones burnt till quite white, and recently heated to redness, will absorb seven times their volume of ammoniacal gas. The analysis of bone enables us to say, that while 100 pounds of bone-dust add to the soil 33 of gelatine, the organized substance of horn, or as much organized matter as is contained in 300 or 400 pounds of blood or flesh; they add, at the same time, more than half their weight of inorganic matter, lime, magnesia, soda, common salt, and phosphoric acid, in combination with some of these-all of which, as we have seen, must be present in a fertile soil, since the plants require a certain supply of them all at every period of their growth, but more especially during the maturation of the straw 
and grain. These substances, like the inorganic matter of plants plowed into the soil, may, and do, exert a beneficial agency upon vegetation after all the organized structure of such decaying plants is broken up and destroyed. One hundred parts of dry bones contain 33 per cent. of dry gelatine, and are equivalent to 250 parts of recent human urine. We do not speak now of the bone-dust which remains after all the animal gelatine is removed, in boiling them to extract size for the calico-printer.

Hors is a still more powerful manure than bone-that is to say, it contains a greater proportion of organized animal matter. The peculiarity is, that horn, hair, and wool, as organized substances, are dry; while blood and flesh contain from 80 to 90 per cent. their weight of water. Hence, a ton of horn-shavings, of hair, or of dry woollen rags, ought to enrich the soil with as much animal matter (and consequently nitrogen) as would be yielded by ten tons of blood. In consequence of this dryness, horn and wool decompose more slowly than blood; and hence, the effect of soft animal matters is more immediate and apparent than that of hard and dry animal matters, the action of which is, nevertheless, stronger, and continues for a longer period.

The refuse of the different manufactories of skin and leather form very useful animal manures; such as the shavings of the currier, furrier's clippings, and the offals of the tan-yard and of the glue-maker. The gelatine contained in every kind of skin is in a state fitted for its gradual decomposition; and when buried in the soil, it lasts for a considerable time, and constantly affords a supply of nutritive matter to the plants in its neighborhood. These manures contain nitrogen as well as phosphates, and, consequently, are well fitted to aid the process of regetable growth.

From what has been stated, we may arrive at the following conclusions :-

1. That fresh human urine yields nitrogen in greater abundance to vegetation than any other material of easy 
acquisition; and that the urine of animals is raluable for the same purpose, but not equally so.

2. That the mixed excrements of man and animals yield (if carefully preserved from further decomposition), not only nitrogen, but other invaluable saline and earthy matters that have been already extracted in food from the soil.

3. That animal substances which, like urine, flesh, and blood, decompose rapidly, are fitted to operate immediately and powerfully on vegetation.

4. That $d r y$ animal sulstances, as horn, hair, or woollen rags, decompose slowly, and (weight for weight) contain a greater quantity of organized as well as unorganized materials, manifesting their influence, it may be, for several seasons.

5. That bones, acting like horn, in so far as their animal matter is concerned, and like it, for a number of seasons more or less, according as they have been more or less finely crushed, may ameliorate the soil by their earthy matter for a long period (even if the jelly they contain have been injuriously removed by the size-maker), permanently improving the condition and adding to the natural capabilities of the land.

\section{CHAPTER IX.}

Of the comparative Value of Vegetable Manure, as contrasted with Animal Excrements.

IT may be asked, if the principal sources of the nitrogen required for the artificial forcing of corn-plants be the feculent excretions of man and animals-if the object be chiefly to replace in the soil those matters which have been abstracted with the previous crop-how is it that such excrements more effectually restore those elements than would occur if the ripe crop were plowed into the 
soil; in other words, how is it that dung and urine are richer in nitrogen than the food from which they are formed?

The answer is easy and obvious. The Buli of a vegetable is chiefly woody fibre or carbon. A horse lives exclusively upon regetables, and discharges from his lungs, in breathing; a large portion of the carbon his food contains; hence, what is left to be thrown off from his kidneys and bowels, contains relatively a greater proportion of nitrogen which could only be otherwise feebly supplied to the soil from the rain-water of the atmosphere, while the air yields to the land carbon in abundance. Nearly the whole of the nitrogen contained in his food (indeed, all beyond what is necessary for the wants of his own living system) is thrown off in his urine and dung. In the food consumed, the carbon was to the nitrogen as 9 to 1 : in that which remains, after breathing has done its work, the carbon is to the nitrogen in the proportion of only 2 to 1 . It is out of this residue, rich in nitrogen, that the several parts of animal bodies are built up. Warm-blooded animals with capacious lungs, double and triple their weight very rapidly after birth: they take in (as lambs or calves after separation from the parent) only vegetable food; but the rapidity of its decomposition is the index or ratio of the rapidity of their growth. Their actions are lively; and the playful exertion of their muscles renders the decomposing play of the heart, and consequently of the lungs, more frequent than when fully grown. During their quick growth, they absorb all the nitrogen their food contains, while they throw off carbon from the lungs. After growth is finished, they still throw off, in breathing, nearly all the carbon, while the residual quantity of nitrogen (not wanted for the purposes of the living system) escapes in the dung and urine. The urine of a child would not, upon putrefaction, disengage the same quantity of ammonia as that of a full-grown man. Hence the reason why bodies can be nourished and built up upon food comparatively poor in nitrogen; and yet 
1 ot only do those same bodies contain nitrogen in quantity, but also their excretions are rich in the same element. The more nitrogen that is appropriated by growing cattle, the less will pass off into the fold-yard; hence it is natural to expect that the manure, either liquid or solid, which accumulates where many young animals are fed, will not be so rich as that yielder by full-grown cattle, unless, by giving richer food to the young cattle than they actually require or can dispose of, the difference to the dung-heap be made up. A little acquaintance, then, with first principles will explain the seeming difficulty, how it is that the dung or urine of animals has a greater fertilizing power than even the whole weight of the food which they have consumed would have, if laid upon the soil. Its carbon has passed through the lungs of animals that have eaten it into the atmosphere: and the soil can always supply itself with sufficient carbon from the decomposition of the carbonic acid of the air: while its natural supply of nitrogen for the plants which grow on its surface is limited to the decomposition of the ammonia, and the erolution of nitrogen from rain-water, - a quantity which, though sufficient for the sustenance of crabs, will not serve for apples; and we must remember, that corn-plants are not in a state of nature, - wild oats or potatoes are widely different from the same plants under the care and culture of man. The difference between a wild and a cultivated vegetable is not merely an increment of size, but the development of those parts which, though naturally containing nitrogen, contain, proportionally, far less than by artificial culture they may be compeller to take up.

The doctrine of the proper application of manures from organized substances offers an illustration of an important part of the economy of nature, and of the happy order in which it is arranged. The death and decay of animal substances tend to resolve organized forms into elementary constituents; and the pernicious effluvia disengaged in the process seem to point out the propricty of burying them in the soil, where they are fitted to become the food of vege- 
tables. The fermentation and putrefaction of organized substances in the free atmosphere are noxious processes; beneath the surface of the ground, they are salutary operations. In this case, the food of plants is prepared where it can be used; and that which would offend the senses and injure the health, if exposed, is converted, by gradual processes, into forms of beauty and of usefulness; the stinking gas is rendered a constituent of the perfume of a flower ; and what might be poison, swells the food of animals and man.

\section{H A P T E R. X.}

Of Manures of Mineral Origin, or Fossil and Artificial or Chemical Manures; their Preparation, and the Manner in which they Act.Of Lime in its Different States; its operation as a manure.-Of Alkalies, and Common Salt, as to their Action upon the Land.

Frour what has been already said, a great variety of substances contribute to the growth of plants, and supply the materials of their nourishment. How matters that have once been living are in turn converted into the substance of other living things, may be comprehended; but it is more difficult to understand those operations by which earthy and saline matters are taken up and consolidated in the fibre of vegetables.

Sir Humphrey Davy, quoting the experiments of continental chemists who had preceded him, states, on their authority, that different seeds sown in fine sand-flour of brimstone, or rust of iron, and supplied only with air and water, produced healthy plants, which by analysis yielded various earthy and saline matters, which were not contained either in the seeds or the material in which they grew ; and hence they and he concluded, that they must have been formed from air or water, in consequence of the agencies of the living organs of the plant. 
It would be impossible to pass this interesting fact, without observing how strikingly it confirms the views advanced in the preceding pages as to the origin of nitrogen from the ammonia in rain-water. Sir Humphrey contends, from some subsequent experiments, that the atmosphere yields no saline matter to plants; but the existence of ammonia in rain-water, if not unknown to that distinguished chemist, was overlooked in his computation.

The only substances that can, with propriety, be called fossil manures, and which are found unmixed with the remains of any organized beings, are certain alkaline earths, or alkalies, and their combinations.

The only alkaline earths which have been hitherto applied in this way, are Lrme and mugnesia. Potash and soda, the two fixed alkalies, are both used in certain of their chemical compounds, but never in a pure or caustic state.

The most common form in which LIME is found on the surface of the earth, is in a state of combination with carbonic acid. We have already alluded to some of its chemical properties in a previous section of this work. When common limestone is burnt in the kiln, the carbonic acid gas is driven off by the heat, and nothing remains but the pure caustic earth. If the fire have been very high, it approaches to one-half the weight of the stone; but, in common cases, limestones, if well dried before burning, do not lose much more than from 35 to 40 per cent., or from 7 parts to 8 out of 20 .

Very few limestones, or chalks, consist entirely of Jime and carbonic acid. Statuary marble is nearly a pure carbonate of lime. When a limestone does not copiously effervesce in acids, and is yet sufficiently hard to scratch glass, it contains the earth of fint, and, probably, the earth of clay. When brownish or yellowish-red, the tinge, in all probability, depends upon the presence of irnn. If not hard enough to scratch glass, if the stone effervesce slowly or but slightly with acids, and the solution have a milky appearance,--most probably magnesia is present. 
Before any opinion be formed of the manner in which the different ingredients in limestones modify their properties, and their consequent action upon the soil, it will be necessary to consider the action of pure, or recently burnt caustic lime, when employed for agricultural purposes.

Quicklime,-in its pure state, whether in powder, or dissolved in minute proportion, in water,-is directly injurious to plants. Grass may be certainly killed by sprinkling it with lime-water; but since lime is a necessary ingredient in soils, and an useful addition in many cases, it evidently must be that its combination with carbonic acidthe state in which it is found naturally - is the circumstance which not merely renders it void of causticity, but so far alters its properties, as to exchange injury for advantage. Lime, if pure, and recently burnt, cannot long remain caustic, inasmuch as it rapidly attracts sufficient carbonic acid from the atmosphere to reduce it to the state of chalk, or a carbonate; and it is a wise arrangement that it is so, - that it is never found, in nature, pure, or free from this acid.

Nevertheless, there are cases in which the application of caustic lime may be requisite. If it be mixed with any moist, fibrous, vegetable matter, there is a strong action between the lime and the vegetable fibrin: they form a lkind of compost together, of which a part is usually soluble in water. By this kind of operation, lime renders matter which was comparatively inert, nutritive, or, at least, soluble; and as charcoal and oxygen abound in all plants, the lime becomes at the same time usefully converted, even by their agency, into a carbonate. It is obvious, then, that the operation of quicklime, and that of marl or chalk, depends upon principles altogether different. Quicklime, in being applied to land, tends to bring any hard vegetable matter that it contains into a more rapid and easy state of decomposition; while chalky forms of lime only add the necessary amount of this earth, so as to furnish the requisite supply to be absorbed as part of the inorganic structure of the plants which grow in that spot, Quicklime, when 
it becomes mild by exposure, acts in the same way as chalk, but, in the act of becoming mild, it prepares soluble out of insoluble matter.

It is upon this circumstance that the operation of lime in the preparation for wheat crops depends, and its efficacy in fertilizing peats, and in bringing into a state of cultivation all soils abounding in hard roots, dry fibres, or undecomposed and, therefore, useless vegetable matter.

So, then, the solution of the question, Whether quicklime ought to be applied to a soil ? depends upon the quantity of the undecomposed regetable matter that soil contains ; and the answer to the question, Whether marl, or any chalky carbonate of lime, ought to be applied? evidently depends upon whether the previous crops have exhausted the requisite quantity of lime necessary to form part of the inorganic material of the crop that is intended to be raised there. All soils are improved by mild lime, because each successive crop takes a portion of lime away. But, perhaps, one of the most important and influential agencies of lime in the soil to which it is added, is to be found in its ready combination with nitric acid, which it assists in forming, from the facility with which it promotes the union of its already existing elements, nitrogen and oxygen. Nitrate of lime, which, by a series of inevitable actions, is produced in the decomposing soil, is very soluble in water: entering readily into the roots of plants, it forms the medium by which lime becomes part of a vegetable, (for, as before stated, the earths and alkalies never enter a plant in a pure, free, caustic, or uncombined state), and producing upon growth effects precisely similar to those of the now well-known nitrate of soda. Plowing, harrowing, digging, and turning over the soil to the action of the air, is useful, chiefly, because it facilitates the more ready action of the atmosphere, indispensable to the formation of these nitrates.

Besides pure, or caustic lime, and its carbonate, in the form of chalk or marl, the application of gypsum, or suLPHATE OF LIME, - sometimes called alabaster, or plaster of 
Paris,-deserves a passing notice. Great difference of opinion has prevailed among agriculturists as to its use. Correct notions as to the nature of vegetable growth, an exact acquaintance with the constitution of plants intended to be raised upon a given locality, and the admitted necessity for an equally exact acquaintance with the existing condition of that soil, so as to adapt the one to the other, -in fact, a better knowledge of agricultural chemistry,is all that alone is wanting, or can solve the variety of opinion as to its employment. Doubtlessly, if lime be deficient in a soil, though marl, or the carbonate, is more easily susceptible of action, the sulphate or gypsum, which is less so, less easily decomposed, is better than none. Sulphuric acid has a stronger affinity for lime than carbonic acid can exert; hence, gypsum does not so readily enter into new combinations. It has been said, that sulphate of lime assists the putrefactive decomposition of animal substances, - that it hastens the evolution of ammonia, and the consequent development of nitrogen; but the experiments of Sir Humphrey Davy disprove this view of the case. It would appear that peat-ashes naturally contain gypsum in abundance. These peat-ashes are used with advantage in some parts of the country, as a top-dressing for cultivated grasses, particularly clover ; and, in examining the ashes of sainfoin and clover, they have been found to contain gypsum in quantity, proving that lime, in the form of a sulphate, is a necessary ingredient in the constitution of some vegetables. The practical deduction from such investigations obviously is, that if clover be intended to be raised upon a soil deficient of lime, in the form of a sulphate, gypsum will not only constitute an advantageous manure, but one that is absolutely essential to the production of a vigorous, abundant, and healthy crop.

Phosphate of lime is another combination of this earth with an acid. It forms the greatest part of calcined bones, of the utility and application of which we have already spoken. It exists in most excrementitious substances, and is an essential constituent of the straw and grain of wheat, 
barley, oats, and rye, and likewise in beans, peas, and vetches. It exists in some places, in these islands, native, but only in small quantities. Phosphate of lime is generally conveyed to the land in the composition of other manure, and is absolutely necessary to corn crops. Boneashes, ground to powder, are useful on arable land that is deficient in lime, or its phosphate, especially if there be a superabundance of vegetable matter. If lime, or its phosphate, be the only deficient ingredient in the land,-if it already contain, or be at the same time supplied with animal manure, yielding nitrogen,- - then bone-dust may prove useful.

WooD-AsHes consist principally of the regetable alkali, or potash, united to carbonic acid; and as this alkali is found in almost all plants, it is not difficult to conceive that it may form an essential part of their organs. The general tendency of the alkalies applied as manure is, to supply the deficiency occasioned by what is removed with the previous crops. Wood-rsh contains not only carbonate of potash, but also the sulphate of potash and silicate of potash ; hence its utility, as affording silex to wheat straw, - a material essential to its firmness and stability. These saline matters in wood-ash are all valuable, as supplying the necessary inorganic constituents of plants; and hence the extensive use of wood-ash, as a manure, in every country where it can readily be procured.

Peat-Ashes vary, in constitution, with the kind of peat from which they have been prepared. They often contain traces of potash and soda, and generally a quantity of sulphate and carbonate of lime, a trace of phosphate of lime, and much siliceous matter. In almost every country where peat abounds, the value of peat-ashes, as a manure, has been more or less generally recognized.

KELP.-The ash left by the burning of sea-weed contains potash, soda, silica, sulphur, and several other of the inorganic constituents of plants, and is usefully and extensively employed in many districts near the sea, where plants naturally requiring these materials grow more luxuriantly 
than in more inland districts. Sea-weeds decompose with great rapidity when collected in heaps and laid upon the land. During their decay, they not only yield inorganic saline matter to the soil, but enrich it with an additional layer of vegetable mould.

Jitraie of soda, and nitrate of potasil, or saltpetre.-These substances have been much commended for their beneficial action upon growing plants. They impart to the leaves a deeper green, and evidently quicken vegetable action: they are applied advantageously to grass and young corn, at the rate of a hundred weight of either to an acre. The nitric acid they contain yields the additional nitrogen beyond the quantity the plants can obtain by decomposing the ammonia contained in the rain that falls upon them; at the same time, the other ingredient--potash or soda, as the case may be--is put within the reach of their roots, to be absorbed as an inorganic, yet necessary constituent.

Common salt, muriate of soda, or, more correctly, a compound of the metal sodium with elementary chlorine, is undoubtedly indispensable to the fertility of many inland soils. It is not without design that the spray of the sea is allowed to be borne by the winds for many miles orer the shore, so supplying an ample dressing of common salt to the land. A minute quantity is absolutely necessary to the healthy growth of all our cultivated crops, and most lands (in this island at least) contain a sufficient quantity of it for the purposes of vegetation. Common salt is found in every species of animal manure, and will be found most requisite in high situations exposed to the washing of heavy rains, which tend to remove the soluble alkaline matters from the soil.

Much diversity of opinion has prevailed as to the utility of this substance. The Cheshire farmers plead in its favor. On the other hand, that salt, in large quantities, renders land barren, was known long before any records of agricultural science existed. We read in Scripture, that Abimelech took the city of Shechem, and sowed the land with salt, that the spot might be for ever unfruitful. Pliny. 
a Latin historian, though he recommends giving salt to cattle, yet affirms, that when strewed over land it renders it barren. But these form no argument against the proper application of it. There can be no question that salt, as well as many other similar mineral substances, is really useful to vegetation; yet the intelligent agriculturist ought not to be surprised to find, that a substance which is useful, because necessary and deficient in one instance, may be positively in excess, and consequently injurious, if added in another. He will try cautiously, and upon a small seale, whether this or that material seems fitted to answer his intention; or, what is far better than blind hit-or-miss experiment, he will endeavor to ascertain the actual constitution of the soil, and not expect to grow wheat where there is no phosphate of lime or silicate of potash; nor plants which thrive best near the sea, in a soil which he knows to be devoid of common salt. If salt be there, it is a needless and foolish waste to attempt to improve the land by adding more. If he has already bricks enough at hand, you must carry the builder mortar : more bricks will not supply the place of mortar. So, if the soil contain lime, or magnesia, or potash, in sufficient abundance for the wants of the plant it is our object artificially to force, it may still be deficient of other materials, and here the skill and science of one man stand in beautiful contrast with the blundering, bungling guesses of another.

At a meeting of the Chemical Scciety, a paper was lately read containing a report of some experiments with saline manures containing nitrogen, conducted on the Manor Farm, Havering-atte-Bower, Essex, in the occupation of C. Hall, Esq., communicated by W. M. F. Chatterley, Esq. The experiments were suggested by the prevailing opinion, that the fertilizing power of some animal manures, and of the salts, nitre, (nitrate of potash), nitrate of soda, and sulphate of ammonia, depend upon the proportion of nitrogen they contain. The salts mentioned are all, from their low price, within the reach of the farmer; and the quantity of the last thrown into the market is 
greatly increasing, from the extension of the new mode of purifying coal-gas from its ammonia, by washing the gas with dilute sulphuric acid. The interest also of experiments with salts is greater than with mixed manures, both to the farmer, who, from the nature of the former substances, may depend upon their uniformity, and to the chemist, as their composition is necessarily known to him. A field of wheat was chosen, which, in the latter end of April, 1842, presented a thin plant; the salts were topdressed over the land by hand, on the 12th of May, and the crop cut on the 10th of August. The soil was rather poor, consisting of a heavy clay upon a subsoil of the London clay. 1. No manure; wheat per acre $1413 \mathrm{lbs} .2$. With 28 lbs. of sulphate of ammonia; wheat, 1612 lbs. 3. With 140 lbs. of the same salt; wheat 1999 lbs. 4 . With 112 lbs. of nitrate of soda; wheat 1905 lbs. 5 . With 112 lbs. of nitre; wheat, 1890 lbs. The increase in the straw was also considerable in all cases, except with the small proportion of sulphate of ammonia. The total increase in the four manured crops was per cent., in the order in which they were enumerated, $-14 \cdot 1,41 \cdot 5,34$, and 33.5 . The cost of the manure for the three last did not greatly differ, being 21s. 9d., 24s. 6d., 27s. 6d.; and the profit on the outlay was, with the small close of sulphate of ammonia, 294 per cent. ; with the large dose, 212 per cent.; with the nitrate of soda, 138 per cent.; and with the nitrate of potash, 92 per cent. The principal conclusions drawn by the author are, that the increase of nitrogen in the crop is greater than is accounted for by the nitrogen of the manures, showing that these manures have a stimulating effect, or enable the plants to draw additional nitrogenized food from the soil and atmosphere; the considerable superiority of sulphate of ammonia over the other salts, and the greater proportional efficiency of a small, than of a large dose of that salt. The sulphate of ammonia costs $17 \mathrm{~s}$. per cwt. It appears best to apply this salt in the proportion of about $1 \mathrm{cwt}$. per acre, at three different dressings: the first quantity when the crop of wheat 
makes its spring growth, or if of oats, when about two inches above the ground; the second quantity about a month afterwards ; and the third at the time of the formation of the ear. To meet the practical difficulty of distributing so small a quantity as one-third of a hundred weight over an acre, about twice the quantity of common salt or of soot may be mixed with the ammoniacal salt. These, and most saline manures, when used as a top-dressing; should be supplied to the plant when dry, after a shower of rain, or during hazy weather.

That which was true in the day of Sir Humphrey Day, when experimental agricultural chemistry was in its infancy, is equally true at the present moment. He observes that " much of the discordance of the evidence relating to the efficacy of saline substances depends upon the circumstance of their having been used in varying proportions, and in general in quantities much too large." That which is salutary and medicinal in moderate doses, not only may be, but is, absolutely poisonous in another.

Sir Humphrey made a number of experiments on the effects of different saline substances on barley and on grass growing in the same garden, the soil of which was a light sand, of which 100 parts were composed of 60 parts of siliceous sand, and 24 parts finely-divided matter, consisting of 7 parts carbonate of lime, 12 parts alumina and silica, less than one part saline matter, principally common salt, with a trace of gypsum and magnesia; the remaining 16 parts were vegetable mould.

The solutions of the saline substances were used twice a week, in the quantity of two ounces, on spots of grass and corn, sufficiently distant from each other to prevent any interference of results. Several of the salts of potash, soda, magnesia, and ammonia, were experimentally and separately employed. He found that in all cases, when the quantity of the salt equalled one-thirtieth part of the weight of the water, the effects were injurious; but least so with the salts of ammonia. When the quantities of the salts were one part in three hundred of the solution, or 1 
pound to 300 pounds of water, the effects were different. Those spots watered with the solution of carbonate of ammonia were most luxuriant of all. This last result is what might be expected (and it agrees well with the theoretic views of later chemists), inasmuch as carbonate of ammonia is made up of carbon, oxygen, hydrogen, and nitrogen; all of which are essential to the supply of the additional quantities artificial plants require beyond that they can naturally obtain from the surrounding atmosphere. $\mathrm{He}$ observes that the solution of nitrate of ammonia seemed to be of no greater use than rain-water, and he attributes its failure to the circumstance of the acid being in excess. But Sir Humphrey was not aware that rain-water actually contains ammonia ; it was left to the genius of Liebig, in our later day, to develope that discovery.

\section{CHAPTER. XI.}

Of the Composition of Productive Soils, and of the Agency of the Elements in their Natural Formation, from the rocks upon which they rest.

WE may now take it for granted, that every practical farmer will admit the position as proved, namely, that there must be an exact adaptation and fitness between the condition of any given soil and the plants intended to be raised upon it; and that, if this condition does not exist naturally, it not only may be, but must be, artificially remedied.

At this stage of the inquiry, it will be our endeavor to anticipate further question, and to give an exact account of the chemical constitution of such soils as are known to be best suited to the cultivation and growth of green as well as corn crops.

There are in existence as many varieties of soils as 
there are species of rocks exposed at the surface of the earth. In fact, there are many more. Independently of the changes produced by cultivation and the exertions of human labor in tearing down and breaking up the surface, the materials of various layers have been mixed together and carried from place to place by various great alterations that, during a succession of ages, have been silently yet constantly carried forward in the system of our globe, together with the united agencies of air, water, and the varying alternations of summer's heat and the cold of winter.

To attempt to class soils with scientific accuracy would be a needless labor; the distinctions adopted by farmers are sufficient for our present purpose, particularly if some degree of exactitude be maintained in the application of terms. A full knowledge of modern geology is not necessary to enable a man to determine whether a field is best suited for arable or grazing purposes ; nor is it our intention needlessly to employ the scientific appellations which would only puzzle because they are incomprehensible to minds unfamiliar to geological nomenclature. The expression " a sandy soil," is well understood; but let it never be applied to any soil that does not contain at least three parts out of four of sand. Then, again, sandy soils that effervesce or give off carbonic acid or fixed air, when vinegar or vitriol is poured upon them, should be distinguished by the name of "sandy limestone soils," to mark them from sandy soils that contain silex or the earth of flint. The term "clayey soil," should not be applied to any land which contains less than one-sixth of an earthy matter not effervescing with acids; while the word "loam" should be limited to such soils as contain one-third of a smooth earthy matter, considerably effervescing with acids. A soil to be considered "peaty" ought to contain at least one-half of vegetable matter.

Soils perform at least three functions in reference to vegetation. They serve as a basis in which plants may fix their roots and sustain themselves in the erect position 
-they are the medium through which the greater part of the inorganic matter of vegetables is supplied to them during their growth-and they allow many chemical changes to take place that are essential to a right preparation of the various kinds of food which are yielded to the growing plant.

The best Natural soILs are those whence the materials have been derived from the breaking up and decomposition, not of one stratum or layer, but of many, divided minutely by air and water, and minutely blended together; and in improving soils by artificial additions, the farmer cannot do better than imitate the processes of nature.

We have spoken of soils as consisting mostly of sand, lime, and clay, with certain saline and organic substances in smaller and varying proportions; but the examination of the ashes of plants shows that a fertile soil must of necessity contain an appreciable quantity of at least eleven different substances, which in most cases exist in greater or less relative abundance in the ash of cultivated plants ; and of these the proportions are not by any means immaterial. The labor requisite for the permanent improvement of land is repaid by correspondent advantage; the materials for the necessary adjustment are seldom far distant. If coarse sand be requisite, it is mostly or often found immediately over the chalky soil that need's it ; and beds of sand and gravel are common below clay. Capital laid out in this way, secures for ever the productiveness and consequent value of the land.

In ascertaining the composition of barren soils with a view to their productiveness, or of partially unproductive land, in order to its amendment, they should be compared with fertile soils in the same neighborhood, and in similar situations; as the difference of composition will, in most cases, indicate the proper methods of improvement. For instance, if on washing a portion of sterile soil it be found to contain largely any salt of iron, or any acid matter, it may be ameliorated with quick-lime, which removes the sourness, or, in other words, combines with and neutralizes 
the acid. For though pure fresh burnt caustic lime is injurious to vegetation, yet in combination with acid (as in chalk) it proves eminently serviceable. A soil, apparently of good texture, was put into the hands of Sir Humphrey Dary for examination, said to be remarkable for its unfitness for agricultural purposes; he found it contained sulphate of iron, or green copperas, and offered the obvious remedy of top-dressing with lime, which decomposes the sulphate. So if there be an excess of lime, in any form, in the soil, it may be removed by the application of sand or clay. Soils too abundant in sand are benefited by the use of clay or marl, or vegetable matter. To a field of light sand that had been much burnt up by a hot summer, the application of peat was recommended as a top-dressing: it was attended not only with immediate advantage, but the good effects were permanent. A deficiency of vegetable or animal matter is easily discoverable, and may as easily be supplied by manure. On the other hand, an excess of vegeiable matter may be removed by paring and burning, or by the application of earthy materials. The effect of paring and burning is easily understood. The matted sods consist of a mixture of much vegetable with a comparatively small quantity of earthy matter; when these are burned, only the ash of the plant is left, intimately mixed with the calcined earth. To strew this mixture over the exposed soil is much the same as dressing it with peat or wood ashes, the beneficial effects of which upon vegetation are almost universally recognized. From what has been already said, it will be easily evident, that the beneficial effect of the burnt ash is chiefly owing to the ready supply of inorganic and saline material it yields to the seeds which may afterwards be scattered there; besides which, the roots of weeds and poorer grasses, if not exterminated by the paring, are so far injured as to lead to their death and subsequent decomposition.

The improvement of peats or log s, or marsh lands, must be preceded by DRAINING, stagnant water being injurious to all the nutritive classes of plants. Soft black peats, when 
drained, are often made productive by the mere application of sand or clay as a top-dressing. The first step to be taken, in order to increase the fertility of nearly all improvable lands, is to DRAIN them. So long as they remain wet, they will continue to be cold. Where too much water is present in the soil, that food of the plant which the soil supplies is so much diluted and weakened that the plant is of necessity scantily nourished. By the removal of the superfluous water, the soil crumbles, becomes less stiff and tenacious, air and warmth gain ready access to the roots of the growing plant; the access of air (and consequently of the carbonic acid which the atmosphere freely supplies) being an essential element in the healthy growth of the most important vegetable productions. Every one knows that when water is applied to the bottom of a flower-pot full of soil it will gradually find its way to the surface, however light that soil may be: so, in sandy soils or subsoils in the open field. If water abound at the depth of a few feet, or if it so abound at certain seasons of the year, such water will rise to the surface; and as the sun's heat causes it to dry off, more water will rise to supply its place. This attraction from beneath will always go on most strongly when the air is dry and warm, and so a double mischief will ensue; the soil will be kept cold and wet; and instead of a free passage of air downwards about the growing roots, there will be established a constant current of water upwards. Of course, the remedy for all this is an efficient system of drainage.

In general, the soils which are made up of the most various materials are those called alluvial, which have been formed from the depositions of floods and rivers. Many of these are extremely fertile. Soils consist of two parts; of an organic part, which can readily be burned away when the surface-soil is heated to redness; and of an inorganic part, which remains fixed in the fire, consisting of earthy and saline substances; from which, if carbonic acid, or any elastic gas be present, it may, however, be driven by the heat. The organic part of soils is 
derived chiefly from the remains of regetables and animals which have lived and died in and upon the soil, which have been spread over it by rivers and rains, or which have been added by the industry of man for the purposes of increased fertility.

This organic part varies much in quantity, as well as quality, in different soils. In peaty soils it is very abundant, as well as in some rich long cultivated lands. In general, it rarely amounts to one-fourth, or 25 per cent., even in our best arable lands. Good wheat soils contain often as little as 8 parts in the 100 of organic animal or vegetable matter: oats and rye will grow in a soil containing only $1 \frac{1}{2}$ per cent.; and barley when only 2 or 3 parts per cent. are present. In very old pasture-lands, and in gardens, vegetable matter occasionally accumulates, so as to be injurious, and overload the upper soil. This decaying vegetable, or animal matter, is the "humus" previously adverted to, and incorrectly supposed, before our day, to afford almost the sole nutriment essentially necessary to the growing plants. That living plants derive from the remains of their decayed predecessors the advantage of being placed in contact with the inorganic or saline materials those plants once contained, is not to be denied. But unless the whole crop were plowed in, every year, this quantity would be exceedingly minute. The true value of green crops plowed into the soil, or of decaying vegetable matter, the "humus" of former writers, is the formation of carbonic acid by the combination of decomposed carbonaceous or woody fibre with atmospheric oxygen; thus supplying to the new and young roots carbon in a form susceptible of being taken up by them.

The inorganic portion of any given soil is again divisible into two portions-namely, that part which is soluble in water, and, therefore, in a state easily susceptible of being taken up by the ressels of a growing vegetable, and of a further and much more bulky portion which is insoluble in water. The soluble portion consists of saline substancesthe insoluble, of earthy materials. 
A single grain of saline matter in every pound of a soil a foot deep, is equal to 500 pounds in every acre, which is more than is carried off from the land in the course of 40 years, supposing that the wheat and barley are sent to market, and the straw and green crops are regularly returned to the soil in the shape of manure.

Sprengel, a German chemist, now at the head of the Prussian agricultural school, whose own taste, as well as his professional duty, have long directed his attention to scientific cultivation of the soil,-has published an exact analysis of two varieties of productive soil, of which the following is an abstract :-

The first is a very fertile alluvial soil from East Friesland, formerly overflowed by the sea, but, for sixty years, cultivated with corn and pulse without manure.

The second is a fertile soil near Göttingen, which produces excellent crops of clover, pulse, rape, potatoes, and turnips; the two last more especially uhen manured with gypsum.

One thousand parts of each of these soils, after washing, gave-

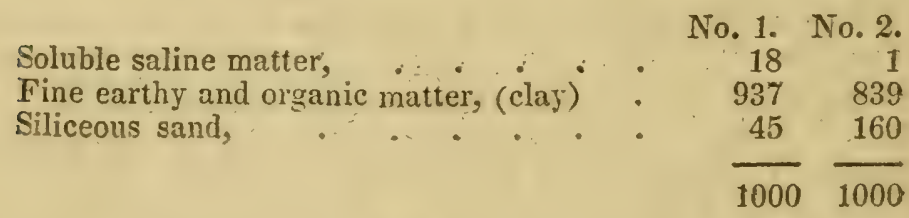

The most striking distinction presented by these numbers is the large quantity of saline matter in the first variety. It consisted of common salt, muriate of potash, the sulphates of potash, gypsum, magnesia, and iron, with phosphate of soda, and other salts. The presence of this comparatively large quantity of these different saline substances, originally derived, no doubt, in great part from the sea, was probably one reason why it could be so long cropped without manure. Its composition illustrates the truth of the statement, that a considerable supply of ALL the 
species of inorganic materials is necessary to render a soil eminently fertile. Not only does this soil contain a comparatively large quantity of the soluble saline matters above enumerated, but it contains also 10 per cent. of organic matter, and some lime. The potash and soda, and the several acids, are also present in sufficient abundance.

In the second instance, a fertile soil, but which could not dispense with manure, there is litile soluble saline matter; and in the insoluble portion, only traces of potash, soda, and important acids. It contains, also, 5 per cent. of organic matter, and 2 per cent. of lime, which smaller proportions, together with the deficiency of allalies, remove this soil from the most naturally fertile class, to that class which is susceptible, in hands of ordinary skill, of being brought to, and leept in a very proluctive condition.

Sir Humphrey Davy examined some productive soils, which were very different in their composition.

We will state the analysis of a fer of them.

Soil from Holkham, Norfolk, described as a "good turnip soil," contained 8 parts out of 9 of siliceous sand; that is, sand with flint earth, or silex: the remaining 1-9th part consisted, in every 100 grains, of-

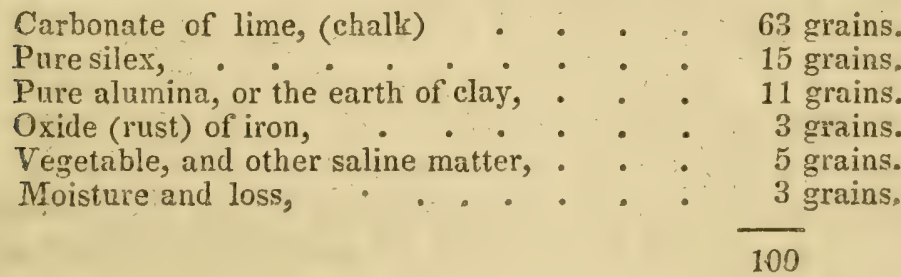

Thus the whole amount of organic matter in this instance is only 1 part in 200 , or one-half per cent.; a fact which, in itself, would demonstrate the fallacy of supposing that decomposed animal and vegetable matter in the soil forms the exclusive supply to growing plants.

In another instance, soil was taken from a field in Sussex, remarkable for its growth of flourishing oak trees. It 
consisted of 6 parts of sand, and 1 part of clay and finelydivided matter. One hundred grains of it yielded, in chemical language-

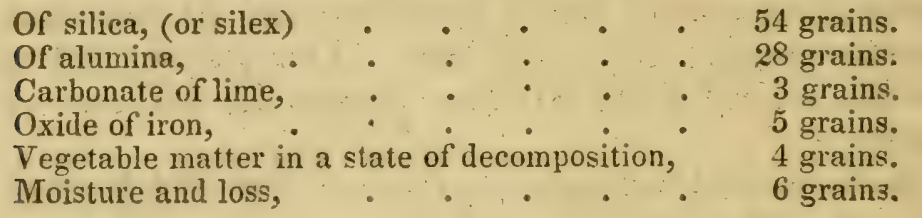

100

To wheat soils, the attention of the practical farmer will be most strongly directed. An ExcELLENT wheat soil from West Drayton, in Middlesex, yielded 3 parts in 5 of siliceous sand; and the remaining two parts consisted of carbonate of lime, silex, alumina, and a minute proportion of decomposing animal and vegetable remains.

Of these soils, the last was by far the most, and the first, the least coherent in texture. In all cases, the constituent parts of the soil which give tenacity and stiffness, are the finely-divided portions; and they possess this quality in proportion to the quantity of alumina (or earth of clay) they contain. A small quantity of this finely-divided matter is sufficient to fit a soil for the growth of turnips, or of barley, as turnips will grow (though it is not to be expected they will thrive) on a soil containing 11 parts out of 12 of sand. Sand in much greater proportion, or rather disproportion, produces sterility. So pure alumina, or pure silex, pure chalk, or magnesia, are incapable of supporting vegeiation; and no soil is fertile that contains 19 parts out of 20 of any one of the materials that have been mentioned.

Sprengel gives also the analysis of an unproductive soil from Luneburg. It contained, in 1000 parts-

Soluble saline matter,

Fine earthy and organic matter, (clay) .

Siliceous sand,
1 part. 599 parts. 400 parts. 
This unfruitful soil, compared with the analysis given of the other two on a previous page, will be found to be the lightest of the three, containing 40 per cent. of sand. But this alone is not enough to account for its barrenness, many light soils containing a larger proportion of sand, and yet sufficiently fertile. One thousand parts of its fine earthy matter contain 40 of organic matter instead of 97 , -778 of silica instead of $648,-91$ of alumina instead of $57,-4$ of lime instead of $59,-1$ of magnesia instead of $10,-81$ of oxide of iron instead of 61 ; while potash, soda, ammonia, chlorine, sulphuric acid, phosphoric acid, carbonic acid, are entirely wanting; such being the ingredients and quantities in 1000 parts of the finer portion of the very fertile soil from East Friesland. The oxide of iron is in excess in the Luneburg barren soil ; there requires, therefore, to be added, not only those substances of which it is destitute, but such other matters as shall prevent the injurious effects of the excessive proportion of iron. This illustration may serve to aid the practical farmer in comprehending how far exact chemical analysis is fitted to throw light upon the capabilities of soils, and to direct agricultural practice. The constitution of a soil, like the constitution of a horse, or a human being, requires to be known and understood, if we would prescribe otherwise than at random, expensively, unprofitably, or injuriously, either for the diseases of the one, or for the deficiencies of the other.

The varying power of soils to absorb and retain water from the air, is much connected with their fertility. Sir Humphrey Davy has remarked upon this; and connecting his statement with the fact, that rain-water always contains ammonia, and, consequently, nitrogen (as one of the elements of ammonia), we can easily understand why it should be so. He observes, that "the soils which are most efficient in supplying a plant with water by absorption and retention from the atmosphere, are those in which there is a due mixture of sand, finely divided clay and chalk, with some animal and vegetable matter; and yet so loose 
and light, as to allow of the action of the air beneath the surface." Sand in excess destroys the requisite stiffness of the soil, but gives little absorbent power.

The absorbent power of land is always greatest on the most fertile soils, thus affording one ready test of productiveness. One thousand grains of soil, rendered perfectly dry by exposure to heat equal to that of boiling-water, ought, by exposure to air, saturated with moisture, to gain in weight, at least, 18 grains, or one-fiftieth; so that the standard of fertility of soils for different plants must vary with the climate, (as well as the rarying constitution of the soil itself), and be particularly influenced by the quantity of rain that falls upon it. The power of soils to absorb moisture ought to be much greater in warm or dry counties, than in cold, marshy places; and the quantity of clay they contain, greater. The inference is obvious: if deficient, it ought to be added. Soils, also, on the slope of a hill, ought to be more absorbent than in plains, or in the bottom of valleys. Their productiveness is also much influenced by the nature of the subsoil on which they rest; for, when soils are immediately situated upon a bed of rock or stone, they dry sooner by the sun's agency, than when the subsoil is clay or marl. A prime cause of the fertility of the land in the moist climate of Ireland is, that happily the surface-soil rests upon a rocky substratum. A clay subsoil will sometimes be of material advantage to a sandy upper-soil, inasmuch as it will retain the necessary moisture in such a manner as to be capable of supplying that lost by the earth above in consequence of evaporation. In the same way, a sandy or gravelly subsoil often corrects the imperfection of too great a degree of absorbent power in the true soil.

In devoting the difierent parts of an estate to the necessary crops, it is perfectly evident that no general principle can be laid down, except when all the circumstances of the nature, composition, and situation of the soil and subsoil are accurately known.

Whatever be the specific variety of the surface-soil, it 
will, of necessity, take its character from the prevalert substratum. In limestone countries, where the surface is a species of marl, the soil is often found only a few inches above the limestone, and its fertility is not impaired by the nearness of the rock: though, in a less absorbent soil, this situation would occasion barrenness; and the sandstone and limestone hills in Derbyshire and North Wales may be easily distinguished at a distance in summer by the different tints of their vegetation. The grass on the sandstone hills usually appears brown and parched, that on the limestone hills flourishing and green.

Each locality will continue to present to the agriculturist facilities for the cultivation of such vegetables as it is best fitted to raise, and for an indefinite period; that is, until the exhaustion of its saline materials, its capability will continue. In clayey soils, it will continue longesi; because, as previously explained, all clays contain potash and soda. But even these in time are exhauster. Air, water, and the changing temperature of the seasons, are at the same time preparing a remedy for the coming deficiency. Fresh surfaces of broken, crumbling rock are in a state of continual formation, exposing to the elements the saline treasures they contain. A period will arrive in the history of all soils, when, if their saline constituents are not artificially replaced, it will be necessary, either by deep plowing, or other mechanical modes of breaking up and exposing the rock from which that soil has been formed, to obtain a fresh supply of soluble alkalies. When the surface of a granite rock has been long subjected to the action of air and water, the lime and the potash it contains are acted on by both ; the felspar, mica, and quartz, of which that rock is compounded, are decomposed. The felspar, which is, as it were, the cement of the stone, forms a fine clay; the mica, partially decomposed, mixes with it as sand; and the undecomposed quartz appears as gravel, or coarse sand, of different degrees of fineness. Then, as soon as the smallest layer of earth is formed in this way, the seeds of mosses, and other 
imperfect vegetables constantly floating in the atmosphere, and which have made that spot their resting-place, begin to vegetate: their annual reproduction and death furnishes a certain quantity of organizable matter, which mixes with the earthy materials of the rock. In this improved soil, more perfect plants are capable of subsisting, the gradual process being, in truth, an epitome of the world's original creation. Fossil geology shows us that such was the process; and that not until a soil was formed by the decay of reeds and mosses, was the earth's surface fitted to rear the stately oak. With every fresh disintegration of the surface, successive quantities of alkaline materials are presented to the growing vegetable.

\section{CHAPTER XII.}

Of the Chemical Analysis of Soils, and how far this is practicable by the Farmer.

Enougr has been already written to show what is essential to the production of heavy crops, and to prove that a naturally good soil can be forced, or an inferior soil amended, only by the addition of such substances as are really requisite in each particular instance; such adaptation, of course, presupposing an exact acquaintance with the nature of the land.

But the practical farmer will anticipate the inquiry, How am I to arrive at this knowlerge? I am no chemist: I can form some general notion of the composition of the soil which I cultivate; and, from experiments (some of which have been fortunate, others confessedly expensive and unproductive), I am enabled to say what seems to agree best with it. Is it necessary to employ a scientific chemist to analyze my wheat soils, or are the means of discovery within my own power? 
In reply to such very natural inquiries-- to a certain extent, the means of analysis are within the reach of every working farmer. Nevertheless it is perfectly true, that the management and tilling of the soil is a branch of practical chemistry; and, like the arts of dyeing, calico-printing, or the smelting of metals, it may advance, to a certain degree of perfection-its present condition (which has been stationary and imperfect for many centuries) -without the aid of science; but it can only have its processes explained, and be led on to shorter, more economical, more productive, and perfect processes, by the aid of scientific principles.

From the analyses of Davy and Sprengel, already given, of soils known to be eminently productive (and two or three such illustrations are as good as a thousand), it is not difficult to say of what materials a good wheat soil ought to consist. It is impossible to compare any given soil with these standards, unless we have a similar examination instituted; and if it can be obtained from the hands of an able investigator, it is always very desirable, so much so as amply to repay the trifling expense. Chemistry has rendered many and great services to agriculture, and can render more: the two sciences ought not to be considered as having no relation to each other; on the contrary, practical farming is only conducted on rational principles when directed by chemical science. Hitherto it has fallen in with the humor or bias of only a few scientific men to enter upon such inquiries. Sir Humphrey Davy, the greatest chemist of his age, devoted his efforts not only laboriously, but most usefully, to the prosecution of agricultural chemistry; and the recent views and discoveries of Liebig, will do much to economize agricultural operations, as well as to direct the farmer to the easiest and shortest modes of doubling his crops. But, generally, the appreciation of such efforts, on the part of learned men, has been so small-the reception of scientific results and suggestions by the farming tenantry, so ungracious, that little wonder can exist that so many have quitted the field in disgust- 
that the majority of able chemists should studiously avoid it. Hence it has happened that, in England, the analysis of soils has rarely been undertaken, except as a matter of professional business. Exact chemical analysis is a difficult art, one which demands much knowledge and skill in practice. It calls for both time and persererance, if valuable, trust-worthy, and minutely correct results are to be obtained. But it is only by aiming after such minutely correct results that chemistry is likely to throw light on the peculiar properties of those soils, which; while they possess much general similarity in appearance, are yet found, in practice, to possess very different agricultural capabilities.

Sir Humphrey Davy has given, with his usual precision, very copious directions for the analysis of soils. But we have no hesitation in affirming, that few practical farmers are likely to attempt the task. Not that the requisite instruments are either numerous or expensive, but that some familiarity with chemical operations is necessary; and that little dependence could be placed upon results which, if incorrect, would mislead, perhaps, more widely than the merest guesses. Fortunately there are to be found men of ability in sufficient numbers to supply the requisite information; and there is nothing more inconsistent in soliciting from a practical chemist a statement as to the actual composition of a given portion of soil, with a view to the supply of its deficiencies, than there is in employing a veterinary surgeon, not only to give an opinion as to the nature of the ailment of a horse, but to arlvise the appropriate remedy.

Undoubtedly the utility and necessity of such interference or assistance may sound strangely-grate harshly upon the long-established usages of that class of farmers with whom, unfortunately, mere exertion is a virtue, and skill or science a presumed apology for laziness. It would appear, however, that in some agricultural districts, a spirit in most rational conformity with such combinations of science with mere brute labor, is beginning to prevail. Early 
in the present year, a meeting of landed gentry and farmers took place in Edinburgh, for the express purpose of forming an association for the application of chemistry to agriculture; a tolerably expressive indication of the state of public feeling in Scotland, and one that, we trust, will be followed up by the organization of kindred institutions throughout the country. The great and leading object of the association is to have a chemist of first-rate eminence, resident in Edinburgh, who, during the winter months, shall devote himself to analyzing such soils, manures, and other substances as may be sent him by farmers, and giving them advice regarding their value and usefulness. In summer he will visit different districts of the country, at the request of members of the association, and give a few lectures in the towns, or advice to individuals, regarding the system of management best suited to different soils. It is easy to see that all this will be attended with very great practical benefits to the country.

We are aware, however, that there are persons who have a distrust of the aid to be had from chemistry in the delicate and refined processes of agriculture; and to them we would address a few words.

Now, the more recondite principles of vegetation are subjects on which neither chemist nor farmer will require to touch. Indeed, there will be no call made on the farmers, or persons wishing the analysis, for any chemical knowledge. They are to submit limestones, bone-dust, guano, and manures of all kinds, marls, decaying rocks, and such like substances, to the chemist, and he is to pronounce on their value, and to point out their utility in reference to different soils, and for raising different crops. He will say, for example, whether the guano has beer robbed of its ammonia, or the bone-dust of its gelatine, or whether the limestone be colored with bituminous matter which will disappear with burning, or with iron which will not; and then he will be able to say what price the article ought to bear, and with what crops, on what soils, and at what periods it ought to be used. On the part of 
the person who sends the substance for analysis, it is plain that no knowledge of chemistry is required; and even the chemist will not find his duty an arduous one. A few chemical tests, and an accurate balance, will be nearly all that he will require; and he will have no occasion to approach those nice and subtile operations of nature, over which there certainly hangs a delicate and almost impenetrable veil.

But the summer duties of the chemist will be even more important than the analyses which are to occupy his winter hours. During that season he will impart information on many of the more recent discoveries and improvements in practical agriculture; and already enough has been done to admit of his giving much valuable and curious information, whether, in the form of lectures, or by communicating with individuals. For example, the good effects of bone-dust, and of the phosphates generally, on peaty soils-of saline compounds for crops of hay on loams in trap districts-and of lime on granitic soils-may be mentioned, and they admit of explanation. They are noticed here as a proof of the advancement already made in this kind of knowledge. But much yet remains to be done; and besides giving information, it will be his duty no less to suggest experiments. He will give instructions to farmers to make trial of substances, the composition of which is known and determinate, on different soils, and with a variety of crops, accurately noting the weight of the produce, both in its dry and moist state. And who does not see that such trials, made on a diversity of soils (for, in this respect, the experiments will have the advantage over any which the chemist could make himself on an experimental farm), will furnish him with results from which he may possibly draw some general principle. This, again, may point the way to other trials and new discoveries; and so on without limit.

Need we say what will be the benefits of all this training and experiment? In the first place there will be a gain to the country at large in the increased productiveness of 
the land; and in this those will be the first to share who first know of the new methods that will give them crops at a lower cost than their neighbors. And, in the second place, a spirit of intelligence and inquiry cannot fail to be diffused among our farmers, of which it will be difficult to estimate the value. Instead of blindly following in the old courses, they will have a pleasure in devising new ones, and will gradually raise themselves in the scale of being. And if it be true that even the mechanical arts will fall off, as De Tocqueville has admirably shown, if their principles are lost sight of, just as copies taken from copies decline at last from the original, much more will the fields of the farmer, changing in their composition with every crop that is taken from them, reward none at last but the intelligent and the skilful.

\section{CHAPTER XIII.}

Of Advertised "Fertilizers" for the Soil.

THE publication of more scientific and enlarged views respecting the nature of vegetable growth, has led to the attempt to furnish mineral compositions to meet the supposed deficiency of saline matters in the soil. Their inventors secure the secret of each such composition by a patent; in other instances they are left unprotected: nevertheless, it is a matter of no difficulty to say of what materials they chiefly consist. Now, there are such things as patent medicines, and, unquestionably, there is scareely one of them that may not be good for some ailment or other. The mischief of such nostrums is, that they are recommended as universal specifics ; they will cure everything. As any one may read of the last new fashionable pills, that they have stood the test of thousands of trials, and proved efficacious in the removal of the direst and most 
diversified evils that can infest humanity; so of these agricultural specifics, it is said that "their efficacy has been submitted to innumerable tests since the ingredients were discovered; by which trials their utility has been amply demonstrated in all instances." Now, this is saying too much. Macassar oil may cause a luxuriant growth of hair; but rubbed upon a deal box, it will not convert it into a hair-trunk before the morning: and so a remedy, said to be universally useful, mostly proves (whether land or living creatures be the subject of experiment) of little use in any instance. In some cases that have fallen under our own notice, the guano, which these mineral manures were intended to supersede, has proved a far more stronglyfertilizing substance. And if there had been no deficiency of the materials of which guano is exclusively composed,if purely saline and earthy, rather than animal matter, had been wanting, the balance of recommendation would undoubtedly have turned the other way. All this shows that it is folly to add to a soil any other matters than precisely those which are exhausted or deficient; and that this can only rationally be attempted after close examination of the materials of which that soil is composed.

Let us suppose that this is done, and that an artificial saline or mineral compost is judiciously and accurately put together, either to meet the deficiency, or added to a tolerably good soil to increase its fertility. The advantages of its use are not overstated in a recent pamphlet.

$1 s t$, It is cheap, compared with its value: a twenty shilling cask will supply an acre.

$2 d$, It is light and easily carried, when compared with carting manure.

$3 d$, It is suitable for small holders who cannot afford soiling, or keeping of cattle for making dung-heaps.

$4 t h$, It enables a tenant-at-will to take a good crop out of done-out land, if his landlord refuse to renew.

$5 t h$, It furnishes to barren land such food for plants as had been deficient; such defects of one or more substances being, in general, the cause of sterility. 
$6 t h$, It enables the cultivator to extract ten times as much vegetable aliment for his plants from the soil, and from other manure, as they could otherwise, in most cases, yield.

This is the language of one who has devoted much time, talent, and energy to the task of improving the soil ; and he believes there are no soils which may not be permanently fertilized by the mineral compost which forms His invention. Thus he speaks of its powers. But bearing in mind the remarks we have already made, every practical farmer must advance upon his own responsibility in making trial of its capabilities; the object of this work being, not the introduction of advertised artificial manures into the notice of the agricultural world, but rather the dissemination of those sound and rational views of the necessary relations between PRACTICAL FARMING and PRACTICAL SCIENCE, without which Agriculture must still lag behind the age, and, though the first and most important of all arts, remain for ever stationary. 
C $149 \times 2^{-6}$ 





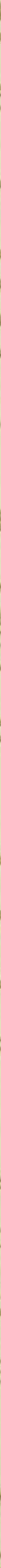




\section{LIBRARY OF CONGRESS}

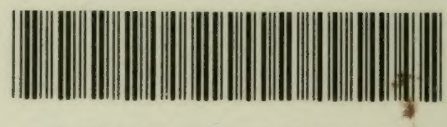
00027553941 